UNIVERSIDADE DE SÃO PAULO

INSTITUTO DE ARQUITETURA E URBANISMO

PROGRAMA DE PÓS-GRADUAÇÃO EM ARQUITETURA E URBANISMO

MARIA LÍDIA GUIMARÃES PANTALEÃO

Análise dos parâmetros que compõem as aberturas envidraçadas: subsídios para a obtenção do "Nível A" no Índice de Consumo da envoltória do RTQ-C na Zona Bioclimática 4 

MARIA LÍDIA GUIMARÃES PANTALEÃO

\section{Análise dos parâmetros que compõem as aberturas envidraçadas: subsídios para a obtenção do "Nível A" no Índice de Consumo da envoltória do RTQ-C na Zona Bioclimática 4}

Dissertação de mestrado, apresentada ao Instituto de Arquitetura e Urbanismo da Universidade de São Paulo, como parte dos requisitos para a obtenção do título de Mestre em Ciências pelo Programa de Pós-Graduação em Arquitetura e Urbanismo.

Área de Concentração: Arquitetura, Urbanismo e Tecnologia

Orientadora: Prof.a. Dra. Rosana Maria Caram Franieck

\section{Versão Corrigida}

(A versão original encontra-se disponível na Unidade que aloja o Programa de Pós-Graduação)

São Carlos

2020 
AUTORIZO A REPRODUCAO TOTAL OU PARCIAL DESTE TRABALHO,

POR QUALQUER MEIO CONVENCIONAL OU ELETRONICO, PARA FINS DE ESTUDO E PESQUISA, DESDE QUE CITADA A FONTE com os dados fornecidos pelo(a) autor(a)

Guimarães Pantaleäo, Naria Lidia

Analise dos parâmetros que compõem as aberturas envidracadas: subsidios para a obtencaio do "Nivel $\mathrm{A}^{*}$ no Indice de Consumo da envoltória do RTQ-C na Zona

Bioclimatica 4 / Maria Lidia Guimaräes pantaleáo: orientadora Rosana Naria Caram Franieck. -- Sào Carlos, 2020 .

$$
161 \mathrm{p} \text {. }
$$

Dissertaçào (Nestrado) - Programa de Pós-Graduação em Arquitetura e Urbanismo, Teoria e História da Arquitetura e do Urbanismo -- Ingtituto de Arquitetura e Urbanismo, Universidade de 9 ào Paulo, 2020

1. Aberturas Envidracadas, 2. Eficiência

Energética. 3. RTQ-C. I'. Caram Eranieck, Rosana Maria, orient. II. Titulo.

Bibliotecária responsável pela estrutura de catalogação da publicação de acordo com a AACR2: Brianda de Oliveira Ordonho Sígolo - CRB - $8 / 8229$ 


\section{FQLHA DEIULGAMENTO}

\section{C'andidato(e) : Maria Lidia Guimaräes Pantaleāo}

Título da dissertaçăo: "Análize dos parằnetros que compōem as aberturas

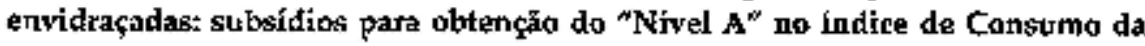
envoltória do RTQ-C na Zona Bioclimática 4"

Dala da detiesa: 23/09/2020

Orientadora: Profa. Dra. Rosana Maria Caram Fraribck

Comissạ̄o [tulkadora:

\section{Reprilado:}

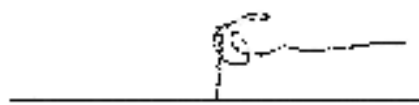

Psofa. Dra. Rogana Maria Caram Franieck (IAL/LSP)

$$
\text { Belenie cyario Dacht }
$$

Prufa. Dra. Helenice Matio Sacht

(Unir.Federal da Integraçāo Latino-Ameriıana)

$$
\text { Năo votante }
$$

Aprovada

$$
\text { Tonsed fapia hukionthales: }
$$

Profa, Dra, Marieli Azoin Lakiantehtrk

(UEM)

Aprovada

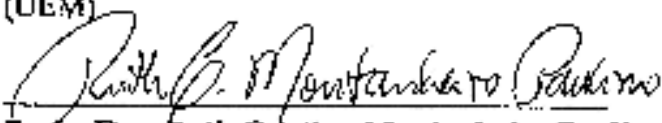

Frofa. Dra. Kutl Cristina Mantanhèiro Padino (UNAÉRP) 



\section{AGRADECIMENTOS}

À minha orientadora Profa. Dra. Rosana Maria Caram, pelos ensinamentos, pela gentileza e por ter acreditado desde o início no meu trabalho.

À Profa. Dra. Kelen Almeida Dornelles e a Profa. Dra. Helenice Maria Sacht pelas construtivas observações feitas durante o meu exame de qualificação.

Aos professores, funcionários e amigos do IAU, que participaram dessa minha caminhada, sempre muito amáveis e colaborativos.

Agradeço aos meus pais Vlady e Lídia (in memoriam), que sempre estiveram presentes em todos os momentos que eu precisei, sendo ambos a razão por eu ter conseguido estar aqui. Aos meus filhos Thays e Thiago, que sempre me deram força e me apoiaram, me incentivando, trocando ideias e me auxiliando no que fosse preciso.

À minha família, que mesmo longe, se mantem tão presente em minha vida. 



\section{RESUMO}

Pantaleão, M.L.G. Análise dos parâmetros que compõem as aberturas envidraçadas: subsídios para a obtenção do "Nível A" no índice de consumo da envoltória do RTQ-C na Zona Bioclimática 4. 2020. 161 f. Dissertação (Mestrado) - Instituto de Arquitetura e Urbanismo, Universidade de São Paulo, São Carlos, 2020.

Uma edificação eficiente é a que desenvolve suas atividades durante o seu uso e operação utilizando o mínimo de energia elétrica e proporcionando aos seus usuários um maior número de horas em conforto. $O$ projeto de um edifício eficiente deve ser pautado em diretrizes fundamentadas no estudo do conforto térmico por meio da compreensão dos parâmetros responsáveis pelo seu consumo energético. Diante deste contexto, esta pesquisa possui como objetivo principal evidenciar os cenários que proporcionem o "Nível A" no Índice de Consumo da envoltória dos edifícios comerciais em Ribeirão Preto, Zona Bioclimática 4. Esta análise é realizada através dos elementos que compõem as aberturas envidraçadas possibilitando a obtenção de subsídios que auxiliem os projetistas na elaboração de uma arquitetura que minimize o gasto de energia elétrica. Para o desenvolvimento deste trabalho, foram levantadas as etiquetas de conservação de energia de três edifícios da cidade pelo método prescritivo do Regulamento de Eficiência Energética dos Edifícios Comerciais, de Serviços e Públicos - o RTQ-C. Os dados obtidos foram utilizados em simulações efetuadas pelos programas Excell e Web prescritivo, para a identificação dos cenários que alcançaram o "Nível $A^{\prime \prime}$. De acordo com os resultados alcançados, foi verificado que, a partir do Percentual de Abertura da Fachada (PAF) de 20\%, não é possível alcançar o "Nível A" apenas com os vidros de alta eficiência, havendo que acrescentar a fachada, elementos de proteção solar. O estudo também evidencia que o Fator de Forma e o Fator Altura que identificam a volumetria da edificação, não contribuem, pela análise do método prescritivo, na eficiência energética da edificação, sendo um fator de controvérsia e passível a maiores pesquisas. Os resultados desta pesquisa foram apresentados a partir de tabelas e diretrizes projetuais de modo a serem utilizados nas etapas iniciais do projeto de arquitetura, vindo a contribuir na produção de edifícios que minimizem o gasto de energia elétrica na cidade de Ribeirão Preto.

Palavras-chave: Aberturas envidraçadas. Eficiência energética. RTQ-C. 



\begin{abstract}
Pantaleão, M.L.G. Analysis of the parameters that compose the glazed openings: subsidies to obtain the "Level A" in the envoltory consumption index of RTQ-C in the Bioclimatic Zone 4. 2020, $161 \mathrm{f}$. Master's of Science Thesis (Msc in Architecture and Urbanism) - Instituto de Arquitetura e Urbanismo, Universidade de São Paulo, São Carlos, 2020.
\end{abstract}

An efficient building is one that develops its activities during its use and operation using minimum electricity and providing its users with a greater number of hours in comfort. The design of this efficient building should be based on guidelines prevenient on the study of thermal comfort through the understanding of the parameters responsible for its energy consumption. In this context, this research has a main objective to highlight the scenarios to provide the "Level A" in the Consumption Index of the wrap of commercial buildings in Ribeirão Preto, Bioclimatic Zone 4. This analysis is performed through the elements that make up the glazed openings, enabling the obtaining of subsidies that assist designers in the elaboration of an architecture that minimizes the expenditure of electricity. For the development of this work, the energy conservation labels of three buildings of the city were raised by the prescriptive methods of the Regulamento de Eficiência Energética dos Edifícios Comerciais, de Serviços e Públicos - RTQ-C. The data obtained were used in simulations performed by the Excel and Webprescritive programs, to identify the scenarios that reached "Level A". According to the results achieved, it was verified that, from the Façade Opening

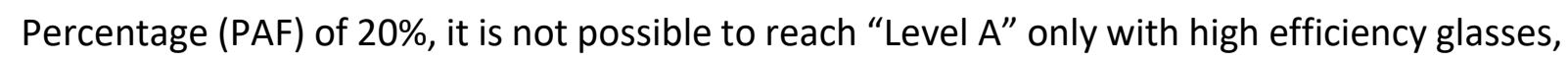
having to add the façade, sun protect elements. The study also shows that the Form Factor and the Height Factor that identify the volumetry of the building do not contribute, by the analysis of that prescriptive method, to the energy efficiency building, being a factor of controversy and subject to further research. The results of this research were presented on tables and projection guidelines in order to be used in the initial stages architectural projects, contributing to the production of buildings that minimize the expenditure of electricity in the city of Ribeirão Preto.

Keywords: Glazed openings. Energy efficiency. RTQ-C. 



\section{LISTA DE FIGURAS}

Figura 1 - Elementos que influenciam o projeto de um edifício com eficiência energética...31 Figura 2 - Esquema ilustrativo dos parâmetros e aspectos que devem ser considerados

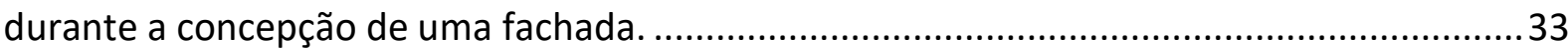

Figura 3 - Processo para projeto e triagem das aberturas envidraçadas................................34

Figura 4 - Combinação dos parâmetros avaliados e principais resultados .............................37

Figura 5 - Selo Procel e Etiqueta de Conservação de Energia ................................................ 41

Figura 6 - Relação do RTQ-C com elementos arquitetônicos ..................................................53

Figura 7 - Modelo 01 - Planta baixa de um edifício, $\mathrm{H=3,00m}$..........................................54

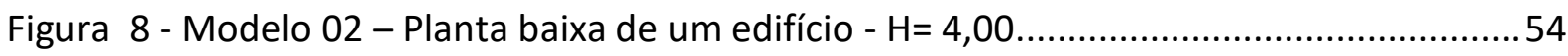

Figura 9 - Modelo 03 - Planta baixo de um edifício - $\mathrm{H}=4 \mathrm{~m}, 12 \mathrm{~m}$ e $20 \mathrm{~m}$.............................55

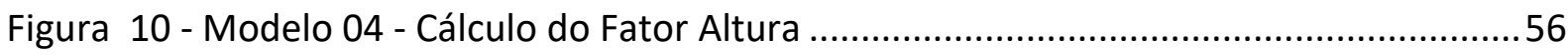

Figura 11 - Extração dos ângulos de sombreamento por média..............................................57

Figura 12 - Auto sombreamento - Edificação no Formato "U" ..............................................57

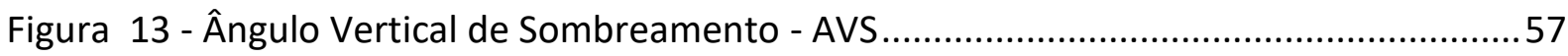

Figura 14 - Incidência da Radiação Solar nos vidros das Fachadas .........................................59

Figura 15 - Fator Solar dos vidros, parcela de radiação incidente. ......................................60

Figura 16 - Quadrante para a definição da orientação de fachadas ......................................61

Figura 17 - Quadro resumo das principais conclusões dos artigos analisados. ......................68

Figura 18 - Classes de Eficiência Energética do INI-C. ...................................................... 71

Figura 19 - ENCE da proposta do novo regulamento de eficiência energética - INI-C...........72

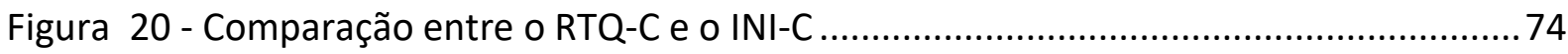

Figura 21 - Fluxograma da Metodologia...............................................................................77

Figura 22 - Crescimento da malha urbana de Ribeirão Preto a partir da aprovação de parcelamentos / loteamentos por década........................................................................ 79

Figura 23 - Dados da Temperatura de Ribeirão Preto (Estação Meteorológica do IAC)......... 80

Figura 24 - Dados da Umidade Relativa e Precipitações de Ribeirão Preto (Estação

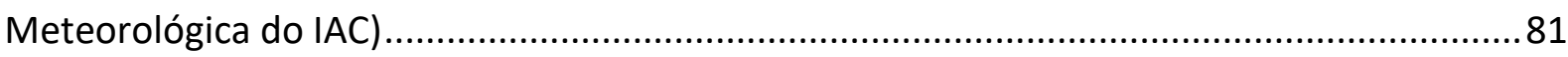

Figura 25 - Carta de Givoni, adaptada para a Zona Bioclimática 4 ...................................... 82

Figura 26 - Programa ZBBR - Classificação Bioclimática dos Municípios Brasileiros...............83

Figura 27 - Diretrizes Construtivas para a ZB4, conforme a NBR15220.............................. 83

Figura 28 - Mapa com indicação dos Edifícios analisados na pesquisa................................ 85

Figura 29 - Edifício 01 - Centro Profissional Ribeirão Shopping .......................................... 86

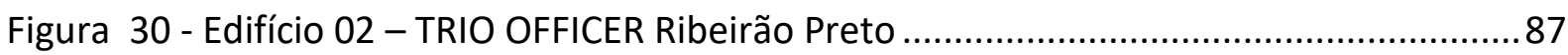

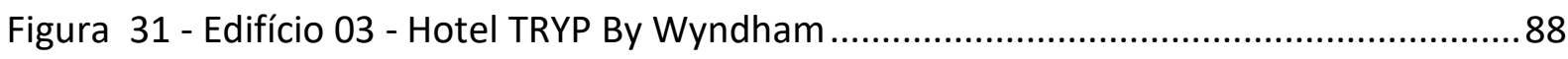

Figura 32 - Planilha de Avaliação da Envoltória.................................................................91

Figura 33 - Planilha para a classificação do Nível de Eficiência Energética do Edifício ...........91

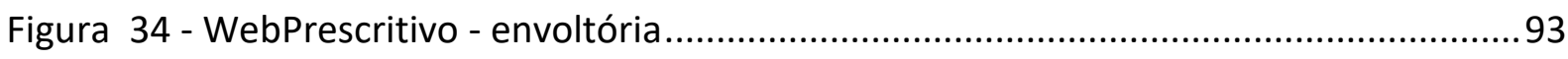

Figura 35 - Equações da Envoltória, levantamento do ICenv..............................................94

Figura 36 - Interface Web para o cálculo da carga térmica anual da envoltória ......

Figura 37 - Valores de ICenv e ICmáximo e minimo - Edifício 01 ..........................................99

Figura 38 - Valores de ICenv e ICmáximo e mínimo - Edifício 02 ..........................................99

Figura 39 - Valores de ICenv e ICmáximo e mínimo - Edifício 03 .......................................100 


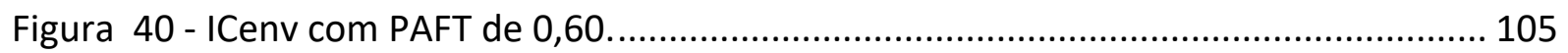

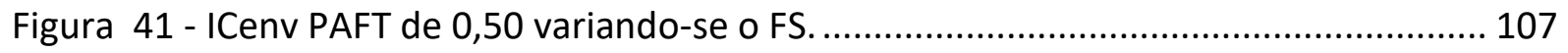

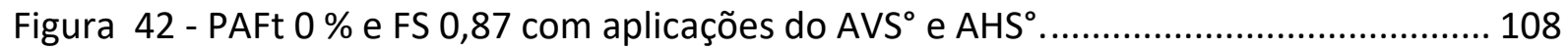

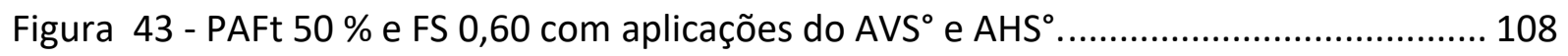

Figura 44 - PAFt 50 \% e FS 0,43 com aplicações do AVS ${ }^{\circ}$ e $A \mathrm{HS}^{\circ}$........................................... 109

Figura 45 - PAFt 50 \% e FS 0,27 com aplicações do AVS $^{\circ}$ e AHS $^{\circ}$.......................................... 109

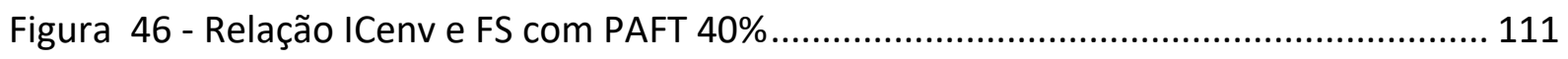

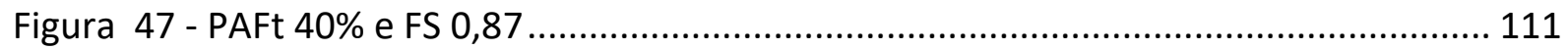

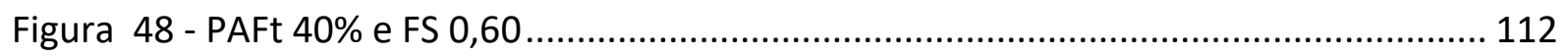

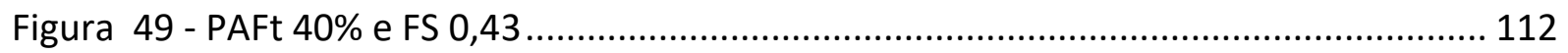

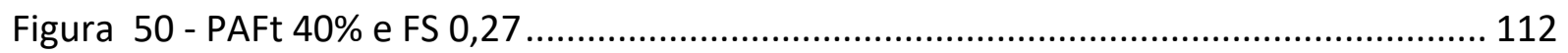

Figura 51 - Relação ICenv e FS com PAFT 30\%............................................................... 114

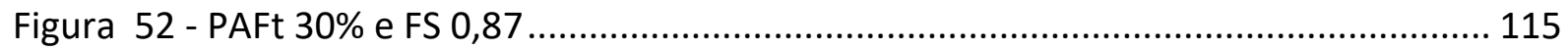

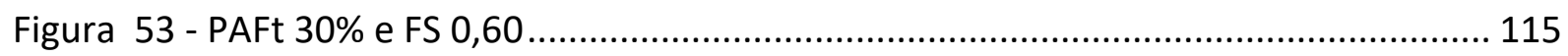

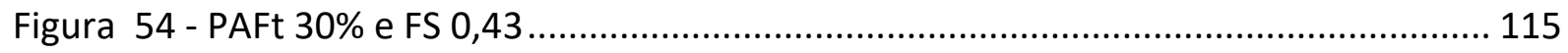

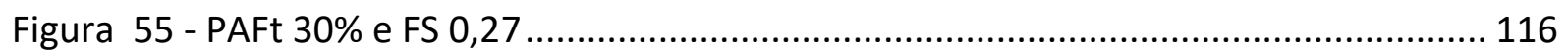

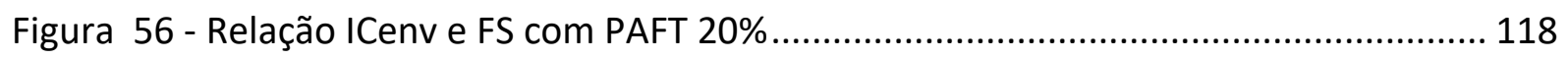

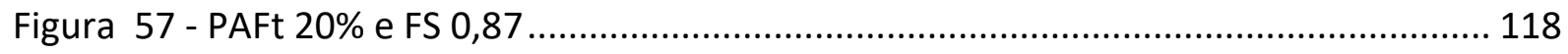

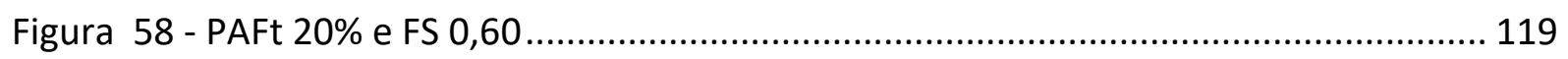

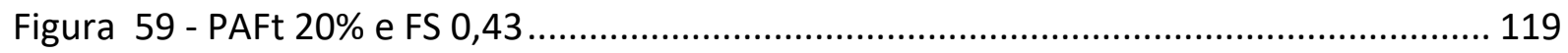

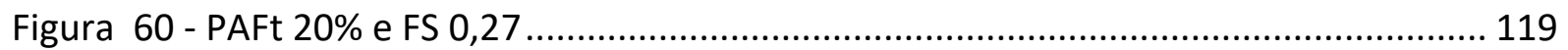

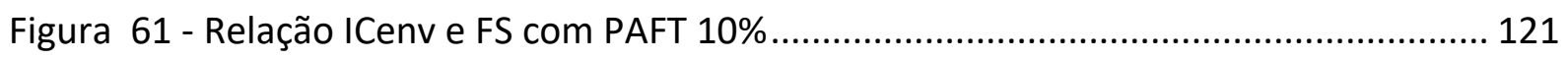

Figura 62 - Resultado dos níveis de eficiência com relação a percentagem de abertura .... 124

Figura 63 - Parte da Tabela dos Grupo climáticos: em destaque a cidade de Ribeirão Preto.

Figura 64 - Etiquetagem pelo Webprescritivo do Edifício 1 com inserção dos pré-requisitos. 


\section{LISTA DE TABELAS}

Tabela 1- Economia de Energia: variáveis arquitetônicas x serviços do edifício . .30

Tabela 2 - Exemplos de Soluções de Projetos e suas performances otimizadas ......................36

Tabela 3 - Intervalo Numérico para o Nível de Eficiência ..........................................................44

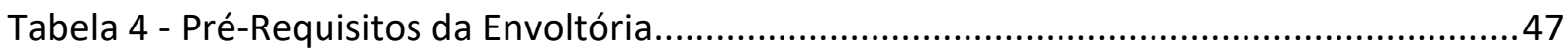

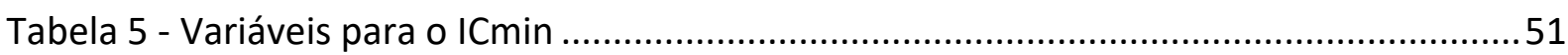

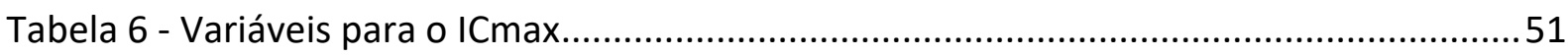

Tabela 7 - Limites dos Intervalos dos níveis de eficiência ......................................................52

Tabela 8 - Radiação global (Ig) durante o dia 22 de dezembro na latitude $20^{\circ}$ Sul .................62

Tabela 9 - Influência média dos parâmetros da envoltória .................................................67

Tabela 10 - Ventos Dominantes - Períodos (Estação Meteorológica do IAC) .......................... 81

Tabela 11 - Dados levantados dos edifícios para o cálculo do ICenv .......................................89

Tabela 12 - Demonstrativo do cálculo das áreas de aberturas das fachadas .........................90

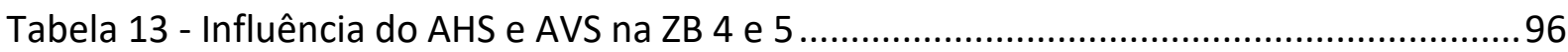

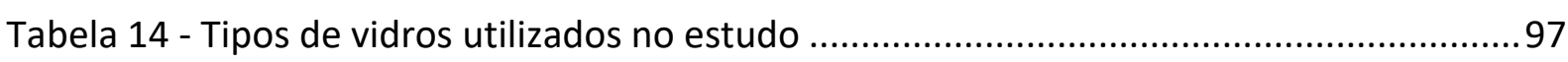

Tabela 15 - Parâmetros utilizados na simulação ..................................................................97

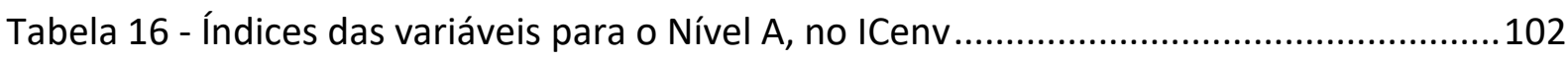

Tabela 17 - Índices das variáveis para o Nível A, no ICenv ..................................................103

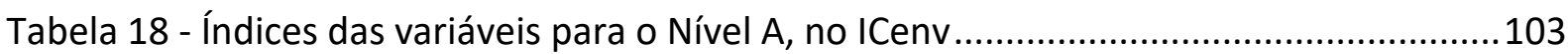

Tabela 19 - Simulação das variáveis com PAFT 60\% fixo .....................................................105

Tabela 20 - Simulação das variáveis com PAFT 50\% $(0,50)$ fixo ............................................107

Tabela 21 - Redução do ICenv (Não Cumulativa) com aumento de AVS e AHS......................109

Tabela 22 - Percentual de Abertura a 50\%, cenário para o Nível A do ICenv ........................110

Tabela 23 - Simulação do Paft a 40\%.................................................................................110

Tabela 24 - Redução do ICenv (Não Cumulativa) com aumento de AVS e AHS .....................113

Tabela 25 - Percentual de Abertura a 40\%, cenários para o Nível A do ICenv........................113

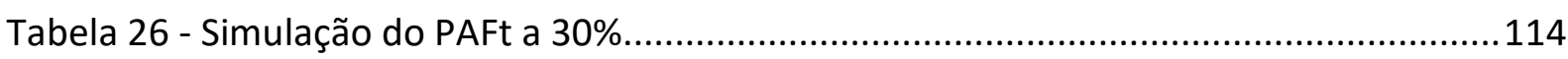

Tabela 27 - Redução do ICenv (Não Cumulativa) com aumento de AVS e AHS.....................116

Tabela 28 - Percentual de Abertura a 30\%, cenários para o Nível A do ICenv.......................117

Tabela 29 - Simulação do PAFt a 20\%................................................................................117

Tabela 30 - Redução do ICenv (Não Cumulativa) com aumento de AVS e AHS ......................120

Tabela 31 - - Percentual de Abertura a 20\%, cenários para o Nível A do ICenv .....................120

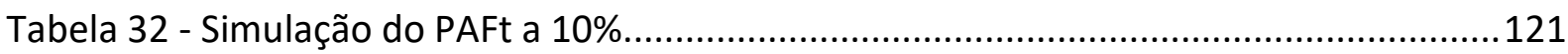

Tabela 33 - Percentual de abertura a 10\%, cenários do Nível A do ICenv .............................122

Tabela 34 - Nível de Eficiência na ZB3 e ZB4 dos edifícios analisados ...................................122

Tabela 35 - Sensibilidade das variáveis do ICenv na ZB 2 e 3 e na ZB 4 e $5 \ldots \ldots \ldots \ldots \ldots . . . . . . . . . .123$

Tabela 36 - Limites dos parâmetros da edificação atendidos pelo método simplificado......127

Tabela 37 - Coeficiente de redução da carga anual da classe D para a classe A (CRCgT D-A)

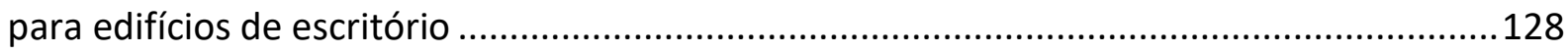

Tabela 38 - Valores de referência para edificações de escritório ...........................................130

Tabela 39 - Intervalos das classes de eficiência energética da envoltória da edificação........131 
Tabela 40 - Parâmetros limites utilizados para a etiquetagem pelo método prescritivo (RTQ-

C) e simplificado (INI-C). 


\section{LISTA DE EQUAÇÕES}

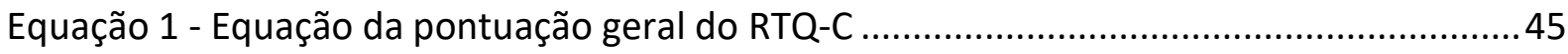

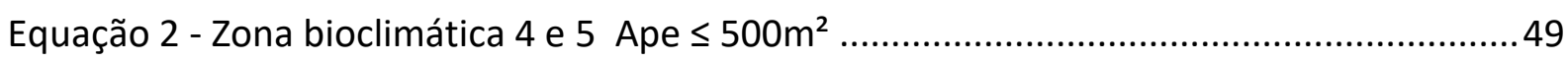

Equação 3 - Zona Bioclimática 4 e 5 Ape $>500 m^{2}$............................................................. 49

Equação 4 - Equação do cálculo do intervalo entre os níveis de eficiência (Brasil, 2010).......52

Equação 5 - Cálculo do intervalo da eficiência .................................................................130 



\section{LISTA DE ABREVIATURAS E SIGLAS}

ABNT Associação Brasileira de Normas Técnicas

AHS Ângulo Vertical de Sombreamento

Ape Áreas de projeção do edifício

Apcob Área de projeção da cobertura

Atot Área total construída

Aenv Área da envoltória

AHS Ângulo Horizontal de Sombreamento

AVS Ângulo Vertical de Sombreamento

ENCE Etiqueta Nacional de Conservação de Energia

FA Fator de Altura

FF $\quad$ Fator de Forma

FS Fator Solar

ICenv Indicador de Consumo da envoltória

INI-C Instrução Normativa INMETRO

INMETRO Instituto Nacional de Metrologia, Normalização e Qualidade Industrial

IPT Instituto de Pesquisas Tecnológicas do Estado de São Paulo

PAF Percentual de Abertura da Fachada

PAFT Percentual Total de Aberturas das Fachadas

PAFo Percentual de Aberturas na Fachada Oeste

PBE Programa Brasileiro de Etiquetagem

PROCEL Programa Nacional de Conservação de Energia

RAC Requisitos de Avaliação da Conformidade do Nível de Eficiência Energética de Edificações

RTQ-C Regulamento Técnico da Qualidade do nível de Eficiência Energética de Edifícios Comerciais, de Serviços e Públicos

RTQ-R Regulamento Técnico da Qualidade do nível de Eficiência Energética de Edifícios Residenciais

Vtot Volume total 



\section{SUMÁRIO}

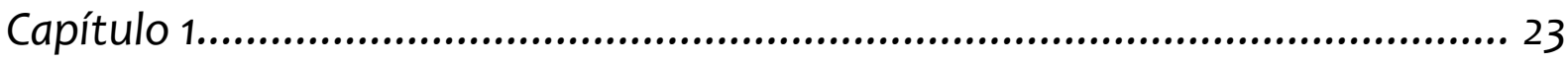

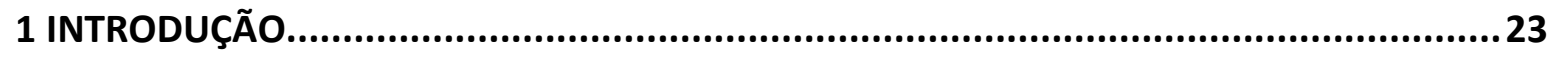

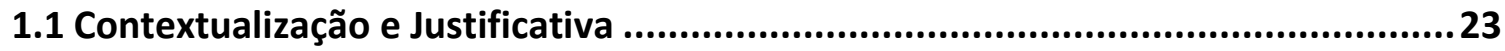

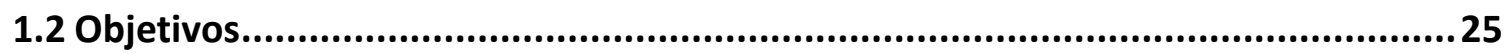

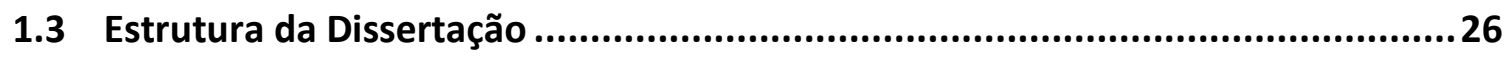

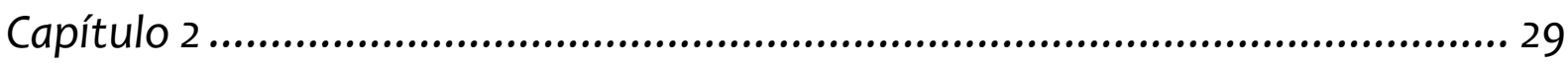

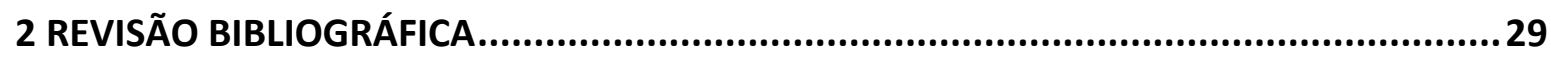

2.1 O Projeto do Edifício com Eficiência Energética .................................................29

2.2 A Influência das aberturas envidraçadas na performance energética do edifício.. 33

2.3 O Regulamento Técnico de Qualidade de Edifícios Comerciais e Públicos - RTQ-C.

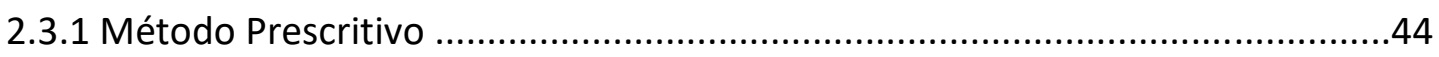

2.3.2 Índice de Consumo da Envoltória ..............................................................48

2.3.3 Variáveis da equação do Índice de Consumo da Envoltória ............................53

2.4 Análises e limitações do método prescritivo .................................................62

2.4.1 Pré-requisitos da envoltória...............................................................63

2.4.2 Método prescritivo x método de simulação computacional .......................... 64

2.4.3 Índice de Consumo da Envoltória (ICenv) - variáveis da envoltória .................. 66

2.5 Aperfeiçoamento do Regulamento Técnico da Qualidade para a Classe de Eficiência Energética dos Edifícios Com., de Serviços e Públicos: Instrução Normativa Inmetro (INI

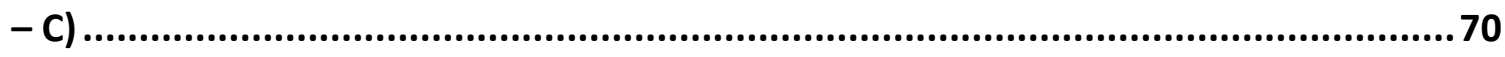

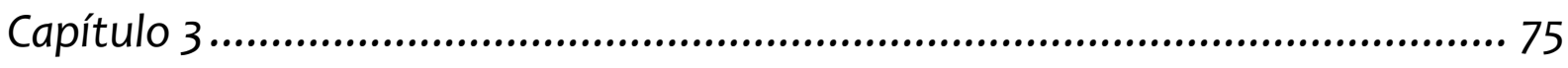

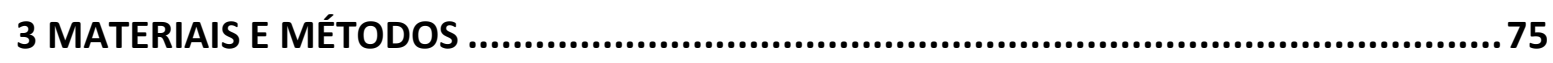

3.1 Caracterização da cidade escolhida................................................................ 78

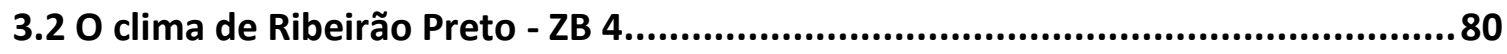

3.3 Edifícios determinados para o estudo de caso ...............................................84 
3.4 Ferramentas utilizadas na pesquisa 90

3.5 Definição dos parâmetros utilizados para a simulação - condições de contorno.. 95

Capítulo 4 .

4 RESULTADOS E DISCUSSÃO 99

4.1 Índice de Consumo das Envoltórias. 99

4.2 Simulações das Variáveis na Equação do Índice de Consumo 100

4.3 Análise comparativa da influência das variáveis do Índice de Consumo da Envoltória entre as Zonas Bioclimáticas 4 e 5 e a 2 e 3.

4.4 Comparação entre o Método prescritivo do RTQ-C e o Método simplificado do INIC. 126

4.5 Subsídios para a obtenção do "Nível A" no índice de consumo da envoltória, pelo RTQ-C em Ribeirão Preto, Zona Bioclimática 4. 


\section{Capítulo 1}

\section{INTRODUÇÃO}

\subsection{Contextualização e Justificativa}

A redução do consumo da energia elétrica tem sido estimulada em todos os setores produtivos, inclusive na construção civil. O projeto de um edifício que consuma menos energia durante o seu uso, mantendo todas as suas funções e fornecendo conforto aos seus usuários, é uma questão fundamental nos dias atuais. De acordo com o relatório de Energy Eficiency of International Energy Agency (IEA, 2019), a eficiência energética é o modo mais rápido e acessível para garantir energia confiável e sustentável para todos no planeta, contribuindo também para a redução das emissões de carbono.

Para a idealização de um edifício com eficiência energética, seus autores precisam ter conhecimento de inúmeras questões relacionadas à implantação da edificação, sua orientação, seu formato, altura, materiais utilizados e parâmetros de projeto. Essas características aliadas a qualidade do processo de construção estabelecem o conforto interno e externo, além do seu desempenho energético (BÉCQUE, et al. 2016). Diante disso, o estudo e divulgação de estratégias projetuais e construtivas que norteiem os agentes responsáveis pela produção dos edifícios se torna relevante para garantir a disseminação do conhecimento de uma arquitetura que minimize o gasto energético.

Dessa forma, esta pesquisa é desenvolvida dentro deste viés e tem como objetivo principal evidenciar os cenários que proporcionem o "Nível A" no Índice de Consumo da envoltória nos edifícios em Ribeirão Preto, Zona Bioclimáticas 4, demonstrando, a partir das interações dos elementos que compõem as aberturas envidraçadas, as composições que alcançam o menor nível no consumo de energia elétrica. Esses indicadores são obtidos por meio de simulações e análises aplicadas às variáveis da equação do Índice de Consumo da envoltória - ICenv, do método prescritivo do Regulamento Técnico da Qualidade para o Nível de Eficiência Energética de Edifícios Comerciais, de Serviços e Públicos - RTQ-C. Esses índices de eficiência 
têm como função respaldar os projetistas nas decisões de projeto com relação às aberturas de um edifício situado em Ribeirão Preto, Zona Bioclimática 4.

As edificações, tanto residenciais quanto comerciais e públicas, são responsáveis pelo consumo de quase $50 \%$ da energia produzida no Brasil, o que afeta também a sustentabilidade do planeta. Segundo Ceotto (2008), "o impacto da construção de edifícios no meio ambiente é muito grande, e é maior na fase de uso e operação do edifício do que durante sua construção".

De acordo com dados do Balanço Energético Nacional (BEN, 2019), os setores comercial e público entre os anos de 2000 a 2018 alcançaram um crescimento de $76 \%$ em sua demanda por energia elétrica. Entre as variações de consumo de energia no biênio 2017/2018, o setor de serviços cresceu $1,0 \%$, o residencial $0,9 \%$.

Durante todo o ciclo de vida dos edifícios comerciais, desde o projeto até a requalificação ou desmonte, a fase de uso e operação representa $80 \%$ do total de seus custos, sendo os maiores gastos proporcionados pelo consumo de energia (eletricidade, gás, diesel) e o consumo de água potável (CEOTTO,2008).

Para a obtenção de uma maior eficiência energética, o edifício deve possuir uma envoltória que atenda às necessidades do clima e das especificidades do edifício pois, "as trocas de energia entre o exterior e o interior das edificações dependerão, fundamentalmente do envelope construtivo e das propriedades termofísicas dos elementos que os compõem" (DORNELLES; RORIZ, 2004). Deste modo, o consumo energético de uma edificação está diretamente associado à sua envoltória, tornando-se mais relevante nos edifícios comerciais onde os maiores gastos de energia se encontram na produção de ambientes climatizados com o intuito de oferecer conforto térmico aos seus usuários (PEDRINI,2003). Essa afirmação evidencia um maior impacto das decisões de projeto nos edifícios comerciais do que nos residenciais quanto ao consumo de energia elétrica.

Dentre os componentes da envoltória de uma edificação, a porcentagem de aberturas em uma fachada é considera como sendo o fator que mais contribui para a elevação da carga térmica do edifício e consequentemente proporcionando um maior gasto energético (ZHAl, et al (2018), BRUGNERA, et al (2019), ELOY, AKUTSU, (2016). Carlo (2008), verifica que o indicador de consumo cresce a partir do aumento da área das aberturas envidraçadas com 
relação à fachada, sendo estas aberturas responsáveis pelos maiores ganhos de calor dos edifícios, ocorrendo um aumento proporcional entre o percentual de abertura da fachada e acréscimos no consumo de energia do edifício (GHISI, TINKER, IBRAHIM, 2005).

O estudo das relações entre as variáveis que compõe as aberturas envidraçadas, e como estas interações afetam a performance de um edifício, contribui na avaliação e tomada de decisões por parte dos projetistas, durante o processo do projeto arquitetônico.

Considerando as pesquisas realizadas, este trabalho tem o intuito de propor diretrizes que minimizem o gasto energético de uma construção a partir do uso mais efetivo das relações entre a área de abertura em uma fachada, o tipo de vidro utilizado para o seu fechamento e a presença ou não de elementos construtivos que exerçam a função de proteção solar. Os cenários de maior eficiência foram organizados através de diretrizes projetuais de modo a facilitar a compreensão desses índices por parte dos desenvolvedores dos projetos de arquitetura.

Sendo desenvolvida em uma fase de aperfeiçoamento do atual regulamento, esta pesquisa se converte em uma ponte entre o regulamento atual - o RTQ-C e a nova proposta - o INI-C, analisando um dos sistemas utilizados pelos dois regulamentos, o sistema da envoltória.

Sendo assim, torna-se importante a partir da promulgação do aperfeiçoamento do regulamento a realização de novos estudos no sentido de ajustar as diretrizes projetuais em relação à nova proposta em exercício.

\subsection{Objetivos}

\subsubsection{Objetivo Geral}

Este trabalho possui como objetivo principal evidenciar os cenários que proporcionem o "Nível A" no Índice de Consumo da envoltória dos edifícios em Ribeirão Preto, Zona Bioclimáticas 4.

\subsubsection{Objetivos Específicos}

Os objetivos específicos são: 
1. Analisar os dados aferidos através das simulações das variáveis do ICenv para obtenção dos índices de aberturas envidraçadas que proporcionem menor consumo ao edifício;

2. Analisar através dos resultados das simulações a influência das variáveis das aberturas envidraçadas no nível de eficiência dos edifícios comerciais em Ribeirão Preto, Zona Bioclimática 4;

3. Estudar as inter-relações existentes entre os parâmetros da equação do índice de consumo da envoltória na redução do ganho de energia térmica através das aberturas envidraçadas dos edifícios;

4. Comparar os níveis de eficiência alcançados pelos edifícios entre duas zonas bioclimáticas, ZB4 e ZB3, com o intuito de evidenciar a interferência do clima no consumo energético do edifício;

5. Comparar os índices de eficiência alcançados por um edifício diante do processo de etiquetagem aplicado através do RTQ-C e de sua proposta de aperfeiçoamento, o INIC, no intuito de avaliar os processos de etiquetagem.

\subsection{Estrutura da Dissertação}

O presente trabalho é estruturado em cinco capítulos, o primeiro capítulo contém a parte introdutória da dissertação, com a apresentação do tema, justificativa e os objetivos da pesquisa.

O Capítulo 2 discorre sobre a revisão bibliográfica com temas pertinentes a pesquisa efetuada tais como, o projeto do edifício com eficiência energética, o Regulamento Técnico da Qualidade dos Edifícios Comerciais e Públicos -o RTQ-C, assim como a sua proposta de aperfeiçoamento, o INI-C e a influência das aberturas envidraçadas das fachadas no aumento do consumo de energia elétrica do edifício.

No Capítulo 3 são apresentados os procedimentos materiais e métodos empregados na construção da pesquisa, assim como a apresentação da cidade escolhida para o estudo, o seu clima, os edifícios estudados e as ferramentas utilizadas para o desenvolvimento da pesquisa. No Capítulo 4 são apresentados os resultados das etiquetagens realizadas nos edifícios escolhidos para o estudo, assim como as simulações das variáveis das aberturas envidraçadas a partir das várias configurações e das condições de contorno consideradas. Efetua-se um 
comparativo, entre a Zona Bioclimática 3 e 4, a partir da análise da influência das variáveis do IC do método prescritivo do RTQ-C na eficiência energética dos edifícios e, por último, desenvolve-se a etiquetagem de um dos edifícios através da nova proposta de eficiência energética - o INI-C, como intuito de se analisar a eficiência do mesmo a partir dos regulamentos estudados. De acordo com as análises efetuadas, são apresentadas as diretrizes projetuais para se alcançar o Nível A no Índice de Consumo da Envoltória no Regulamento de Eficiência Energética, o RTQ-C, em Ribeirão Preto, Zona Bioclimática 4.

Por fim, no Capítulo 5 são apresentadas as considerações finais e diretrizes para trabalhos futuros. 


\section{Capítulo 2}

\section{REVISÃO BIBLIOGRÁFICA}

\subsection{O Projeto do Edifício com Eficiência Energética}

Um edifício eficiente é segundo Lamberts et al (2007), capaz de propiciar o conforto térmico, acústico e visual do usuário despendendo o mínimo possível de energia elétrica. Esse conceito soma-se ao de Meier, Olofsson e Lamberts (2002), no qual uma edificação eficiente deve "possuir tecnologias que reduzam efetivamente o consumo de energia, prover as necessidades de uso ao qual esta é destinada e ser operada de forma eficiente evitando desperdícios".

O edifício eficiente, deste modo, deve apresentar alto desempenho em seus sistemas como um todo, sendo sobretudo o seu projeto desenvolvido para favorecer a economia de energia. Estudo efetuado por Pacheco, Ordóñez e Martínez (2012), através da identificação dos parâmetros que contribuem para uma maior economia de energia, demonstrou que uma construção eficiente promove a redução dos custos durante a vida útil do edifício, compensando o investimento inicial nas medidas de eficiência, além de colaborar com a redução das emissões de carbono para atmosfera, inserindo a eficiência energética como uma parte importante da sustentabilidade.

Para a compreensão de iniciativas que proporcionem uma arquitetura eficiente, várias pesquisas foram efetuadas para a interpretação dos parâmetros que influenciam no consumo energético de uma edificação. Omer (2008), estabelece que a maioria da energia despendida pelo edifício é gerada para suprir os sistemas de refrigeração, aquecimento e iluminação.

O Regulamento Técnico da Qualidade do Nível de Eficiência Energética de Edifícios Comerciais, de Serviços e Públicos, o RTQ-C (Brasil, 2010), estabelece três sistemas que determinam a demanda de energia do edifício: a envoltória, o sistema de lluminação e o sistema de condicionamento de ar. Estes são calculados separadamente, possuindo cada sistema o seu peso de influência no consumo energético. De acordo com o regulamento, a envoltória corresponde a $30 \%$, a lluminação $30 \%$ e o condicionamento de ar $40 \%$ do total dos gastos energéticos de um edifício. 
Em Pedrini (2003), é observado o uso de ferramentas de eficiência energética durante a concepção de um projeto de arquitetura, confrontando a contribuição das decisões arquitetônicas com relação aos equipamentos em um edifício de escritórios. Na tabela 1 podese constatar, segundo a pesquisa, que as soluções de projeto (variáveis arquitetônicas) podem economizar mais energia do que a eficiência do ar condicionado e da iluminação artificial, transcorrendo essa verificação em diferentes orientações, (PEDRINI, 2003).

Tabela 1- Economia de Energia: variáveis arquitetônicas $x$ serviços do edifício

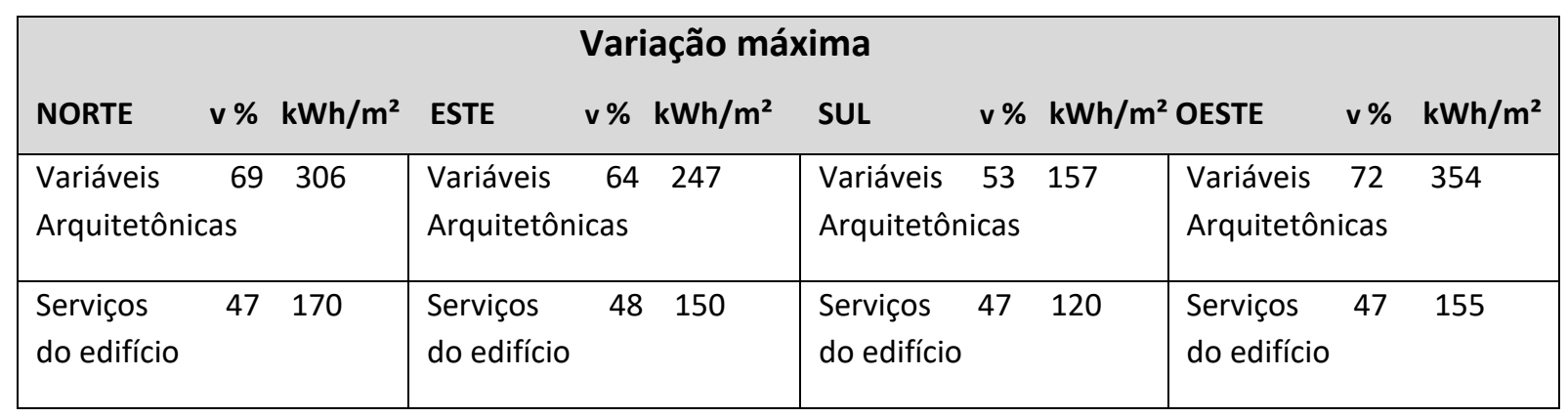

Fonte: PEDRINI, (2003) adaptado pela autora

Porém, deve-se considerar a eficiência energética do edifício desde as etapas iniciais de projeto para que se consiga a eficácia desejada. A adoção de técnicas que proporcionem edifícios eficientes deve ser praticada pelos projetistas desde a etapa de levantamento do escopo do projeto, facilitando a adoção de desenhos, formas e materiais que contribuam para um maior equilíbrio térmico no projeto, " a tomada de decisões nos estágios iniciais de um projeto arquitetônico tem impacto significativo na eficiência energética e desempenho interno dos edifícios" (POLLOCK et al, 2009). Do mesmo modo, em Hong, Chou e Bong (2000), foi averiguado que as decisões de projetos como: orientação escolhida, forma do edifício, aberturas e materiais de construção tomadas desde as primeiras etapas causam mais impacto na performance da eficiência energética de uma edificação.

Carlo (2008), coloca que "cada parâmetro participante do desempenho energético de uma edificação impacta no consumo de energia de uma forma distinta". Assim, o estudo destes parâmetros é uma importante condição na obtenção de diretrizes projetuais que reduzam o consumo de energia desde o lançamento inicial da volumetria do edifício, na identificação da melhor orientação para as aberturas, sua materialidade e a utilização dos sistemas construtivos corretos. 
A pesquisa realizada sobre eficiência energética em edifícios residenciais por Pacheco, Ordóñez, Martínez (2012), relaciona a eficiência energética de um edifício a sete parâmetros que são desenvolvidos durante o projeto de arquitetura. A figura 1 apresenta esses elementos e suas subdivisões.

Figura 1 - Elementos que influenciam o projeto de um edifício com eficiência energética.

\begin{tabular}{|l|l|}
\hline PARÂMETROS & SUBDIVISÕES \\
\hline $\begin{array}{l}\text { Estudo da Forma para otimização da energia do } \\
\text { edifício. }\end{array}$ & $\begin{array}{l}\text { Compacidade; } \\
\text { Fator de Forma; } \\
\text { Otimização da forma com relação ao clima; } \\
\text { Custo do ciclo de vida e forma do edifício }\end{array}$ \\
\hline Orientação & $\begin{array}{l}\text { Orientação e radiação solar recebida; } \\
\text { Forma e Orientaçã; } \\
\text { Orientação e áreas planas; } \\
\text { Orientação do edifício e demanda de energia; }\end{array}$ \\
\hline Envelope do edifício e Demanda de Energia. & $\begin{array}{l}\text { Otimização no limite de Transmitância; } \\
\text { Isolamento do edifício e a análise econômica; } \\
\text { O estudo ambiental do envelope do edifício. }\end{array}$ \\
\hline O Sombreamento dos edifícios & $\begin{array}{l}\text { O coeficiente de sombra. } \\
\text { Eficácia nos dispositivos de sombreamento; } \\
\text { Vantagens energéticas do sombreamento em climas } \\
\text { quentes; } \\
\text { Sombreamento móveis e pendentes; } \\
\text { Sombreamento efetuados por edifícios vizinhos; } \\
\text { Benefícios energéticos do sombreamento em climas } \\
\text { frios. }\end{array}$ \\
\hline Sistemas Passivos & $\begin{array}{l}\text { Aquecimento Passivo; } \\
\text { Resfriamento Passivo. }\end{array}$ \\
\hline Janelas & $\begin{array}{l}\text { lluminação e conforto térmico interno; } \\
\text { Tipos de Vidros; } \\
\text { Películas de Proteção; } \\
\text { Ângulo de Incidência; } \\
\text { Vidro com seleção do espectro luminoso; } \\
\text { Vidro e soluções construtivas. }\end{array}$ \\
\hline
\end{tabular}

Fonte: Pacheco, Ordóñez e Martínez (2012).

Esses parâmetros geralmente são desenvolvidos pelos projetistas de uma forma empírica, baseada no senso comum ou nas percepções individuais, o que gera o desenvolvimento de um projeto que não possui uma assertiva ou comprovação com relação à sua eficiência (PEDRINI, 2003)

Diante das exigências atuais de desempenho energético de edificações, os projetistas necessitam dar respostas efetivas às demandas existentes no mercado proporcionando um projeto de qualidade comprovada. Deste modo, destaca-se a importância no cumprimento de Normas Técnicas Brasileiras (NBRs) e a adoção de regulamentos e certificações que validem o 
projeto e comprovem seu desempenho, além de ferramentas que contribuam para o estudo da eficiência energética aplicada ao projeto desde as etapas iniciais.

Entre as principais normas brasileiras que direcionam o projeto do edifício com relação ao conforto térmico e desempenho dos sistemas construtivos temos: a Norma de Desempenho Térmico de Edificações, a NBR 15220 (ABNT, 2005) e a Norma de Desempenho de Edificações Habitacionais, a NBR 15575 (ABNT, 2013).

A NBR 15220, pode ser usada em edifícios não residenciais, mas sua base é para construções residenciais unifamiliares de interesse social de até três pavimentos enquanto a NBR 15575, embora tenha sido ampliada com relação a sua primeira edição de 2005, é específica para edificações residenciais. Devido a essa lacuna existente quanto a normatização para a avaliação da eficiência energética de edifícios não residenciais, foi lançado em 2010 o Regulamento Técnico da Qualidade dos Edifícios Comerciais de Serviços e Públicos, o RTQ-C, que dispõe de parâmetros e diretrizes para a análise da eficiência energética de edificações comerciais e públicas.

Essas normativas vêm de encontro à necessidade de se reestabelecer uma arquitetura adaptada ao local que proporcione redução no consumo de energia e contribua para o conforto térmico e lumínico do ser humano e, consequentemente, para o seu bem-estar e produtividade.

Cabe ao profissional compreender, estudar e analisar os parâmetros que envolvem essas normativas, utilizando de forma criativa soluções que otimizam o conforto e a economia de energia na busca por uma arquitetura com qualidade.

Entre esses parâmetros, pesquisas demonstram que elevado ganho térmico nos edifícios são proporcionados pelas aberturas envidraçada existentes em suas fachadas onde, através destas, os raios solares (ondas curtas) adentram os ambientes e aquecem as superfícies internas (ondas longas) aumentando a carga térmica interna da edificação. No próximo capítulo, esse tema será abordado para uma maior compreensão do fenômeno. 


\subsection{A Influência das aberturas envidraçadas na performance energética do edifício.}

Aspectos relacionados às fachadas dos edifícios possuem inter-relações no consumo de energia da edificação, dificultando por parte dos projetistas, uma tomada de decisão que proporcione ao mesmo tempo qualidade estética, conforto visual, vista para o exterior e eficiência energética.

Sacht (2012), em estudo sobre sistema de fachadas inovadoras e conforto térmico em Portugal, discorre que:

" as fachadas contribuem de forma significativa para a redução dos consumos de energia nos edifícios ao funcionar como uma barreira seletiva em relação às condições climáticas, permitindo manter condições de conforto interiores, sem recurso a sistemas mecânicos de climatização, ou pelo menos, reduzindo ao mínimo a necessidade de recorrer a este tipo de sistemas"

Deste modo, as fachadas são um subsistema complexo do edifício que apresentam inúmeros parâmetros que devem ser analisados para a sua especificação. A figura 2 apresenta alguns requisitos que devem ser analisados para o projeto de uma fachada:

Figura 2 - Esquema ilustrativo dos parâmetros e aspectos que devem ser considerados durante a concepção de uma fachada.

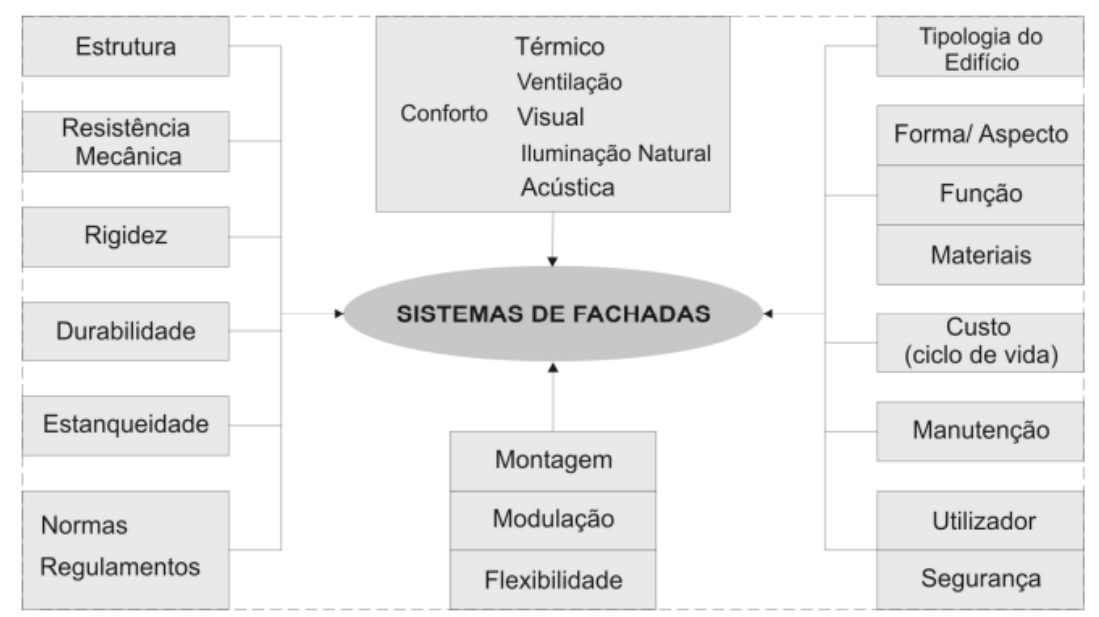

Fonte: Sacht (2012)

Entre os aspectos que influenciam o conforto térmico de um edifício e consequentemente no seu consumo de energia com relação as fachadas estão: as áreas das aberturas envidraçadas, sombreamentos dessas aberturas por elementos construtivos, orientação solar, tipos de vidros e sistemas construtivos. Pode-se também acrescentar a estes elementos, 
condicionantes externos como: sombreamento de edifícios vizinhos e condições climáticas do local de implantação.

Carmody, et al. (2004), em pesquisa realizada em diferentes cidades dos Estados Unidos, evidenciou alguns parâmetros que precisam ser avaliados no projeto de aberturas envidraçadas, identificando o desempenho de diversas composições e ordenando o processo de análise desses fatores, conforme apresenta a figura 3.

Figura 3 - Processo para projeto e triagem das aberturas envidraçadas

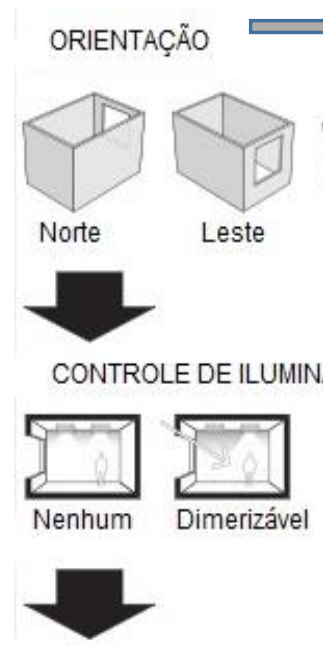

Se o clima e tipo de edifício são conhecidos,

determine a orientação.

Se outras condições são conhecidas determine a entrada de luz natural e as condições de controle.

ÁREA DE ABERTURA EM RELAÇÃO À ÁREA DE FACHADA (WWR)
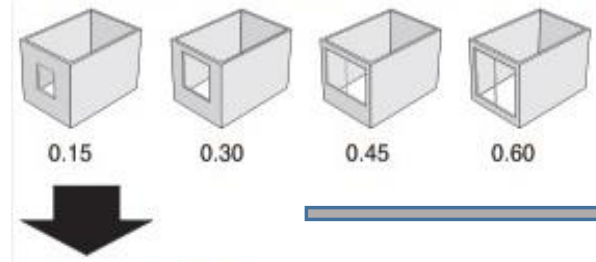

$0.30 \quad 0.45 \quad 0.60$

Se a orientação e área são conhecidas, determine os sombreamentos.

SOMBREAMENTO

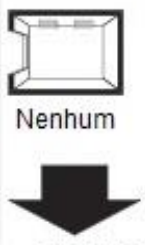

TIPO DE VIDRO

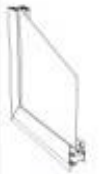

A

Incolor Incolor

Simples Duplo

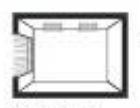

Interno

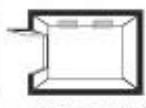

Horizontal

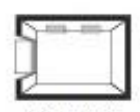

Vertical

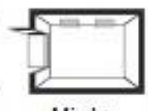

Misto
Se outras condições são conhecidas, determine o tipo de vidro.

Fonte: Carmody et al. (2004, pag.131), adaptado pela autora. 
O correto dimensionamento das aberturas nas fachadas, ainda na fase inicial da concepção do edifício, é essencial no desenvolvimento de um projeto com eficiência energética.

A otimização das áreas das aberturas envidraçadas é a condição ideal que se deseja alcançar em um projeto, pois proporciona a entrada de luz natural ao mesmo tempo que assegura um maior conforto térmico.

Estudos foram elaborados com o objetivo de especificar a área ideal de janelas envidraçadas envolvendo parâmetros que se contrapõem. Em Ghisi, Tinker e Ibrahim (2005), simulações computacionais foram realizadas através do programa Visual DOE, no intuito de encontrar a área ideal de uma janela em uma sala, visando a melhoria da eficiência energética em comparação com a área encontrada na literatura para promover vistas para o exterior. Foram analisadas diversas cidades do Brasil e uma do Reino Unido. Entre as conclusões obtidas para a cidade de Florianópolis-SC, comparando-se a área ideal de janelas para o consumo de energia com a área ideal para se obter vistas para o exterior, contatou-se que " a área ideal de janela para se obter a eficiência energética é sempre menor do que a área ideal para garantir vistas ", assim, a aplicação da área indicada pela literatura para obtenção de vistas aumentará o consumo de energia do edifício (GHISI; TINKER e IBRAHIM, 2005).

De acordo com o estudo acima citado, foi constatado que o uso de amplas aberturas é um recurso utilizado para a obtenção de vistas para o exterior e aproveitamento da iluminação natural, o que acarreta um aumento do consumo energético pela maior entrada de raios solares pelas janelas (raios de ondas curtas), proporcionando um aumento na carga térmica interna do edifício. Mangkutu, Rohmah, Asri (2016), em estudo realizado através de simulações computacionais em um edifício de escritórios, em regiões de baixa latitude (Bandung, Indonésia, $6.93^{\circ} \mathrm{S}$ ), demonstra a importância na adoção de critérios para a otimização do desenho e tamanho da janela, tais como: a orientação escolhida, a refletância do material adotado para composição da alvenaria externa e ao tamanho da janela com relação a parede (window-to wall ratio ${ }^{1}$ - WWR). No processo de otimização das soluções encontradas, constatou-se que o melhor resultado apresentou a janela para a orientação sul, a parede possuindo uma refletância de 0,8 e a relação entre a abertura envidraçada e a parede (WWR) de $30 \%$.

\footnotetext{
${ }^{1}$ É a porcentagem da área envidraçada de uma fachada, determinada a partir da divisão da área envidraçada de uma fachada pela sua área total.
} 
São diversos os parâmetros envolvidos que influenciam na performance da fachada de um edifício. Em estudo realizado por Zhai, et al (2018), é demonstrada a importância da otimização simultânea das características das aberturas como, WWR, tipo de vidros e características dos gases que compõe os vidros duplos para a obtenção de um balanço entre energia consumida, qualidade térmica interna e performance visual. Através de simulações realizadas pelo programa Energy-plus e algoritmos (NSGA-II), os pesquisadores obtiveram vários resultados de soluções projetuais através da interação dos parâmetros levantados na pesquisa, tais simulações foram embasadas em informações climáticas da cidade de Xi'an China ( $34^{\circ} 16^{\prime} \mathrm{N}$ e $\left.108^{\circ} 54^{\prime} \mathrm{E}\right)$, assim como em dados de uso, ocupação e equipamentos para um edifício de escritórios, como demonstrado na tabela 2.

Tabela 2 - Exemplos de Soluções de Projetos e suas performances otimizadas

\begin{tabular}{|c|c|c|c|c|c|}
\hline & $\begin{array}{l}\text { Solução de } \\
\text { Projeto } 01\end{array}$ & $\begin{array}{l}\text { Solução de } \\
\text { Projeto } 02\end{array}$ & $\begin{array}{l}\text { Solução de } \\
\text { Projeto } 03\end{array}$ & $\begin{array}{l}\text { Solução de } \\
\text { Projeto } 04\end{array}$ & $\begin{array}{l}\text { Solução de } \\
\text { Projeto } 05\end{array}$ \\
\hline WWR & 0,4 & 0,1 & 0,9 & 0,5 & 0,9 \\
\hline $\begin{array}{l}\text { Vidro externo da janela de } \\
\text { vidro duplo }\end{array}$ & $\begin{array}{l}\text { LoEClear } \\
6 \mathrm{~mm}\end{array}$ & $\begin{array}{l}\text { LoEClear } \\
6 \mathrm{~mm}\end{array}$ & Lowlron $6 \mathrm{~mm}$ & $\begin{array}{l}\text { LoEClear } \\
6 \mathrm{~mm}\end{array}$ & $\begin{array}{l}\text { Bronze } \\
6 \mathrm{~mm}\end{array}$ \\
\hline $\begin{array}{l}\text { Gás do preenchimento da } \\
\text { janela de vidro duplo }\end{array}$ & Argon13mm & Argon13mm & Argon13mm & Argon13mm & Air3mm \\
\hline $\begin{array}{l}\text { Vidro interno da janela de } \\
\text { vidro duplo }\end{array}$ & Lowlron $5 \mathrm{~mm}$ & $\begin{array}{l}\text { Grey } \\
6 \mathrm{~mm}\end{array}$ & Lowlron $5 \mathrm{~mm}$ & $\begin{array}{c}\text { Clear } \\
12 \mathrm{~mm}\end{array}$ & Grey $6 \mathrm{~mm}$ \\
\hline \multicolumn{6}{|l|}{ Objetivos Otimizados } \\
\hline $\begin{array}{l}\text { Total anual do consumo } \\
\text { de energia aquecimento, } \\
\text { resfriamento e iluminação } \\
(\mathrm{kWh} / \mathrm{m} 2 . \mathrm{a})\end{array}$ & 54 & 59 & 94 & 56 & 95 \\
\hline $\begin{array}{l}\text { Número de Horas onde o } \\
\text { desempenho térmico não } \\
\text { se encontra na ASHRAE } \\
55=2004 \text {, região para } \\
\text { roupas de inverno ou } \\
\text { verão }(\mathrm{hr})\end{array}$ & 1364 & 1281 & 2339 & 1488 & 2547 \\
\hline $\begin{array}{l}\text { Relação de horas com } \\
\text { iluminação natural abaixo } \\
\text { de 500lux. }\end{array}$ & 0,46 & 1,00 & 0,00 & 0,19 & 0,47 \\
\hline
\end{tabular}

Fonte: Zhai, et al (2018), adaptado pelo autor

Segundo Zhai et al (2018), as soluções apresentadas colocam os projetistas no controle de seus projetos e do desempenho que desejam atingir. Sendo o foco principal do projeto a eficiência energética, o projetista poderá ter como primeira opção a solução de número 01. Sendo o objetivo o conforto térmico, este poderá optar pela solução de número 02, e optando pela solução de número 03 , o projeto terá como diretriz a vista para o exterior. Pode-se notar 
pela tabela 2, que o consumo cresce com o aumento da área de abertura envidraçada chegando a alcançar $70 \%$ a mais no consumo de energia.

Com o objetivo de analisar escritórios de plantas livres, identificando e determinando seu consumo energético em três Zonas Bioclimáticas do Brasil a ZB1 (Curitiba), ZB3 (São Paulo) e ZB8 (Manaus), Brugnera, et al (2019) considera as influência de diversos parâmetros atuantes nas variações de consumo das fachadas como: percentual de aberturas, tipo de vidros, existência ou não de sombreamentos, temperatura de setpoint do resfriamento do arcondicionado e o sistema construtivo da fachada (Fachada Tradicional - FT, e Fachada de Cortina de Vidro- FC). Os seguintes dados foram mantidos fixos na pesquisa: orientação NorteSul, densidade de pessoas e equipamentos, a geometria do edifício e o tamanho do dispositivo de sombreamento. Os parâmetros foram analisados através de simulações computacionais utilizando-se o software Energy Plus.

Através das simulações foram gerados os principais resultados, conforme a figura 4 .

Figura 4 - Combinação dos parâmetros avaliados e principais resultados

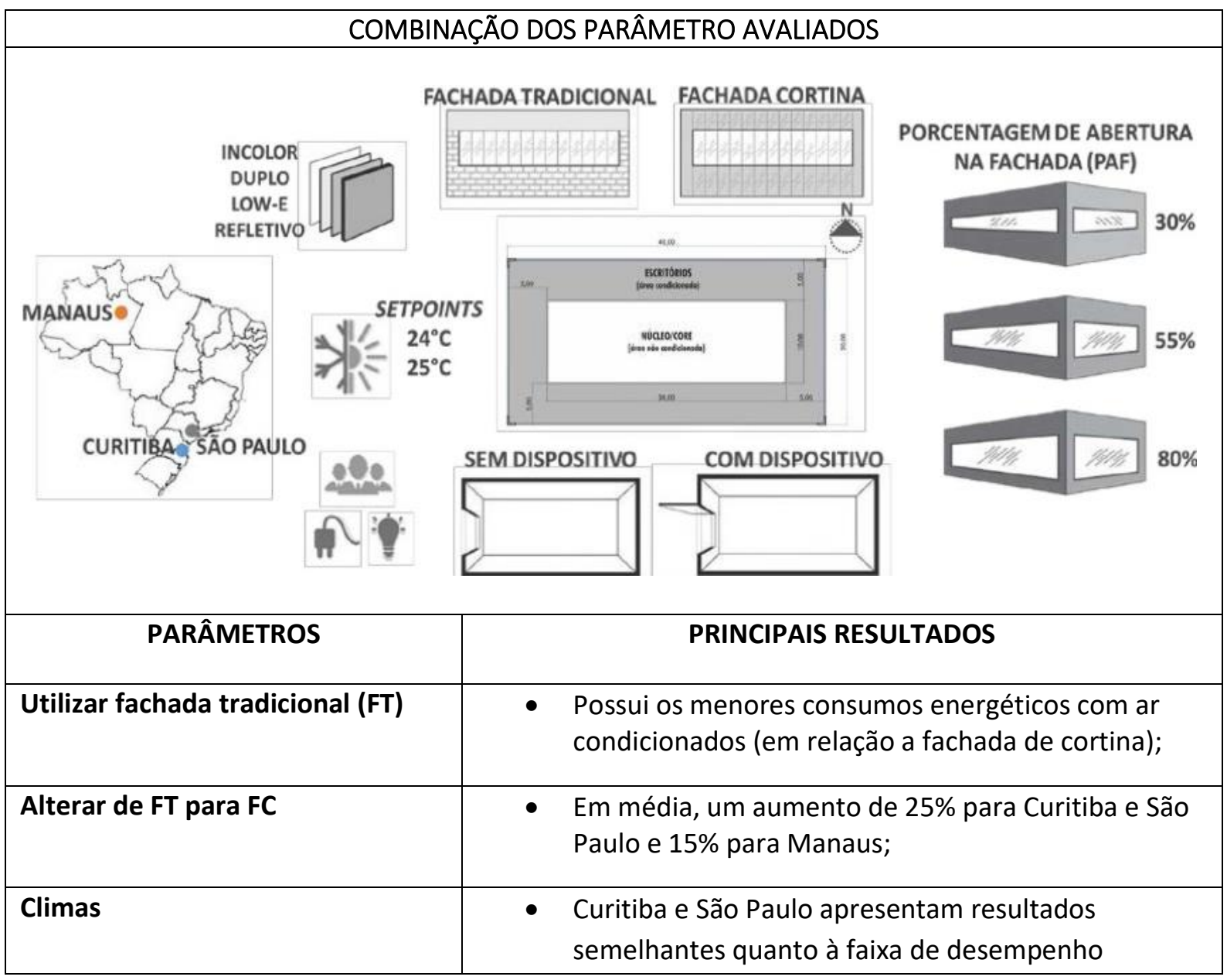




\begin{tabular}{|l|l|}
\hline & $\begin{array}{l}\text { energético, diferenciando-se nesse aspecto ao clima } \\
\text { de Manaus, devidos às altas temperaturas mantidas } \\
\text { ao longo de todo o ano; }\end{array}$ \\
\hline $\begin{array}{l}\text { Parâmetros relacionados às } \\
\text { disposituras (PAF, tipos de vidros }\end{array}$ & $\begin{array}{l}\text { O PAF foi o que mais impactou o consumo } \\
\text { energético. O tipo de vidro teve impacto nas } \\
\text { maiores aberturas (PAFs } 55 \% \text { e } 80 \% \text { ), enquanto a } \\
\text { utilização do dispositivo de sombreamento sempre } \\
\text { reduziu o consumo energético nas diversas } \\
\text { situações avaliadas nesse estudo; }\end{array}$ \\
\hline $\begin{array}{l}\text { Alteração do self-point de } \\
\text { resfriamento do ar condicionado }\end{array}$ & $\begin{array}{l}\text { Mudar Temperatura de } 24^{\circ} \text { para } 25^{\circ} \text { mudou o } \\
\text { desempenho em todos os cenários, reduzindo o } \\
\text { consumo de energia em até } 16,4 \% \text { em média. }\end{array}$ \\
\hline
\end{tabular}

Fonte: Brugnera, et al (2019), adaptado pelo autor.

Os resultados demonstram a influência das aberturas no aquecimento interno do edifício, sendo este parâmetro o que mais impacta seu consumo energético. A relação da porcentagem de aberturas com o tipo de vidro é estabelecida na medida em que a área total de abertura passa de $55 \%$ da área da fachada, no qual o tipo de vidro começa a ter maior influência no consumo, variando de acordo com o local da simulação.

De acordo com as pesquisas analisadas, verifica-se a importância da análise dos parâmetros das fachadas que influenciam no desempenho do edifício, seja quanto à eficiência energética, conforto térmico ou conforto visual. As interações entre as variáveis que afetam a performance de um edifício e a compreensão destes conceitos por parte dos projetistas contribui na avaliação e tomada de decisões durante o processo projetual, direcionando de forma mais assertiva, uma concepção energicamente mais eficiente a partir dos estudos preliminares e anteprojetos.

O Regulamento Técnico de Qualidade dos Edifícios Comerciais e Públicos (RTQ-C), recomenda diretrizes construtivas e parâmetros projetuais que reduzam o consumo de energia dos edifícios. Com o intuito de contrapor as variáveis da fachada estudando suas interações dentro da fórmula do índice de consumo da envoltória, a utilização do regulamento e de sua metodologia fornece dados relevantes para se alcançar o Nível A do consumo energético do regulamento (nível mais eficiente), produzindo nos projetistas uma percepção do desempenho de cada parâmetro estudado. 
Em estudo realizado com o objetivo de oferecer diretrizes projetuais para alcançar o Nível A no índice de consumo da envoltória das edificações (ICenv), Eloy, Akutsu (2016), realizaram uma análise estrutural nas variáveis da envoltória que compõe a fórmula do Índice de Consumo do método prescritivo do RTQ-C. Os resultados foram validados através de simulações computacionais aplicadas à Zona Bioclimática 3. Entre as conclusões apresentadas, foi verificado que o Percentual de Aberturas nas fachadas (PAF), é a variável que mais interfere no resultado do nível de eficiência. O melhor nível do sistema da envoltória é alcançado utilizando-se um PAF de até $21 \%$ com vidro de FS de 0,49 ou um PAF entre $21,6 \%$ e $24 \%$ com um FS de 0,25. O AVS, ângulo vertical de sombreamento é o segundo parâmetro de maior interferência. Verificou-se durante a aplicação do regulamento, que os resultados obtidos durante o emprego do AVS, não condizem com a sua real contribuição na atenuação do calor absorvido pelas fachadas da zona bioclimática estudada, corroborando uma apreensão errônea das diretrizes construtivas.

Os estudos destacam assim a importância das aberturas envidraçadas no consumo de energia do edifício, assim como a relevância da adoção de medidas de eficiência energética desde os estágios iniciais de projeto.

Para a promoção da eficiência energética em edifícios não residenciais, o Brasil possui o Regulamento Técnico de Qualidade de Edifícios Comerciais, de Serviços e Públicos (RTQ-C), que se encontra em processo de atualização. A proposta do atual regulamento será apresentada nos próximos capítulos.

\subsection{O Regulamento Técnico de Qualidade de Edifícios Comerciais e Públicos - RTQ-C.}

O Regulamento Técnico da Qualidade do Nível de Eficiência Energética de Edifícios Comerciais, de Serviços e Públicos, o RTQ-C, foi publicado pela Portaria n ${ }^{\circ}$ 372, de 17 de setembro de 2010 (substituindo a no 163 de 2009) e pertence ao Programa Brasileiro de Etiquetagem do Instituto Nacional de Metrologia, Qualidade e Tecnologia, o INMETRO. O regulamento foi formulado em resposta à Lei $n^{\circ}$ 10295, de 17 de outubro de 2001 que deliberou sobre a Política Nacional da Conservação de Uso de Energia (BRASIL, 2001)

Essa lei foi regulamentada em junho de 2019 pelo Decreto $n^{\circ} 9864$ (revogando o Decreto $\mathrm{n}^{\circ}$ 4059 de dezembro de 2001) que possui, entre outras deliberações, a de "implementar a 
Política Nacional de Conservação e Uso Racional de Energia, instituída pela Lei no 10.295, de 17 de outubro de 2001, em consonância com o planejamento energético nacional" (BRASIL, 2019).

A partir de 2001, foi formado um "Grupo técnico para eficientização de energia nas edificações do país", propondo a padronização de medidas que objetivassem uma construção com uso responsável da energia elétrica (BRASIL, 2001). Através desse grupo, em 2003, foi criado o Programa de Eficiência Energética em Edificações, o PROCEL Edifica, que emprega a eficiência energética sob os seguintes aspectos: o da arquitetura bioclimática e o das certificações de materiais e equipamentos elétricos, o da remoção de barreiras à aplicação da preservação de energia, o da regulamentação e da legislação. Através do PROCEL Edifica foi desenvolvido o Programa Brasileiro de Etiquetagem em Edifícios - o PBE Edifica (LAMBERTS et al, 2007).

Ao Programa Brasileiro de Etiquetagem, além do RTQ-C, acrescentam-se o Regulamento Técnico da Qualidade para o Nível da Eficiência Energética de Edificações Residenciais, o RTQ-R (BRASIL, 2012) e os Requisitos de Avaliação da Conformidade do Nível de Eficiência Energética de Edificações - o RAC (BRASIL, 2013), bem como os manuais específicos e a documentação integrante das regulamentações.

O regulamentos RTQ-C e RTQ-R possuem os procedimentos para avaliação de uma construção ou um projeto quanto ao nível de eficiência energética. O RAC contém a descrição das etapas que precisam ser cumpridas, indicando documentação e procedimentos para a submissão do projeto e obtenção da etiqueta, as ENCEs - Etiquetas Nacionais de Conservação de Energia, concedida pelo INMETRO.

O RAC inicialmente foi lançado para edificações comerciais em 2010, e para edificações residenciais em 2012, mas a contar de 2013 foi emitido um RAC único que engloba as duas certificações.

Pelo programa de etiquetagem, existem duas maneiras de evidenciar os indicadores de economia de energia elétrica de uma edificação: Selo Procel de Edificações e a Etiquetagem.

O Selo Procel é concedido pela Eletrobrás e objetiva a identificação dos projetos que possuem níveis superiores de eficiência inseridos em uma mesma categoria. Para uma edificação conseguir o Selo Procel, esta deve possuir a etiqueta total, ou seja, ser avaliada nos três sistemas, a envoltória, iluminação e condicionamento de ar e ter alcançado a Etiqueta Nível A 
nas três avaliações. O selo possui caráter voluntário e pode ser adquirido com a avaliação do projeto executivo, validado após o edifício construído.

A segunda forma é pela Etiquetagem, programa executado pelo INMETRO e coordenado pela Eletrobrás, que verifica o grau de conservação de energia alcançado pelo edifício, podendo este alcançar desde o Nível A (mais eficiente) ao Nível E (menos eficiente). A etiquetagem pode também ser realizada na etapa de projeto ou com edifício construído, sendo que, após a finalização da construção a etiqueta do projeto deverá ser refeita. A etiquetagem possui caráter obrigatório para edificações públicas federais desde 2014 sendo voluntário para as demais edificações. A figura 5, apresenta os exemplos do Selo Procel e da Etiqueta.

Figura 5 - Selo Procel e Etiqueta de Conservação de Energia
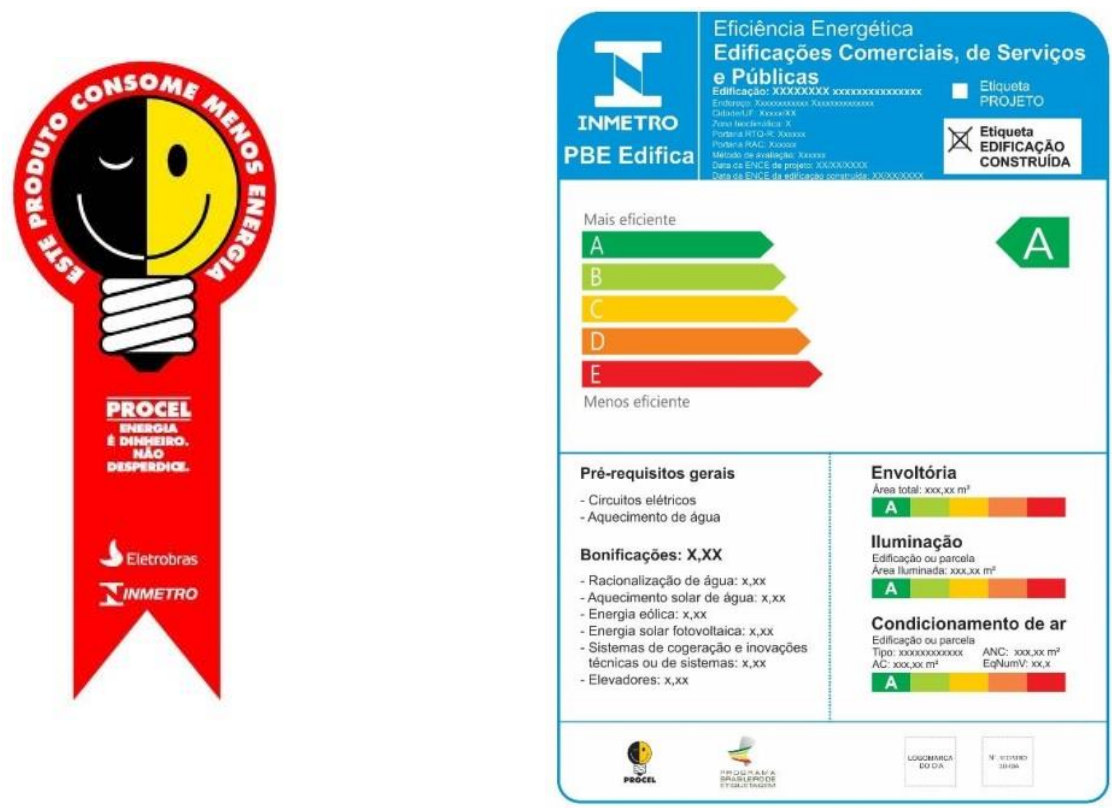

Fonte: Brasil, 2017.

O Selo Procel Edificações alcançou reconhecimento internacional em 2014 quando conquistou a equivalência com o Selo LEED - Leadership in Energy and Enviromental Design - certificação de sustentabilidade. A utilização do Selo Procel fornece um "caminho alternativo (Alternative Compliance Path)" para a comprovação do pré-requisito de performance energética mínima de Atmosfera e Energia da metodologia LEED. Do mesmo modo, a certificação de Alta Qualidade Ambiental de sustentabilidade, AQUA-HQE desenvolvida pela Fundação Vanzolini, utiliza o RTQ-C e o RTQ-R em duas das catorze categorias de análises do AQUA, garantindo a eficiência energética e o conforto térmico das edificações (Brasil, 2015). 
O RTQ-C foi elaborado com a finalidade de suprir lacunas existentes nas Normas Técnicas Brasileiras - as NBRs, com referência à regulamentação de projetos e edifícios quanto à sua eficiência no uso racional da energia elétrica. O RTQ-C é um regulamento que fornece diretrizes para a avaliação de projetos e edificações quanto à sua capacidade de economizar energia, seja na utilização de componentes construtivos, seja em parâmetros projetuais mais eficientes.

\begin{abstract}
"Nesse sentido, o RTQ-C surge como uma ferramenta para estimular o emprego de técnicas de projeto e estratégias bioclimáticas para a criação de soluções arquitetônicas mais adequadas ao ambiente climático em que estão inseridas. Ressalta-se que objetivo do RTQ-C não é fixar parâmetros, e sim estimular que os projetistas lancem mão de medidas combinadas para maior eficiência das edificações" (LAMBERTS, FOSSATI, p 67, 2010).
\end{abstract}

Essa certificação foi elaborada levando-se em conta o clima brasileiro através da divisão deste em oito zonas bioclimáticas de acordo com a Norma de Desempenho Térmico de Edificações, NBR 15220 - Parte 3, de 2005. Conforme a norma, foram estabelecidas equações de cálculo diferenciadas para cada zona bioclimática. O RTQ-C sendo uma certificação é um "mecanismo de mercado que visa promover a eficiência energética de uma edificação de elevado desempenho ao compara-la ao com o mínimo obrigatório" (CASALS, 2006).

O Regulamento examina edifícios condicionados, não condicionados e parcialmente condicionados podendo estes serem analisados pelo método prescritivo e pelo método de simulação computacional. O método prescritivo foi elaborado tendo em vista as características tipológicas mais difundidas nos edifícios nacionais. É um método mais simplificado da verificação da eficiência dos edifícios, e foi especificado como "um agrupamento de regras gerais para identificar a eficiência do edifício aplicando-se a grande maioria de tipologias construídas atualmente no país" (CARLO, LAMBERTS, 2010). O método de simulação computacional, mais dispendioso, porém mais completo, permite a etiquetagem de projetos com volumes e soluções de fachadas mais elaboradas, podendo também avaliar a eficiência da ventilação natural em um projeto.

O método prescritivo foi escolhido para ser utilizado nesse trabalho por ser o mais empregado para a análise do RTQ-C: de cento e trinta e nove (139) edificações que obtiveram seus projetos etiquetados de 2009 a 2019, cento e nove (109) foram pelo método prescritivo, vinte e oito (28) pelo método de simulação e dois (02) pelos dois métodos (BRASIL, 2020). 
Ao ser efetuado o levantamento do desempenho energético global da edificação, compara-se o edifício analisado com um modelo com as mesmas características, mas que atenda aos parâmetros máximos e mínimos de eficiência (CARLO, 2008). Essas regras estabelecem indicadores que verificam o nível de eficiência da edificação nos sistemas avaliados. Segundo Carlo (2008), é importante salientar que o regulamento determina os níveis de eficiência de um edifício, não sendo o seu intuito alcançar uma construção com alta eficiência, mas inibir a execução de construções energeticamente ineficientes.

Para o projeto do edifício ser etiquetado, um relatório completo é enviado para um Organismo de Inspeção - OIA, acreditado pelo INMETRO, contendo o projeto completo, toda a documentação e planilhas requeridas através do RAC. Este projeto pode também ser analisado primeiramente pelo consultor de eficiência energética que avalia o projeto em sua fase de "anteprojeto", de modo que por meio desta análise, seja desenvolvido um relatório que orienta os autores com relação à qualidade da eficiência do projeto para uma possível etiqueta Nível A. Sendo assim, ao ser avaliado para o processo de etiquetagem, o projeto em fase de "anteprojeto" se encontra bem definido, com seus volumes, orientações de fachadas e aberturas determinadas, o que dificulta e onera quaisquer modificações.

Cabe aqui salientar, que foi publicado no Diário Oficial da União em 12 de julho de 2018 uma consulta pública para o aperfeiçoamento do RTQ-C que ficou em vigor até 12 de setembro de 2018. Segundo a Portaria ${ }^{\circ}$ 248, de 10 de julho de 2018, a partir da Consulta Pública, um Texto da Portaria Definitiva será proposto e colocado em consulta, onde as questões e propostas efetuadas pelos órgãos que se manifestarem serão analisadas.

Entre as sugestões de aprimoramento do RTQ-C, pode-se evidenciar algumas questões que participam diretamente da eficiência da envoltória como: a entrada de dados diferenciados por fachadas, a avaliação de vidros com controle solar, a consideração do ângulo de obstrução vizinha e a verificação da iluminação e ventilação natural, que sempre foram questionamento levantados por diversos pesquisadores e que vem sendo tratadas no texto de alteração do novo regulamento (Brasil, 2018).

O método prescritivo do RTQ-C foi utilizado para o levantamento da etiquetagem dos edifícios analisados nesta pesquisa o que torna relevante uma apresentação mais detalhada do mesmo, a seguir. 


\subsubsection{Método prescritivo}

Conforme o Manual para aplicação do RTQ-C, o regulamento é um documento que fornece parâmetros para a avaliação das edificações quanto a sua economia de energia (BRASIL, 2017). As edificações são classificadas em níveis, desde o mais eficiente (Nível A) ao menos eficiente (Nível E), conforme a pontuação levantada através da equação de cada sistema analisado. Os níveis de eficiência energéticos possuem relação com o percentual de horas ocupadas em conforto térmico, proporcionadas através de uma determinada envoltória. Na tabela 3 são apresentados o intervalo numérico e o percentual de horas de conforto empregados para cada nível de eficiência.

Tabela 3 - Intervalo Numérico para o Nível de Eficiência

\begin{tabular}{c|c|c}
\hline EqNum ou PT & Nível de Eficiência & $\begin{array}{c}\text { Porcentual de horas ocupadas } \\
\text { em conforto (POC) }\end{array}$ \\
\hline $4,5 \leq x<5$ & A & POC $\geq 80 \%$ \\
\hline $3,5 \leq x<4,5$ & B & $70 \% \geq P O C \leq 80 \%$ \\
\hline $2,5 \leq x<3,5$ & C & $60 \% \geq P O C \leq 70 \%$ \\
\hline $1,5 \leq x<2,5$ & D & $50 \% \geq P O C \leq 60 \%$ \\
\hline$X<1,5$ & E & $P O C<50 \%$ \\
\hline
\end{tabular}

Fonte: Brasil, 2017

Segundo Carlo (2008), a eficiência energética prevê o consumo mínimo de energia elétrica de uma edificação, sem prejudicar o conforto, a saúde e as tarefas executadas pelos usuários. De acordo com o Manual do RTQ-C, no cálculo da eficiência são analisados três sistemas, o da envoltória, o da iluminação e o do condicionamento de ar.

A envoltória é o conjunto dos "planos externos da edificação, compostos de fachadas, empenas, cobertura, brises, marquises, aberturas, assim como quaisquer elementos que os compõem" (Brasil, 2017), e que determina uma série de parâmetros referentes às características físicas da construção como altura, forma, fachadas, aberturas, volume, orientação, materiais, etc.

No sistema de iluminação, são levantadas as cargas de seus componentes, levando-se em consideração os níveis mínimos de iluminância que devem ser considerados para cada atividade exercida nos diversos ambientes. A análise da carga da iluminação é feita por meio da Densidade de Potência Instalada (DPI). Quanto menor a potência instalada, mantendo-se os níveis de iluminância adequados, mais eficiente será o sistema. 
Por último, a eficiência do sistema de condicionamento de ar que é verificada de duas maneiras: quando o sistema é executado através de equipamentos individuais (modelo Split), são utilizadas as etiquetas de eficiência do próprio aparelho fornecidas pelo INMETRO. Se o sistema for equipado por aparelhos de distribuição central que não possuem etiqueta do INMETRO, é necessário seguir as prescrições que constam no regulamento.

A etiquetagem pode ser efetuada nos três sistemas ou em um ou dois sistemas, gerando as etiquetas parciais de energia. A envoltória da edificação deve ser sempre avaliada em sua totalidade, já o sistema de iluminação e condicionamento de ar podem ser executados em partes da edificação. O processo da etiquetagem pode ser executado após a construção pronta ou durante a fase do projeto de arquitetura, havendo a necessidade da verificação pós obra para a obtenção da etiqueta final.

Segundo o regulamento, para a edificação poder ser etiquetada esta deve possuir prérequisitos gerais que tornam o edifício "elegível ao processo de etiquetagem" (BRASIL,2017) Esses pré-requisitos são: a separação dos circuitos elétricos por uso final, sistemas de água quente, onde é calculada a demanda e levantados os índices e os sistemas de aquecimento que devem ser utilizados. Os pré-requisitos determinam o índice máximo de eficiência entre A e E que a edificação pode alcançar.

Calculando-se cada sistema em separado, os resultados são inseridos na seguinte equação geral (método prescritivo), conforme mostra a equação 1.

Equação 1 - Equação da pontuação geral do RTQ-C

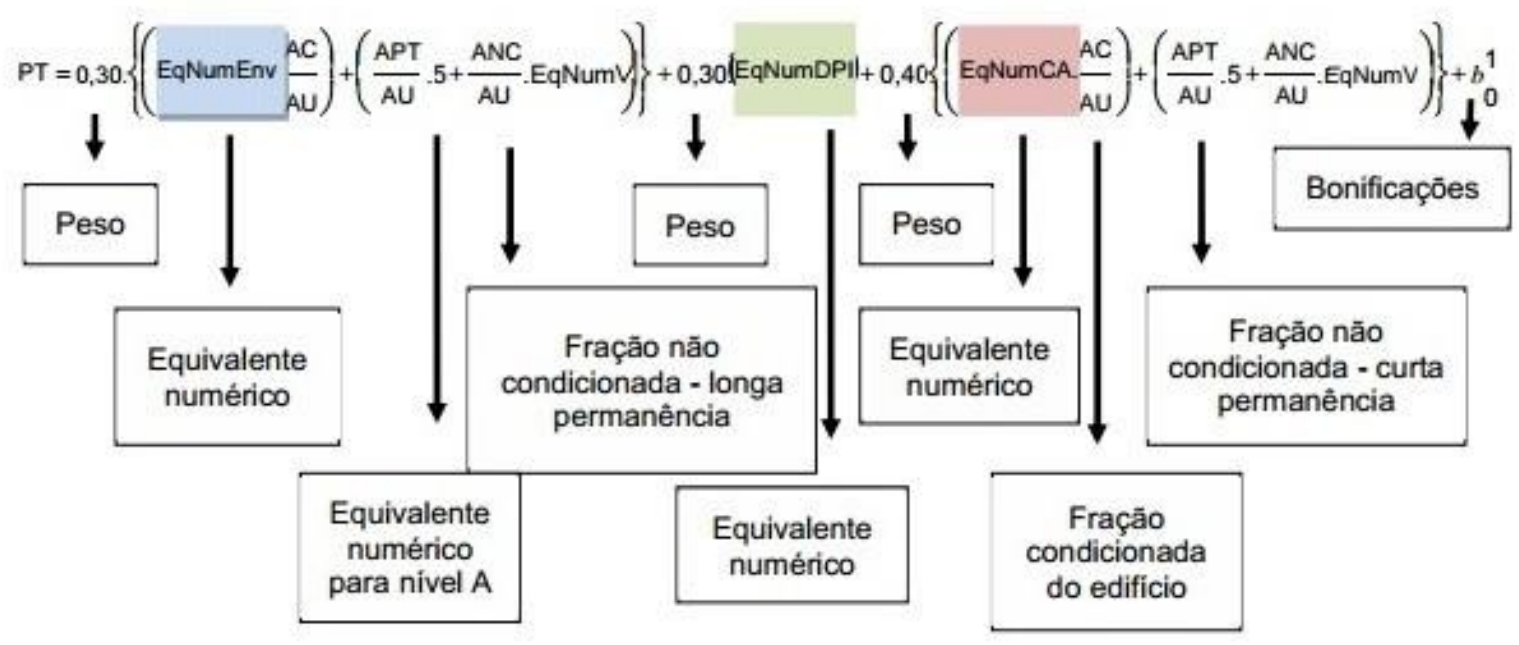

Fonte: BRASIL, 2017 
Onde:

- EqNumEnv é o equivalente numérico da envoltória;

- PT é a pontuação alcançada pelos sistemas;

- EqNumDPI é o equivalente numérico do sistema de iluminação, identificado pela sigla DPI (Densidade de Potência de lluminação);

- EqNum CA é o equivalente numérico do sistema de condicionamento de ar;

- EqNumV é o equivalente numérico de Ambientes não condicionados ou/Ventilados Naturalmente;

- $\quad$ AC é a área de piso de ambientes condicionados;

- $\quad A U$ é a área útil;

- APT é área de piso dos ambientes de permanência temporária ou transitória, desde que não condicionados.

- $\mathrm{AC}$ é a área de piso de ambientes condicionados;

- ANC é a área de piso de ambientes não condicionados de permanência prolongada;

- b, são as bonificações, que valem de 0 a 1.

$\mathrm{Na}$ equação 1 , cada sistema possui um peso relativo à sua contribuição quanto ao consumo de energia do edifício.

Segundo Carlo e Lamberts (2010), "a ventilação natural é um parâmetro de correção do nível de eficiência energética para edifícios que ofereçam condições adequadas de conforto sem precisar de condicionamento parcial". A parcela da ventilação, o EqNumV (equivalente numérico da ventilação) está presente na envoltória e no condicionamento de ar. Pode-se notar pela fórmula que quanto maior a área dos ambientes ventilados naturalmente (desde que comprovado), mais eficiente será a envoltória e, consequentemente, melhores serão as condições de conforto do edifício

Deste modo, de acordo com a metodologia, o EqNumV por sua complexidade de análise só é obtido por meio da simulação. Assim, mesmo utilizando-se do método prescritivo, temos que adotar a simulação para calcularmos o EqNumV se forem avaliadas áreas de permanência prolongada utilizando-se somente com o uso da ventilação natural. Desta maneira, pelo método prescritivo são avaliados edifícios que possuem suas áreas de permanência prolongada totalmente condicionadas. 
As bonificações são pontos adicionais, (de 0 a 1 ), obtidos através de economias no consumo de água ou eletricidade, desde que comprovadas por planilhas de cálculo ou simulação. Esta pontuação pretende estimular o uso de energias limpas, como solar, e a aplicação de inovações do setor construtivo de economia de energia.

Além dos pré-requisitos gerais, segundo o regulamento, cada sistema possui um pré-requisito específico que no caso do não atendimento limita a pontuação dos sistemas. Na envoltória, caso transcorra a avaliação sem o atendimento ao pré-requisito, o equivalente numérico poderá ser rebaixado ou chegar a "E". A tabela 4 especifica os pré-requisitos da envoltória nas diversas zonas bioclimáticas.

Tabela 4 - Pré-Requisitos da Envoltória

\begin{tabular}{|c|c|c|c|c|}
\hline Nível & \multicolumn{2}{|c|}{ Transmitâcia (U) } & Absortância $(\alpha)$ & PAZ \\
\hline & Cobertura (Ucob) & Paredes (Upar) & $\begin{array}{c}\text { Coberturas e } \\
\text { Paredes Externas }\end{array}$ & Mávimo de 50 \\
\hline$A$ & $\begin{array}{l}\text { ZB } 1 \text { e } 2: \\
\text { Amb.Cond: } \cup A C \leq 0,5 \\
\text { Amb. N Cond: } U A N C \leq 1,0 \\
\text { ZB } 3 \text { a 8: } \\
\text { Amb.Cond: } \cup A C \leq 1,0 \\
\text { Amb. N Cond: } \text { UANC } \leq 2,0\end{array}$ & $\begin{array}{l}Z B 1 \text { e } 2: U \leq 1,00 \\
Z B \text { a } 6: U \leq 3,7 \\
Z B 7 \text { e } 8: \\
U \leq 2,5(C T \leq 80) \\
U \leq 3,7(C T>80)\end{array}$ & $\begin{array}{l}\text { ZB } 2 \text { a 8: } \\
\text { Coberturas e Paredes: } \\
\alpha<0,5\end{array}$ & $\begin{array}{l}\text { 2) Fator Solar dos } \\
\text { Vidros de acordo } \\
\text { com o PAZ: }\end{array}$ \\
\hline B & $\begin{array}{l}\text { ZB } 1 \text { e } 2 \text { : } \\
\text { Amb.Cond: } \text { UAC } \leq 1,0 \\
\text { Amb. N Cond: } \text { UANC } \leq 1,5 \\
\text { ZB } 3 \text { a 8: } \\
\text { Amb.Cond: } \text { UAC } \leq 1,5 \\
\text { Amb. N Cond: } \text { UANC } \leq 2,0\end{array}$ & $\begin{array}{l}Z B \text { Z e } 2: U \leq 2,00 \\
Z B \text { a } 6: U \leq 3,7 \\
Z B 7 \text { e } 8: \\
U \leq 2,5(C T \leq 80) \\
U \leq 3,7(C T>80)\end{array}$ & $\begin{array}{l}\text { ZB } 2 \text { a 8: } \\
\text { Coberturas e Paredes: } \\
\alpha<0,5\end{array}$ & $\begin{array}{l}2,1 \text { a } 3 \% F S=0,67 \\
3,1 \text { a } 4 \%: F S=0,52 \\
4,1 \text { a } 5 \%: F S=0,30\end{array}$ \\
\hline C e D & $U \leq 2,0$ & $\begin{array}{l}\text { ZB } 1 \text { a } 6: U \leq 3,7 \\
Z B 7 \text { e } 8: \\
U \leq 2,5(C T \leq 80) \\
U \leq 3,7(C T>80)\end{array}$ & & \\
\hline
\end{tabular}

Fonte: Brasil,2017.

A transmitância térmica, corresponde à transmissão de calor por unidade de tempo, sendo medida levantando-se as áreas dos elementos opacos das fachadas e coberturas da edificação, e calculada através do método de cálculo empregado pela NBR 15220 - Parte 2 (ABNT, 2005). A transmitância exigida dependerá da Zona Bioclimática de implantação da edificação e do nível de eficiência que se pretende atingir.

Conforme a tabela apresentada, o pré-requisito da absortância solar é exigido somente para os níveis A e B em paredes e coberturas nas Zonas Bioclimáticas de 2 a 8. Para o cálculo da absortância, quando não há possibilidade de medição, são utilizadas a cores para sua referência. Utiliza-se para tal, a NBR 15220 (ABNT, 2005), a tese de Kellen Dornelles (Dornelles, 
2008), e o Catálogo de Propriedades Térmicas de Paredes e Coberturas e Vidros do INMETRO (Brasil, 2013), que fornece um banco de dados sobre a absortância das cores.

O Percentual de Abertura Zenital (PAZ) permite um máximo de $5 \%$ para os níveis A e B de eficiência energética, variando conforme o fator solar do vidro utilizado.

Os pré-requisitos são levantados e analisados para verificação de índices mínimos de eficiência. O cumprimento desse parâmetro entra como condicionante para a obtenção da etiqueta, mas não influenciam no Índice de Consumo da Envoltória - ICenv, razão pela qual não serão considerados nesse estudo. Após a determinação dos pré-requisitos específicos, procede-se a determinação do ICenv, que será detalhado a seguir.

\subsubsection{O Índice de consumo da Envoltória}

O Índice de Consumo da Envoltória (ICenv) é um número adimensional e o seu objetivo é demonstrar a influência da envoltória no gasto energético de uma edificação. O cálculo do ICenv é determinado por intermédio de equações, desenvolvidas por meio de simulações de modelos de edifícios que foram captados a partir de pesquisas e levantamentos fotográficos em várias capitais do Brasil. (SANTOS, SOUZA,2012).

A envoltória é a casca da edificação, protege o interior das ações do tempo, ficando esta exposta as intempéries. É na envoltória onde ocorrem as trocas térmicas da edificação, sendo esta responsável pelo ganho ou perda de calor do edifício. Quanto menor o ICenv, mais eficiente é a envoltória da edificação e, consequentemente, menor é o gasto do edifício referente ao consumo de energia.

Para o método prescritivo, segundo o RTQ-C, as equações do Indicador de Consumo são fornecidas para as diferentes Zonas Bioclimáticas (ABNT, 2005,) e dependendo da Área de Projeção do Edifício (APE) e do Fator de Forma (FF), máximo e mínimo permitido.

Algumas Zonas Bioclimáticas foram agrupadas, pois, segundo o Manual do RTQ-C (Brasil, 2017), "as simulações não mostraram diferenças significativas entre o consumo de energia de edificações simuladas nas referidas zonas", possuindo uma equação para a representação destas, como a ZB2 e ZB3, ZB4 e ZB5, ZB6 e ZB7. Abaixo são apresentadas divisões das equações para as Zonas Bioclimáticas conforme o RTQ-C: 
- Equação para a Zona Bioclimática 1

$A P E \leq 500 \mathrm{~m}^{2}$

Limite: Fator de forma máximo (Aenv/Vtot) $=0,60$

APE $>500 \mathrm{~m}^{2}$

Limite: Fator de forma mínimo (Aenv/Vtot) $=0,17$

- Equação para a Zona Bioclimáticas 2 e 3

$A P E \leq 500 \mathrm{~m}^{2}$

Limite: Fator de forma máximo (Aenv/Vtot) $=0,70$

APE $>500 \mathrm{~m}^{2}$

Limite: Fator de forma mínimo (Aenv/Vtot) $=0,15$

- Equação para a Zonas Bioclimáticas 4 e 5

$A P E \leq 500 \mathrm{~m}^{2}$

Limite: Fator de forma máximo (Aenv/Vtot) $=0,75$

Ape $>500 \mathrm{~m}^{2}$

Limite: Fator de forma mínimo $($ Aenv/Vtot $)=$ livre

- Equação para a Zona Bioclimática 6 e 7

$A P E \leq 500 \mathrm{~m}^{2}$

Limite: Fator de forma máximo (Aenv/Vtot) $=0,60$

Ape $>500 \mathrm{~m}^{2}$

Limite: Fator de forma mínimo (Aenv/Vtot) $=0,17$

- Equação para a Zonas Bioclimáticas 8

$A P E \leq 500 \mathrm{~m}^{2}$

Limite: Fator de forma máximo (Aenv/Vtot) $=0,48$

$A P E>500 \mathrm{~m}^{2}$

Limite: Fator de forma mínimo (Aenv/Vtot) $=0,17$

Este estudo tem como objetivo obter subsídios através da manipulação das variáveis da fórmula do Índice de Consumo da Envoltória na Zona Bioclimática 4, razão pela qual apresentaremos a fórmula relativa a essa Zona Bioclimática.

Equação 2: Zona bioclimática 4 e 5 Ape $\leq 500 \mathrm{~m}^{2}$

Limite: Fator de forma máximo (Aenv/Vtot) $=0,75$

ICenv $=135,39 . F A-207,12 . F F+4,61 . P A F T+8,08 . F S+0,31 . A V S-0,07$ AHS -

82, 34.FA. FF + 3,45 PAFT.FS - 0, 005.PAFT.FS.AVS.AHS +171,27 Eq. 2

Equação 3 - Zona Bioclimática 4 e 5 Ape $>500 m^{2}$

Limite: Fator de forma mínimo (Aenv/Vtot) = livre

ICenv $=511$, 12. FA + 0.92. FF - 95, 71 PAFT - 99, 79. FS - 0, 52. AVS - 0, 29 AHS -

$-380,83 . F A . F F+4,27 / F F+729,20 . P A F T . F S+77,15$

Eq. 3 
Onde:

- ICenv é o Indicador de Consumo da envoltória (adimensional);

- AHS é o Ângulo Horizontal de Sombreamento (adimensional), relativo as proteções solares verticais, altera-se entre $0^{\circ}$ e $45^{\circ}$;

- AVS é o Ângulo Vertical de Sombreamento (adimensional), relativo as proteções solares horizontais, entre $0^{\circ}$ e $45^{\circ}$;

- FF é o Fator de Forma, (Aenv/Vtot), adimensional;

- FA é o Fator Altura, (Apcob/ Atot), adimensional;

- FS é o Fator Solar médio dos vidros (adimensional);

- PAFT é o Percentual de Abertura na Fachada total (\%);

- Vtot é o Volume Total da Edificação $\left(\mathrm{m}^{3}\right)$;

- Atot é o Área total construída $\left(\mathrm{m}^{2}\right)$;

- Aenv é a Área da envoltória $\left(\mathrm{m}^{2}\right)$;

- Apcob é a Área de projeção da cobertura $\left(\mathrm{m}^{2}\right)$;

- PAFo é a Percentual de Abertura na Fachada Oeste (\%).

Estas variáveis são calculadas por meio de dados retirados do projeto de Arquitetura do edifício. O projeto precisa estar na fase de "Anteprojeto", com as plantas, os cortes e as fachadas bem definidas para que se possa proceder a obtenção dos parâmetros.

Nas extrações dos dados, as fachadas são separadas pelas orientações Norte, Sul, Leste e Oeste, de onde é retirado o percentual de aberturas de cada fachada. Se o percentual de abertura da Fachada Oeste (PAFo) for igual ou maior que o Percentual total das aberturas (PAFT) mais $20 \%$, substitui-se na equação o PAFT pelo PAFo para o cálculo do ICenv (BRASIL, 2010).

O indicador de consumo do edifício obtido através da equação é comparado a uma escala numérica que o classifica de $A$ à $D$, sendo o conceito " $A$ " referente ao edifício de maior eficiência, e o conceito " $\mathrm{D}$ ", de menor eficiência. Acima desse índice, a envoltória será classificada com o nível "E".

Para a organização dessa escala numérica segundo o regulamento, são retirados mais dois índices, o Índice de Consumo Mínimo (ICmin), e o Índice de Consumo Máximo (ICmax). 
O ICmin representa o indicador de um modelo de máxima eficiência energética baseado no próprio edifício. Os parâmetros são alterados para um PAFT com índice mínimo e um FS com valor máximo e que corresponde a um FS característico de vidros comuns de $3 \mathrm{~mm}$ de espessura, conforme a tabela 3.

Tabela 5 - Variáveis para o ICmin

\begin{tabular}{cc}
\hline \multicolumn{3}{c}{ Variáveis para ICmín } \\
\hline PAFt & 0,05 \\
\hline FS & 0,87 \\
\hline AVS & 0 \\
\hline AHS & 0 \\
\hline
\end{tabular}

Fonte: Brasil, 2017

O ICmax representa o limite mínimo de eficiência que a envoltória deve obter para atingir o nível D na classificação. Para se conseguir esse modelo utiliza-se a mesma equação do ICenv, mas com as variáveis alteradas, ampliando-se as áreas de aberturas do edifício e aumentando o Fator Solar do vidro (o que diminui a sua eficácia), como pode ser conferido na tabela 4:

Tabela 6 - Variáveis para o ICmax

\begin{tabular}{cc}
\hline \multicolumn{3}{c}{ Variáveis para ICmáx } \\
\hline PAFt & 0,60 \\
\hline FS & 0,61 \\
\hline AVS & 0 \\
\hline AHS & 0 \\
\hline
\end{tabular}

Fonte: Brasil, 2017

Observa-se nas tabelas 3 e 4, que o FS empregado vai de 0,61 a 0,87 para a obtenção desses índices, ou seja, o RTQ-C não emprega vidros de alta performance que possuem o Fator Solar reduzido, o que limita o levantamento da eficiência pelo método prescritivo de um edifício que utiliza tal material, tornando-o menos eficiente e prejudicando a avaliação da etiquetagem. O não emprego de vidros de alta performance deve-se,

"a uma limitação mostrada no desenvolvimento do método e se origina da
ausência do fator solar como dado de entrada direto na simulação no
programa EnergyPlus. Ele foi adotado na equação por ser o parâmetro que
melhor descreve o desempenho do vidro, mas as características do vidro
para modelagem no programa referem-se a refletâncias, absortâncias e
emissividades" (CARLO; LAMBERTS, 2010). Segundo Carlo e Lamberts (2010), a conversão do fator solar para as características técnicas dos vidros não é possível devido ao tipo de dado técnico fornecidos pelos catálogos dos fabricantes e a forma de cálculo efetuada pelo mesmo, o Fator Solar utilizado pelo método 
prescritivo limita-se ao mínimo de 0,61, cujas informações sobre as características técnicas dos vidros eram conhecidas.

Atualmente, algumas das características técnicas dos vidros de alta performance são disponibilizadas pelos fabricantes, fato este que possibilitou a incorporação da característica de transmitância térmica do vidro, além do FS, à proposta do novo regulamento de eficiência energética.

Os ângulos de sombreamento não são considerados nos modelos, seja no mais eficiente, seja no menos eficiente. As variáveis da envoltória serão abordadas mais detalhadamente no capítulo 2.3.3.

Após a obtenção do ICmax e ICmin calcula-se o valor "i", que representa o intervalo de mudança entre um nível e outro, onde o edifício deve ser inserir. Esse cálculo é efetuado através da equação 4.

Equação 4 - Equação do cálculo do intervalo entre os níveis de eficiência (Brasil, 2010)

$$
I=\frac{I C \text { máxD }-I C \text { mín }}{4} \text { eq. } 4
$$

Após o cálculo do "i", entra-se na tabela 7, encontrando a partir dos intervalos calculados, o nível de eficiência do edifício analisado.

Tabela 7 - Limites dos Intervalos dos níveis de eficiência

\begin{tabular}{ccc}
\hline & IC mínimo e máximo para cada nível & \\
\hline $\begin{array}{c}\text { Níveis de } \\
\text { Eficiência }\end{array}$ & Limite mínimo & Limite máximo \\
\hline$A$ & - & IC máxD - 3i \\
\hline$B$ & ICmáxD $-3 i+0,01$ & ICmáxD - 2i \\
\hline$C$ & ICmáxD $-2 i+0,01$ & ICmáxD - i \\
\hline$D$ & ICmáxD $-i+0,01$ & ICmáxD \\
\hline$E$ & ICmáxD $+0,01$ & - \\
\hline
\end{tabular}

Fonte: Brasil, 2017.

O RTQ-C aborda para o cálculo da eficiência do edifício vários aspectos da arquitetura, a compreensão dos elementos arquitetônicos usados pelo RTQ-C adquire importância para a concepção de um projeto com eficiência energética. A figura 6 procura elucidar onde são abordados no RTQ-C os elementos arquitetônicos. 
Figura 6 - Relação do RTQ-C com elementos arquitetônicos

\begin{tabular}{|c|c|c|}
\hline \multirow{6}{*}{$\begin{array}{l}\text { M } \\
\mathbf{O} \\
\mathbf{R} \\
\mathbf{F} \\
\mathbf{O} \\
\mathrm{L} \\
\mathbf{O} \\
\mathbf{G} \\
\mathbf{I} \\
\mathbf{A}\end{array}$} & ASPECTOS DA ARQUITETURA & ABORDAGEM nO RTQ-C \\
\hline & Orientação & $\begin{array}{l}\text { Percentual de Aberturas } \\
\text { (PAFT/PAFO) - Equação }\end{array}$ \\
\hline & Aberturas & Percentual de Abertura (PAFt) - \\
\hline & Proteções Solares & Equação \\
\hline & Função & Regulamento Específico: Comercial \\
\hline & Forma & Fator Forma e Fator Altura - (Equação) \\
\hline \multirow[t]{2}{*}{ MATERIAL } & Fechamentos Opacos & $\begin{array}{l}\text { Transmitância e Absortância (Pré- } \\
\text { Requisitos) }\end{array}$ \\
\hline & Fechamentos Transparentes & Fator Solar (Equação) \\
\hline
\end{tabular}

Fonte: IPOG, 2014

Para o cálculo do ICenv são usadas variáveis que precisam ter seus valores extraídos do projeto de arquitetura. No próximo capítulo serão abordados os conceitos dessas variáveis que fazem parte da equação de cálculo do índice de consumo da envoltória. O resultado do cálculo do ICenv demonstra a eficiência energética das fachadas, porcentagem de aberturas envidraçadas e o Fator Solar do vidro, relacionado ao volume da edificação (CARLO, LAMBERTS, 2010).

Nas equações das diferentes zonas bioclimáticas, cada variável possui um peso que lhe foi atribuído, relacionado à área de projeção e as análises dos parâmetros relativos a cada zona. Este peso influencia a eficiência, aumentando-a ou reduzindo-a, conforme o fator que the é conferido. A equação é composta das variáveis de Fator de Forma, Fator Altura, Fator Solar, Percentual de Abertura de Fachadas e Ângulos de Sombreamento, descritos a seguir.

\subsubsection{Variáveis da equação do Índice de Consumo da Envoltória}

\section{Fator de Forma - FF}

O Fator de Forma (FF) representa a volumetria do edifício e evidencia a relação das fachadas com o volume total do prédio. É descrito pela equação da área da envoltória sobre o volume: Aenv / Venv. 
No somatório das áreas da envoltória são consideradas "todas as áreas em contato externo com o meio ambiente" (CARLO; LAMBERTS, 2010), com exceções das lajes sobre pilotis que não são consideradas pelo regulamento.

Mantendo-se a mesma área de projeção do edifício e a mesma altura, constata-se que o Fator de Forma aumenta à medida que o edifício amplia sua área de fachada, permanecendo o volume total constante. Essa correspondência, para efeito de projeto, demonstra a modificação do formato do edifício (mais alongado ou retangular) com o aumento do FF, apresentado na figura 7 e 8.

Figura 7 - Modelo 01 - Planta baixa de um edifício, H=3,00m.
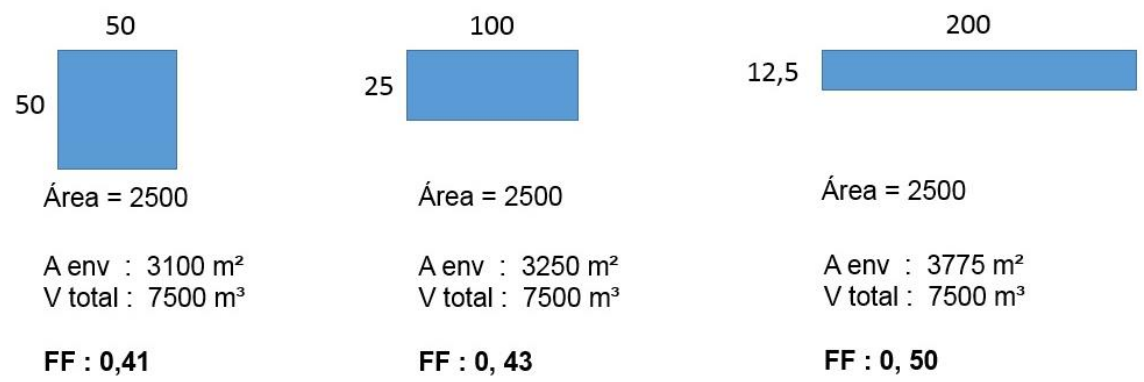

Fonte: a autora (2020)

Na figura 8, o modelo 02 apresenta uma altura de 4,00m. Conservando-se a mesma proporção do modelo 01 quanto ao aumento de área de fachada, nota-se que pelo fato do modelo 02 possuir um volume total maior, o FF possui um valor menor.

Figura 8 - Modelo 02 - Planta baixa de um edifício - $\mathrm{H}=4,00$
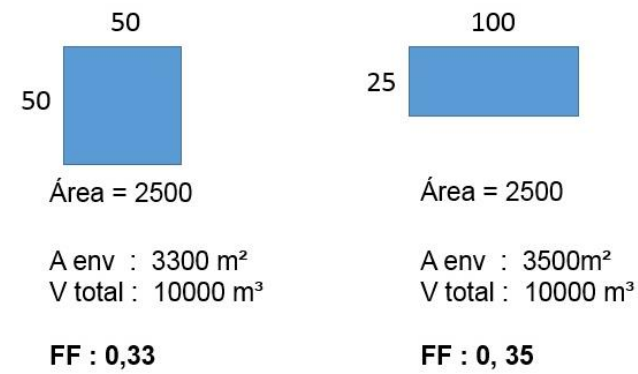

12,5

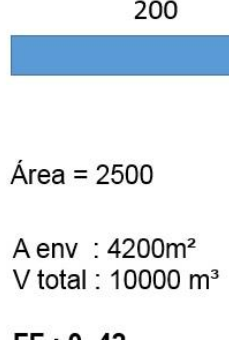

Fonte: a autora (2020) 
Com relação a um modelo que permanece com a mesma área de projeção, ao aumentarmos a sua altura, o fator de forma diminui, ou seja, em um edifício de mesma forma o FF diminui à medida que se aumenta a altura do edifício. A figura 9 demonstra essa afirmação.

Figura 9 - Modelo 03 - Planta baixo de um edifício - $\mathrm{H}=4 \mathrm{~m}, 12 \mathrm{~m}$ e $20 \mathrm{~m}$
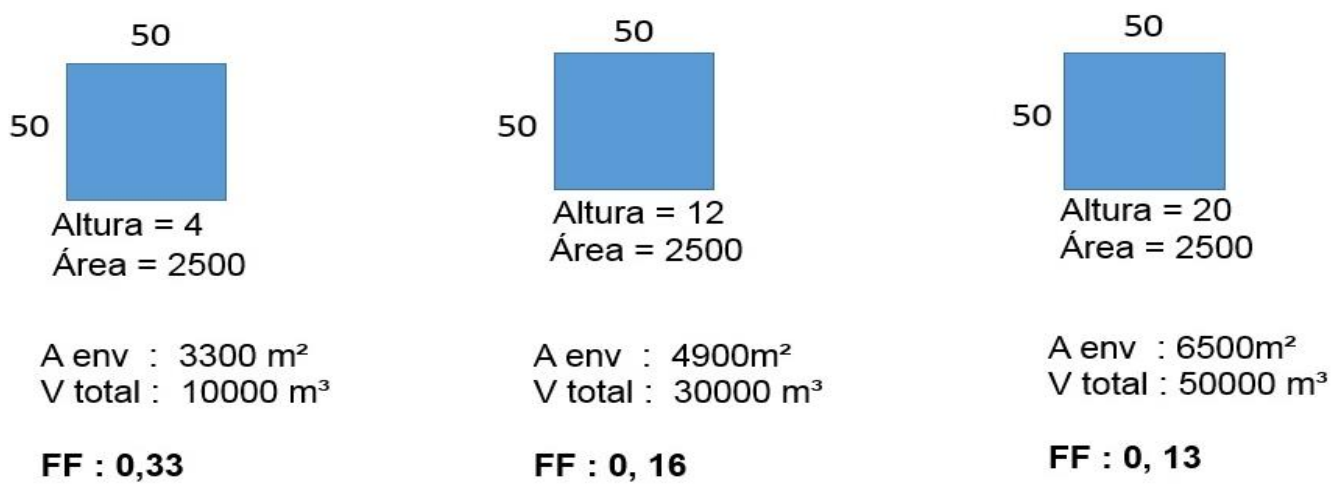

Fonte: a autora (2020)

O Fator de Forma no RTQ-C possui, de acordo com a zona bioclimática e a área de projeção do edifício, restrições de valores máximos e mínimos que devem ser observados durante o levantamento dos dados da edificação analisada. No caso de o Fator de Forma do edifício encontrar-se fora dos valores estipulados, utiliza-se o FF mínimo e/ou máximo fornecido pelo regulamento. O valor do Fator de Forma possui variação de 0 a 1 (BRASIL,2017).

\section{Fator Altura - FA}

O Fator Altura (FA), é a relação entre a área da projeção horizontal da cobertura da edificação (Apcob) e a área total de pisos de todos os pavimentos do edifício (Atot), ou seja, FA = Apcob /Atot, (BRASIL, 2017).

O FA representa o número de pavimentos de uma edificação. A figura 10 apresenta edifícios modelos de um a cinco pavimentos, onde o Fator Altura diminui à medida que os pavimentos são acrescentados, e consequentemente, aumenta-se a área total da edificação sem a alteração da área de projeção da cobertura. Quando o edifício possui um só pavimento Apcob $=$ Atot $=F A=1$. 
Figura 10 - Modelo 04 - Cálculo do Fator Altura

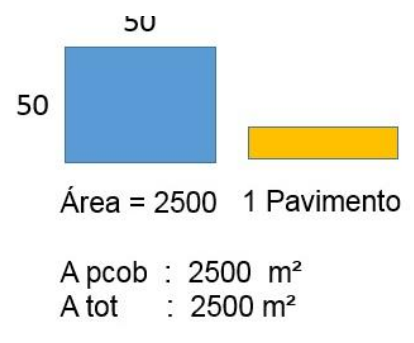

FA : 1

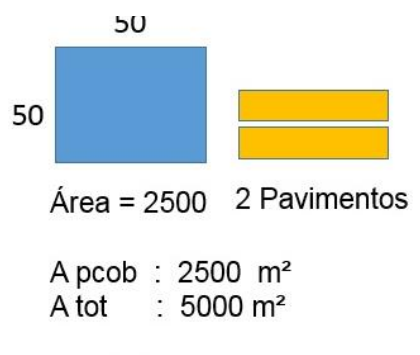

FA : 0,5

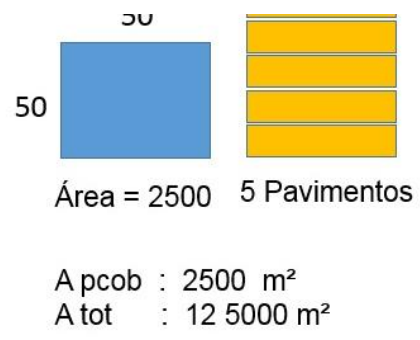

FA : 0,2

Fonte: a autora (2020)

Os Fatores Alturas junto com o Fator de Forma caracterizam a volumetria do edifício analisado. Essa volumetria (FF e FA), influencia na quantidade de radiação solar que cada fachada recebe, promovendo espaços interiores diversos e que afetam o comportamento térmico e a eficiência energética da edificação (LAMBERTS, et al).

Nesta pesquisa, durante a simulação, estes parâmetros irão se manter inalterados na equação do Índice de Consumo de cada edifício, pois ao modifica-los, altera-se também o edifício analisado.

\section{Ângulos de Sombreamentos - AVS e AHS}

O RTQ-C utiliza uma média ponderada da somatória de dois ângulos de sombreamento, o Ângulo Vertical (AVS) e o Ângulo Horizontal (AHS) em função das áreas de aberturas. Esses dados são extraídos das plantas baixas e cortes do projeto de arquitetura.

Estes ângulos demonstram a interferência das projeções de elementos construtivos no "sombreamento" das aberturas envidraçadas externas. Os ângulos são medidos da extremidade do elemento construtivo ou da proteção solar até as aberturas no plano vertical da fachada (Brasil, 2017)

O AHS, conforme demonstra a figura 11, é medido em planta e refere-se às proteções verticais. A abertura possuindo dois ângulos de AHS, utiliza-se o ângulo resultante da média ponderada entre os dois ângulos. Se existir um só ângulo e o outro for igual a zero, divide-se este por dois. O valor máximo empregado pelo regulamento é de $45^{\circ}$. 
Figura 11 - Extração dos ângulos de sombreamento por média.
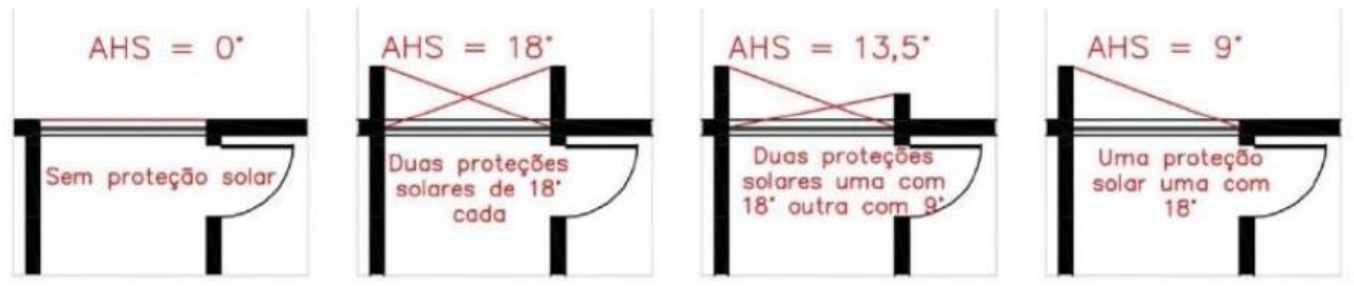

Fonte:

Brasil, 2017

Os ângulos produzidos pelo auto sombreamento também são aplicados a partir da média ponderada, como podemos ver na figura 12. Nesta, a parede vertical ao plano da abertura é considerada no RTQ-C como elemento de sombreamento. O RTQ-C, não utiliza nessa versão do regulamento sombreamentos recebidos por outras edificações, sendo este item corrigido na versão a ser lançada.

Figura 12 - Auto sombreamento - Edificação no Formato "U"

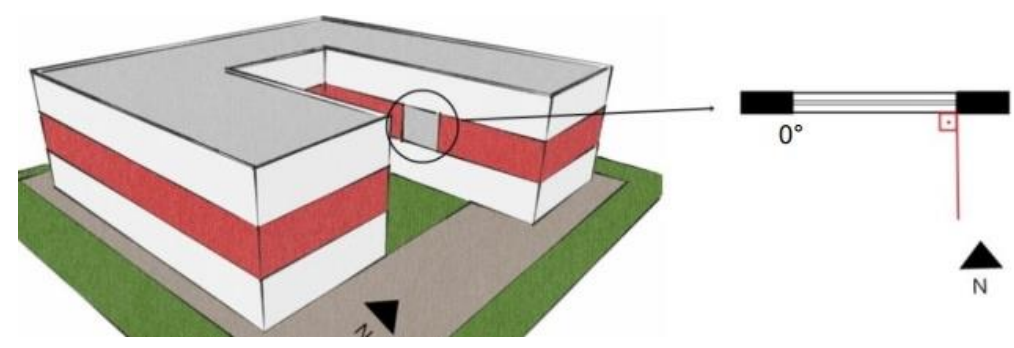

Fonte: Brasil, 2017

Conforme a figura 13, o AVS é medido em corte e se refere às proteções horizontais. Cada abertura possui um ângulo de AVS. O valor máximo estipulado pelo regulamento é de $45^{\circ}$. Pode-se notar que à medida que essas proteções crescem em sua profundidade, cresce também o ângulo formado com o plano vertical (AVS).

Figura 13 - Ângulo Vertical de Sombreamento - AVS
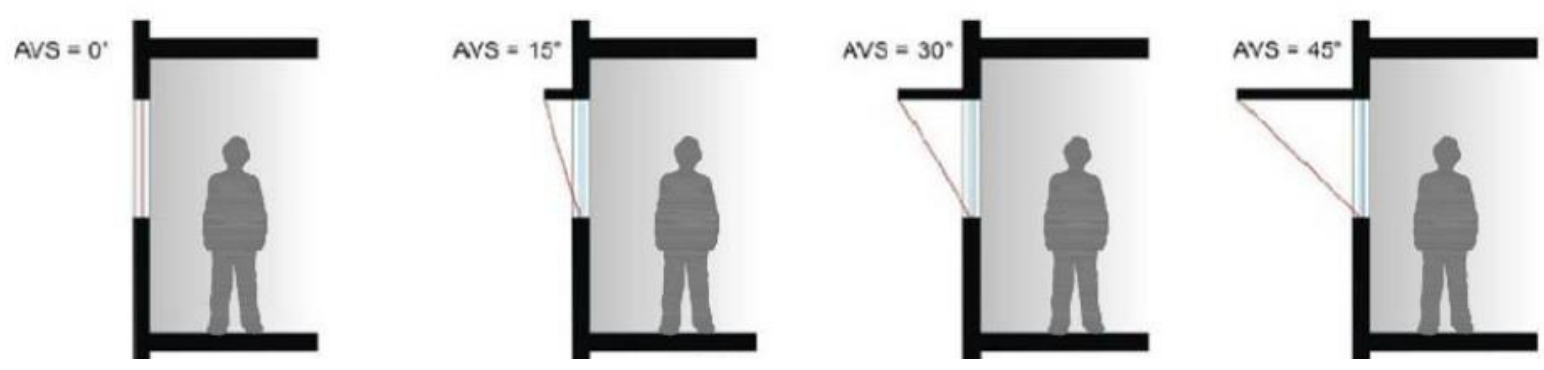

Fonte: Brasil, 2017 
O levantamento dos ângulos de sombreamento é feito por abertura envidraçada, não se levando em conta a orientação solar. Assim, o posicionamento do elemento de sombreamento, seja na fachada Norte ou na fachada Sul, é indiferente, possuindo todos o mesmo peso. Deste modo, a influência destes elementos na abertura se torna prejudicada a partir do momento que não existe o levantamento da real posição solar e nem a separação desses elementos por fachadas. No documento de aprimoramento do regulamento, as orientações solares passam a ser levantadas por fachada.

A influência dos ângulos de sombreamento no ICenv tem sido levantada por diversos pesquisadores. Em pesquisa sobre a aplicação do RTQ-C, Lamberts, Fossati (2010), levantaram dez edifícios de escritório em Florianópolis (ZB3), com o objetivo de avaliar o nível de eficiência energética em suas envoltórias. O estudo constatou que em um dos edifícios analisados que (não possui AVS), no ICenv foi alcançado o Nível E. O mesmo edifício ao se modificar na equação o valor do AVS, de $0^{\circ}$ para $45^{\circ}$ ou AVS e AHS com ângulos iguais a $25^{\circ}$, este alcançava o Nível A.

Pesquisas feitas por Santos, Souza (2012), demonstram incoerências nos resultados dos ângulos de Sombreamento, de modo que ao se utilizar para estudo um edifício sem proteção solar em Belo Horizonte (ZB3), foi verificado que com a inserção de pequenos brises verticais o ICenv decrescia do Nível A para B. Esta verificação contrapõe a afirmação de Lamberts, Fossati (2010), na qual, " a ausência de sombreamento nas aberturas contribui para um aumento no consumo de energia dos edifícios e menor classificação do nível de eficiência em função da obtenção de indicadores de consumo mais elevados".

Estes estudos demonstram a sua importância na medida em que testam a eficiência do Regulamento e apontam os tópicos com os quais devam haver maiores pesquisas.

Salienta-se aqui novamente o reconhecimento das restrições do regulamento, porém se destaca a necessidade de sua utilização para a compreensão, por parte dos projetistas, do desempenho dos elementos construtivos e de sua correta utilização no projeto como parte integrante na eficiência energética dos edifícios.

\section{Fator Solar}


As fachadas são constituídas por materiais opacos e transparentes que durante o dia recebem a radiação solar. $O$ vidro como elemento transparente promove o fechamento das aberturas separando o meio interno do externo, podendo ser acompanhado ou não de elementos opacos no caixilho que o auxilia na vedação das aberturas.

Os vidros das aberturas recebem a radiação solar que é decomposta em parcelas: a primeira é refletida ao meio externo, a segunda é absorvida pelo vidro e retransmitida ao meio interno e externo por condução e a terceira é refratada para o meio interno pelo vidro, como apresenta a figura 14.

Figura 14 - Incidência da Radiação Solar nos vidros das Fachadas

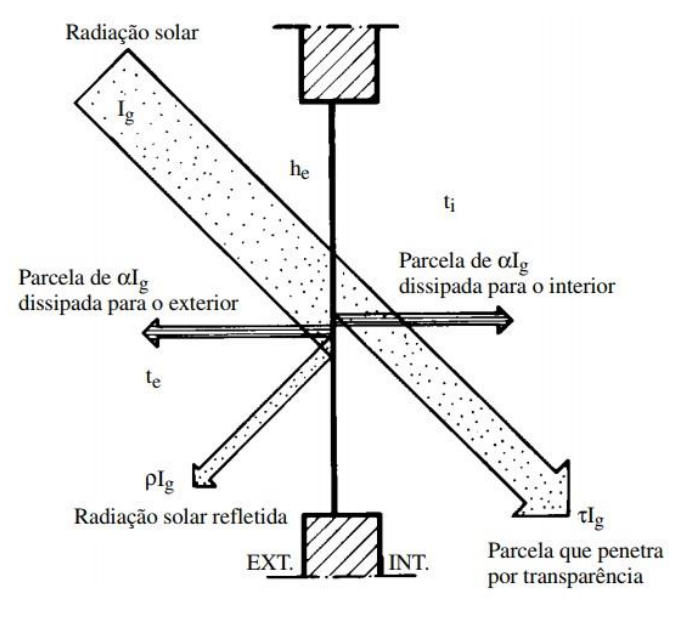

Fonte: FROTA; SCHIFFER ,2001

A radiação que atravessa as aberturas envidraçadas é resultante do ângulo de incidência do raio solar com relação à superfície vertical do vidro, além das características físicas do material, como a absortividade da superfície externa do fechamento, a transmitância térmica e transmissividade do vidro, dependendo também da resistência superficial externa que foi tabelada em 0,04 $\mathrm{m}^{2} \mathrm{~K} / \mathrm{W}$ (ABNT 2005).

A relação entre a radiação incidente no vidro e as parcelas que penetram no interior do ambiente é chamada de Fator Solar (LAMBERTS, DUTRA, PEREIRA,2012), abreviado por FS. A figura 15 indica as parcelas de radiação que penetram no ambiente através do vidro e a equação do Fator Solar com suas variáveis conforme a NBR 15220 (ABNT, 2005). A radiação recebida pela fachada sofre alterações conforme o ângulo que o raio solar faz com o plano vertical do vidro. Quanto maior o ângulo de incidência, maior é a radiação que penetra no 
ambiente (menos reflexão), e quanto menor o ângulo, menor é a radiação que penetra no interior (maior reflexão).

Figura 15 - Fator Solar dos vidros, parcela de radiação incidente.

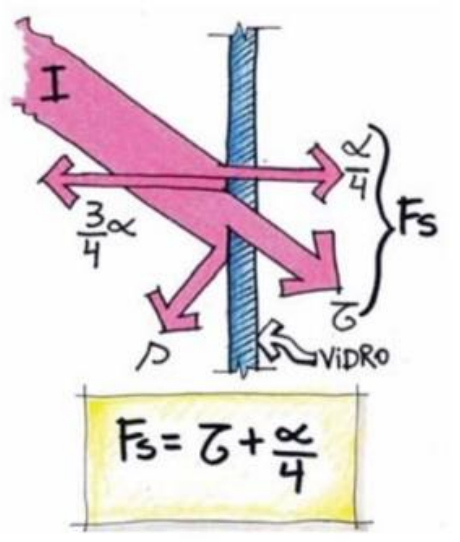

$$
\mathrm{F}_{\mathrm{S}}=\tau+\left(\mathrm{U} \cdot \alpha \cdot \mathrm{R}_{\mathrm{SE}}\right) \text { Onde: }
$$

$\mathrm{F}_{\mathrm{S}}$ Fator Solar dos elementos transparentes ou translúcidos $\left[\mathrm{J} / \mathrm{m}^{2} \mathrm{~K}\right]$;

$\tau$. Transmissividade do vidro ;

U Transmitância térmica do componente $\left[\mathrm{W} /\left(\mathrm{m}^{2} . \mathrm{K}\right)\right]$;

$\alpha$ Absortividade da superfície externa do fechamento;

$R_{\mathrm{SE}}$ Resistência superficial externa $\left(0,04 \mathrm{~m}^{2} . \mathrm{K} / \mathrm{W}\right)$

Fonte: Lambert, Dutra, Pereira, 2012.

No RTQ-C a influência do FS no vidro assume pesos diferenciados variando conforme a equação do índice de consumo utilizada. Em cada equação o FS possui contribuições diferenciadas influenciando em maior ou menor grau o consumo de energia do edifício. 0 Regulamento utiliza para o FS o ângulo de incidência ortogonal à superfície, considerando o valor máximo da radiação incidente na abertura envidraçada.

O Fator Solar do vidro é fornecido pelo catálogo do fabricante, em porcentagem, e utilizado no cálculo como um valor fracionado (Brasil, 2017). O método prescritivo considera o Fator Solar dos vidros entre 0,61 (ICmaxD) e 0,87 (ICmin), (CARLO, LAMBERT, 2010).

\section{Percentual de Abertura nas Fachadas - PAF}

Essa variável é calculada pela soma das áreas de aberturas verticais envidraçadas (com fechamento transparente ou translúcido) dividida pela área total de fachada da edificação (BRASIL, 2017).

As aberturas verticais, de acordo com o regulamento, são as que possuem um ângulo superior a $60^{\circ}$ em relação ao plano horizontal da edificação. As aberturas que possuem ângulos maiores ou iguais a $60^{\circ}$ são consideradas como aberturas zenitais (PAZ) e são utilizadas na avaliação dos pré-requisitos do regulamento. 
As áreas de aberturas transparentes em uma edificação facilitam a entrada da radiação solar para o interior do edifício, aumentando sua carga térmica e consequentemente seu consumo de energia. Carlo (2008) demonstra que o indicador de consumo é crescente com o aumento da área de aberturas. Em pesquisa realizada sobre a aplicação do RTQ-C em dez edifícios de escritório em Florianópolis, Lambert, Fossati (2010), constataram que os edifícios que possuíam percentuais de aberturas de $49 \%$, 51\% e 55\% obtiveram na classificação Nível D, e os de percentual mais baixo nas aberturas, com 17\% e 19\%, classificação Nível A.

No regulamento as aberturas são diferenciadas por orientação somente com relação as aberturas da fachada oeste, o PAFo, sendo que estas ao serem maiores que o PAFt mais $20 \%$ são utilizadas no cálculo do índice de consumo ao invés do valor do PAFt.

As orientações das fachadas são estipuladas a partir da figura 16, que representa o quadrante que a fachada deverá estar inserida para que esta pertença a orientação Norte, Sul, Leste ou Oeste. Com o Norte da figura apontado para a mesma direção do Norte geográfico marcado na implantação, a reta ortogonal a fachada deverá estar dentro de um dos quadrantes delimitados abaixo para pertencer a orientação descriminada.

Figura 16 - Quadrante para a definição da orientação de fachadas

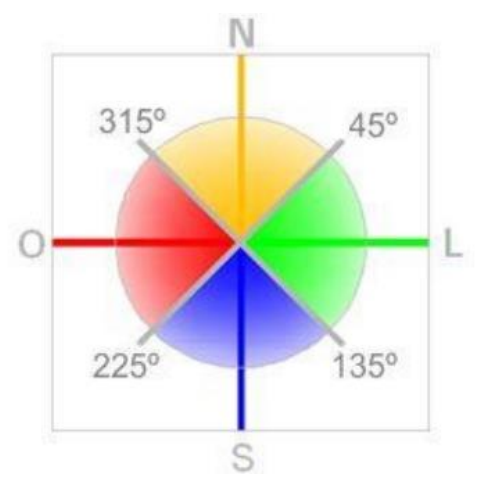

Fonte: BRASIL (2017)

O uso simplificado das orientações prejudica a correta avaliação da radiação solar que incide sobre a fachada.

Segundo os dados da radiação solar incidente nas superfícies verticais (fachadas), Frota e Shiffer (2004), apresentam os dados de radiação solar global sobre os planos verticais e horizontais para a Latitude $20^{\circ} \mathrm{Sul}$, conforme a tabela 8. 
Tabela 8 - Radiação global (Ig) durante o dia 22 de dezembro na latitude $20^{\circ}$ Sul

\begin{tabular}{|c|c|c|c|c|c|c|c|c|c|c|c|c|c|c|c|}
\hline \multirow{2}{*}{ Orientação } & \multicolumn{13}{|c|}{ Hora } & \multicolumn{2}{|c|}{ Total } \\
\hline & $06 \mathrm{~h}$ & $07 \mathrm{~h}$ & $08 \mathrm{~h}$ & 09h & $10 \mathrm{~h}$ & $11 \mathrm{~h}$ & $12 \mathrm{~h}$ & $13 \mathrm{~h}$ & $14 \mathrm{~h}$ & $15 \mathrm{~h}$ & $16 \mathrm{~h}$ & $17 \mathrm{~h}$ & $18 \mathrm{~h}$ & & \\
\hline Norte & 20 & 38 & 50 & 58 & 63 & 68 & 65 & 68 & 63 & 58 & 50 & 38 & 20 & 659 & \\
\hline Nordeste & 114 & 299 & 412 & 407 & 344 & 225 & 65 & 68 & 63 & 58 & 50 & 38 & 20 & 2163 & \\
\hline Leste & 241 & 583 & 746 & 657 & 511 & 309 & 65 & 68 & 63 & 58 & 50 & 38 & 20 & 3409 & . \\
\hline Sudeste & 239 & 547 & 673 & 578 & 446 & 288 & 107 & 68 & 63 & 58 & 50 & 38 & 20 & 3175 & \\
\hline Sul & 108 & 213 & 234 & 194 & 158 & 138 & 124 & 138 & 158 & 194 & 234 & 213 & 108 & 2214 & \\
\hline Sudoeste & 20 & 38 & 50 & 58 & 63 & 69 & 107 & 288 & 446 & 578 & 673 & 547 & 239 & 3175 & $\underline{\text { DO }}$ \\
\hline Oeste & 20 & 38 & 50 & 58 & 63 & 68 & 65 & 309 & 511 & 657 & 746 & 583 & 241 & 3409 & \\
\hline Noroeste & 20 & 38 & 50 & 58 & 63 & 68 & 65 & 225 & 344 & 407 & 412 & 299 & 114 & 2163 & \\
\hline
\end{tabular}

Fonte: Frota e Shiffer (2001)

Verifica-se através da tabela 8, que existem diferenças relevantes de valores de radiação solar total no dia 22 de dezembro entre as orientações (assim como nos outros dias do ano). É observado que os maiores valores acontecem na orientação Leste e Oeste, sendo os valores nas orientações Sudeste e Sudoeste maiores do que na Norte e Sul. Deste modo um exame das fachadas de um edifício com suas devidas orientações se torna importante para uma análise mais correta de sua eficiência energética. Na proposta do novo regulamento, as fachadas são levantadas a partir das oito orientações.

No projeto de arquitetura, as áreas das aberturas estão ligadas a vários fatores que devem ser analisados em conjunto como: conforto térmico, lumínico e acústico do ambiente, promoção de vistas para o exterior, consumo de energia do edifício e o fator estético. Essas análises dificultam a compreensão, por parte dos projetistas, na elaboração de estudos que respondam da melhor maneira a todos estes parâmetros ao mesmo tempo.

A proposta desta pesquisa é propor a análise de alguns parâmetros das aberturas envidraçadas, contrapondo-os, de forma a facilitar a compreensão de seus pesos no índice de consumo da envoltória, e consequentemente, fornecer aos projetistas subsídios para a elaboração de projeto de edifícios que minimizem o consumo de energia.

\subsection{Análises e limitações do método prescritivo}

A partir da Portaria 372 de 17 de setembro de 2010, que regulamentou o RTQ-C, diversas pesquisas foram efetuadas no intuito de colaborar com a compreensão de sua aplicação, analisar suas limitações e sugerir aprimoramentos. 
Através de abordagens diferenciadas, o RTQ-C teve a sua aplicação analisada através de diversos aspectos, entre eles comparar os dois métodos de aplicação, o prescritivo e o de simulação, analisar as restrições da metodologia e sugerir modificações, identificar a influência de suas variáveis no conforto térmico dos ambientes e desenvolver o aprendizado da metodologia.

A apreensão dessas pesquisas se faz importante pois o Regulamento de Eficiência Energética terá uma nova versão, e a análise dos pontos de discussões levantados sobre o regulamento vigente servirá como base de verificação de suas limitações e como referência para a compreensão do novo regulamento.

A seguir, serão apresentadas pesquisas a partir de 2009 para que a extensão de sua aplicabilidade possa ser compreendida. A análise destaca o Sistema da Envoltória e o modelo prescritivo de aplicação, que é a base desse projeto de pesquisa.

\subsubsection{Pré-requisitos da envoltória}

Desde que foi lançado, o levantamento dos dados para a aplicação do regulamento é uma etapa trabalhosa e evidencia a ausência de informações corretas e padronizadas, seja em projetos arquitetônicos, seja nos catálogos técnicos dos fabricantes de materiais de construção (Santos, 2009). Utilizada como pré-requisito específico da envoltória para a etiquetagem, a absortância solar das superfícies é um parâmetro que possui índices obrigatórios para se adquirir o nível A e B de eficiência nas zonas bioclimáticas de 2 a 8 . Em Dornelles, Santos e Souza (2010), ao se analisar a envoltória de um edifício público na zona bioclimática 3 em fase de projeto, constata-se a "dificuldade de conseguir uma quantificação exata dos dados da absortância de cada material utilizado em uma edificação e a obtenção de valores mais acurados, o que dificulta a aplicação do RTQ-C". Santos (2009), também ratifica a "inexistência de um amplo banco de dados que quantifique a absortância de materiais", o que prejudica o uso do regulamento.

Devido a insuficiência desses parâmetros, nas duas pesquisas citadas foi utilizada a NBR 15220 - Desempenho Térmico das Edificações ( ABNT,2005) para a complementação de dados, onde "exigiu-se frequentes aproximações" ( DORNELLES, SANTOS E SOUZA , 2010), o que prejudica a avaliação da eficiência do edifício, pois variações pequenas na absortância influenciam no 
nível da eficiência, podendo ocorrer variações do Nível A ao C (SANTOS ,2009), o que constata também a importância da revisão de Normas Técnicas Brasileiras que são utilizadas na composição do regulamento.

Em Dornelles, Santos e Souza (2010), fica evidenciado o fato de que no cálculo da absortância, além (da cor da fachada), deve-se considerar o material e a sua textura, o que implica em uma maior medição desses parâmetros em laboratórios para ampliação dos dados gerados para consulta.

A transmitância térmica de paredes e coberturas também é um parâmetro de pré-requisito do regulamento e possui índices obrigatórios a serem cumpridos para o Nível A B, C, D e E nas diferentes Zonas Bioclimáticas. Por não possuir uma relação linear com o consumo de energia, a transmitância dificulta a compreensão de sua atuação na eficiência energética além do isolamento térmico que esta proporciona através dos materiais, " a influência do parâmetro da transmitância térmica das paredes depende da presença e comportamento de outros parâmetros presentes na edificação" (MELO, LAMBERTS, 2008).

Em pesquisa através da aplicação do método prescritivo para a verificação de sua sensibilidade face à variação da carga térmica interna em edifícios de escritórios (ZB1), Brandalise, et al (2014), concluíram que, em edifícios de elevada densidade de carga térmica (DCI), os que obtiveram Nível B consumiam menos energia do que os de Nível A:

"Coberturas e paredes configuradas para atender o Nível B de transmitância apresentam um consumo de energia inferior que a envoltória que atende $o$ Nível A. Isso ocorre, pois, um maior isolamento da envoltória não permite a saída do ar quente gerado através de equipamentos e pessoas" (BRANDALISE, et al, 2014).

O estudo demonstrou a necessidade de revisão das transmitâncias térmicas aplicadas em paredes e coberturas de edifícios com elevada $\mathrm{DCl}$ no método prescritivo.

\subsubsection{Método Prescritivo versus Método de Simulação Computacional}

O Método Prescritivo do RTQ-C, por ser um método simplificado, foi desenvolvido no intuito de disseminar mais facilmente a aplicação do Regulamento, e restringe seu uso a edificações com volumetrias e fachadas mais simples, como a maior parte dos edifícios que serviram de modelos para o desenvolvimento da fórmula estatística do Índice de Consumo da Envoltória 
(Carlo, 2008). Em Pedrini, et al (2010), ao aplicar os dois métodos do regulamento para encontrar o nível de eficiência energética em três edifícios de envoltórias diferenciadas na Zona Bioclimática 8, conclui-se que "o método prescritivo, por ser um método simplificado, deixa de contemplar soluções arquitetônicas de comprovada eficiência energética em função das simplificações de análises das variáveis que influenciam o consumo energético". O método de simulação, aplicado na pesquisa através do programa Energy-Plus, por sua vez, é confirmado como ferramenta de análise de consumo energético das edificações, superando as limitações do método prescritivo (PEDRINI, et al ,2010). A sua aplicação, porém, permanece restrita a ambientes específicos, como em universidades ou por especialistas da área de eficiência energética, o que dificulta sua aplicabilidade por parte dos projetistas.

Em Carlo, Lamberts (2010), ao aplicar os dois métodos em edifícios de escritórios na cidade de Florianópolis ( ZB3), são ressaltadas as limitações do método prescritivo, como o uso da simulação para o cálculo da ventilação natural, o limite de análise das diferentes volumetrias ou as restrições ao uso de vidros de alta eficiência energética, mas coloca que " o método apresenta um elevado potencial de análise para uma variedade de casos e medidas de conservação de energia, cujas combinações são incontáveis". Melo, et al (2011), através da aplicação do RTQ-C em edifícios comerciais também na cidade de Florianópolis, corrobora com a afirmação das limitações do método prescritivo, onde "o modelo simplificado conduz a um menor nível de eficiência energética quando comparado com o nível obtido através do método de simulação", partindo da premissa de que o método de simulação proporciona resultados mais corretos. Em Silva, Almeida e Andreasi (2012), em pesquisa efetuada com o objetivo da validação do método prescritivo, aplicando-se o RTQ-C em uma instituição de ensino (ZB6), foi concluído que quando confrontado os dois métodos (prescritivo e simulação), os resultados da pesquisa apresentaram divergência no sistema da envoltória, obtendo-se Nível A na simulação computacional e Nível B no prescritivo.

Estas pesquisas demonstram que o método prescritivo, embora seja aplicado para a maioria dos edifícios (já que grande parte das edificações possuem volumetrias simples), não avalia com eficiência modelos que possuem características externas distintas, com volumetrias diferenciadas ou fachadas mais complexas, evidenciando assim a importância de sua atualização para suprir tais deficiências. 


\subsection{3 Índice de Consumo da envoltória (ICenv) - variáveis da envoltória}

O Índice de Consumo da Envoltória (ICEnv) baseia-se em equações fornecidas pelo regulamento e são diferenciadas pelas Zonas Bioclimáticas e pelo fator de forma (FF). As variáveis que compõem a equação trazem as características da fachada e volumetria da edificação, como: percentual de abertura (PAFT), fator solar do vidro (FS), sombreamentos proporcionados pelo próprio edifício ou por elementos adicionados a fachadas (AVS e AHS) e as características da edificação, volumetria e altura (FF e FA). Vários estudos elaborados a partir do emprego do ICEnv proporcionam análises e discussões sobre os efeitos desses parâmetros na eficiência energética do edifício, tornando-se uma ferramenta que corrobora com a formulação de estratégias de projeto para se alcançar a eficiência, " o RTQ-C é uma ferramenta que estimula o emprego de técnicas de projetos e estratégias bioclimáticas para a criação de soluções arquitetônicas mais adequadas ao clima que estão inseridas" (FOSSATI; LAMBERT; 2010).

Eloy, Akutsu (2016) em pesquisa executada através do método prescritivo, em trinta edificações comerciais (ZB3), com o intuito de fornecer diretrizes arquitetônicas para obtenção do Nível A em eficiência energética, constataram que o "PAF é a variável que mais impacta no resultado da classificação, seguida pelo AVS ". A pesquisa fornece a relação das áreas de aberturas das fachadas com as variáveis do fator solar e ângulos de sombreamentos. Os edifícios com percentuais de aberturas maiores possuem classificação nos níveis de eficiência menores, como foi observado em Lamberts; Fossati (2010) onde, ao se analisar a eficiência energética em edifícios de escritórios em Florianópolis (ZB3), é verificado que os edifícios que possuíam as fachadas com percentual de aberturas entre $49 \%$ e 55\% recebiam a etiqueta Nível $D$, enquanto o Nível A era alcançado para os que apresentavam as aberturas entre $17 \%$ e $19 \%$ da área da fachada, concluindo que quanto maior o PAFt, menor a eficiência da edificação. Do mesmo modo, estudo realizado por Carlo, Maciel (2011), sobre a análise da sensibilidade das variáveis do Icenv, aplicadas em todas as Zonas Bioclimáticas de 1 a 8, constatou-se " que o PAFt é o parâmetro que exerce maior sensibilidade, devido a influência que as quantidades de aberturas exercem nas necessidades de: aquecimento na ZB1, de aquecimento e resfriamento na ZB2, ZB3 e na ZB4 e ZB5, de resfriamento na ZB7, na ZB6 e ZB8 ". 
A tabela 9, apresenta as médias dos pesos dos parâmetros da envoltória levantados por Carlo, Maciel (2011).

Tabela 9 - Influência média dos parâmetros da envoltória

\begin{tabular}{cccccc}
\hline \multirow{2}{*}{$\begin{array}{c}\text { Zonas } \\
\text { Bioclimáticas }\end{array}$} & Área de projeção & \multicolumn{4}{c}{ Parâmetros } \\
\cline { 2 - 5 } ZB1 & Ape $>500 \mathrm{~m}^{2}$ & 68,72 & 3,14 & 13,37 & 14,77 \\
\cline { 2 - 5 } & Ape $\leq 500 \mathrm{~m}^{2}$ & 32,58 & 25,18 & 29,63 & 12,60 \\
\hline \multirow{2}{*}{ ZB 2 e 3 } & Ape $>500 \mathrm{~m}^{2}$ & 58,06 & 8,29 & 24,72 & 8,94 \\
\cline { 2 - 5 } ZB 4 e 5 & Ape $\leq 500 \mathrm{~m}^{2}$ & 36,23 & 17,64 & 29,47 & 16,66 \\
\cline { 2 - 5 } & Ape $>500 \mathrm{~m}^{2}$ & 46,39 & 45,31 & 5,34 & 2,96 \\
\hline \multirow{2}{*}{ ZB 7 } & Ape $\leq 500 \mathrm{~m}^{2}$ & 14,84 & 26,18 & 45,58 & 13,39 \\
\hline \multirow{2}{*}{ ZB6 e 8 } & Ape $>500 m^{2}$ & 56,42 & 19,17 & 10,20 & 14,20 \\
\cline { 2 - 5 } & Ape $\leq 500 m^{2}$ & 8,84 & 21,60 & 31,44 & 38,12 \\
\cline { 2 - 5 } & Ape $>500 m^{2}$ & 68,56 & 5,13 & 19,30 & 7,00 \\
\hline
\end{tabular}

Fonte: Carlo, Maciel (2011).

Pode-se notar, através da tabela 9, que na ZB4, em edifícios de área de projeção (Ape) maior que $500 \mathrm{~m}^{2}$, o PAFT é o parâmetro que mais influência no consumo de energia. Na mesma zona bioclimática em questão (ZB4), o FS apresenta um comportamento diferenciado das outras zonas bioclimáticas, apresentando um peso quase igual ao do PAFT, o que define a importância da área da janela e do tipo de vidro escolhido para a eficiência energética de edifícios projetados neste clima.

Os ângulos de sombreamento AVS e AHS são variáveis que apresentam os seus resultados abordados em diversos estudos sobre o regulamento. O levantamento dos ângulos de sombreamento sem se levar em conta a orientação da fachada, latitude local, horários e épocas do ano levantam incertezas sobre os resultados desses parâmetros (FERREIRA, SOUZA, 2010). Em pesquisa realizada por Pacheco, et al (2012) , ao se analisar a influência dos ângulos de sombreamento no resultado do ICenv na Zona Bioclimática 8, constatou-se que "em edifícios com pequenos valores de PAFTs, os ângulos de sombreamento não interferem na alteração de nível da etiqueta " o que contraria a Norma Brasileira de Desempenho Térmico em Edificações (ABNT, 2005), no qual o sombreamento é uma das principais estratégias bioclimáticas para essa área devido ao potencial de redução da carga térmica, aumentando a eficiência energética do edifício. No cálculo de ponderação dos ângulos de sombreamentos, é computado também o auto sombreamento, mas é preterido os sombreamentos causados por construções vizinhas. Em Fernandes (2012), em estudo sobre a influência do sombreamento do entorno no nível da etiqueta de eficiência, é colocado que: 


\begin{abstract}
"Nos edifícios (modelos) analisados que se situavam em áreas adensadas e possuíam um elevado consumo de energia devido aos efeitos de ondas de calor que ocorriam nessas áreas, estes, obtiveram a redução do sistema de condicionamento de ar utilizando para o cálculo de análise o sombreamento do entorno. Sugere-se através deste estudo a inclusão no Índice de Consumo da Envoltória do sombreamento causados por edificações vizinhas" (FERNANDE ,2012).
\end{abstract}

O fator solar dos vidros (FS), é a variável da equação da envoltória que apresenta a menor influência no Indicador de Consumo nas diversas Zonas Bioclimáticas, salvo a ZB4 e 5, onde o FS se equipara ao PAFt no impacto da mudança no Nível de Eficiência (CARLO; MACIEL, 2011).

Em pesquisa realizada por Eloy; Akutsu (2016), é atestado que " o FS possui pequena influência sobre o resultado da equação da envoltória. Sua utilização é relevante quando o Icenv está próximo à alteração do nível de classificação energética", em pesquisa realizada para a Zona Bioclimática 3.

Os estudos denotam a relevância do tema e a importância da compreensão dos efeitos desses parâmetros no conforto térmico e na eficiência energética no edifício. A regulamentação de Normas Técnicas e a disseminação, aprendizado e aplicação destas por todos os projetistas, arquitetos ou engenheiros que estão envolvidos com Projetos de Edificações é fundamental para que ocorra uma melhoria na qualidade ambiental dos edifícios construídos além da redução dos seus gastos energéticos durante a sua vida útil.

De acordo com as pesquisas efetuadas sobre o RTQ-C, vários aspectos foram levantados, seja identificando lacunas no regulamento ou contribuindo com sugestões para o seu aprimoramento. A figura 17 resume essas informações.

Figura 17 - Quadro resumo das principais conclusões dos artigos analisados.

\begin{tabular}{|c|l|c|l|}
\hline $\begin{array}{c}\text { PARÃMETRO } \\
\text { ESTUDADO }\end{array}$ & $\begin{array}{c}\text { AUTOR e } \\
\text { MÉTODO DE } \\
\text { ANÁLISE }\end{array}$ & $\begin{array}{c}\text { TIPOLOGIA E } \\
\text { ZB }\end{array}$ & \multicolumn{1}{c|}{ CONCLUSÕES } \\
\hline \multirow{2}{*}{ Absortância } & $\begin{array}{l}\text { SANTOS (2009) } \\
- \text { Simulação e } \\
\text { Prescritivo }\end{array}$ & Público-ZB3 & $\begin{array}{l}\text { Ausência de informações corretas e dados } \\
\text { técnicos nos projetos de arquitetura e nos } \\
\text { catálogos técnicos de materiais. }\end{array}$ \\
\cline { 2 - 5 } & $\begin{array}{l}\text { DORNELLES, } \\
\text { SANTOS, SOUZA } \\
\text { (2010) } \\
\text { - Prescritivo }\end{array}$ & Público-ZB3 & $\begin{array}{l}\text { A Inexistência de um amplo banco de dados } \\
\text { sobre absortância dos materiais. }\end{array}$ \\
\hline Transmitância & $\begin{array}{l}\text { BRANDALISE; } \\
\text { CUNHA e } \\
\text { OLIVEIRA (2014). } \\
\text { - Prescritivo }\end{array}$ & $\begin{array}{l}\text { Escritórios } \\
\text { ZB 1 } 1\end{array}$ & $\begin{array}{l}\text { Propõe para o método prescritivo, a revisão das } \\
\text { transmitâncias térmicas aplicadas em paredes e } \\
\text { coberturas em edifícios com elevada Densidade } \\
\text { de Carga Térmica (DCI). }\end{array}$ \\
\hline
\end{tabular}




\begin{tabular}{|c|c|c|c|}
\hline \multirow{5}{*}{$\begin{array}{l}\text { Método } \\
\text { Prescritivo } \\
\text { contra } \\
\text { Método } \\
\text { Simulação }\end{array}$} & $\begin{array}{l}\text { CARLO (2008). } \\
\text { - Simulação } \\
\text { - Estatístico }\end{array}$ & $\begin{array}{l}\text { Desenvolvimento } \\
\text { do RTQ-C } \\
\text { Todas as } \\
\text { tipologias em } \\
\text { diferentes ZBs. } \\
\end{array}$ & $\begin{array}{l}\text { Aplicação fica restringida a projetos } \\
\text { simplificados; } \\
\text { Não contempla soluções de comprovada } \\
\text { eficiência energética. }\end{array}$ \\
\hline & $\begin{array}{l}\text { PEDRINI, et al } \\
\text { (2010) }\end{array}$ & $\begin{array}{l}\text { Comerciais } \\
\text { ZB } 8\end{array}$ & $\begin{array}{l}\text { Deixa de contemplar soluções arquitetônicas de } \\
\text { comprovada eficiência energética, face as } \\
\text { simplificações de análise das variáveis. }\end{array}$ \\
\hline & $\begin{array}{l}\text { CARLO, LAMBERTS } \\
\text { (2010). } \\
\text { - Prescritivo e } \\
\text { Simulação }\end{array}$ & $\begin{array}{l}\text { Edifício de } \\
\text { Escritórios } \\
\text { ZB3 }\end{array}$ & $\begin{array}{l}\text { O RTQ-C utiliza a simulação no cálculo da } \\
\text { ventilação natural; } \\
\text { O RTQ-C restringe o uso de vidros de alta } \\
\text { eficiência energética nas equações. }\end{array}$ \\
\hline & $\begin{array}{l}\text { MELLO, et al } \\
\text { (2011) } \\
\text { - Prescritivo e } \\
\text { Simulação }\end{array}$ & $\begin{array}{l}\text { Públicos } \\
\text { ZB } 3\end{array}$ & $\begin{array}{l}\text { O método prescritivo conduz a uma menor } \\
\text { eficiência do modelo analisado se comparado } \\
\text { ao método de simulação. }\end{array}$ \\
\hline & $\begin{array}{l}\text { SILVA, ALMEIDA E } \\
\text { ANDREASI (2012) } \\
\text { - Prescritivo e } \\
\text { Simulação }\end{array}$ & $\begin{array}{l}\text { Públicos } \\
\text { ZB } 6\end{array}$ & $\begin{array}{l}\text { O método de simulação é uma ferramenta de } \\
\text { análise do consumo energético das edificações } \\
\text { que supera as limitações do método prescritivo; } \\
\text { Método mais caro e restringido a aplicações em } \\
\text { universidades e através de especialistas na } \\
\text { área. }\end{array}$ \\
\hline \multirow{6}{*}{$\begin{array}{c}\text { Variáveis da } \\
\text { Envoltória }\end{array}$} & $\begin{array}{l}\text { AKUTZO; ELOY } \\
\text { (2016) } \\
\text { - Prescritivo RTQ-C }\end{array}$ & $\begin{array}{l}\text { Comerciais } \\
\text { ZB } 3\end{array}$ & $\begin{array}{l}\text { Através do RTQ-C, método prescritivo, } \\
\text { determina-se diretrizes construtivas para a } \\
\text { alcançar o Nível A em eficiência para a zona } \\
\text { bioclimática } 3 \text {. }\end{array}$ \\
\hline & $\begin{array}{l}\text { LAMBERTS; } \\
\text { FOSSATI (2010) } \\
\text {-Prescritivo RTQ -C }\end{array}$ & $\begin{array}{l}\text { Escritórios } \\
\text { ZB } 3\end{array}$ & $\begin{array}{l}\text { O Método Prescritivo contribui para a adoção } \\
\text { de soluções construtivas mais eficientes } \\
\text { energeticamente nos projetos das edificações. }\end{array}$ \\
\hline & $\begin{array}{l}\text { CARLO; MACIEL } \\
\text { (2011). } \\
\text { Prescritivo RTQ-C } \\
\text { - Estatístico Monte } \\
\text { Carlo }\end{array}$ & $\begin{array}{l}\text { Volumetrias } \\
\text { Variadas } \\
\text { Da ZB } 1 \text { à } \\
\text { ZB } 8\end{array}$ & $\begin{array}{l}\text { Cada variável das equações do ICenv atua } \\
\text { diferentemente em cada zona bioclimática. } \\
\text { Possuindo maior ou menor influência ou pesos } \\
\text { para cada zona bioclimática (de } 1 \text { a 8). }\end{array}$ \\
\hline & $\begin{array}{l}\text { FERREIRA; } \\
\text { SOUZA,2010 } \\
\text { - Simulação }\end{array}$ & $\begin{array}{l}\text { Público } \\
\text { ZB } 3\end{array}$ & $\begin{array}{l}\text { Os brises dimensionados pelo RTQ-C e pelo } \\
\text { método da temperatura neutra demonstram } \\
\text { um impacto semelhante na redução do } \\
\text { consumo de energia; }\end{array}$ \\
\hline & $\begin{array}{l}\text { FERNANDES } \\
(2012) \\
\text { - Simulação }\end{array}$ & $\begin{array}{l}\text { Comerciais } \\
\text { ZB } 8\end{array}$ & $\begin{array}{l}\text { Não é levado em conta para os ângulos de } \\
\text { sombreamento a orientação da fachada, } \\
\text { latitude, local, horários e épocas do ano; } \\
\text { Propõe acrescentar no RTQ-C, os ângulos de } \\
\text { sombreamento das edificações vizinhas do } \\
\text { edifício analisado. }\end{array}$ \\
\hline & $\begin{array}{l}\text { PEDRINI, et al } \\
(2012) \\
\text { - Prescritivo RTQ-C }\end{array}$ & $\begin{array}{l}\text { Modelos } \\
\text { ZB } 8\end{array}$ & $\begin{array}{l}\text { Diretrizes para a aplicação dos ângulos de } \\
\text { sombreamento; } \\
\text { A aplicação do AHS e o AVS simultaneamente em } \\
\text { um PAFT de 0,36, prejudicou o nível de } \\
\text { eficiência, o que contradiz a literatura. }\end{array}$ \\
\hline
\end{tabular}

Fonte: a autora (2020) 


\subsection{Aperfeiçoamento do Regulamento Técnico da Qualidade para a Classe de Eficiência} Energética dos Edifícios Com., de Serviços e Públicos: Instrução Normativa Inmetro (INI - C)

Através de estudos e aplicações do RTQ-C (algumas já analisadas nesta pesquisa), foram levantadas limitações do método atual de avaliação. Lamberts, Cleto (2019), afirmam que a proposta de aperfeiçoamento surgiu após a verificação das restrições pertinentes ao método atual, entre elas:
a. "Abertura de proteções solares: não diferenciáveis por orientação;
b. Vidros de controle solar: não apresenta boa resposta no método prescritivo,
c. Parâmetros são ponderados para toda a edificação;
d. Levantamento de dados significativa: alguns com pouca influência;
e. Considera apenas um tipo de HVAC: split no método prescritivo;
f. Entorno edificado: não considera;
g. Pré-requisitos: penalizam a edificação, parede e cobertura;
h. Um padrão de carga térmica interna de uso e ocupação;
i. Uso de ventilação natural não é considerado no atual método prescritivo" (LAMBERTS, CLETO, 2019).

Deste modo, se fez necessário o desenvolvimento de uma nova proposta de avaliação da eficiência energética das Edificações Comerciais, de Serviços e Públicas.

Através da Portaria no 248, de 10 de julho de 2018 (BRASIL,2018), a proposta de aperfeiçoamento do regulamento foi liberada para consulta pública, permanecendo pelo prazo de sessenta dias. O prazo de promulgação da nova norma era em agosto de 2019 (Anexo I), o que não aconteceu, permanecendo até o dia de depósito desta dissertação sem prazo definido.

Uma das limitações levantadas do atual método de avaliação (RTQ-C) é que este não quantifica a eficiência energética gerada pela edificação analisada, o que dificulta a percepção da eficácia dessas medidas aplicadas ao edifício, "apesar de permitir a classificação da eficiência de um edifício de $A$ a $E$, não fornece a ideia de grandeza relacionada ao consumo real da edificação" (DESTRO, 2019).

O novo procedimento para a determinação da Classe de Eficiência Energética da Edificação, intitulado como Instruções Normativas Inmetro (INI-C), verifica a eficiência energética das edificações mediante o seu desempenho no consumo de Energia Primária² (BRASIL, 2018),

\footnotetext{
${ }^{2}$ Energia Primária é a forma de enegia disponível na naturez, que não foi submetida a qualquer processo de conversão ou transformação (LAMBERTS, R.; CLETO, 2018).
} 
resultante do somatório das Energias Elétrica e Térmica, adequadamente transformadas segundo fatores de conversão. É incluído no levantamento o potencial de geração local de energia renovável do edifício (solar ou fotovoltaica), promovendo a auto geração de energia elétrica.

Para efetuar a verificação da eficiência energética de uma edificação, compara-se o consumo de energia primária do edifício real ao mesmo edifício com características de referência préestabelecidas para alcançar a Classe D em eficiência energética. O percentual de economia alcançado pelo edifício real com relação ao edifício de referência estabelece a classe de eficiência alcançada (CB3E, 2017). A figura 18, apresenta as diversas Classes de Eficiência Energética para o INI-C.

Figura 18 - Classes de Eficiência Energética do INI-C.

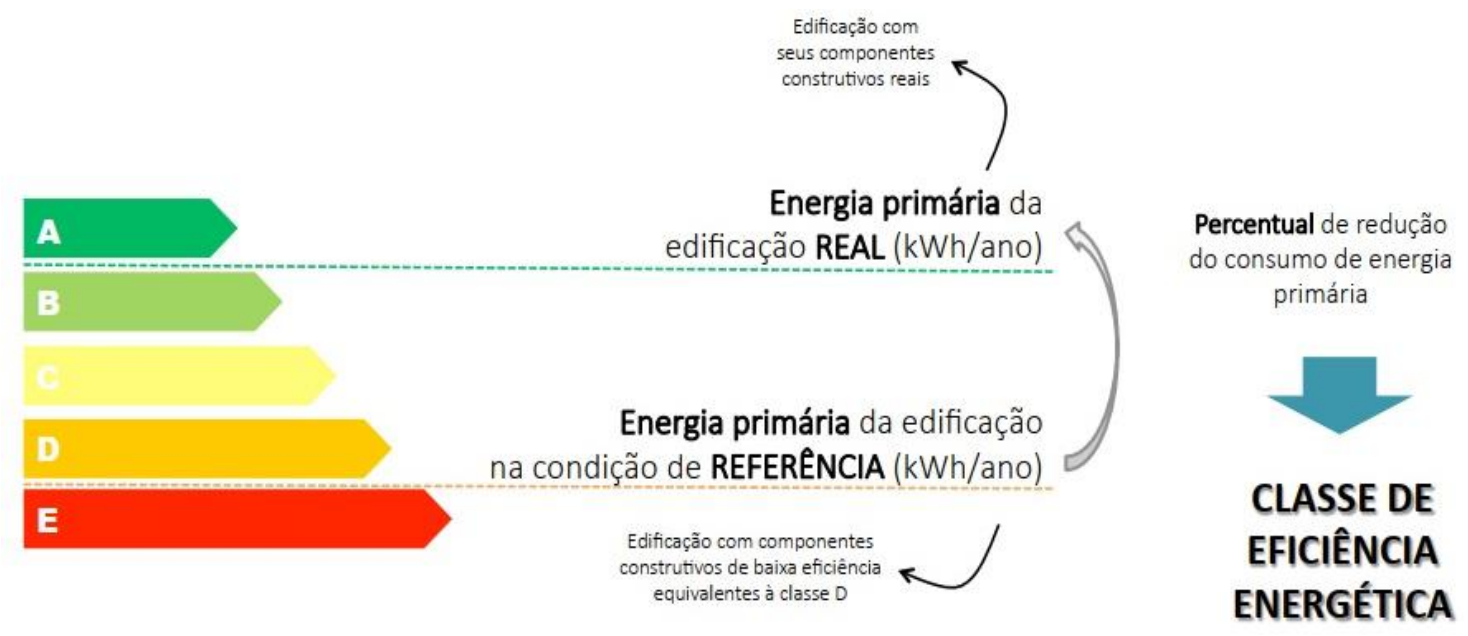

Fonte: CB3E, 2019

A avaliação do sistema aplica-se a edifícios condicionados, parcialmente condicionados e não condicionados. Aos sistemas já avaliados pelo RTQ-C (envoltória, iluminação e arcondicionado) foi acrescentado o sistema de aquecimento de água para a verificação pelo novo método.

A Etiqueta Nacional de Conservação de Energia (ENCE) pode ser obtida através da avaliação de todos os sistemas em conjunto (ENCE geral), somente para o sistema da Envoltória (ENCE parcial), ou mediante algumas composições entre os sistemas (ENCE parcial), sendo a avaliação do sistema da envoltória sempre obrigatório na composição de uma ENCE parcial. 
A ENCE pode ser obtida através do projeto, mas o nível de Eficiência Energética deve ser confirmado através da ENCE da Edificação construída (CB3E, 2017). Na etiqueta foram acrescentadas páginas adicionais com dados complementares sobre os sistemas avaliados, além de aspectos sobre o uso racional de água e emissões de $\mathrm{CO} 2$, que possuem caráter informativo, não interferindo na avaliação final do nível da eficiência. Foram acrescentados também o uso de sistemas alternativos de geração de energia (solar, fotovoltaica) utilizados pelo edifício. A etiqueta possui um QR code na página inicial, que ao ser escaneado redireciona a visualização para as demais páginas que possuem informações adicionais sobre as classificações parciais dos sistemas, como apresenta a figura 19.

Figura 19 - ENCE da proposta do novo regulamento de eficiência energética - INI-C.

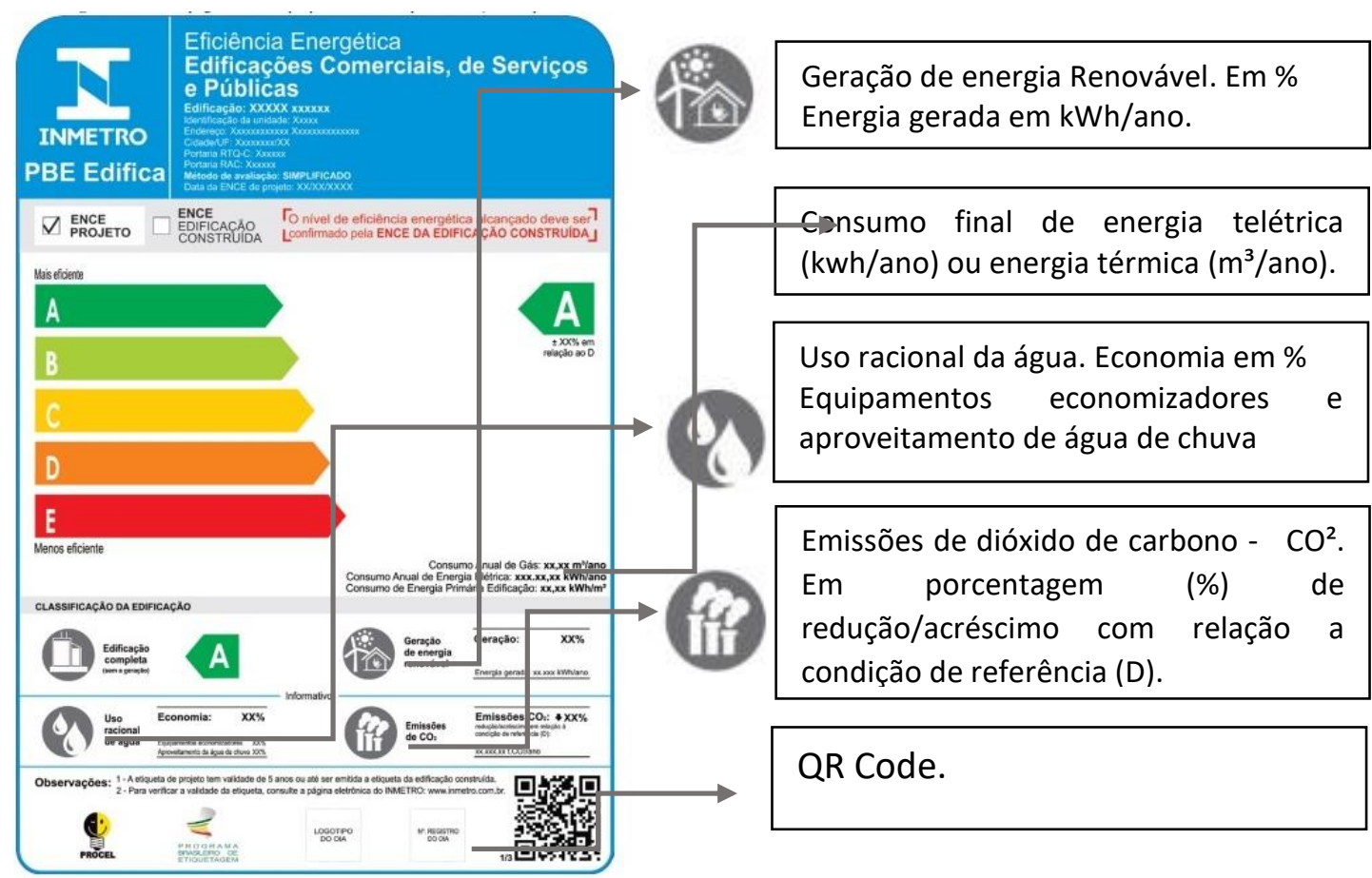

FONTE: CB3E, 2017

Para a verificação da classe de eficiência, o novo regulamento mantém dois métodos de avaliação: o método simplificado e o método de simulação. Com exceção da Envoltória em edificações naturalmente iluminadas (que só podem ser avaliadas pelo método de simulação) e do sistema de aquecimento de água (que deve ser avaliado pelo método simplificado), os dois métodos podem ser utilizados para o levantamento da eficiência dos demais sistemas.

O método simplificado, atende à maioria das soluções arquitetônicas mais utilizadas, sendo sua aplicação mais fácil e acessível, porém menos flexível e possuindo a necessidade de seguir 
alguns requisitos estipulados pelo regulamento. O método de simulação é mais flexível quanto à diversidade de projetos elaborado, porém o programa computacional deve atender à requisitos mínimos estipulados pela nova metodologia. (CB3E, 2017).

Dentre os aprimoramentos inseridos no novo regulamento, encontra-se o uso de diversas tipologias comparadas entre si, relacionando o edifício em análise com outro de mesma atividade, favorecendo assim, um cálculo mais aproximado no número de horas de ocupação, densidade de potência de equipamentos e iluminação (DPE e DPI), set point do ar condicionado, entre outros (BRASIL,2018). As tipologias levantadas que apresentam condições de referências específicas são:
a) edificações de escritórios;
b) edificações educacionais (de ensino médio e superior);
c) edificações de hospedagem (pequenas, médias e grandes);
d) edificações hospitalares (cínicas e hospitais);
e) edificações de varejo (lojas, lojas de departamento, shopping center e mercados);
f) edificações de alimentação (restaurantes e praças de alimentação).

No caso do edifício não se inserir em nenhuma das tipologias levantadas, utiliza-se uma tabela de condições de referência geral justificando o seu uso. No caso da existência de mais de uma tipologia na edificação analisada, a verificação da eficiência deve ocorrer em separado para cada tipologia, utilizando-se as condições de referências adequadas (BRASIL, 2018).

Quanto ao aspecto climático, adota-se a classificação de climas proposta por Roriz (2014), diferentemente do RTQ-C, que se baseia na NBR 15220-2 (ABNT,2005). Ressalta-se que "o zoneamento bioclimático apresentado na NBR 15220-2 não foi empregado pela crescente discussão sobre a necessidade de uma nova classificação dos climas nacionais" (BAVARESCO, et al, 2017). Roriz (2014), subdivide os climas nacionais utilizando os parâmetros de temperatura média anual, desvio padrão de temperatura média, amplitude média anual e desvio padrão de amplitude. A figura 20 apresenta de forma comparativa as principais alterações entre o regulamento atual, o RTQ-C, e a nova proposta, o INI-C quanto ao sistema da envoltória. 
Figura 20 - Comparação entre o RTQ-C e o INI-C

\begin{tabular}{|c|c|}
\hline RTQ-C - Portaria INMETRO n 372/2010 & INI-C - Portaria INMETRO n 248/ 2018 \\
\hline $\begin{array}{l}\text { O edifício é analisado em sua totalidade. Com o } \\
\text { levantamento da área e volume. }\end{array}$ & $\begin{array}{l}\text { O edifício é dividido através da planta baixa em zonas } \\
\text { térmica perimetrais e internas. }\end{array}$ \\
\hline $\begin{array}{l}\text { O levantamento de dados da envoltória é feito no } \\
\text { edifício como um todo. }\end{array}$ & $\begin{array}{l}\text { O edifício é analisado através de três diferentes } \\
\text { pavimentos: o térreo, o tipo e a cobertura }\end{array}$ \\
\hline $\begin{array}{l}\text { Não difere as fachadas quanto as orientações. O } \\
\text { percentual de abertura da fachada oeste -PAFTo - } \\
\text { somente é levantado para ser utilizado caso seja } \\
\text { maior que o PAFT. }\end{array}$ & As fachadas são diferenciadas por orientações. \\
\hline $\begin{array}{l}\text { Os ângulos de sombreamento são levantados e } \\
\text { ponderados independente da fachada. }\end{array}$ & $\begin{array}{l}\text { Os ângulos de sombreamento são levantados por } \\
\text { fachada. }\end{array}$ \\
\hline O sombreamento externo não é aplicado & $\begin{array}{l}\text { O sombreamento externo é aplicado através do } \\
\text { ângulo de obstrução vizinha - AOV. }\end{array}$ \\
\hline $\begin{array}{l}\text { As características térmicas dos materiais opacos } \\
\text { (transmitância e absortância) são utilizadas como } \\
\text { pré-requisitos da avaliação. }\end{array}$ & $\begin{array}{l}\text { As características térmicas dos materiais opacos são } \\
\text { aplicadas no levantamento da eficiência da } \\
\text { envoltória e diferenciado por fachada. Adiciona-se a } \\
\text { característica da Capacidade Térmica do material. }\end{array}$ \\
\hline $\begin{array}{l}\text { O FS é a única característica de análise do vidro, não } \\
\text { sendo utilizado no } \mathrm{ICmax} \text {, vidro de controle solar. }\end{array}$ & $\begin{array}{l}\text { Os vidros são analisados pelo FS e transmitância } \\
\text { térmica, sendo estes diferenciados por fachadas. São } \\
\text { utilizados vidros de controle solar. }\end{array}$ \\
\hline Não há diferenciação por tipologias & $\begin{array}{l}\text { Os edifícios são diferenciados por tipologia para a } \\
\text { entrada de dados (equipamento, densidade de } \\
\text { potência de iluminação e densidade de pessoas) } \\
\text { Os edifícios analisados são comparados a outro } \\
\text { edifício de referência de mesma tipologia. }\end{array}$ \\
\hline $\begin{array}{l}\text { Para a classificação climática das cidades, adota-se a } \\
\text { NBR } 15220 \text { - } 2 \text { (ABNT, 2005). }\end{array}$ & $\begin{array}{l}\text { Para a classificação climática das cidades, adota-se } \\
\text { RORIZ, (2014). }\end{array}$ \\
\hline $\begin{array}{l}\text { Possui uma equação para todas as volumetrias } \\
\text { analisadas }\end{array}$ & $\begin{array}{l}\text { Existe uma relação entre o clima (da implantação da } \\
\text { edificação) e a volumetria (FF) desta, que gera um } \\
\text { coeficiente de redução. Levando-se emconta } \\
\text { volumetrias diferenciadas. }\end{array}$ \\
\hline $\begin{array}{l}\text { Não existe a percepção (medição) em quanto as } \\
\text { medidas de eficiência aplicadas a construção } \\
\text { minimizam consumo de energia. }\end{array}$ & $\begin{array}{l}\text { As medidas de eficiência são transformadas em } \\
\text { energia primaria e quantificadas ao final do } \\
\text { levantamento da classe de eficiência. }\end{array}$ \\
\hline
\end{tabular}




\section{Capítulo 3}

\section{MATERIAIS E MÉTODOS}

Este trabalho possui como objetivo principal evidenciar os cenários que proporcionem o "Nível A" no Índice de Consumo da envoltória dos edifícios em Ribeirão Preto, Zona Bioclimáticas 4.

No sentido de alcançar esse objetivo, a metodologia da pesquisa é desenvolvida através de simulações e análises dos parâmetros que constituem as aberturas envidraçadas de uma fachada (percentual de aberturas, fator solar dos vidros e os ângulos de sombreamentos dos elementos construtivos), com o intuito de evidenciar os índices desses parâmetros que proporcionem o Nível $A$ na equação do ICenv do método prescritivo do RTQ-C. A metodologia se dividirá em etapas, de forma a responder aos objetivos propostos.

Inicialmente, ocorre a apresentação da cidade da qual serão obtidos os dados dos edifícios escolhidos para o estudo, justificando a sua escolha, a da Zona Bioclimática, da área de delimitação da pesquisa e dos próprios edifícios. As edificações para análise foram pesquisadas dentro de um período de seis anos, de 2012 a 2018, com volumes diferenciados e elegíveis, segundo o regulamento, para a aplicação do método prescritivo.

No segundo momento é realizado o processo de etiquetagem da eficiência das envoltórias dos edifícios, sem a utilização dos pré-requisitos (transmitância e absortância), para a obtenção do nível de consumo das envoltórias e do levantamento dos parâmetros da equação do IC. A escolha da utilização de dados de edifícios existentes ao invés de desenvolver modelos é justificada por duas razões: analisar o padrão de construção que está sendo praticado na cidade escolhida e, empregar os parâmetros das envoltórias dessas construções para o desenvolvimento da pesquisa.

Por meio da etiquetagem calcula-se os índices de consumo das envoltórias dos edifícios estudados obtendo-se também, através de dados fornecidos pelo regulamento, o seu índice de consumo mínimo e o máximo. Através do programa Excel e do WEBprescritivo, as simulações dos cenários são empregadas para verificação dos índices (dos parâmetros) que forneçam o Nível A no consumo da envoltória, respondendo ao OBJETIVO 1: 
1. Analisar os dados aferidos através das simulações das variáveis do ICenv para obtenção dos índices que proporcionem menor consumo ao edifício.

Após os dados obtidos pelas simulações, processa-se a análise da contribuição de cada variável na alteração do Índice de Consumo da Envoltória - ICenv, e de suas inter-relações respondendo aos OBJETIVOS 2 E 3:

2. Analisar através dos resultados das simulações a influência das variáveis das aberturas envidraçadas no nível de eficiência dos edifícios comerciais em Ribeirão Preto, Zona Bioclimática 4.

3. Estudar as inter-relações existentes entre os parâmetros da equação do índice de consumo da envoltória quanto a redução no ganho de energia térmica das aberturas envidraçadas dos edifícios.

Após o estudo da interferência das variáveis no ICenv em edifícios situados no ZB4, efetua-se a comparação entre duas zonas Bioclimáticas, a ZB 3 e a ZB4. A influência das variáveis do índice de consumo da envoltória na ZB3, foi fundamentado no estudo de Eloy, D.; Akutsu, M. (2016). Procede-se a comparação e análise das diferentes contribuições das variáveis em climas diferenciados, através da equação do ICenv respondendo ao OBJETIVO 4:

4. Comparar os níveis de eficiência alcançados pelos edifícios entre duas zonas bioclimáticas, ZB4 e ZB3, com o intuito de evidenciar a interferência do clima no consumo energético do edifício.

Por fim, é levantada a etiquetagem de um dos edifícios utilizados na pesquisa pela nova proposta de aperfeiçoamento do RTQ-C, O INI-C, com a análise do processo e o nível de eficiência alcançado, atendendo ao OBJETIVO 5:

5. Comparar o índice de eficiência alcançado por um edifício diante do processo de etiquetagem aplicado através do RTQ-C e de sua proposta de aperfeiçoamento, o INIC.

Os resultados obtidos serão ordenados com o objetivo de indicar os parâmetros que assegurem o menor índice de consumo em configurações específicas (Fator de Forma e Fator Altura) para o projeto das aberturas envidraçadas nos edifícios analisados. Os resultados irão também atestar a influência das variáveis da fachada no índice de consumo das edificações, 
evidenciando indicadores para alcançar o nível $A$ no ICenv, podendo estes serem utilizados desde a fase inicial do projeto, alcançando assim o objetivo principal da pesquisa.

Figura 21 - Fluxograma da Metodologia

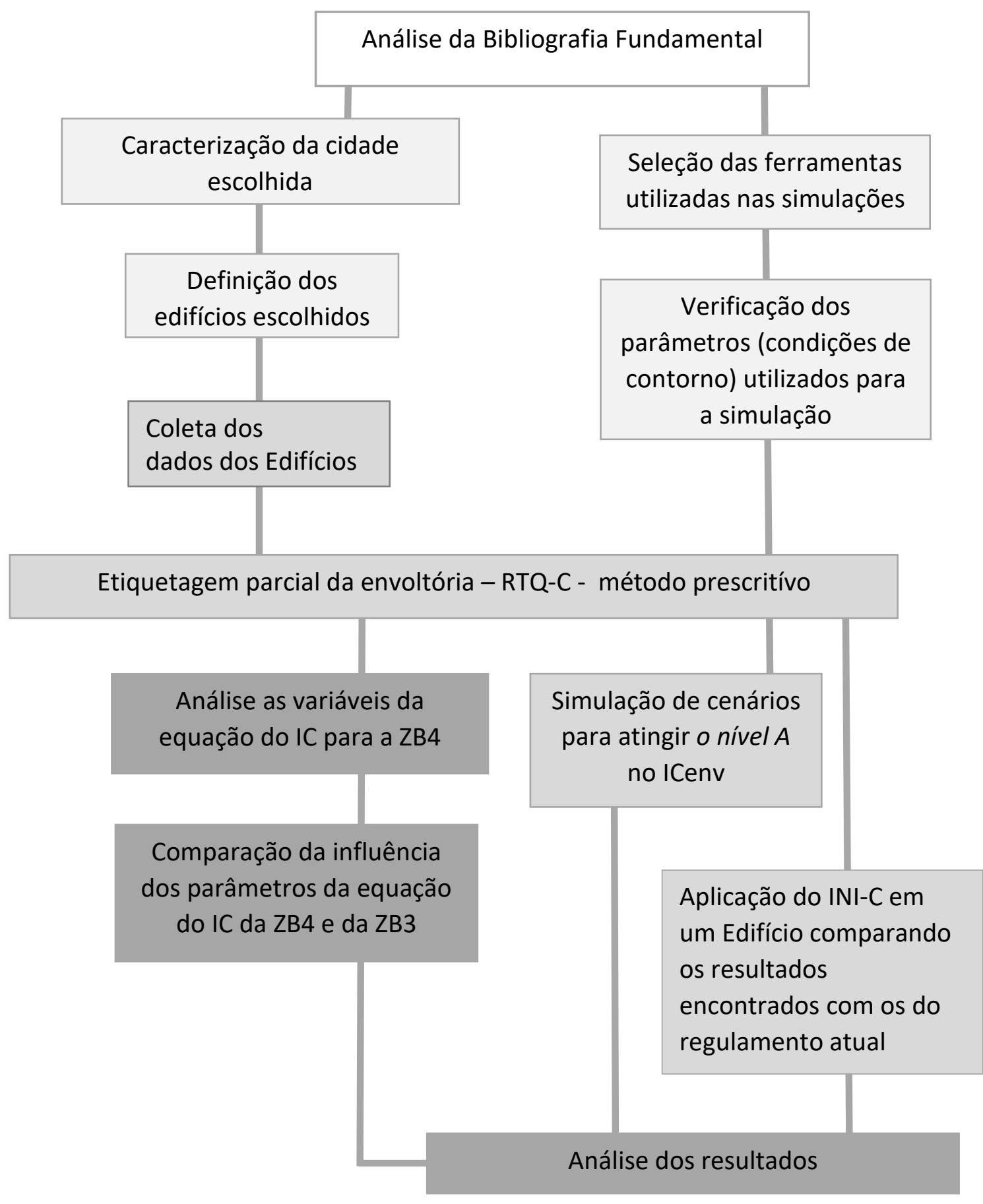

LEGENDA:

$$
\text { Levantamento }
$$

Coleta de dados

Análises 


\subsection{Caracterização da cidade escolhida}

A cidade de Ribeirão Preto foi escolhida para esse trabalho por estar na Zona Bioclimática 4, e por ser uma cidade que se constitui como polo regional de atividades comerciais e prestação de serviços.

Instituída por lei em 2016, a região Metropolitana de Ribeirão Preto incorpora 34 municípios e 4 sub-regiões, o que evidencia ainda mais a condição da cidade de polo gerador de serviços. Segundo Geraldi (2017), " Ribeirão Preto é a cidade sede e recebe todos os dias, para trabalhar e estudar, uma população flutuante que se desloca e volta todos os dias para seus lares nas denominadas cidades dormitório do entorno".

A cidade teve o seu desenvolvimento apoiado no agronegócio que deteve um alto crescimento econômico na década de 1980 que foi fundamentado pelo incremento da exportação do setor onde "observou-se uma ampliação do setor terciário na região, tendo Ribeirão Preto como sede das principais instituições financeiras e negociais, mantendo-se entre as mais importantes regiões do país até os dias atuais" (ZAMBONI, 2018).

A cidade de Ribeirão Preto é subdividida em Zonas, a saber, a Central, Zona Norte, Zona Sul, Zona Leste e Zona Oeste. Apoiado pelo Plano Diretor de 1995 (atualmente em revisão), a cidade teve o seu crescimento urbano sustentado em um vetor direcionado para a Zona Sul, onde manteve desde os anos 2000 uma forte urbanização, com a construção de inúmeros edifícios comerciais e residenciais.

Apoiado por esse crescimento populacional na Zona Sul, cresce também a demanda por prestação de serviços. Segundo a Secretaria de Planejamento de Ribeirão Preto, 250 (duzentos e cinquenta) Edifícios Comerciais com gabaritos altos e baixos ${ }^{3}$ tiveram seus projetos aprovados para construção entre os anos de 2010 a 2018, que foi o período onde ocorreu o maior índice de aprovação e conclusão de projetos comerciais na cidade. Os Edifícios Altos somam 37 ao todo sendo que destes, 70\% (27) se encontram na Zona Sul, pelo seu maior apelo ao crescimento e valorização do metro quadrado. Esse levantamento foi efetuado pelo autor no site da Secretaria de Planejamento de Ribeirão Preto e se encontra no Anexo II, pág.

\footnotetext{
${ }^{3}$ Segundo a prefeitura de Ribeirão Preto, edifícios altos são aqueles cuja a altura seja superior a 10,0(dez) metros a partir da calçada, e edifícios baixos são aqueles que possuam cota inferior a 10,0(dez) metros a partir da calçada.
} 
144 (Ribeirão Preto, 2020). A figura 22 apresenta o crescimento de Ribeirão Preto em várias décadas, onde podemos identificar o crescimento da Zona Sul principalmente a partir de 2010.

Figura 22 - Crescimento da malha urbana de Ribeirão Preto a partir da aprovação de parcelamentos / loteamentos por década.

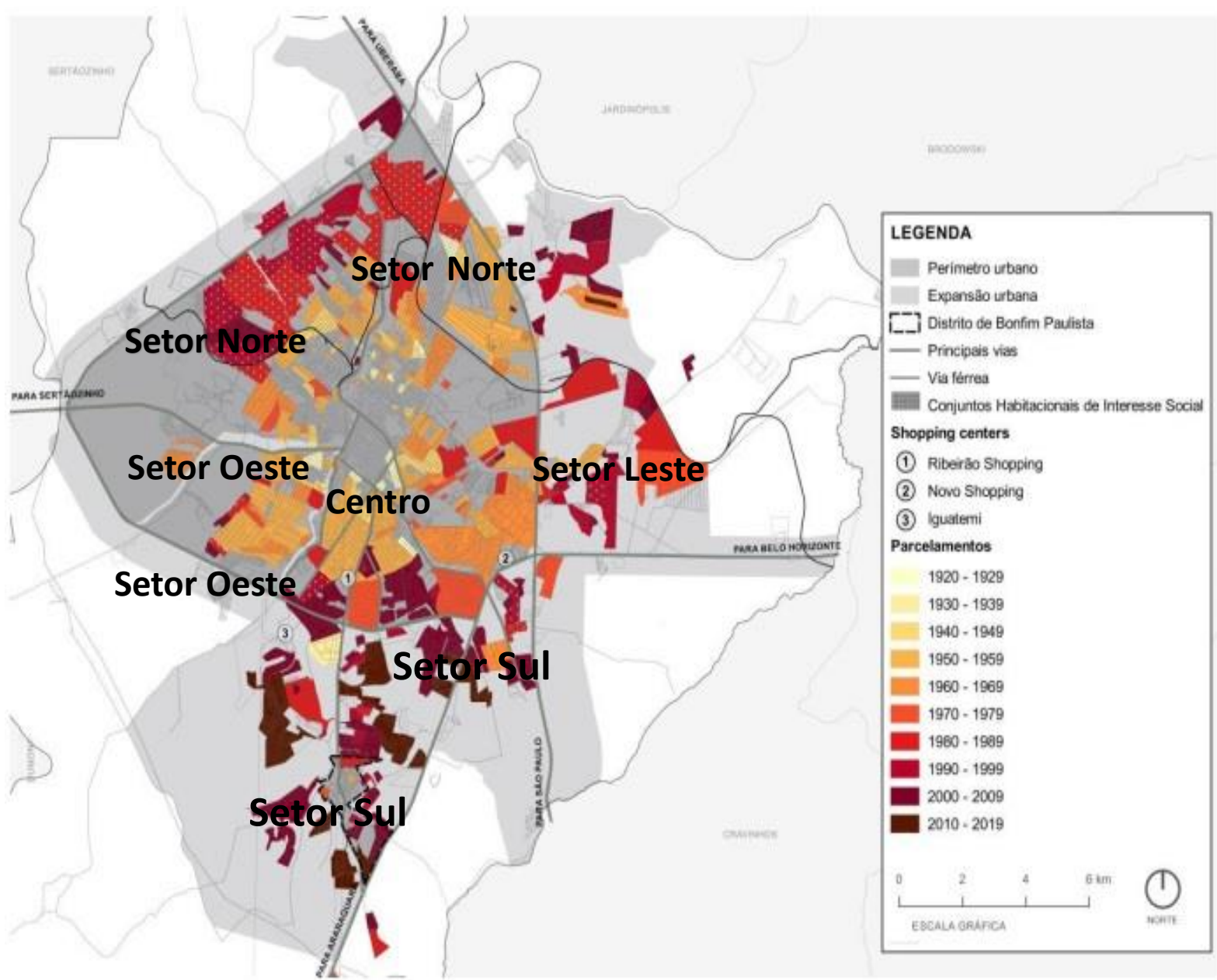

Fonte: Secretaria de Planejamento e Gestão de Ribeirão Preto - Prefeitura Municipal de Ribeirão Preto, 2015; Melo, 2017; Pesquisa de Campo, 2017. Organização: Débora Prado Zamboni. Elaboração: Bruna de Souza Fernandes.

Acompanhando essa demanda, é fundamental que a construção civil incorpore os conceitos da Eficiência Energética nos futuros projetos, ampliando o conhecimento dos seus autores, seja construtores, incorporadores e projetistas em normas e regulamentos que forneçam esses parâmetros para uma construção de maior qualidade ambiental. 


\subsection{O clima de Ribeirão Preto - ZB 4}

Ribeirão Preto se encontra na Latitude $21^{\circ} 10^{\prime} 39^{\prime \prime} \mathrm{S}$, Longitude $47^{\circ} 49^{\prime} 15^{\prime \prime \prime \prime} \mathrm{O}$, e a $531 \mathrm{~m}$ de altitude, na região sudeste do Brasil (Ribeiro, 2008). O conhecimento climático da região estudada é fundamental em pesquisas relacionadas ao conforto térmico e eficiência energética, onde o uso de estratégias bioclimáticas aplicadas à arquitetura atenua a carga térmica incorporada pelo edifício através dos efeitos da temperatura e radiação solar.

As variáveis climáticas que mais influenciam no conforto térmico são: temperatura de bulbo seco (temperatura do ar), umidade relativa do ar, ventos, radiação solar e as precipitações (LAMBERTS, et al, 2012). Em estudo efetuado por Ribeiro (2008), foram obtidos através da estação meteorológica do Instituto Agronômico (IAC) os dados climáticos da cidade de Ribeirão Preto. Essas informações seguem o padrão das normais climatológicas, e se encontram dentro do período de 1955 a 1998. A figura 23 apresenta os dados das temperaturas ao longo desse período de trinta anos. O gráfico demonstra que o período entre os meses de agosto a março é o mais quente durante o ano, permanecendo as médias máximas acima dos $29^{\circ}$.

Figura 23 - Dados da Temperatura de Ribeirão Preto (Estação Meteorológica do IAC)

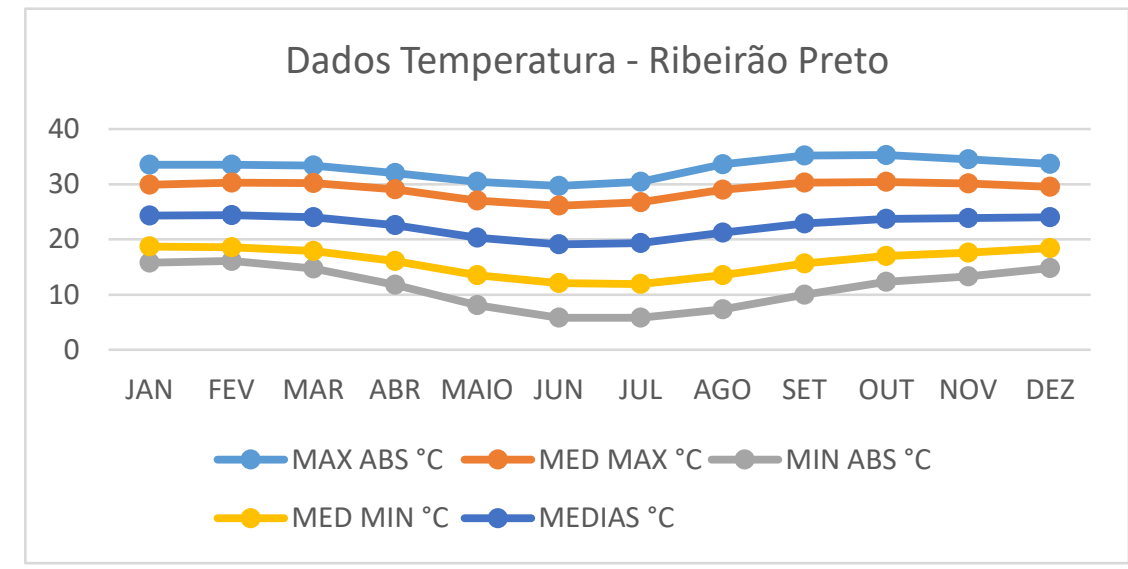

Fonte: Ribeiro (2008)

A figura 24 demonstra os dados da umidade relativa e precipitações de Ribeirão Preto. Verifica-se que os meses mais secos se situam de maio a setembro, indicando deste modo, um inverno seco e um verão mais chuvoso. 
Figura 24 - Dados da Umidade Relativa e Precipitações de Ribeirão Preto (Estação Meteorológica do $\mathrm{IAC})$

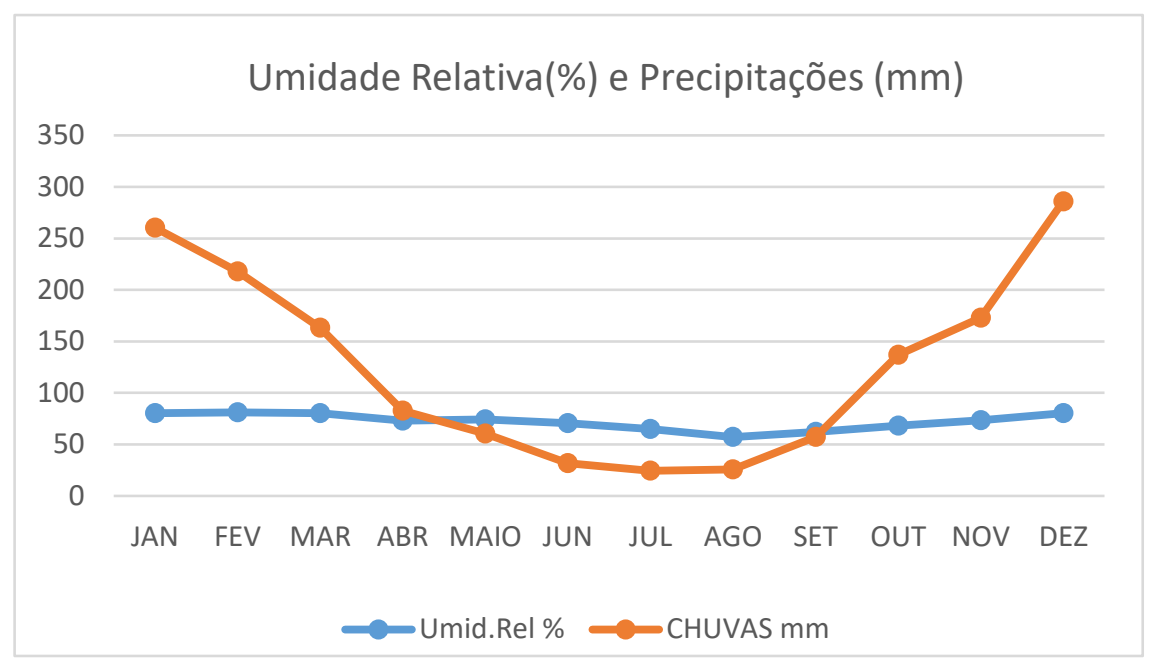

Fonte: Ribeiro (2008), adaptado pelo autor

Com exceção do mês de janeiro cuja direção é NW o restante do ano a direção predominante é a Sudeste. Segundo a Escala de Beaufort (CEMTEC, 2015) que classifica a intensidade dos ventos, os ventos com velocidade menor de $1,8 \mathrm{~km} / \mathrm{h}$ são caracterizados como ventos calmos ou calmaria, os ventos entre 1,8 a 6,0 km/h são aragens leves ou quase calmos e de 7,0 a $11,0 \mathrm{~km} / \mathrm{h}$ são brisas leves ou aragens. Deste modo, a ventilação natural durante todo o ano em Ribeirão Preto é um parâmetro que contribui muito pouco para a dispersão do calor (por convecção) nas edificações. Os dados de velocidade e direção dos ventos são observados na tabela 10.

Tabela 10 - Ventos Dominantes - Períodos (Estação Meteorológica do IAC)

\begin{tabular}{lcccccccccccc}
\hline & JAN & FEV & MAR & ABR & MAIO & JUN & JUL & AGO & SET & OUT & NOV & DEZ \\
\hline VEL km/h & 5,76 & 5,04 & 4,8 & 5,4 & 5,04 & 5,04 & 6,48 & 7,2 & 8,2 & 8,28 & 7,92 & 6,84 \\
\hline DIR. & NW & SE & SE & SE & SE & SE & SE & SE & SE & SE & SE & SE \\
\hline
\end{tabular}

Fonte: Ribeiro, (2008), adaptado pelo autor

Segundo a norma NBR 15220 (ABNT, 2005b), Ribeirão Preto pertence a Zona Bioclimática 4. O zoneamento bioclimático brasileiro tem por objetivo, categorizar cidade selecionadas conforme a configuração climática, dividindo-as em Zonas Bioclimáticas. Através da análise climática, são atribuídos parâmetros e diretrizes construtivas que propiciem ou contribuam no conforto térmico passivo nas construções. 
Essa norma foi formulada para edificações habitacionais de interesse social de até três pavimentos, sendo suas recomendações utilizadas para edifícios com diversas funções, configurações e gabaritos.

No intuito do desenvolvimento das diretrizes de conforto térmico, foi adaptada a carta bioclimática de Givoni para a Zona Bioclimática 4, composta de 17 cidades e apresentada na figura 25.

Figura 25 - Carta de Givoni, adaptada para a Zona Bioclimática 4

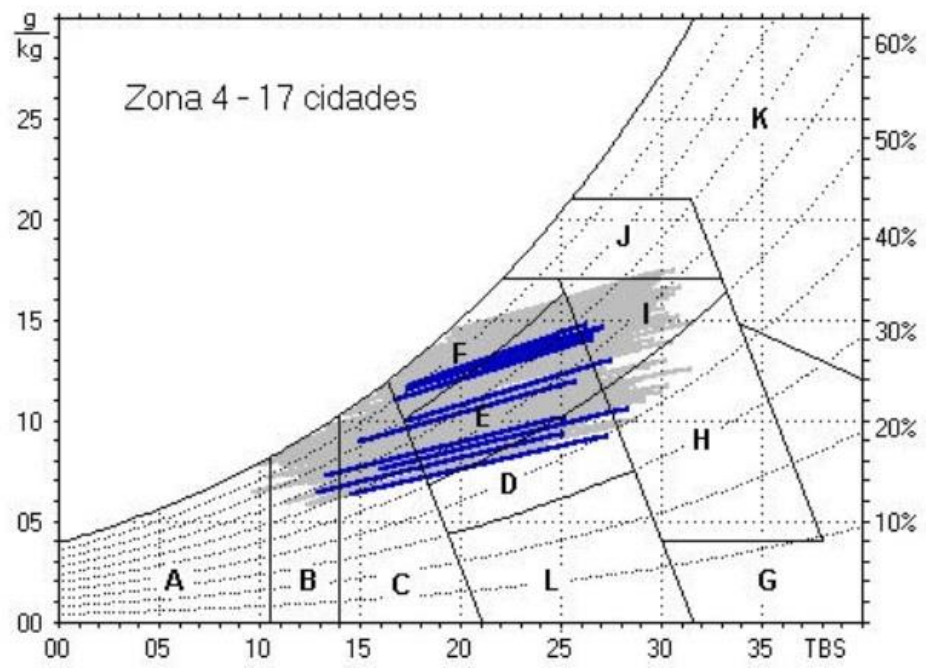

\section{LEGENDA - Zonas Térmicas}

A: Aquecimento artificial;

B: Aquecimento Solar passivo da edificação;

C: Inécia térmica e Aquecimento solar;

D: Conforto térmico;

E: Conforto térmico;

F: Ventilação Natural;

G: Resfriamento Evaporativo;

$\mathrm{H}$ : Massa Térmica para resfriamento

I: Massa térmica para resfriamento;

$\mathrm{J}$ : Ventilação seletiva para o verão

L: Umidificação

Fonte: ABNT (2005)

Por intermédio da Carta de Givoni, pode-se constatar as estratégias de condicionamento térmico passico para a ZB4: para o verão, o resfriamento evaporativo, a massa térmica para o resfriamento $(H)$ e a ventilação seletiva nos períodos quentes (J), e para o inverno, aquecimento solar da edificação (B) e vedações internas pesadas (C), conforme a NBR 15220 (ABNT,2005b).

Na figura 26, o programa do Zoneamento Bioclimático Brasileiro - ZBBR (RORIZ, 2004), proporciona através da inclusão dos parâmetros de localização, latitude e longitude a visualização das recomendações construtivas para a zona bioclimática da cidade estudada. Nesta figura são apresentadas as diretrizes construtivas e projetuais para a cidade de Ribeirão Preto. 
Figura 26 - Programa ZBBR - Classificação Bioclimática dos Municípios Brasileiros

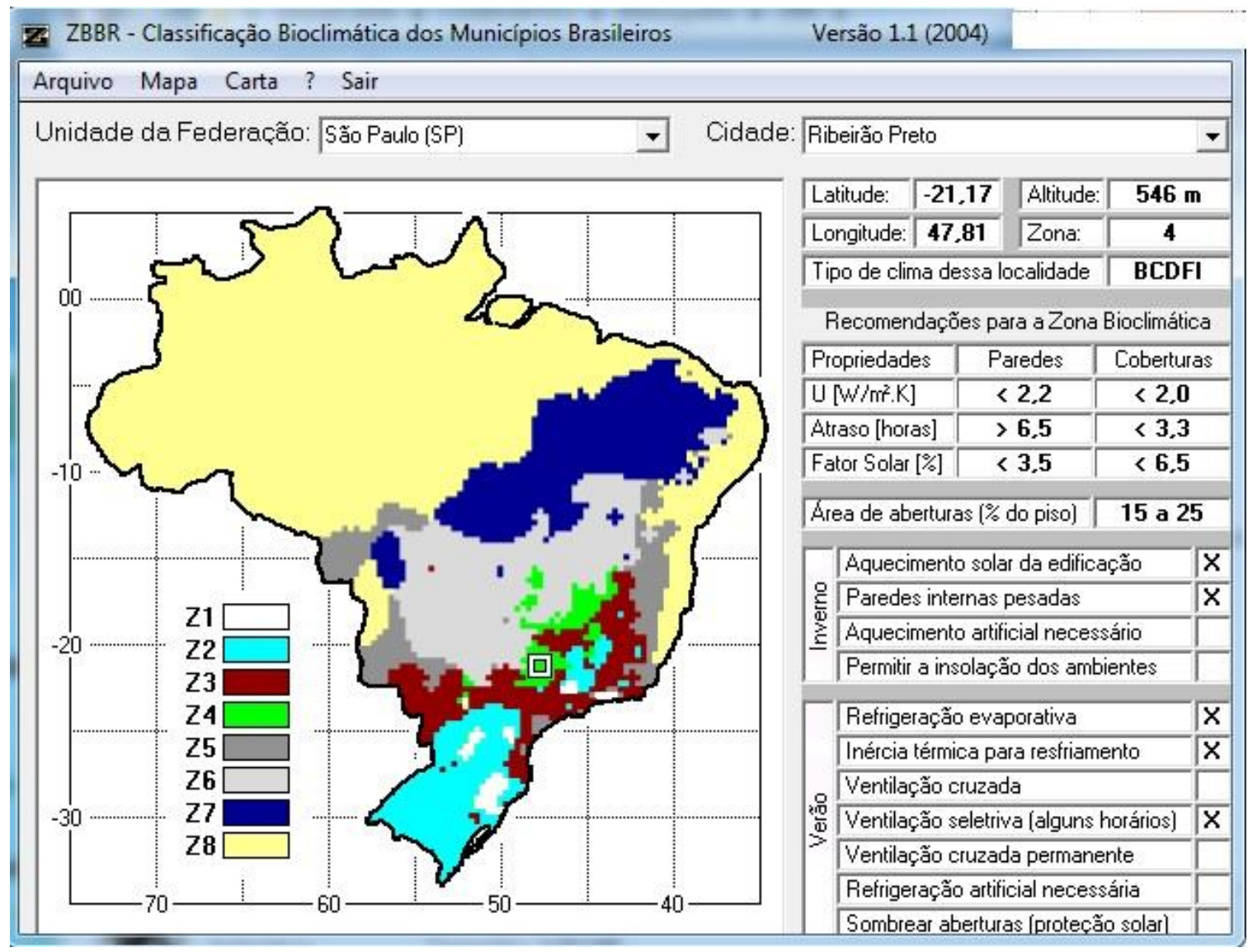

Fonte: Roriz, 2004

As diretrizes construtivas fornecidas pela norma NBR 15220 (ABNT,2005b) proporcionam parâmetros de grandezas das aberturas, sendo este estimado em três índices: pequeno, médio e grande, fornecendo também, orientações para o seu sombreamento. As vedações da envoltória (paredes e coberturas) foram especificadas na Parte 3, e detalhadas em anexo na mesma norma. A figura 27 apresenta as diretrizes construtivas fornecidas para a Zona Bioclimática 4.

Figura 27 - Diretrizes Construtivas para a ZB4, conforme a NBR15220.

\section{Diretrizes Construtivas - Zona Bioclimática 4.}

\section{Aberturas para ventilação}

Sombreamento das Aberturas

Vedações Externas - Paredes

Vedações Externas - Coberturas
Médias

Sombrear Aberturas

Pesada

Leve refletora

Fonte: ABNT, 2005 


\subsection{Edifícios determinados para o estudo de caso}

Os edifícios escolhidos para essa pesquisa estão situados na Zona Sul de Ribeirão Preto e foram entregues nos últimos seis anos, de 2012 a 2018, época que ocorreu a expansão de edifícios altos comerciais na região. Esta área, como foi levantada, detém o maior crescimento em número de edifícios para o setor terciário, sendo as duas tipologias escolhidas, edifício corporativo e hotel os setores com maior número de construções nesse período (Rib. Preto, 2018). Os edifícios adotados são construções de volumetria simples e sem complexidade arquitetônica quanto ao sombreamento das aberturas ou das fachadas, podendo estes, serem etiquetados através do método prescritivo do RTQ-C. Estes edifícios também foram escolhidos por apresentarem envoltórias diferenciadas entre si. Os levantamentos foram efetuados através de visitas ao local e projetos arquitetônicos cedidos pelos seus administradores.

Essas edificações possuem funções diferentes, mas são etiquetadas pelo método prescritivo, pois este, não possui diferenciação por tipologias arquitetônicas (entre comerciais, públicos e institucionais). Entre as reformulações aplicadas ao novo método de avaliação de eficiência (INI-C) se encontra a introdução da diferenciação por funções.

Foram escolhidas duas tipologias que evidenciam a vocação da cidade como polo de serviços e a atual tendência de verticalização da área, sendo 2 edifícios corporativos e 1 hotel:

A escolha dos edifícios representativos para o estudo foi fundamentada nos seguintes elementos:

- Edifício Corporativo 01- Centro Profissional Ribeirão Shopping - localizado na Zona Sul, entregue em 2012, edifício elegível para aplicação do RTQ-C pela sua simplicidade volumétrica e formal. Sem elementos de sombreamentos adicionados ao edifício, as aberturas estão expostas aos raios solares, o que permite uma melhor avaliação quanto a interferência destes na classificação da eficiência.

Está disposto longitudinalmente na direção Norte/sul, onde as maiores fachadas estão voltadas para o este e oeste, ocasionando longos períodos diários de exposição aos raios solares.

- O edifício Corporativo 02 - Edifício Trio Office - localizado na Zona Sul, entregue em 2013, segue as mesmas especificações do Edifício 01, possui duas torres uma 
residencial e outra corporativa, sendo esta última a levantada para a pesquisa. Possui como diferencial tanto a aplicação de vidros nas fachadas sobrepostos a estrutura como aplicados em caixilhos. As maiores fachadas encontram-se na orientação Norte/Sul.

- O edifício 03 - Hotel TRYP By Wyndham - localizado na Zona Sul, entregue em 2017. Edifício elegível para aplicação do RTQ-C. Não possui elementos de sombreamento nas fachadas. Como diferencial possui a tipologia e o fato de possuir o Selo Procel Edifica, alcançando na etiquetagem o Nível $A$ de eficiência energética (BRASIL, 2020), sendo o único edifício etiquetado na cidade em estudo, e o fato de possuir o auto sombreamento pela sua implantação em "L".

A figura 28, apresenta uma imagem do Google Maps com a localização dos edifícios levantados.

Figura 28 - Mapa com indicação dos Edifícios analisados na pesquisa.

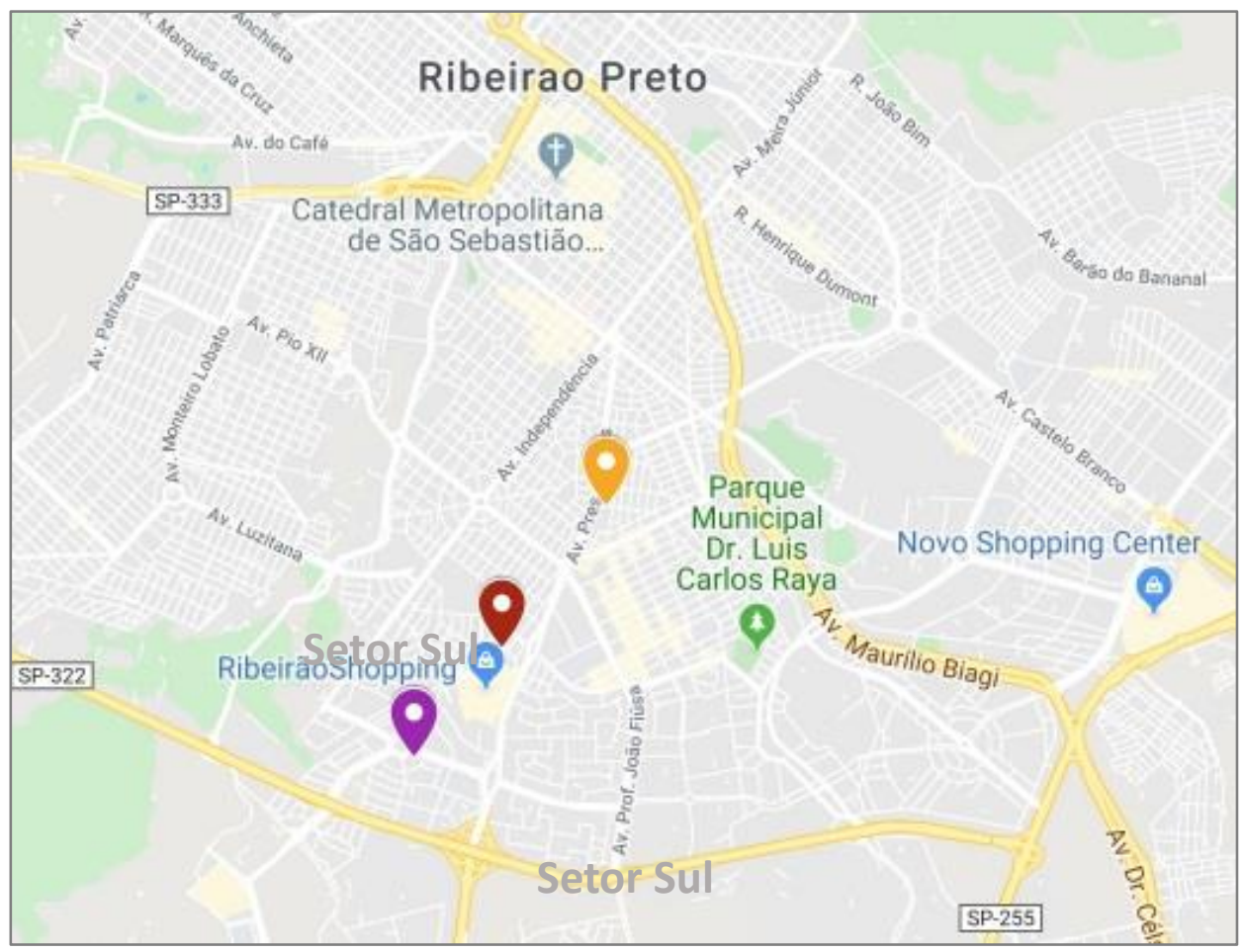

Fonte: Google Maps - editado pela autora

Legenda:

Edifício 01 


\section{Edifícios Escolhidos para o estudo - Fichas técnicas}

Figura 29 - Edifício 01 - Centro Profissional Ribeirão Shopping

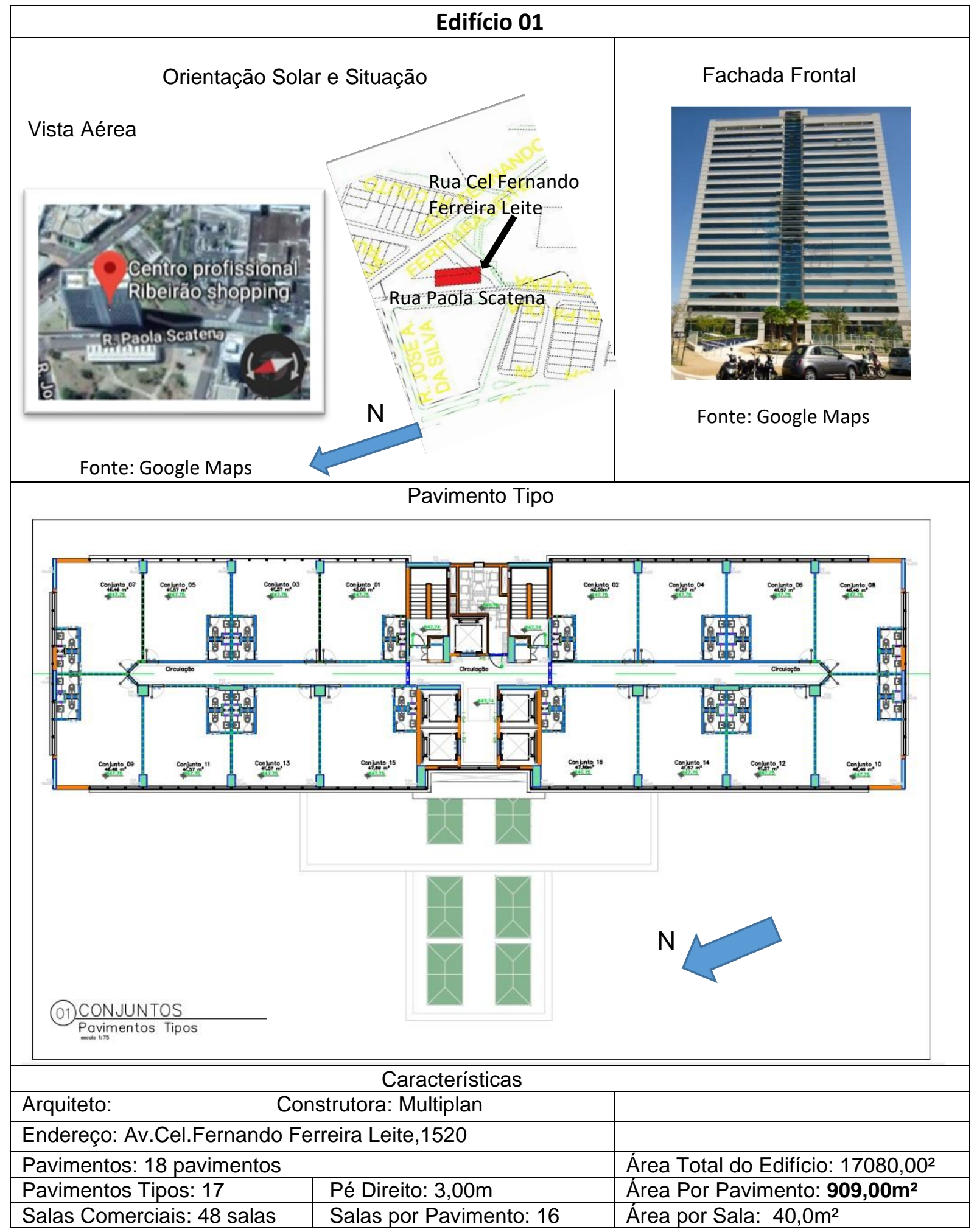


Figura 30 - Edifício 02 - TRIO OFFICER Ribeirão Preto

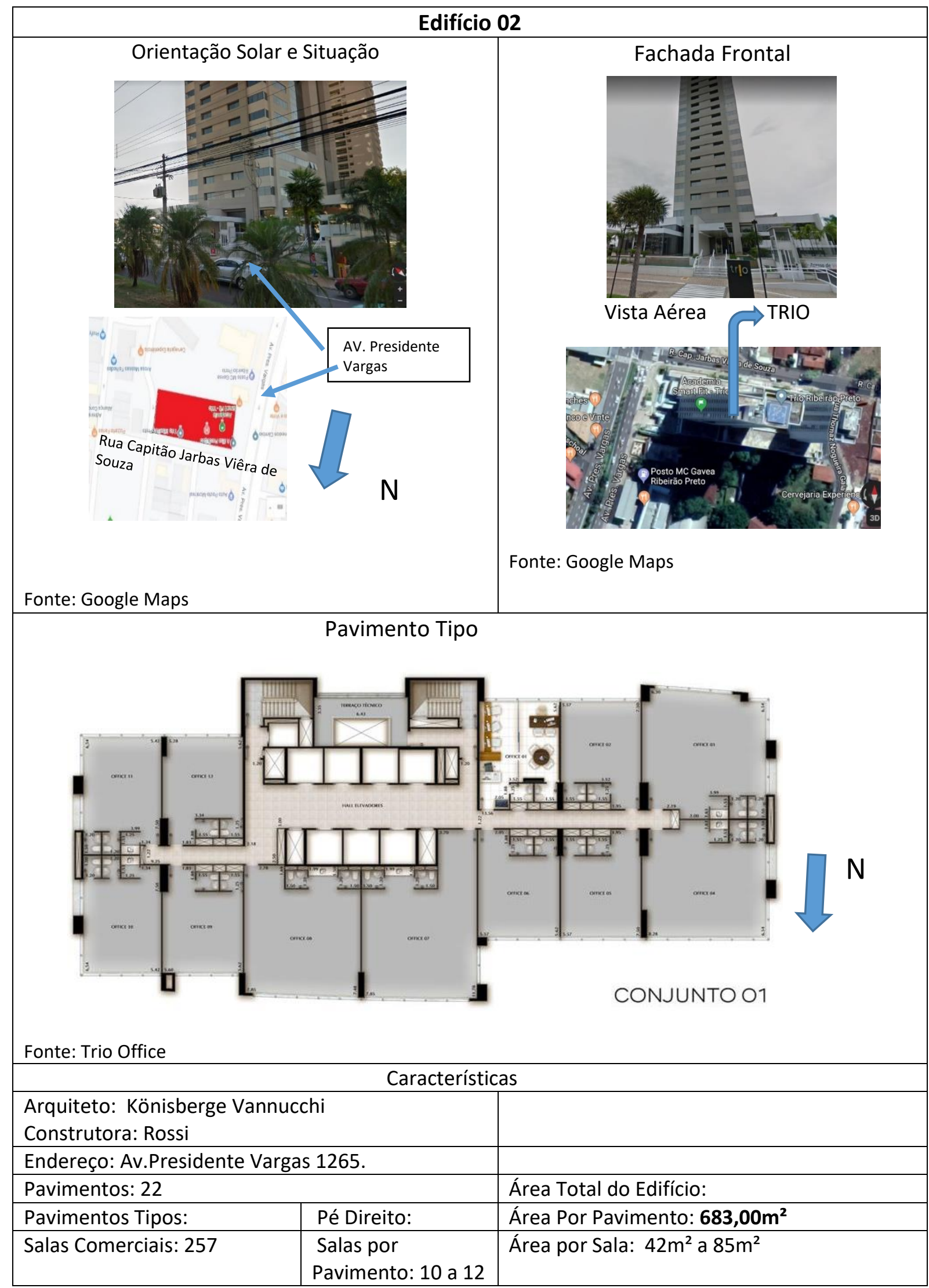


Figura 31 - Edifício 03 - Hotel TRYP By Wyndham

\begin{tabular}{|c|c|c|}
\hline \multicolumn{3}{|c|}{ Edifício 03} \\
\hline 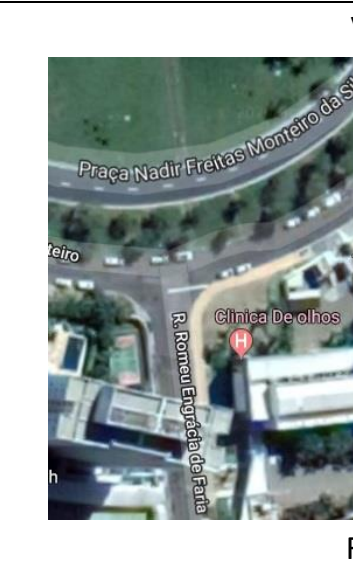 & $\frac{\text { ea }}{4\left(\frac{4}{4}\right)}$ & Fachada Frontal \\
\hline \multicolumn{2}{|l|}{ Pavimento Tipo } & 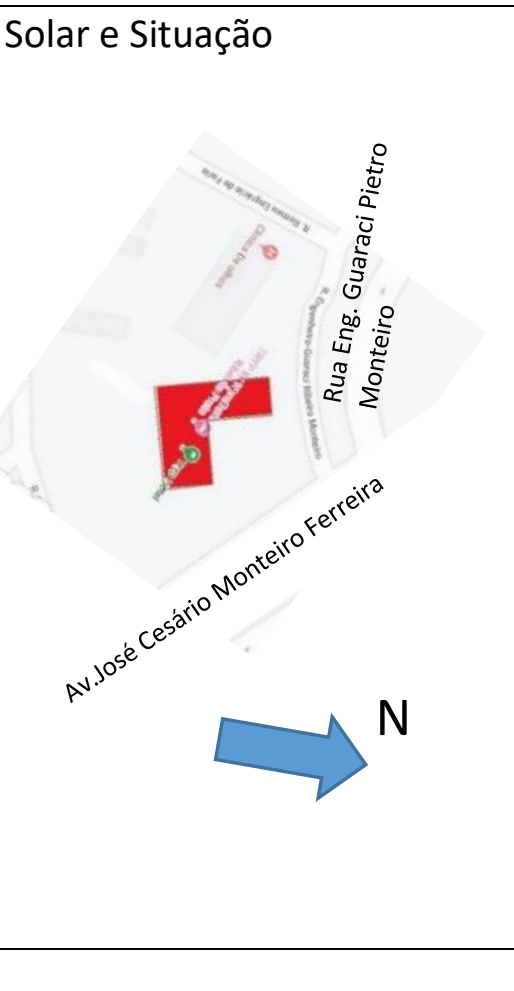 \\
\hline \multicolumn{2}{|c|}{$\begin{array}{l}\text { Arquiteto: NB2 Arquitetura } \\
\text { Construtora: ENOCH }\end{array}$} & \\
\hline \multirow{2}{*}{\multicolumn{2}{|c|}{$\begin{array}{l}\text { Endereço: Av.Dr. José Cesário Monteiro da Silva Filho,150 } \\
\text { Pavimentos: } 22\end{array}$}} & \\
\hline & & Área Total do Edifício: $21779 \mathrm{~m}^{2}$ \\
\hline Pavimentos Tipos: & Pé Direito: & Área Por Pavimento: $683,00 \mathrm{~m}^{2}$ \\
\hline Salas Comerciais: 257 & Salas por Pavimento: 10 a 12 & Área por Sala: $42 \mathrm{~m}^{2}$ a $85 \mathrm{~m}^{2}$ \\
\hline
\end{tabular}




\subsubsection{Levantamento dos dados dos edifícios}

Através dos projetos de arquitetura foram levantados os seguintes dados dos edifícios estudados, apresentados pela tabela 11 e que serão empregados no cálculo do índice de Consumo da Envoltória (ICenv).

Tabela 11 - Dados levantados dos edifícios para o cálculo do ICenv

\begin{tabular}{lllll}
\hline Itens Avaliados & Sigla & Edif. 01 & Edif. 02 & Edif. 03 \\
& & & & \\
\hline Área de projeção do edifício $\left(\mathrm{m}^{2}\right)$ & Ape & 859,40 & 975,13 & 895,18 \\
\hline Área de projeção da cobertura $\left(\mathrm{m}^{2}\right)$ & Apcob & 859,40 & 1735,11 & 1309,34 \\
\hline Área total do piso $\left(\mathrm{m}^{2}\right)$ & Atot & 16328,6 & 22427,90 & 15218,08 \\
\hline Área da Envoltória $\left(\mathrm{m}^{2}\right)$ & Aenv & 9499,40 & 12906,59 & 10937,33 \\
\hline Ângulo Vertical de sombreamento (graus) & AVS & 0,22 & 5,41 & 4,88 \\
\hline Ângulo Horizontal de sombreamento (graus) & AHS & 0,38 & 2,51 & 11,59 \\
\hline Percentual de abertura na fachada (\%) & PAFT & 31,76 & 31,49 & 13,74 \\
\hline Percentual de abertura da fachada Oeste (\%) & PAFo & 36,40 & 34,27 & 8,79 \\
\hline Volume total da edificação (m $\left.{ }^{3}\right)$ & Vtot & 51641,35 & 79075,73 & 53138,43 \\
\hline Fator Solar (adimensional) & FS & 0,27 & 0,46 & 0,28 \\
\hline Fator de Forma - Aenv/Vtot - (adimensional) & FF & 0,18 & 0,16 & 0,21 \\
\hline Fator de Altura - Apcob/Atot- (adimensional) & FA & 0,05 & 0,08 & 0,09 \\
\hline Zona Bioclimática & ZB & 4 & 4 & 4 \\
\hline
\end{tabular}

Fonte: autora (2020)

Conforme as características físicas levantadas dos três edifícios, as áreas do percentual de abertura da fachada oeste (PAFo), não excedeu ao percentual total de aberturas das fachadas (PAFT) mais 20\%, sendo utilizados os percentuais do PAFT para o cálculo do IC, conforme o regulamento (BRASIL, 2010).

O fator solar do edifício 02 na tabela 10 já se encontra calculado através da ponderação com relação as aberturas, possuindo o valor final de 0,46 . O vidro utilizado nos pavimentos tipo é o laminado incolor de 8mm - Reflecta Cinza possui um FS de 0,39 e os vidros do térreo - vidro temperado $10 \mathrm{~mm}$ com FS de 0,87 .

A tabela 12 apresenta a diferença dos índices de aberturas em razão das orientações das fachadas. 
Tabela 12 - Demonstrativo do cálculo das áreas de aberturas das fachadas

\begin{tabular}{cccccccccc}
\hline & \multicolumn{3}{c}{ Área de Fachada $\left(\mathbf{m}^{\mathbf{2}}\right)$} & \multicolumn{3}{c}{ Área de Abertura $\left.\mathbf{( m}^{\mathbf{2}}\right)$} & \multicolumn{3}{c}{ PAF (\%) } \\
\hline & Ed.01 & Ed.02 & Ed.03 & ED.01 & Ed.02 & Ed.03 & Ed.01 & Ed.02 & Ed.03 \\
\hline Norte & 924,00 & 3888,50 & 2339,02 & 233,58 & 1590,4 & 293,52 & 25,57 & 40,80 & 12,54 \\
\hline Sul & 924,00 & 3888,50 & 2719,99 & 167,58 & 862,09 & 462,49 & 18,13 & 22,17 & 17,0 \\
\hline Leste & 3396,00 & 1711,30 & 2228,68 & 1236,26 & 489,46 & 361,49 & 36,40 & 28,60 & 16,21 \\
\hline Oeste & 3396,00 & 1683,18 & 2340,04 & 1236,26 & 576,85 & 205,60 & 36,40 & 34,27 & 8,79 \\
\hline Total & 8640,00 & 11171,48 & 9628,03 & 2777,10 & 3518,8 & 1323,10 & 31,76 & 31,49 & 13,74 \\
\hline \multicolumn{1}{c}{ Fonte: Autora (2020) }
\end{tabular}

Como vimos no capítulo 2.3.3 (PAF), o RTQ-C emprega as orientações somente para a utilização do percentual de abertura da fachada oeste caso seja necessário. Essa limitação prejudica a análise da eficiência energética do edifício.

\subsection{Ferramentas utilizadas na pesquisa}

\section{Leitura de Plantas, Cortes e Fachadas dos Edifícios}

No levantamento de dados dos edifícios escolhidos no estudo de caso foi utilizado o programa Autocad da Autodesk. Esse programa foi empregado pelo fato dos arquivos fornecidos dos edifícios, plantas, cortes e vistas, serem arquivos DWG, abertos pelo autocad.

\section{Etiquetagem da envoltória dos edifícios escolhidos para o estudo de caso}

Para medir o consumo da envoltória de um edifício, o RTQ-C dispõe de equações de regressão linear desenvolvidas por simulação computacional através de modelos representativos das características mais comuns dos edifícios nacionais, foram elaboradas a partir de dados coletados em edificações de cinco estados brasileiros com funções corporativas, comerciais, hoteleiras, institucionais e públicas (Carlo,2008), dos quais forneceram as características básicas da construção civil brasileira até aquele momento.

Essas equações são diferenciadas por zonas bioclimáticas (ABNT, 2005b), e pela área de projeção do edifício, como foi apresentado no capítulo 2.4 .2 deste estudo.

No intuito de facilitar o levantamento dos dados e os cálculos das equações algumas ferramentas foram utilizadas nesta pesquisa e serão apresentadas a seguir:

- Planilha QUALI-A 


\begin{tabular}{l}
\hline Código do Cliente: \\
\hline Cidade/UF: \\
\hline Zona Bioclimática: \\
\hline
\end{tabular}

\section{CLASSIFICAÇÃO DO NÍVEL DE EFICIÊNCIA ENERGÉTICA DA ENVOLTÓRIA}

\begin{tabular}{|c|c|c|c|}
\hline PRÉ-REQUISITOS & SIGLA & VALOR & EqNum Máx. \\
\hline Absortância Paredes & aPar & & \\
\hline Absortância Cobertura & $\alpha C O B$ & & \\
\hline Transm. Cobertura Área Condicionada $\left[\mathrm{W} /\left(\mathrm{m}^{2} . \mathrm{K}\right)\right]$ & $\begin{array}{l}\text { UCOB } \\
\text { Cond }\end{array}$ & & \\
\hline $\begin{array}{l}\text { Transm. Cobertura Área Não Condicionada } \\
{\left[W /\left(m^{2} . K\right)\right]}\end{array}$ & $\begin{array}{l}\text { UCOB } \\
\text { NCond. }\end{array}$ & & \\
\hline Transmitância paredes $\left[\mathrm{W} /\left(\mathrm{m}^{2} . \mathrm{K}\right)\right]$ & Upar & & \\
\hline Capacidade Térmica Parede $\left[\mathrm{kJ} /\left(\mathrm{m}^{2} . \mathrm{K}\right)\right]$ & CTPar & & \\
\hline Percentual de Abertura Zenital (\%) & PAZ & - & \\
\hline Fator Solar da Abertura Zenital & FS & - & \\
\hline
\end{tabular}

\begin{tabular}{|c|c|c|}
\hline DADOS DO EDIFÍCIO & SIGLA & VALOR \\
\hline Área de projeção da cobertura do edifício $\left(\mathrm{m}^{2}\right)$ & Apcob & \\
\hline Área de projeção do edifício $\left(\mathrm{m}^{2}\right)$ & Ape & \\
\hline Área total de piso $\left(\mathrm{m}^{2}\right)$ & Atot & \\
\hline Área da envoltória $\left(\mathrm{m}^{2}\right)$ & Aenv & \\
\hline Ângulo Vertical de Somb. (graus) & AVS & \\
\hline Ângulo Horizontal de Somb.(graus) & AHS & \\
\hline Percentual de Abertura na Fachada (\%) & PAFT & \\
\hline Volume total da edificação $\left(\mathrm{m}^{2}\right)$ & Vtot & \\
\hline Fator solar & FS & \\
\hline Zona Bioclimática & ZB & \\
\hline
\end{tabular}

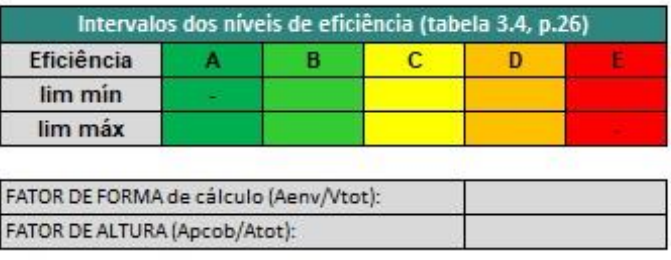

Indicador de Consumo (adimensional)

\section{ICenv}

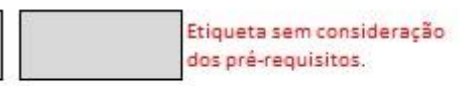

Resultados:

\begin{tabular}{|c|c|}
\hline EqNum dos Pré-requisitos & \\
\hline EqNum ICenv & 1 \\
\hline EqNumEnv & $\mathbf{1}$ \\
\hline
\end{tabular}
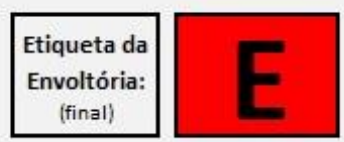

Fonte: Quali-A, curso Consultor de Etiquetagem, 2018

- Programa WebPrescritivo

O programa WebPrescritivo é uma ferramenta ainda em desenvolvimento disponibilizada na internet pelo PBEEdifica (Programa Brasileiro de Etiquetagem em Edificações), para avaliação da eficiência energética dos edifícios levantados pelo método prescritivo para edifícios comerciais, públicos e de serviços (Webprescritivo, 2020). Foi desenvolvido pela equipe do Projeto S3E, uma parceria entre laboratórios de conforto de universidades públicas, que teve seu término em 2018.

Na planilha disponibilizada, são inseridos os dados obtidos através dos levantamentos dos edifícios. A etiqueta da envoltória pode ser levantada individualmente, podendo 
também ser calculada com ou sem os dados dos pré-requisitos. A figura 34 apresenta a interface onde são preenchidos os dados relativos a envoltória do edifício.

O WebPrescritivo foi utilizado nessa pesquisa para ratificar e facilitar o cálculo do nível de eficiência alcançado pelos edifícios utilizados no estudo de caso e nas simulações.

Figura 34 - WebPrescritivo - envoltória

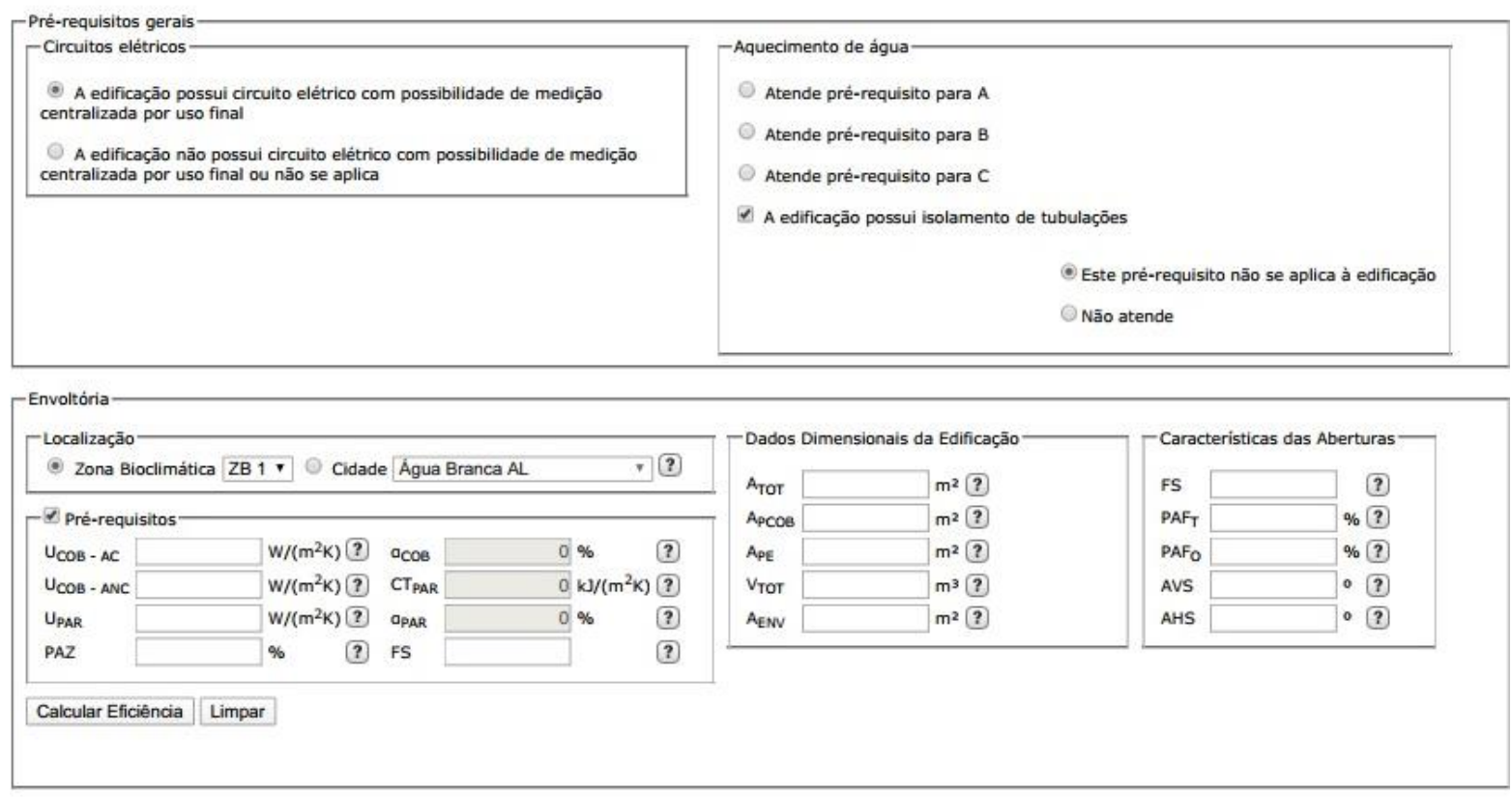

Fonte: Laboratório de Eficiência Energética da UFSC-LABEE.

- Planilha das Equações da Envoltória das Zonas Bioclimáticas

Planilha fornecida através do curso sobre o RTQ-C pela UFSC (Universidade Federal de Santa Catarina), realizado pelo autor. A planilha possui todas as equações fornecidas para as diferentes zonas climáticas o que facilita a comparação da eficiência do edifício nos diferentes climas do Brasil, conforme o zoneamento bioclimático brasileiro (ABNT 2005b). A planilha fornece o ICenv na forma numérica, o que auxilia a compreensão dos resultados durante a manipulação das variáveis. Na figura 35, é apresentada a planilha em questão. 
Figura 35 - Equações da Envoltória, levantamento do ICenv.

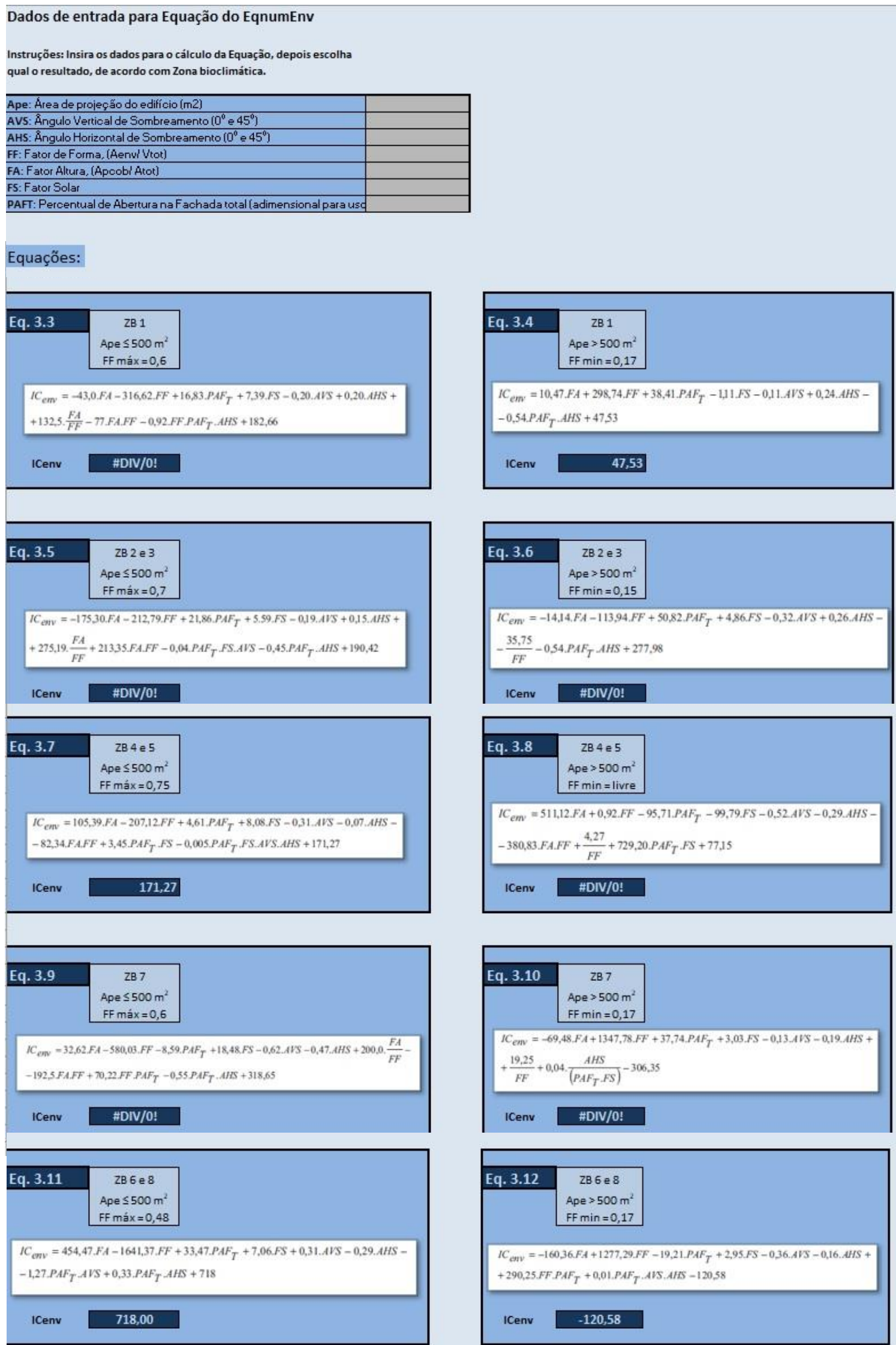

Fonte: LABEE - Laboratório de Eficiência Energética em Edificações, UFSC ,2014. 
Para se efetuar a etiquetagem do edifício 01 através da nova proposta do regulamento, o INIC, foi empregada uma ferramenta disponibilizada na internet e descrita a seguir:

- Interface Web

Rede neural disponível online, que funciona para facilitar o cálculo da carga térmica total anual através da entrada de dados relativos as zonas térmicas do edifício analisado. Os dados são inseridos de acordo com o estado, número de zonas térmicas, tipologia analisada, características térmicas dos materiais de paredes e coberturas, contato ou não com o solo, orientação solar das fachadas, densidade de potência de equipamento e de iluminação, entre outros.

Essa interface Web será utilizada para a etiquetagem parcial do sistema da envoltória pela nova proposta do regulamento de eficiência energética INI-C. A figura 36 apresenta parte da interface de entrada dos dados.

Figura 36 - Interface Web para o cálculo da carga térmica anual da envoltória

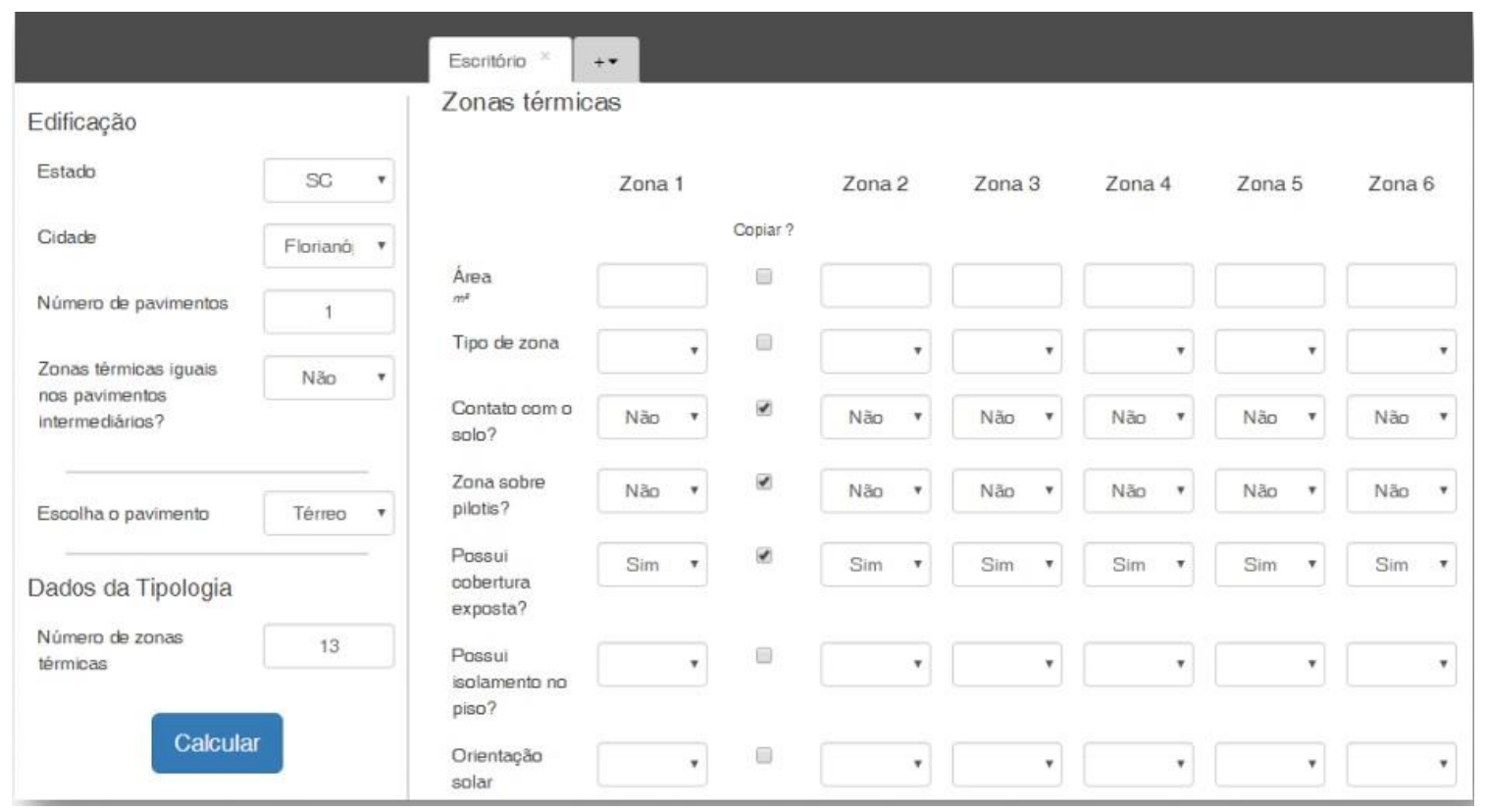

Fonte: Brasil, 2018

\subsection{Definição dos parâmetros utilizados para a simulação - condições de contorno}

Após a etiquetagem dos edifícios, as variáveis são simuladas no Excel e Webprescritivo. Os dados coletados das simulações são inseridos em planilhas do Excel para uma melhor 
compreensão dos resultados e aferição dos índices que proporcionem o Nível A na etiquetagem.

Os cenários são modificados com a alteração dos índices das variáveis com o propósito de compreender as interferências destas no nível de eficiência alcançado diante de cada contexto apresentado.

Para essas simulações foram estipuladas as seguintes condições de contorno das variáveis do indicador de consumo:

a) Fator Altura - FA e Fator de Forma - FF permanecem fixos e inalterados, pois segundo o Regulamento, representam a forma do edifício, altera-los representaria a alteração do edifício em si;

b) os ângulos de sombreamentos AVS e AHS são utilizados no RTQ-C a partir de uma média ponderada da somatória dos ângulos verticais e horizontais levantados nos projetos em função das áreas de aberturas e sombreamentos causados por elementos construtivos (brises, beirais, peitoris, etc.) e pelo próprio edifício em si mesmo ( BRASIL, 2010) Em estudo realizado por Carlo, Maciel (2011) sobre a análise da sensibidade das variáveis do RTQ-C, em todas as zonas bioclimáticas, constatou-se a limitada influência desse parâmetro na ZB4 em edifícios que possuem a área de projeção maior que $500,00 \mathrm{~m}^{2}$;

Tabela 13 - Influência do AHS e AVS na ZB 4 e 5

\begin{tabular}{|c|c|c|c|c|c|}
\hline \multirow{2}{*}{$\begin{array}{l}\text { Zona } \\
\text { Bioclimática }\end{array}$} & \multirow{2}{*}{$\begin{array}{l}\text { Área de } \\
\text { Projeçãoo }\end{array}$} & \multicolumn{4}{|c|}{ Parâmetros } \\
\hline & & PAFT & FS & AVS & AHS \\
\hline \multirow[t]{2}{*}{$Z B 4$ e 5} & Ape $>500 \mathrm{~m}^{2}$ & 46,39 & 45,31 & 5,34 & 2,96 \\
\hline & Ape $<500 m^{2}$ & 14,84 & 26,18 & 45,58 & 13,39 \\
\hline
\end{tabular}

Fonte: Carlo, Maciel (2011)

Deste modo, foram adotados três índices para análise:

- $0^{\circ}$ o que representaria as aberturas sem sombreamento, e corresponde a maioria dos edifícios representativos da construção nacional (Carlo, 2008);

- $45^{\circ}$ que representa o ângulo máximo de sombreamento estipulado pelo RTQC, (BRASIL, 2010).

- $22^{\circ}$ o que retrata um cenário médio aos já acima apresentados. 
C) A porcentagem total das áreas de Aberturas das Fachadas - PAFt, para aplicação no RTQ-C possui o valor mínimo de 0,05 para o cálculo do ICmin (modelo mais eficiente) e o máximo de 0,60 para o cálculo do ICmax (modelo menos eficiente) durante a análise do nível de consumo da envoltória do edifício (IBRASIL,2010). Como demonstra Carlo, Maciel (2011), o PAFt é a variável que mais influência na eficiência da fachada na ZB4, sendo que qualquer aumento em seu índice, provoca aumento no consumo do edifício e interfere na mudança de nível no ICenv. Desta maneira, a pesquisa utilizará como PAFT inicial o índice de $10 \%(0,10)$ e o final de $60 \%(0,60)$ com o aumento a cada 0,10 para que essa interferência possa ser melhor analisada.

d) O Fator Solar - FS, para o ICmin do regulamento é utilizado o índice de 0,87 e para o ICmax o índice de 0,61. Vidros com fator solar igual ou próximos a esses índices serão utilizados na pesquisa. Como o FS é uma variável que na ZB4 para edifícios com ape > $500 \mathrm{~m}^{2}$ contribui tanto quanto o PAFt para o consumo do edifício (CARLO; MACIEL; 2011), torna-se importante a análise da influência de vidros de alta performance no ICenv. Deste modo os vidros analisados estão representados através da tabela 14.

Tabela 14 - Tipos de vidros utilizados no estudo

\begin{tabular}{llllll}
\hline Vidro & Fabricante & Produto & $\begin{array}{l}\text { Esp. } \\
\mathbf{m m}\end{array}$ & Processo & FS \\
\hline 1 & Guardian & Neutral 14 Clear & 8,0 & Laminado com Incol. & 0,22 \\
\hline 2 & Cebrace & $\begin{array}{l}\text { Cool Lite KNT } \\
\text { Incolor }\end{array}$ & 8,0 & Laminado com Incol. & 0,43 \\
\hline 3 & Guardian & Neutral 70 Clear & 8,0 & Laminado com Incol. & 0,60 \\
\hline 4 & -------- & Simples Incolor & 6,0 & $-------{ }^{---}$ & 0,87 \\
\hline
\end{tabular}

Fonte: BRASIL, 2013

A tabela 15, apresenta o resumo das condições de contorno utilizadas para a simulação das variáveis.

Tabela 15 - Parâmetros utilizados na simulação

\begin{tabular}{lllll}
\hline Variáveis & PAFt \% & FS & AVS $^{\circ}$ & AHS $^{\circ}$ \\
\hline Índices & $\begin{array}{l}10 ; 20 ; 30 ; 40 ; \\
50 ; 60\end{array}$ & $\begin{array}{l}0,22 ; 0,43 ; 0,60 \\
\text { e } 0,87\end{array}$ & $0 ; 22$ e 45 & $0 ; 22$ e 45 \\
& & & \\
\hline
\end{tabular}

Fonte: a autora (2020) 


\section{Capítulo 4}

\section{RESULTADOS E DISCUSSÃO}

A seguir serão apresentados os resultados relativos a etiquetagem dos edifícios selecionados (através do atual regulamento de eficiência - o RTQ-C), os resultados das simulações efetuadas por meio dos softwares apresentados, a análise das equações dos IC relativos à ZB3 e ZB4 e a etiquetagem do edifício 01 pela proposta de aperfeiçoamento do regulamento vigente (INIC).

\section{1 Índice de Consumo das Envoltórias}

Através dos levantamentos dos dados dos edifícios escolhidos e a aplicação destes na Equação 03 foi possível identificar os valores dos seus índices de consumo das envoltórias (ICenv). As figuras 37, 38 e 39, apresentam os valores alcançados pelas envoltórias para cada edifício estudado e os limites estabelecidos para a classificação máxima (Nível A) e mínima (nível E) de eficiência, segundo o método prescritivo do RTQ-C.

Figura 37 - Valores de ICenv e ICmáximo e minimo - Edifício 01

\begin{tabular}{|c|c|c|c|c|c|}
\hline \multicolumn{3}{|c|}{ Indicador de Consumo (adimensional) } & ICenv & 129,10 & B \\
\hline Eficiência & A & B & $\mathrm{C}$ & D & $\bar{E}$ \\
\hline lim mín & - & 115,99 & 168,11 & 220,23 & 27235 \\
\hline lim máx & 115,98 & 168,10 & 220,22 & 272,34 & \\
\hline
\end{tabular}

Fonte: a autora

Figura 38 - Valores de ICenv e ICmáximo e mínimo - Edifício 02

\begin{tabular}{|l|l|l|}
\hline Indicador de Consumo (adimensional) & ICenv & $\mathbf{1 6 3 , 8 7}$ \\
\hline
\end{tabular}

\begin{tabular}{|c|c|c|c|c|c|}
\hline Eficiência & A & B & C & D & E \\
\hline lim mín & - & 130,44 & 182,56 & 234,68 & 286,79 \\
\hline lim máx & 130,43 & 182,55 & 234,67 & 286,78 & \\
\hline
\end{tabular}


Figura 39 - Valores de ICenv e ICmáximo e mínimo - Edifício 03

\begin{tabular}{|c|c|c|c|c|c|}
\hline \multicolumn{3}{|c|}{ Indicador de Consumo (adimensional) } & ICenv & 116,39 & \\
\hline Eficiência & A & B & $\mathrm{C}$ & D & E \\
\hline lim mín & - & 127,56 & 179,68 & 231,80 & 28392 \\
\hline lim máx & 127,55 & 179,67 & 231,79 & 283,91 & \\
\hline
\end{tabular}

Fonte: a autora

Os três edifícios utilizam em seus projetos, vidros de alta performance, respectivamente com 0,27, 0,39 e 0,28 de fator solar. No cálculo do Índice de Consumo Máximo, segundo o RTQ-C, o fator mínimo para o cálculo é de 0,61 o que acaba depreciando a avaliação do nível de eficiência dos edifícios que utilizam esse tipo de material.

Pela etiquetagem efetuada o edifício 01 e 02 obtiveram Nível B no ICenv e o edifício 03 Nível A. A edifício 03 como já foi colocado, possui selo Procel Edifica, onde obteve o Nível A em todos os sistemas etiquetados, entre eles o da envoltória.

\subsection{Simulações das Variáveis na Equação do Índice de Consumo}

As tabelas a seguir apresentam os resultados das simulações efetuadas a partir dos dados extraídos de cada edifício estudado e a aplicação dos cenários utilizando as condições de contorno dos parâmetros do ICenv, descritos no capítulo 3.5.

Foram executadas 504 simulações no intuito de extrair os índices apresentados. Os resultados foram aferidos nas planilhas do Excel já descritas e no Webprescritivo para comparação e verificação dos resultados encontrados, com o propósito de validação dos índices obtidos.

Os dados inseridos nas planilhas para as simulações são divididos em dados fixos e móveis. 0 dado levantado de cada edifício como: Fator Altura - FA (Apcob/ Atot) e Fator de Forma - FF (Aenv/Vtot) e a Área de projeção do Edifício - Ape, permanecem fixos durante as simulações efetuadas. É inserido o número da Zona Bioclimática e efetuadas as simulações de acordo com as especificações abaixo:

a) Simulação 01:

Dados fixos: FF, FA, PAFT de $60 \%$

Dados móveis: FS: $0,87,0,60,0,43$ e 0,27 e AVS e AHS $\left(0^{\circ}, 22^{\circ}\right.$, e $\left.45^{\circ}\right)$. 
De acordo com as simulações foi possível analisar qual a contribuição do fator solar do vidro e dos ângulos das proteções solares, na eficiência energética da fachada com o percentual de $60 \%$ de aberturas. Não sendo obtida nenhum cenário que alcançasse o Nível A do regulamento.

Número de Simulações: 96 (nos três edifícios)

b) Simulação 02:

Dados fixos: FF, FA e PAFT de $\mathbf{5 0 \%}$

Dados móveis: FS: $0,87,0,60,0,43$ e 0,27 e AVS e AHS $\left(0^{\circ}, 22^{\circ}\right.$, e $\left.45^{\circ}\right)$.

Após as simulações foi obtido um cenário que atingiu o Nível $\mathbf{A}$ utilizando neste vidro de FS de 0,27 e as proteções solares com ângulos máximos $\left(45^{\circ}\right)$

Número de Simulações: 96 (nos três edifícios)

c) Simulação 03:

Dados fixos: FF, FA e PAFT de $\mathbf{4 0 \%}$

Dados móveis: FS: $0,87,0,60,0,43$ e 0,27 e AVS e AHS $\left(0^{\circ}, 22^{\circ}\right.$, e $\left.45^{\circ}\right)$.

Após as simulações foram obtidos 04 cenários que alcançaram o Nível A. Estes cenários foram obtidos mediante a utilização de vidros de $\mathrm{FS}=0,27$ e com a contribuição de proteção solares.

Número de Simulações: 96 (nos três edifícios)

d) Simulação 04:

Dados fixos: FF, FA e PAFT de $\mathbf{3 0 \%}$

Dados móveis: FS: $0,87,0,60,0,43$ e 0,27 e AVS e AHS $\left(0^{\circ}, 22^{\circ}\right.$, e $\left.45^{\circ}\right)$.

Após as simulações foram obtidos 07 cenários que alcançaram o Nível A. Estes cenários foram obtidos com vidros de $F S=0,27$ e $F S=0,43$, ambos com a contribuição de proteção solares.

Número de Simulações: 96 (nos três edifícios)

e) Simulação 05:

Dados fixos: FF, FA e PAFT de $\mathbf{2 0 \%}$

Dados móveis: FS: $0,87,0,60,0,43$ e 0,27 e AVS e AHS $\left(0^{\circ}, 22^{\circ}\right.$, e $\left.45^{\circ}\right)$.

Após as simulações foram obtidos 17 cenários que alcançam o Nível A. O PAFT de $20 \%$ é o índice que apresenta uma maior flexibilidade de composições, podendo-se alcançar o maior nível de eficiência com os quatro FS utilizados e diversas configurações de proteções solares. 
Número de Simulações: 96 (nos três edifícios)

f) Simulação 06:

Dados fixos: FF, FA e PAFT de $10 \%$

Dados móveis: FS: $0,87,0,60,0,43$ e 0,27 e AVS e AHS $\left(0^{\circ}, 22^{\circ}\right.$, e $\left.45^{\circ}\right)$.

As simulações demonstraram que com o PAFT de $10 \%$, foi possível alcançar o Nível A no regulamento somente com o fator solar do vidro.

Número de Simulações: 96 (nos três edifícios)

Total de Simulações: 504.

Os resultados apresentados a seguir indicam os índices das variáveis relativas ao ICenv para alcançar o Nível A em eficiência pela equação do método prescritivo do RTQ - C.

\section{Edifício 01}

- Fator de Forma: $F F=0,18$

- Fator Altura: $\mathrm{FA}=0,05$

Tabela 16 - Índices das variáveis para o Nível A, no ICenv

\begin{tabular}{|c|c|c|c|c|c|c|c|}
\hline \multirow{2}{*}{ FS } & \multicolumn{6}{|c|}{ PAFT \% } & \\
\hline & 60 & 50 & 40 & 30 & 20 & 10 & \\
\hline \multirow{6}{*}{0,27} & - & $45^{\circ} / 45^{\circ}$ & $45^{\circ} / 0^{\circ}$ & $22^{\circ} / 0^{\circ}$ & $22^{\circ} / 0^{\circ}$ & \multirow{6}{*}{$x^{\circ} / X^{\circ}$} & \multirow{17}{*}{$\mathrm{AVS}^{\circ} / \mathrm{AHS}^{\circ}$} \\
\hline & - & - & $22^{\circ} / 45^{\circ}$ & $0 \% 45^{\circ}$ & $0 \% 22^{\circ}$ & & \\
\hline & - & - & $45^{\circ} / 22^{\circ}$ & $45^{\circ} / 0^{\circ}$ & $22^{\circ} / 22^{\circ}$ & & \\
\hline & - & - & $45^{\circ} / 45^{\circ}$ & $22^{\circ} / 22^{\circ}$ & $22^{\circ} / 45^{\circ}$ & & \\
\hline & - & - & - & $45^{\circ} / 22^{\circ}$ & $45^{\circ} / 22^{\circ}$ & & \\
\hline & - & - & - & $45^{\circ} / 45^{\circ}$ & $45^{\circ} / 45^{\circ}$ & & \\
\hline \multirow{5}{*}{0,43} & - & - & - & $45^{\circ} / 45^{\circ}$ & $22^{\circ} / 0^{\circ}$ & \multirow{5}{*}{$X^{\circ} / X^{\circ}$} & \\
\hline & - & - & - & - & $22^{\circ} / 22^{\circ}$ & & \\
\hline & - & - & - & - & $22^{\circ} / 45^{\circ}$ & & \\
\hline & - & - & - & - & $45^{\circ} / 22^{\circ}$ & & \\
\hline & - & - & - & - & $45^{\circ} / 45^{\circ}$ & & \\
\hline \multirow{4}{*}{0,60} & - & - & - & - & $45^{\circ} / 0^{\circ}$ & \multirow{4}{*}{$x^{\circ} / X^{\circ}$} & \\
\hline & - & - & - & - & $22^{\circ} / 45^{\circ}$ & & \\
\hline & - & - & - & - & $45^{\circ} / 22^{\circ}$ & & \\
\hline & - & - & - & - & $45^{\circ} / 45^{\circ}$ & & \\
\hline \multirow{2}{*}{0,87} & - & - & - & - & $45^{\circ} / 22^{\circ}$ & \multirow{2}{*}{$X^{\circ} / X^{\circ}$} & \\
\hline & - & - & - & - & $45^{\circ} / 45^{\circ}$ & & \\
\hline
\end{tabular}

Fonte: a autora (2020)

\section{Edifício 02}

- Fator de Forma: $F F=0,16$

- Fator Altura: $\mathrm{FA}=0,08$ 
Tabela 17 - Índices das variáveis para o Nível A, no ICenv

\begin{tabular}{|c|c|c|c|c|c|c|c|}
\hline \multirow{2}{*}{ FS } & \multicolumn{6}{|c|}{ PAFT \% } & \\
\hline & 60 & 50 & 40 & 30 & 20 & 10 & \\
\hline \multirow{6}{*}{0,27} & - & $45^{\circ} / 45^{\circ}$ & $45^{\circ} / 0^{\circ}$ & $22^{\circ} / 0^{\circ}$ & $22^{\circ} / 0^{\circ}$ & \multirow{6}{*}{$X^{\circ} / X^{\circ}$} & \multirow{17}{*}{$\mathrm{AVS}^{\circ} / \mathrm{AHS}^{\circ}$} \\
\hline & - & - & $22^{\circ} / 45^{\circ}$ & $0 \% 45^{\circ}$ & $0 \% 22^{\circ}$ & & \\
\hline & - & - & $45^{\circ} / 22^{\circ}$ & $45^{\circ} / 0^{\circ}$ & $22^{\circ} / 22^{\circ}$ & & \\
\hline & - & - & $45^{\circ} / 45^{\circ}$ & $22^{\circ} / 22^{\circ}$ & $22^{\circ} / 45^{\circ}$ & & \\
\hline & - & - & - & $45^{\circ} / 22^{\circ}$ & $45^{\circ} / 22^{\circ}$ & & \\
\hline & - & - & - & $45^{\circ} / 45^{\circ}$ & $45^{\circ} / 45^{\circ}$ & & \\
\hline \multirow{5}{*}{0,43} & - & - & - & $45^{\circ} / 45^{\circ}$ & $22^{\circ} / 0^{\circ}$ & \multirow{5}{*}{$X^{\circ} / X^{\circ}$} & \\
\hline & - & - & - & - & $22^{\circ} / 22^{\circ}$ & & \\
\hline & - & - & - & - & $22^{\circ} / 45^{\circ}$ & & \\
\hline & - & - & - & - & $45^{\circ} / 22^{\circ}$ & & \\
\hline & - & - & - & - & $45^{\circ} / 45^{\circ}$ & & \\
\hline \multirow{4}{*}{0,60} & - & - & - & - & $45^{\circ} / 0^{\circ}$ & \multirow{4}{*}{$x^{\circ} / X^{\circ}$} & \\
\hline & - & - & - & - & $22^{\circ} / 45^{\circ}$ & & \\
\hline & - & - & - & - & $45^{\circ} / 22^{\circ}$ & & \\
\hline & - & - & - & - & $45^{\circ} / 45^{\circ}$ & & \\
\hline \multirow{2}{*}{0,87} & - & - & - & - & $45^{\circ} / 22^{\circ}$ & \multirow{2}{*}{$X^{\circ} / X^{\circ}$} & \\
\hline & - & - & - & - & $45^{\circ} / 45^{\circ}$ & & \\
\hline
\end{tabular}

Fonte: a autora (2020)

\section{Edifício 03}

- Fator de Forma: $F F=0,21$

- Fator Altura: $F A=0,09$

Tabela 18 - Índices das variáveis para o Nível A, no ICenv

\begin{tabular}{|c|c|c|c|c|c|c|c|}
\hline \multirow{2}{*}{ FS } & \multicolumn{6}{|c|}{ PAFT \% } & \\
\hline & 60 & 50 & 40 & 30 & 20 & 10 & \\
\hline \multirow{6}{*}{0,27} & - & $45^{\circ} / 45^{\circ}$ & $45^{\circ} / 0^{\circ}$ & $22^{\circ} / 0^{\circ}$ & $22^{\circ} / 0^{\circ}$ & \multirow{6}{*}{$X^{\circ} / X^{\circ}$} & \multirow{17}{*}{$\mathrm{AVS}^{\circ} / \mathrm{AHS}$} \\
\hline & - & - & $22^{\circ} / 45^{\circ}$ & $0 \% 45^{\circ}$ & $0^{\circ} / 22^{\circ}$ & & \\
\hline & - & - & $45^{\circ} / 22^{\circ}$ & $45^{\circ} / 0^{\circ}$ & $22^{\circ} / 22^{\circ}$ & & \\
\hline & - & - & $45^{\circ} / 45^{\circ}$ & $22^{\circ} / 22^{\circ}$ & $22^{\circ} / 45^{\circ}$ & & \\
\hline & - & - & - & $45^{\circ} / 22^{\circ}$ & $45^{\circ} / 22^{\circ}$ & & \\
\hline & - & - & - & $45^{\circ} / 45^{\circ}$ & $45^{\circ} / 45^{\circ}$ & & \\
\hline \multirow{5}{*}{0,43} & - & - & - & $45^{\circ} / 45^{\circ}$ & $22^{\circ} / 0^{\circ}$ & \multirow{5}{*}{$X^{\circ} / X^{\circ}$} & \\
\hline & - & - & - & - & $22^{\circ} / 22^{\circ}$ & & \\
\hline & - & - & - & - & $22^{\circ} / 45^{\circ}$ & & \\
\hline & - & - & - & - & $45^{\circ} / 22^{\circ}$ & & \\
\hline & - & - & - & - & $45^{\circ} / 45^{\circ}$ & & \\
\hline \multirow{4}{*}{0,60} & - & - & - & - & $45^{\circ} / 0^{\circ}$ & \multirow{4}{*}{$X^{\circ} / X^{\circ}$} & \\
\hline & - & - & - & - & $22^{\circ} / 45^{\circ}$ & & \\
\hline & - & - & - & - & $45^{\circ} / 22^{\circ}$ & & \\
\hline & - & - & - & - & $45^{\circ} / 45^{\circ}$ & & \\
\hline \multirow{2}{*}{0,87} & - & - & - & - & $45^{\circ} / 22^{\circ}$ & \multirow{2}{*}{$X^{\circ} / X^{\circ}$} & \\
\hline & - & - & - & - & $45^{\circ} / 45^{\circ}$ & & \\
\hline
\end{tabular}

Fonte: a autora (2020) 
As tabelas 16, 17 e 18 apresentam os cenários para a obtenção do Nível A no índice de consumo da envoltória nos edifícios estudados.

Fica evidenciado através das tabelas apresentadas, que os três edifícios possuem os mesmos cenários para a obtenção do Nível A, ou seja, os mesmos índices aplicados aos parâmetros analisados de FS, AVS e AHS em função dos percentuais de aberturas são os mesmos nos três edifícios, apesar destes, apresentarem Fator de Forma e Fator Altura distintos.

Desta forma, é possivel pressupor que as relações estabelecidas entre as variáveis da equação do ICenv podem não sofrer influência do Fator de Forma e do Fator Altura da edificação, o que pode ser um indicativo de que estes índices, estabelecidos através das simulações, poderiam ser usados para edifícios com outras volumetrias, desde que Ape $>500 \mathrm{~m}^{2}$ (equação da ZB4 usada nessa pesquisa).

A volumetria e forma de uma edificação atuam de forma relevante em sua eficiência energética, aumentando ou diminuindo as áreas das fachadas expostas à radiação e atuando deste modo, na variação da carga térmica no interior do edifício. Estas variáveis não atuarem na contribuição energética é um ponto a ser revisto dentro do regulamento. Para que essa afirmação seja confirmada, é necessário que outros edifícios com volumetrias distintas as já analisadas sejam também estudadas (outros FF e FA).

Os resultados alcançados foram obtidos fixando-se o FF e o FA de cada edifício e manipulando as demais variáveis da fórmula (FS, AVS e AHS), em função do PAFT, de modo a obter as condições necessárias entre estas para a obtenção do Nível A.

Como os cenários para a obtenção do nível máximo de eficiência do ICenv pelo método prescritivo, são os mesmos para os três edifícios, serão apresentadas as discussões e análises das simulações de cada índice de PAFT estipulado pelo estudo, 10\%,20\%,30\%, 40\%, 50\% e 60\% apenas no Edifício 03, visto que estes serão iguais nos demais.

\section{Percentual total de aberturas de fachadas:}

\section{PAFT 60\%}

A tabela 19 indica que com o percentual de aberturas das fachadas em $60 \%(0,6)$ não foi possível alcançar o Nível A no ICenv pelo método prescritivo. 
Tabela 19 - Simulação das variáveis com PAFT 60\% fixo

\begin{tabular}{|c|c|c|c|c|c|c|c|c|c|c|c|}
\hline Variáveis & $\begin{array}{c}\text { Edif. } 01 \\
\text { ICenv }\end{array}$ & $\begin{array}{c}\text { Edif. } \\
01 \mathrm{~A} \\
\text { IC } \min \end{array}$ & $\begin{array}{c}\text { Edif. } \\
\text { 01B } \\
\text { IC max }\end{array}$ & $\begin{array}{c}\text { Sim } \\
01\end{array}$ & $\begin{array}{c}\mathrm{Sim} \\
02\end{array}$ & $\begin{array}{c}\mathrm{Sim} \\
03\end{array}$ & $\begin{array}{l}\mathrm{Sim} \\
04\end{array}$ & $\begin{array}{l}\text { Sim } \\
05\end{array}$ & $\begin{array}{c}\text { Sim } \\
06\end{array}$ & $\begin{array}{l}\mathrm{Sim} \\
07\end{array}$ & $\begin{array}{l}\text { Sim } \\
08\end{array}$ \\
\hline $\mathrm{FF}$ & 0,21 & 0,21 & 0,21 & 0,21 & 0,21 & 0,21 & 0,21 & 0,21 & 0,21 & 0,21 & 0,21 \\
\hline FA & 0,09 & 0,09 & 0,09 & 0,09 & 0,09 & 0,09 & 0,09 & 0,09 & 0,09 & 0,09 & 0,09 \\
\hline PAFT & 0,1374 & 0,05 & 0,6 & 0,6 & 0,6 & 0,6 & 0,6 & 0,6 & 0,6 & 0,6 & 0,6 \\
\hline $\mathrm{AVS}^{\circ}$ & 4,88 & 0 & 0 & 0 & 45 & 0 & 45 & 0 & 45 & 0 & 45 \\
\hline $\mathrm{AHS}^{\circ}$ & 11,59 & 0 & 0 & 0 & 45 & 0 & 45 & 0 & 45 & 0 & 45 \\
\hline FS & 0,28 & 0,87 & 0,61 & 0,87 & 0,87 & 0,6 & 0,6 & 0,43 & 0,43 & 0,27 & 0,27 \\
\hline ICmax & & & 284,88 & & & & & & & & \\
\hline $\mathrm{ICmin}$ & & 76,40 & & & & & & & & & \\
\hline ICenv & 117,13 & & & 372,6 & 336,2 & 281,5 & 245,0 & 224,0 & 187,6 & 170,0 & 133,6 \\
\hline $\begin{array}{l}\text { Nível de } \\
\text { Eficiência }\end{array}$ & Nível A & Nível A & Nível D & $\begin{array}{c}\text { Nível } \\
\text { E }\end{array}$ & $\begin{array}{c}\text { Nível } \\
\text { E }\end{array}$ & $\begin{array}{c}\text { Nível } \\
\text { D }\end{array}$ & $\begin{array}{c}\text { Nível } \\
\text { D }\end{array}$ & $\begin{array}{c}\text { Nível } \\
\text { C }\end{array}$ & $\begin{array}{c}\text { Nível } \\
\text { C }\end{array}$ & $\begin{array}{c}\text { Nível } \\
\text { B }\end{array}$ & $\begin{array}{c}\text { Nível } \\
B\end{array}$ \\
\hline
\end{tabular}

Fonte: a autora (2020)

A tabela apresentada demonstra a influência da escolha do vidro nas alterações dos níveis de consumo da envoltória. Alterando-se o FS (de 0,87 a 0,27), os níveis evoluem do E para o B. Os ângulos de sombreamento não possuem o mesmo peso, sendo a sua contribuição máxima ( $45^{\circ}$ no AVS e $45^{\circ}$ no AHS) aplicadas a todos os índices de FS, insuficiente para alteração do nível da eficiência.

O nível do ICenv do edifício 03 analisado é Nível A, com IC =117,13, ao substituirmos o FS de 0,28 pelo de 0,87 e o PAFT de 0,13 para 0,6, o Nível decai para $\mathbf{E}$.

A figura 40 apresenta as variações dos índices de consumo da envoltória (que aumenta a eficiência à medida que a pontuação diminui), durante a aplicação dos diferentes tipos de vidro, sem a interferência dos ângulos de sombreamentos. A figura apresenta também os níveis de eficiência alcançados em cada simulação.

Figura 40 - ICenv com PAFT de 0,60.

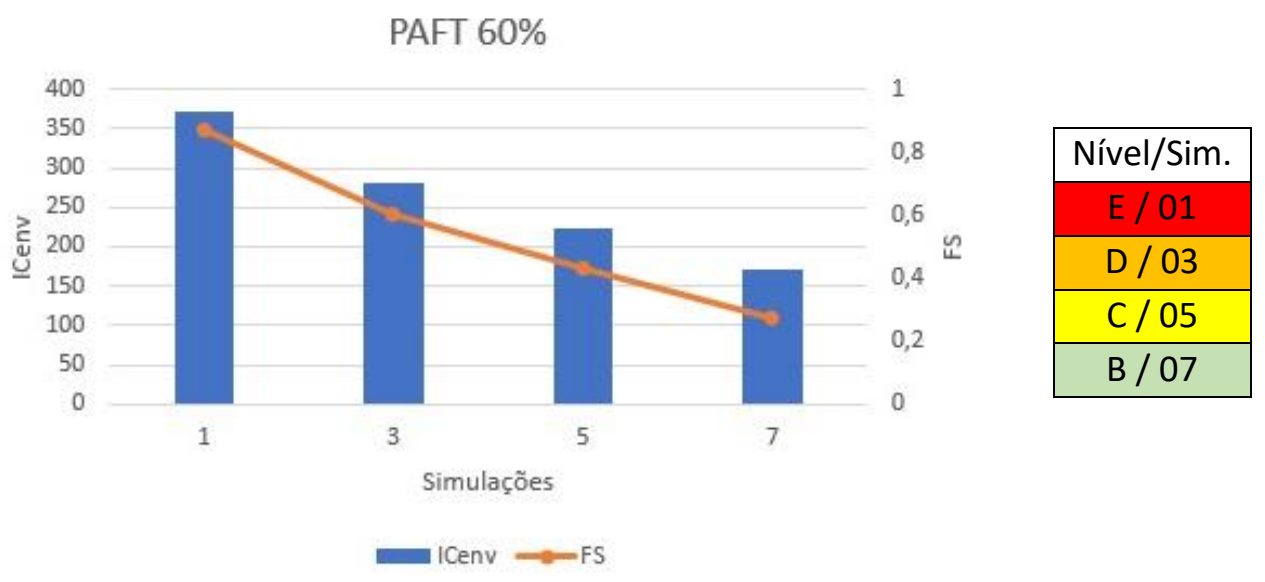


Fonte: a autora (2020)

Segundo o gráfico, o ICenv decai a partir da introdução de vidros com FS mais eficientes com relação a entrada de energia térmica para o interior do edifício:
a) sim.1 para sim.3: FS 0,87 para 0,60 - Diferença de 91,19 pontos (AVS e AHS=0);
b) sim.3 para sim.5: FS 0,60 para 0,43 - Diferença de 57,42 pontos (AVS e AHS=0);
c) sim.5 para sim.7: FS 0.43 para 0,27 - Diferença de 54,03 pontos (AVS e AHS=0).

Quando se introduz os ângulos de sombreamentos (AVS e AHS), o ICenv decai, mas não o suficiente para alterar o nível de eficiência:
a) sim.01 para sim.02: FS 0,87-AVS/AHS $=0$ para AVS/AHS $=45^{\circ} /$ Diferença de 36,45 pontos;
b) sim.03 para sim.04: FS 0,60 - AVS/AHS $=0$ para AVS/AHS $=45^{\circ} /$ Diferença de $\mathbf{3 6 , 4 5}$ pontos;
c) $\operatorname{sim} .05$ para sim.06: FS 0,43 - AVS/AHS $=0$ para AVS/AHS $=45^{\circ} /$ Diferença de $\mathbf{3 6 , 4 5}$ pontos;
d) $\operatorname{sim} .07$ para sim.08: FS 0,27 - AVS/AHS $=0$ para AVS/AHS $=45^{\circ} /$ Diferença de $\mathbf{3 6 , 4 5}$ pontos.

Verifica-se a presença de uma constante na alteração do ICenv que se faz a partir da influência dos vidros utilizados (FS de 0,27, 0,43, 0,60 e 0,87) e a contribuição dos sombreamentos com seus ângulos máximos (AVS e AHS $=45^{\circ}$ ).

Pode-se concluir que com o PAFT de 60\%, independente do fator solar do vidro, a diferença entre não ter nenhum sombreamento ou ter o sombreamento máximo (AVS e AHS de $45^{\circ}$ ) é de 36,45 pontos na redução no índice de consumo da envoltória (ICenv). O que, apesar de ser uma contribuição importante, esta não é suficiente para a alteração do seu nível de eficiência. De acordo o a tabela 19, com PAFT de 60\%, o Nível B é o nível máximo de eficiência a ser alcançado pelos cenários simulados, mesmo com o vidro de alta performance e índices máximos de sombreamentos permitidos pelo regulamento.

\section{PAFT 50\%}

Com o percentual de abertura da fachada com $50 \%(0,5)$ não foi possível alcançar o Nível A no ICenv somente com a redução do FS, como demonstra a tabela 20. 0 índice de consumo 
mínimo alcançado é de 158,9 pontos, indo do Nível E com o vidro de FS 0,87 ao Nível B com o vidro de FS 0,27.

Tabela 20 - Simulação das variáveis com PAFT 50\% $(0,50)$ fixo

\begin{tabular}{|c|c|c|c|c|c|c|c|}
\hline Variáveis & $\begin{array}{l}\text { Edif. } 01 \\
\text { ICenv }\end{array}$ & $\begin{array}{c}\text { Edif. } \\
01 \mathrm{~A} \\
\text { IC } \min \end{array}$ & $\begin{array}{c}\text { Edif. } \\
\text { 01B } \\
\text { IC max }\end{array}$ & $\begin{array}{c}\text { Sim } \\
01\end{array}$ & $\begin{array}{l}\text { Sim } \\
02\end{array}$ & $\begin{array}{l}\text { Sim } \\
03\end{array}$ & $\begin{array}{l}\mathrm{Sim} \\
04\end{array}$ \\
\hline $\mathrm{FF}$ & 0,21 & 0,21 & 0,21 & 0,21 & 0,21 & 0,21 & 0,21 \\
\hline FA & 0,09 & 0,09 & 0,09 & 0,09 & 0,09 & 0,09 & 0,09 \\
\hline PAFT & 0,1374 & 0,05 & 0,6 & 0,5 & 0,5 & 0,5 & 0,5 \\
\hline $\mathrm{AVS}^{\circ}$ & 4,88 & 0 & 0 & 0 & 0 & 0 & 0 \\
\hline $\mathrm{AHS}^{\circ}$ & 11,59 & 0 & 0 & 0 & 0 & 0 & 0 \\
\hline FS & 0,28 & 0,87 & 0,61 & 0,87 & 0,60 & 0,43 & 0,27 \\
\hline ICmax & & & 284,88 & & & & \\
\hline $\mathrm{ICmin}$ & & 76,40 & & & & & \\
\hline ICenv & 117,13 & & & 318,8 & 247,3 & 202,3 & 159,9 \\
\hline $\begin{array}{l}\text { Nível de } \\
\text { Eficiência }\end{array}$ & Nível A & Nível A & Nível D & $\begin{array}{c}\text { Nível } \\
\text { E }\end{array}$ & $\begin{array}{l}\text { Nível } \\
\text { D }\end{array}$ & $\begin{array}{l}\text { Nível } \\
\text { C }\end{array}$ & $\begin{array}{c}\text { Nível } \\
\text { B }\end{array}$ \\
\hline
\end{tabular}

Fonte: a autora (2020)

Na tabela 20 pode-se observar que mesmo com a redução do PAFT de $60 \%$ para $50 \%$ e aumentando a eficácia do vidro, não foi possível atingir o Nível A. Com a redução do FS alterase o nível de eficiência, conseguindo resultados melhores.

A figura 41 apresenta a variação dos índices de consumo da envoltória com os diferentes tipos de vidros utilizados. Existe uma redução no ICenv de 150,89 pontos, cerca de $99 \%$ quando se altera o FS de 0,87 para 0,27. Essa redução de consumo proporciona à envoltória da edificação a alteração do Nível E para o Nível B.

Figura 41 - ICenv PAFT de 0,50 variando-se o FS.

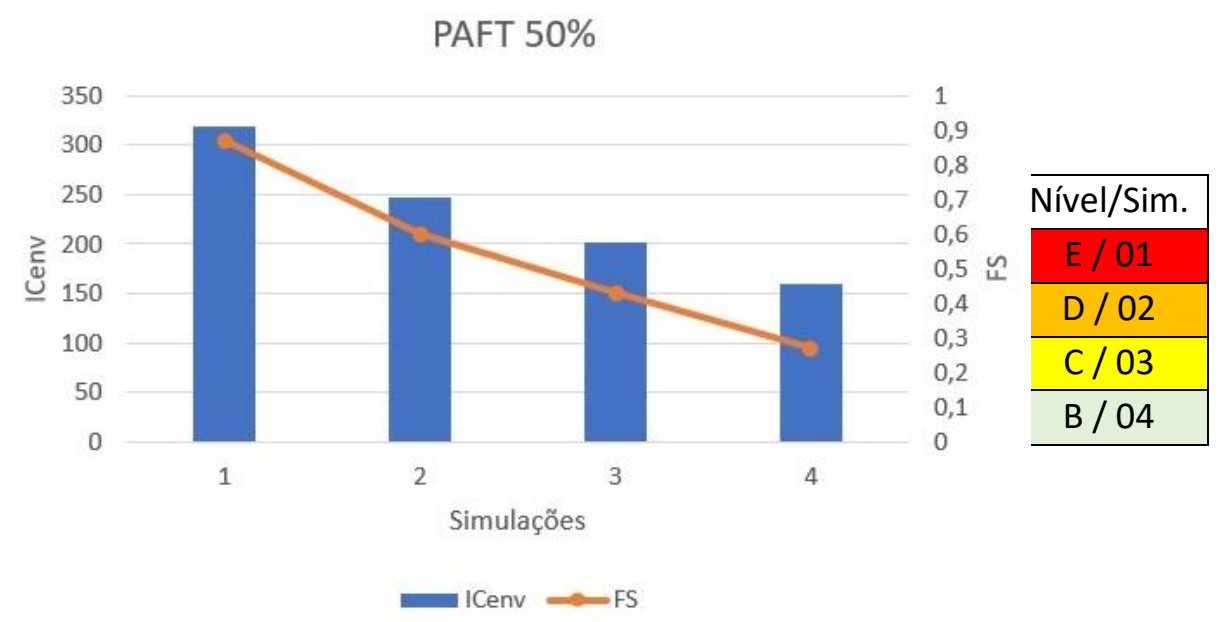

Fonte: a autora (2020) 
O vidro que proporciona maior redução da energia térmica, o de FS 0,27 não foi suficiente para atingir o nível mínimo de consumo, tendo que adicionar a contribuição dos ângulos de sombreamentos, como demonstram os gráficos a seguir.

Nas figuras 42,43,44 e 45, são apresentados os gráficos com as reduções do ICenv em função da inclusão inicialmente do AVS $\left(22^{\circ}\right.$ e $\left.45^{\circ}\right)$, e em seguida do AHS $\left(22^{\circ}\right.$ e $\left.45^{\circ}\right)$. Cada gráfico possui um FS diferenciado.

Figura 42 - PAFt 0 \% e FS 0,87 com aplicações do AVS e AHS .

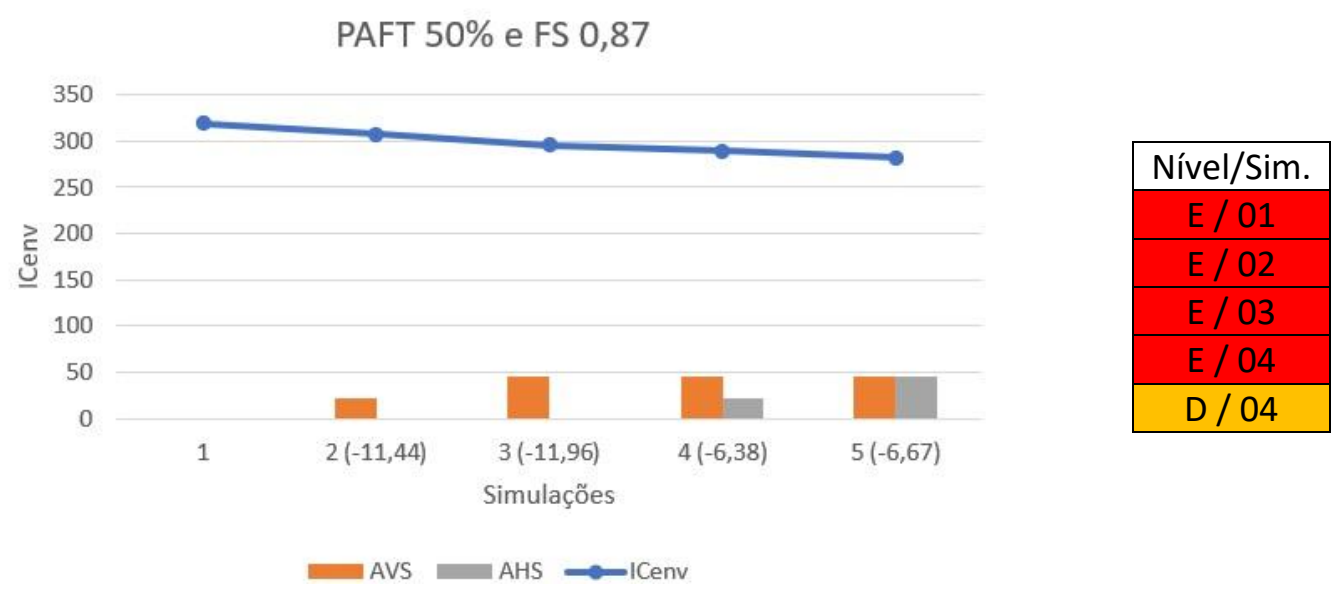

Fonte: a autora (2020)

Figura 43 - PAFt 50 \% e FS 0,60 com aplicações do AVS e AHS .

PAFT $50 \%$ e FS 0,60

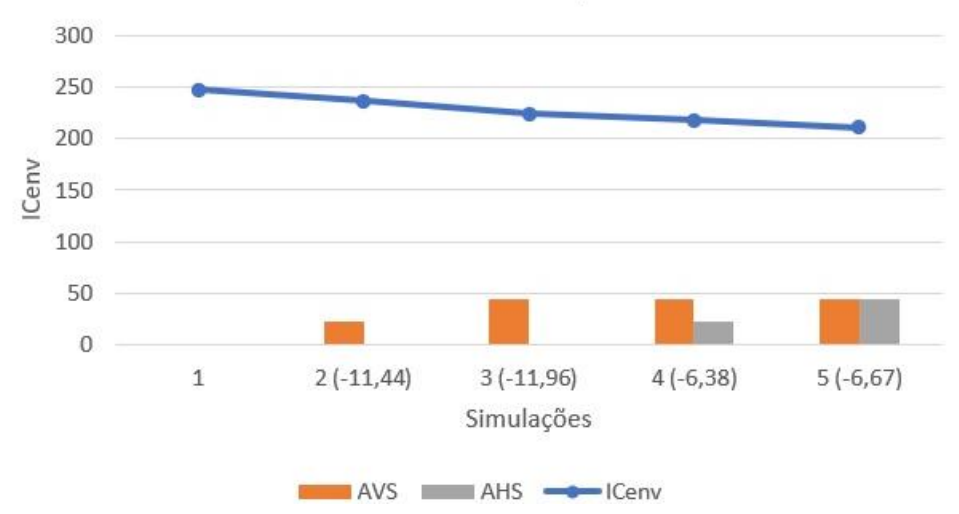

\begin{tabular}{|c|}
\hline Nível/Sim. \\
\hline $\mathrm{D} / 01$ \\
\hline $\mathrm{D} / 02$ \\
\hline $\mathrm{C} / 03$ \\
\hline $\mathrm{C} / 04$ \\
\hline $\mathrm{C} / 04$ \\
\hline
\end{tabular}

Fonte: a autora (2020) 
Figura 44 - PAFt 50 \% e FS 0,43 com aplicações do AVS e AHS .

PAFT $50 \%$ e FS 0,43

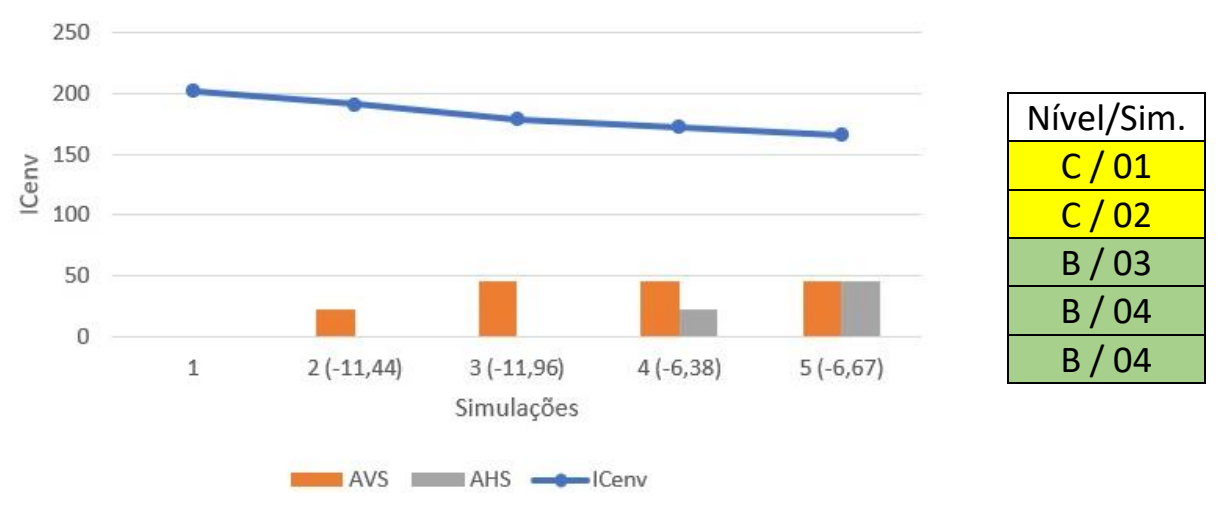

Fonte: a autora (2020)

Figura 45 - PAFt $50 \%$ e FS 0,27 com aplicações do AVS ${ }^{\circ}$ e $A H S^{\circ}$.

PAFT $50 \%$ e FS 0,27

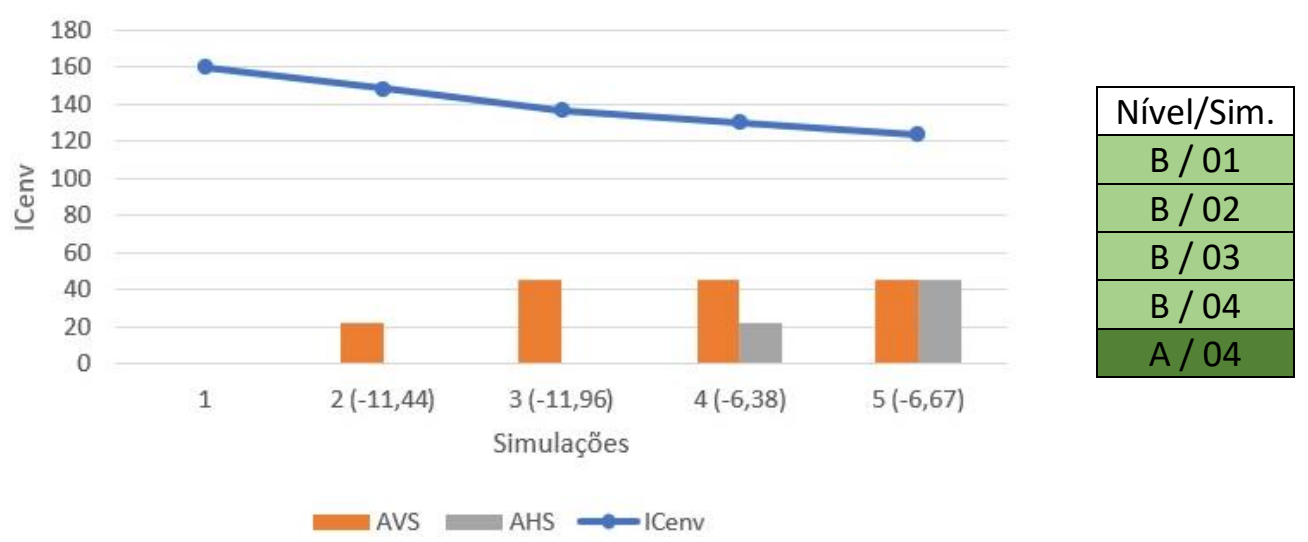

Fonte: a autora (2020)

Os gráficos apresentam a redução do ICenv em relação ao aumento do AHS e AVS. Observase que independente do FS a redução (não cumulativa) do ICenv entre uma simulação e outra permanece constante:

Tabela 21 - Redução do ICenv (Não Cumulativa) com aumento de AVS e AHS

\begin{tabular}{cccccc}
\hline Simulação & AVS $^{\circ} / \mathbf{A H S}^{\circ}$ & FS & $\begin{array}{c}\text { Redução do } \\
\text { ICenv (pontos) }\end{array}$ \\
\hline 01 & 0 & $/$ & 0 & $.87 / .60 / .43 / .27$ & \\
\hline 02 & 22 & $/$ & 0 & $.87 / .60 / .43 / .27$ & $-11,44$ \\
\hline 03 & 45 & $/$ & 0 & $.87 / .60 / .43 / .27$ & $-11,96$ \\
\hline 04 & 45 & $/$ & 22 & $.87 / .60 / .43 / .27$ & $-6,38$ \\
\hline 05 & 45 & $/$ & 45 & $.87 / .60 / .43 / .27$ & $-6,67$ \\
\hline
\end{tabular}

Fonte: a autora (2020) 
A tabela 21 indica que com o PAFT de 50\%, independente do FS, a contribuição da redução do ICenv com a aplicação do AVS e AHS é sempre constante, possuindo o AVS uma contribuição maior na redução do que o AHS como também é demonstrado na fórmula do índice de consumo da envoltória da ZB 4 e 5.

Devido à baixa contribuição dos ângulos de sombreamento no índice de consumo da envoltória na ZB 4, estes parâmetros só efetivam uma mudança no nível de eficiência quando para isso se necessita de um número pequeno de pontos para essa alteração, o que é confirma do na pesquisa de Carlo, Maciel (2011).

O Nível A do ICenv com o PAFt de 50\% é alcançado a partir do cenário estabelecido na tabela 22:

Tabela 22 - Percentual de Abertura a 50\%, cenário para o Nível A do ICenv

\begin{tabular}{cccccc}
\hline PAFT \% & Nível & ICenv & FS & AVS $^{\circ}$ & AHS $^{\circ}$ \\
\hline $\mathbf{5 0}$ & A & 126,41 & 0,27 & 45 & 45 \\
\hline \multicolumn{5}{c}{ Fonte: a autora }
\end{tabular}

\section{PAFT 40\%}

A tabela 23 indica que, com o PAFT de $40 \%$ não foi possível alcançar o Nível A reduzindo somente o Fator Solar (FS) do vidro. Alcança-se, contudo, índices de consumos menores do que com o PAFT de 50\%. O Nível D é obtido com o vidro de FS 0,87 e o Nível B com os vidros de FS 0,43 e 0,27 .

Tabela 23 - Simulação do Paft a 40\%

\begin{tabular}{|c|c|c|c|c|c|c|c|}
\hline Variáveis & $\begin{array}{c}\text { Edif. } \\
01 \\
\text { ICenv }\end{array}$ & $\begin{array}{l}\text { Edif. } \\
01 \mathrm{~A} \\
\text { IC min }\end{array}$ & $\begin{array}{l}\text { Edif. } \\
01 \mathrm{~B} \\
\text { IC } \\
\max \end{array}$ & $\begin{array}{c}\text { Sim } \\
01\end{array}$ & $\begin{array}{c}\text { Sim } \\
02\end{array}$ & $\begin{array}{c}\text { Sim } \\
03\end{array}$ & $\begin{array}{c}\text { Sim } \\
04\end{array}$ \\
\hline $\mathrm{FF}$ & 0,21 & 0,21 & 0,21 & 0,21 & 0,21 & 0,21 & 0,21 \\
\hline FA & 0,09 & 0,09 & 0,09 & 0,09 & 0,09 & 0,09 & 0,09 \\
\hline PAFT & 0,1374 & 0,05 & 0,6 & 0,4 & 0,4 & 0,4 & 0,4 \\
\hline AVS $^{\circ}$ & 4,88 & 0 & 0 & 0 & 0 & 0 & 0 \\
\hline $\mathrm{AHS}^{\circ}$ & 11,59 & 0 & 0 & 0 & 0 & 0 & 0 \\
\hline FS & 0,28 & 0,87 & 0,61 & 0,87 & 0,60 & 0,43 & 0,27 \\
\hline ICmax & & & 284,88 & & & & \\
\hline ICmin & & 76,40 & & & & & \\
\hline ICenv & 117,13 & & & 264,9 & 213,1 & 180,5 & 149,8 \\
\hline $\begin{array}{l}\text { Nível de } \\
\text { Eficiência }\end{array}$ & Nível A & Nível A & Nível D & $\begin{array}{c}\text { Nível } \\
\text { D }\end{array}$ & $\begin{array}{l}\text { Nível } \\
\text { C }\end{array}$ & $\begin{array}{c}\text { Nível } \\
\text { B }\end{array}$ & $\begin{array}{c}\text { Nível } \\
\mathrm{B}\end{array}$ \\
\hline
\end{tabular}


A figura 46 apresenta a evolução da redução do ICenv devido a aplicação de vidros com FS menores.

Figura 46 - Relação ICenv e FS com PAFT 40\%

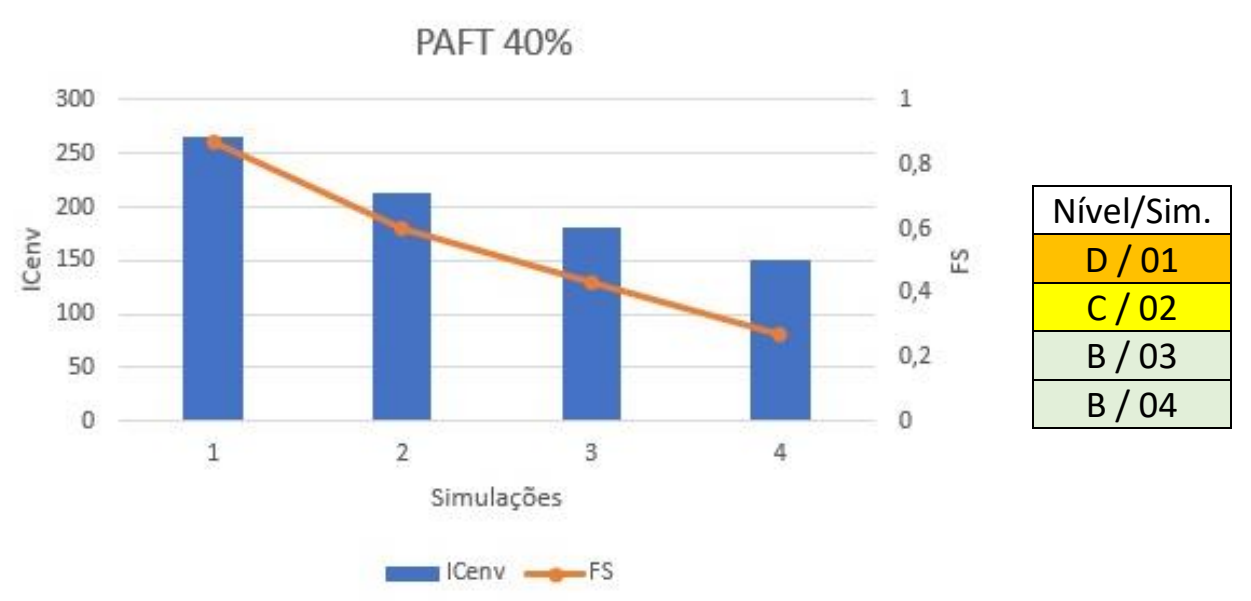

Fonte: a autora

Com o PAFt de 40\%, é preciso incorporar elementos de sombreamentos ou auto sombreamento para alcançar o Nível A.

Nas figuras 47, 48, 49 e 50 são apresentadas as reduções do ICenv em função da inclusão inicialmente do AVS $\left(22^{\circ} \mathrm{e} 45^{\circ}\right)$, e em seguida do AHS $\left(22^{\circ} \mathrm{e} 45^{\circ}\right)$. Cada gráfico apresenta um FS diferenciado.

Figura 47 - PAFt 40\% e FS 0,87

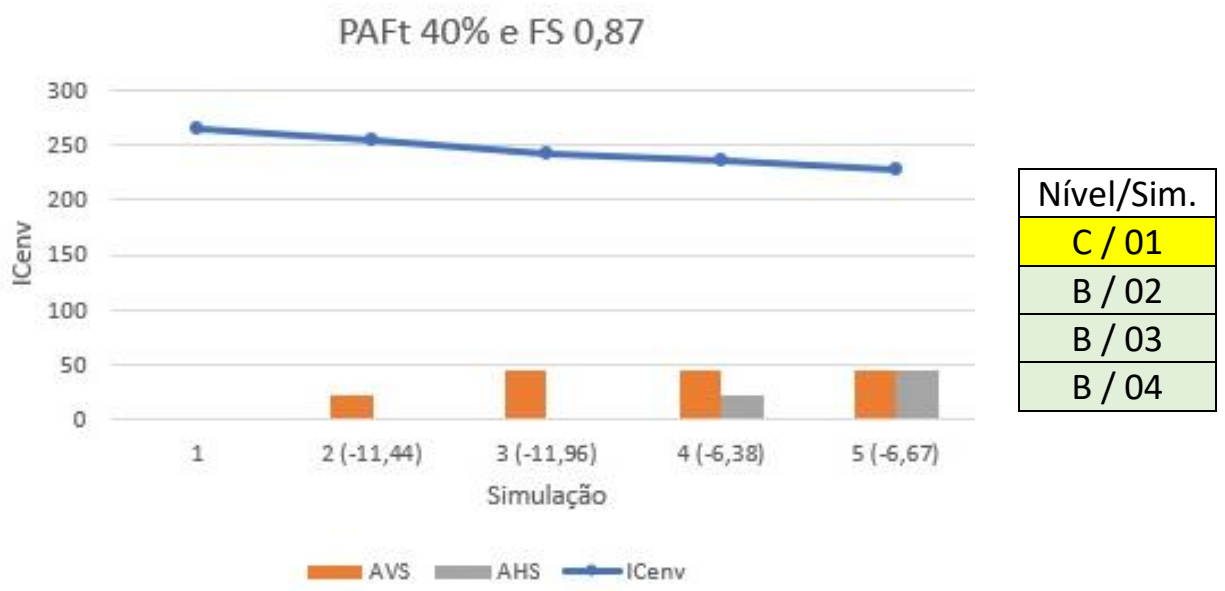

Fonte: a autora 
Figura 48 - PAFt $40 \%$ e FS 0,60

\section{PAFT $40 \%$ e FS 0.60}

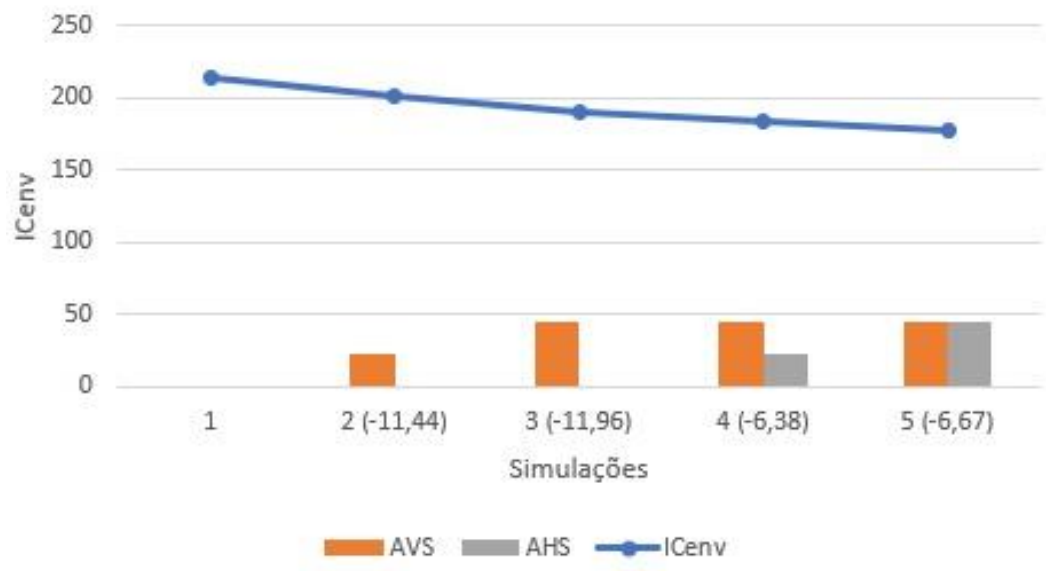

Nível/Sim. $\mathrm{C} / 01$ $\mathrm{B} / 02$ $\mathrm{B} / 03$ B / 04

Fonte: a autora (2020)

Figura 49 - PAFt 40\% e FS 0,43

PAFt $40 \%$ e FS 0,43

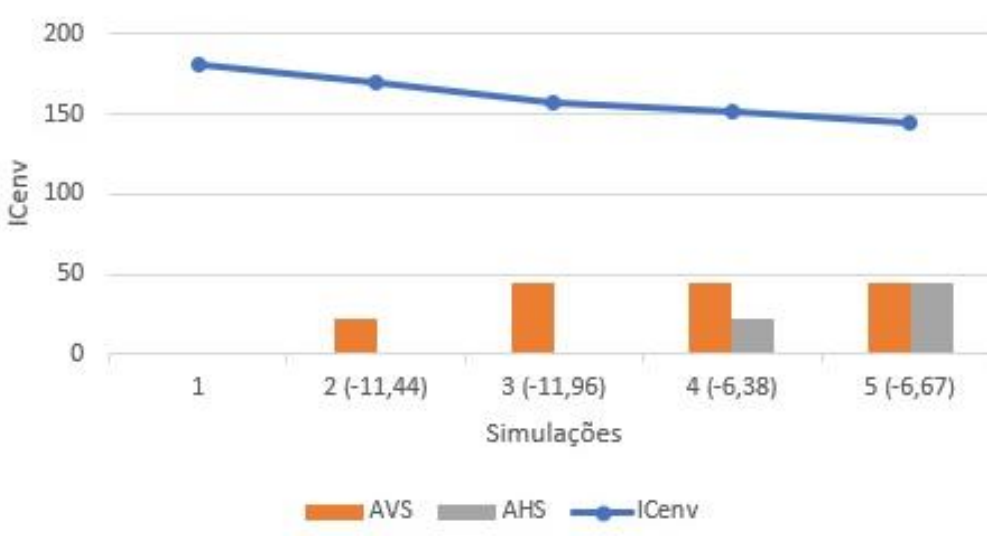

Fonte: a autora (2020)

Figura 50 - PAFt 40\% e FS 0,27

PAFt de $40 \%$ e FS de 0,27

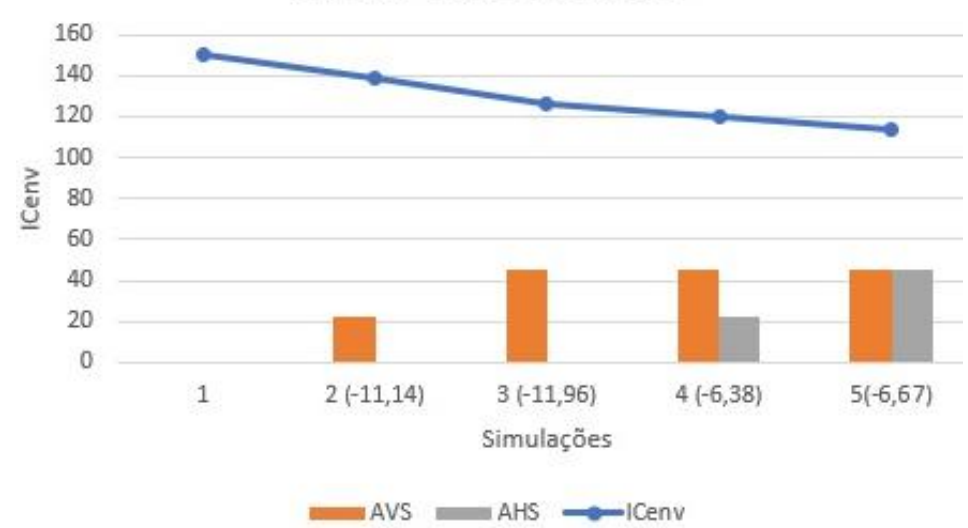

Nível/Sim. $\mathrm{C} / 01$ $\mathrm{B} / 02$ $\mathrm{B} / 03$ $\mathrm{B} / 04$

Fonte: a autora (2020) 
As figuras acima apresentam a redução do ICenv em relação ao aumento do AHS e AVS. Observa-se que independente do FS a redução (não cumulativa) do ICenv entre uma simulação e outra permanece constante.

Tabela 24 - Redução do ICenv (Não Cumulativa) com aumento de AVS e AHS

\begin{tabular}{cccccc}
\hline Simulação & AVS $^{\circ} / \mathbf{A H S}^{\circ}$ & FS & $\begin{array}{c}\text { Redução do } \\
\text { ICenv }\end{array}$ \\
\hline 01 & 0 & $/$ & 0 & $.87 / .60 / .43 / .27$ & \\
\hline 02 & 22 & $/$ & 0 & $.87 / .60 / .43 / .27$ & $-11,44$ \\
\hline 03 & 45 & $/$ & 0 & $.87 / .60 / .43 / .27$ & $-11,96$ \\
\hline 04 & 45 & $/$ & 22 & $.87 / .60 / .43 / .27$ & $-6,38$ \\
\hline 05 & 45 & $/$ & 45 & $.87 / .60 / .43 / .27$ & $-6,67$ \\
\hline
\end{tabular}

Fonte: a autora (2020)

A tabela 24 aponta que com o PAFT de $40 \%$ (da mesma forma do que o de $50 \%$ ), independente do FS, a contribuição da redução do ICenv com a aplicação do AVS e AHS é sempre constante, possuindo o AVS uma contribuição maior na redução do que o AHS.

O Nível A do ICenv com o PAFt a 40\% é alcançado a partir dos cenários da tabela 25:

Tabela 25 - Percentual de Abertura a 40\%, cenários para o Nível A do ICenv

\begin{tabular}{cccccc}
\hline PAFT \% & Nível & ICenv & FS & AVS $^{\circ}$ & AHS $^{\circ}$ \\
\hline \multirow{3}{*}{40} & A & 126,41 & 0,27 & 45 & 0 \\
\cline { 2 - 6 } & A & 125,32 & 0,27 & 22 & 45 \\
\cline { 2 - 6 } & A & 120,03 & 0,27 & 45 & 22 \\
\cline { 2 - 6 } & A & 113,36 & 0,27 & 45 & 45 \\
\hline
\end{tabular}

Fonte: o autor

\section{PAFT 30\%}

A tabela 26 demonstra que também com o PAFt de 30\% não é possível alcançar o Nível A reduzindo somente o Fator Solar (FS) do vidro, alcança-se, contudo, índices de consumos menores do que com o PAFt de $50 \%$ e $40 \%$. Com a redução do ICenv, o vidro de FS de 0,87 proporciona o Nível C, alcançando-se o Nível B com os vidros de fator solar de 0,60, 0,43 e 0,27 . 
Tabela 26 - Simulação do PAFt a 30\%

\begin{tabular}{|c|c|c|c|c|c|c|c|}
\hline Variáveis & $\begin{array}{c}\text { Edif. } \\
01 \\
\text { ICenv }\end{array}$ & $\begin{array}{l}\text { Edif. } \\
01 \mathrm{~A} \\
\text { IC min }\end{array}$ & $\begin{array}{c}\text { Edif. } \\
01 \mathrm{~B} \\
\text { IC } \\
\max \end{array}$ & $\begin{array}{c}\text { Sim } \\
01\end{array}$ & $\begin{array}{c}\text { Sim } \\
02\end{array}$ & $\begin{array}{c}\text { Sim } \\
03\end{array}$ & $\begin{array}{c}\text { Sim } \\
04\end{array}$ \\
\hline FF & 0,21 & 0,21 & 0,21 & 0,21 & 0,21 & 0,21 & 0,21 \\
\hline $\mathrm{FA}$ & 0,09 & 0,09 & 0,09 & 0,09 & 0,09 & 0,09 & 0,09 \\
\hline PAFT & 0,1374 & 0,05 & 0,6 & 0,3 & 0,3 & 0,3 & 0,3 \\
\hline AVS $^{\circ}$ & 4,88 & 0 & 0 & 0 & 0 & 0 & 0 \\
\hline $\mathrm{AHS}^{\circ}$ & 11,59 & 0 & 0 & 0 & 0 & 0 & 0 \\
\hline $\mathrm{FS}$ & 0,28 & 0,87 & 0,61 & 0,87 & 0,60 & 0,43 & 0,27 \\
\hline ICmax & & & 284,88 & & & & \\
\hline ICmin & & 76,40 & & & & & \\
\hline ICenv & 117,13 & & & 211,1 & 179,0 & 158,7 & 140,0 \\
\hline $\begin{array}{l}\text { Nível de } \\
\text { Eficiência }\end{array}$ & Nível A & Nível A & Nível D & $\begin{array}{l}\text { Nível } \\
\text { C }\end{array}$ & $\begin{array}{c}\text { Nível } \\
\text { B }\end{array}$ & $\begin{array}{c}\text { Nível } \\
\text { B }\end{array}$ & $\begin{array}{c}\text { Nível } \\
\text { B }\end{array}$ \\
\hline
\end{tabular}

Fonte: a autora (2020)

A figura 51 apresenta a evolução na redução do ICenv devido a aplicação de vidros com FS menores.

Figura 51 - Relação ICenv e FS com PAFT 30\%

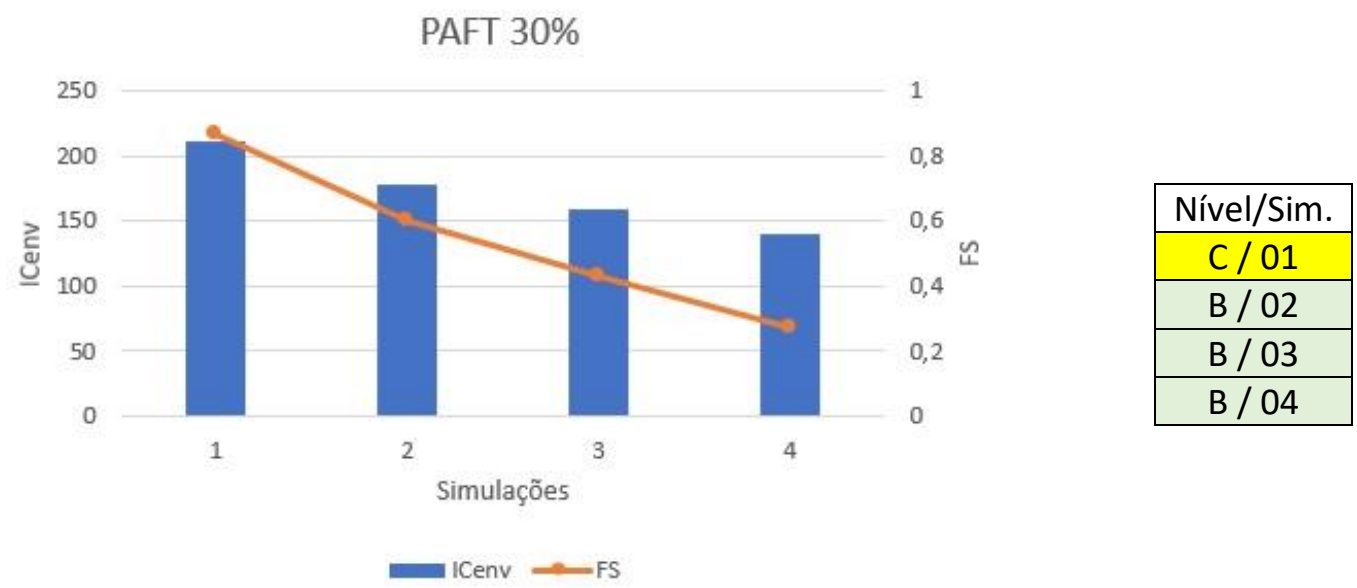

Fonte: a autora (2020)

Com o PAFt de $30 \%$, também é preciso incorporar elementos de sombreamentos ou auto sombreamento para alcançar o Nível A.

Nas figuras 52, 53, 54 e 55, são apresentadas as reduções do ICenv em função da inclusão inicialmente do AVS $\left(22^{\circ}\right.$ e $\left.45^{\circ}\right)$, e em seguida do AHS $\left(22^{\circ}\right.$ e $\left.45^{\circ}\right)$. Cada gráfico possui um FS distinto. 
Figura 52 - PAFt 30\% e FS 0,87

PAFt $30 \%$ e FS 0,87

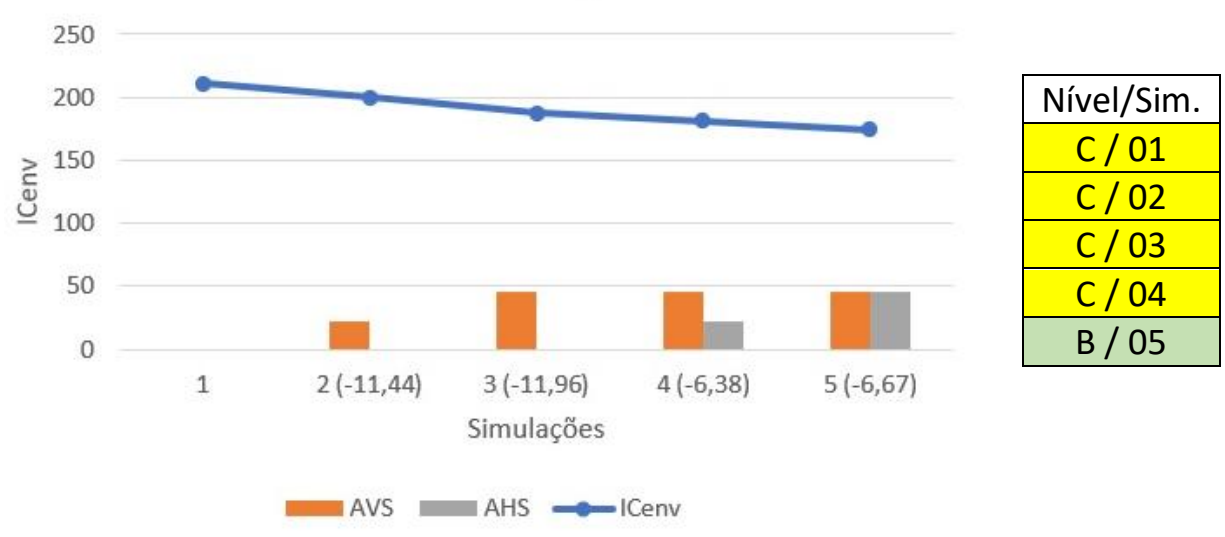

Fonte: a autora (2020)

Figura 53 - PAFt 30\% e FS 0,60

PAFt $30 \%$ e FS 0,60

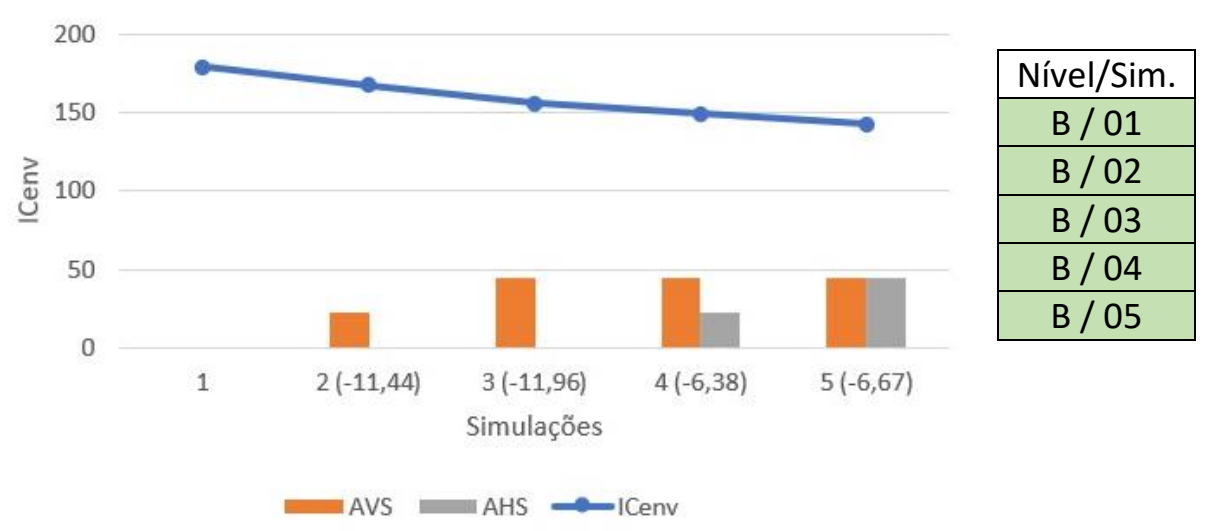

Fonte: a autora (2020)

Figura 54 - PAFt 30\% e FS 0,43

PAFt $30 \%$ e FS 0,43

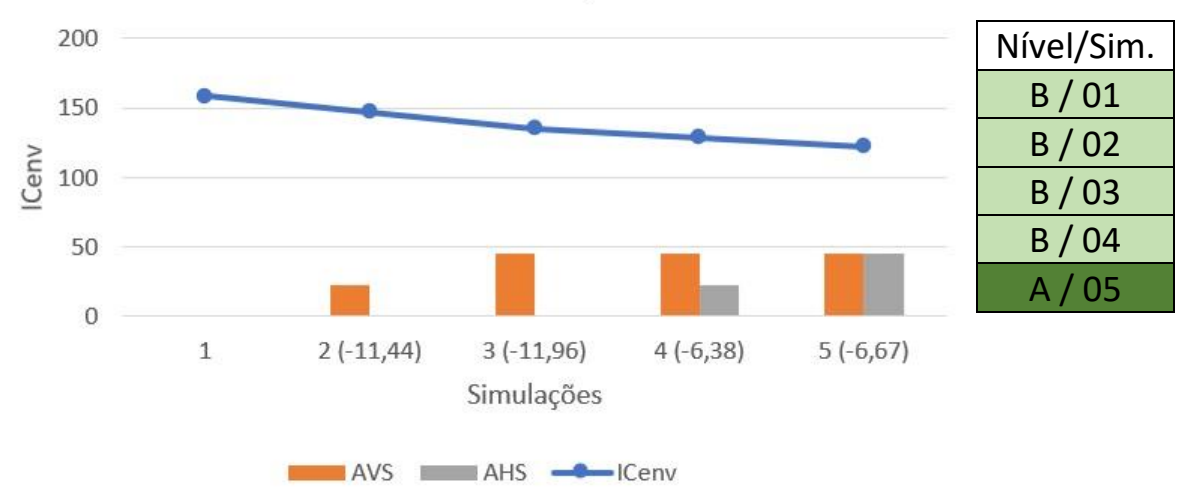

Fonte: a autora (2020) 
Figura 55 - PAFt 30\% e FS 0,27

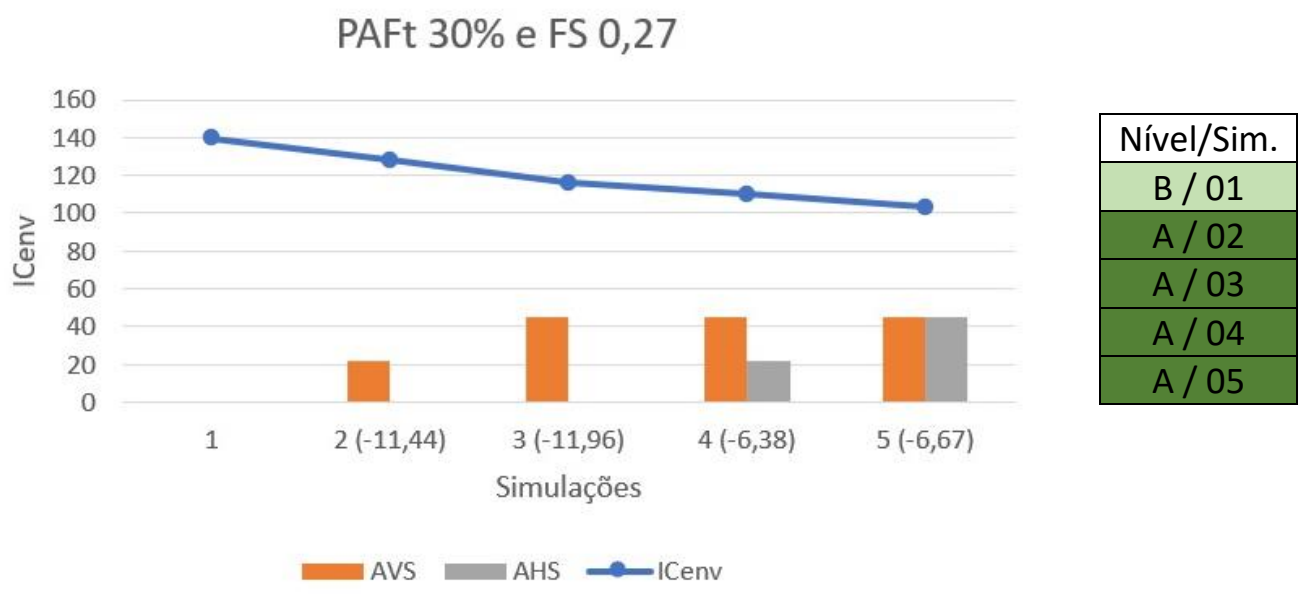

Fonte: a autora (2020)

Os gráficos acima apresentam a redução do ICenv em relação ao aumento do AHS e AVS. Observa-se que independente do FS a redução (não cumulativa) do ICenv entre uma simulação e outra permanece constante

A tabela 27 indica que da mesma forma que os anteriores, com o PAFT de $30 \%$, independente do FS, a contribuição da redução do ICenv com a aplicação do AVS e AHS é sempre constante, possuindo o AVS uma contribuição maior na redução do que o AHS.

Tabela 27 - Redução do ICenv (Não Cumulativa) com aumento de AVS e AHS

\begin{tabular}{ccccccc}
\hline Simulação & PAFT & \multicolumn{2}{c}{ AVS $^{\circ}$ AHS $^{\circ}$} & FS & $\begin{array}{c}\text { Redução do } \\
\text { ICenv }\end{array}$ \\
\hline 01 & $40 \%$ e $30 \%$ & 0 & $/$ & 0 & $.87 / .60 / .43 / .27$ & \\
\hline 02 & $40 \%$ e $30 \%$ & 22 & $/$ & 0 & $.87 / .60 / .43 / .27$ & $-11,44$ \\
\hline 03 & $40 \%$ e $30 \%$ & 45 & $/$ & 0 & $.87 / .60 / .43 / .27$ & $-11,96$ \\
\hline 04 & $40 \%$ e $30 \%$ & 45 & $/$ & 22 & $.87 / .60 / .43 / .27$ & $-6,38$ \\
\hline 05 & $40 \%$ e $30 \%$ & 45 & $/$ & 45 & $.87 / .60 / .43 / .27$ & $-6,67$ \\
\hline
\end{tabular}

Fonte: a autora (2020)

O Nível A do ICenv com o PAFt a 30\% é alcançado a partir dos cenários da tabela 28: 
Tabela 28 - Percentual de Abertura a 30\%, cenários para o Nível A do ICenv

\begin{tabular}{cccccc}
\hline PAFT \% & Nível & ICenv & FS & AVS $^{\circ}$ & AHS $^{\circ}$ \\
\hline \multirow{6}{*}{30} & A & 128,26 & 0,27 & 22 & 0 \\
\cline { 2 - 6 } & A & 126,65 & 0,27 & 0 & 45 \\
\cline { 2 - 6 } 30 & A & 116,30 & 0,27 & 45 & 0 \\
\cline { 2 - 6 } & A & 121,88 & 0,27 & 22 & 22 \\
\cline { 2 - 6 } & A & 109,92 & 0,27 & 45 & 22 \\
\cline { 2 - 6 } & A & 103,25 & 0,27 & 45 & 45 \\
& A & 122,28 & 0,43 & 45 & 45 \\
\hline
\end{tabular}

Fonte: a autora (2020)

\section{PAFT 20\%}

A tabela 29 indica que, com o PAFt de $20 \%$, da mesma forma que as outras porcentagens de aberturas já analisadas, não é possível atingir o Nível A reduzindo somente o Fator Solar (FS) do vidro. Índices de consumos menores são alcançados com relação ao PAFt de 50\%, de 40\% e o de 30\%. Com a redução do ICenv, o Nível B de eficiência energética é alcançado por todos os tipos de vidros da pesquisa (FS diferenciados).

Tabela 29 - Simulação do PAFt a 20\%

Fonte: a autora

\begin{tabular}{|c|c|c|c|c|c|c|c|}
\hline Variáveis & $\begin{array}{c}\text { Edif. } \\
01 \\
\text { ICenv }\end{array}$ & $\begin{array}{l}\text { Edif. } \\
01 \mathrm{~A} \\
\text { IC min }\end{array}$ & $\begin{array}{l}\text { Edif. } \\
01 \mathrm{~B} \\
\text { IC } \\
\max \end{array}$ & $\begin{array}{l}\text { Sim } \\
01\end{array}$ & $\begin{array}{l}\text { Sim } \\
02\end{array}$ & $\begin{array}{c}\text { Sim } \\
03\end{array}$ & $\begin{array}{l}\text { Sim } \\
04\end{array}$ \\
\hline FF & 0,21 & 0,21 & 0,21 & 0,21 & 0,21 & 0,21 & 0,21 \\
\hline FA & 0,09 & 0,09 & 0,09 & 0,09 & 0,09 & 0,09 & 0,09 \\
\hline PAFT & 0,1374 & 0,05 & 0,6 & 0,2 & 0,2 & 0,2 & 0,2 \\
\hline AVS $^{\circ}$ & 4,88 & 0 & 0 & 0 & 0 & 0 & 0 \\
\hline $\mathrm{AHS}^{\circ}$ & 11,59 & 0 & 0 & 0 & 0 & 0 & 0 \\
\hline FS & 0,28 & 0,87 & 0,61 & 0,87 & 0,60 & 0,43 & 0,27 \\
\hline ICmax & & & 284,88 & & & & \\
\hline ICmin & & 76,40 & & & & & \\
\hline ICenv & 117,13 & & & 157,2 & 144,8 & 137,0 & 129,6 \\
\hline $\begin{array}{l}\text { Nível de } \\
\text { Eficiência }\end{array}$ & Nível A & Nível A & Nível D & $\begin{array}{c}\text { Nível } \\
\text { B }\end{array}$ & $\begin{array}{c}\text { Nível } \\
\text { B }\end{array}$ & $\begin{array}{l}\text { Nível } \\
\text { B }\end{array}$ & $\begin{array}{c}\text { Nível } \\
\text { B }\end{array}$ \\
\hline
\end{tabular}

(2020)

A figura 56, apresenta a evolução na redução do ICenv devido a aplicação de vidros com FS menores. 
Figura 56 - Relação ICenv e FS com PAFT 20\%

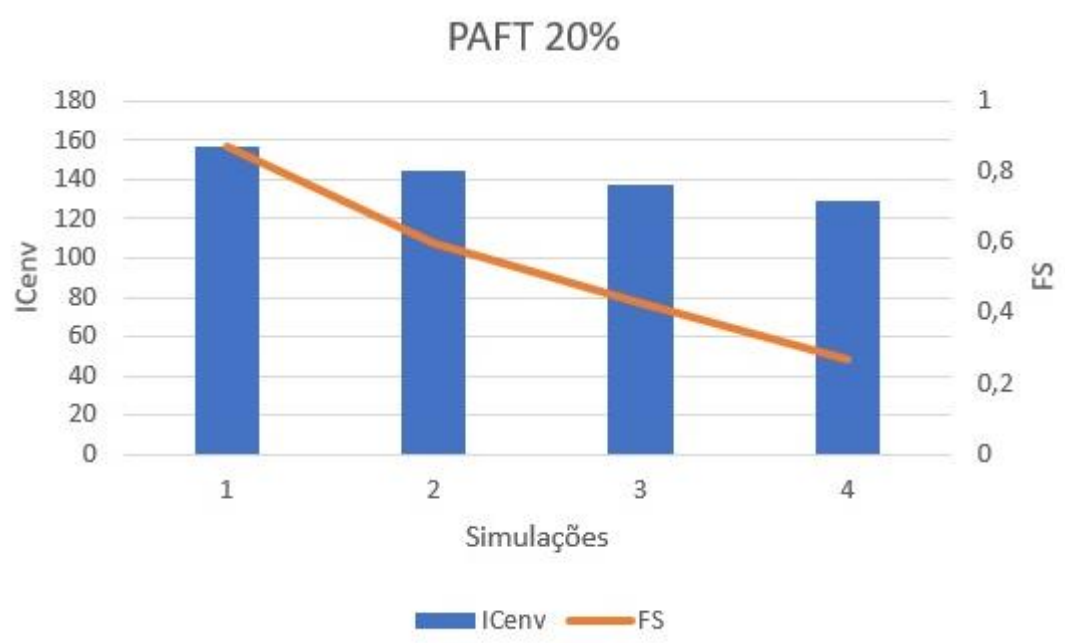

\begin{tabular}{|c|}
\hline Nível/Sim. \\
\hline B / 01 \\
\hline B / 02 \\
\hline B / 03 \\
\hline B / 04 \\
\hline
\end{tabular}

Fonte: a autora (2020)

Com o PAFt de $20 \%$, também é preciso incorporar elementos de sombreamentos ou auto sombreamento para alcançar o Nível A.

Nas figuras 57, 58, 59 e 60 são apresentadas as reduções do ICenv em função da inclusão inicialmente do AVS $\left(22^{\circ} \mathrm{e} 45^{\circ}\right)$, e em seguida do AHS $\left(22^{\circ}\right.$ e $\left.45^{\circ}\right)$. Cada gráfico possui um FS distinto.

Figura 57 - PAFt 20\% e FS 0,87

PAFt $20 \%$ e FS 0,87

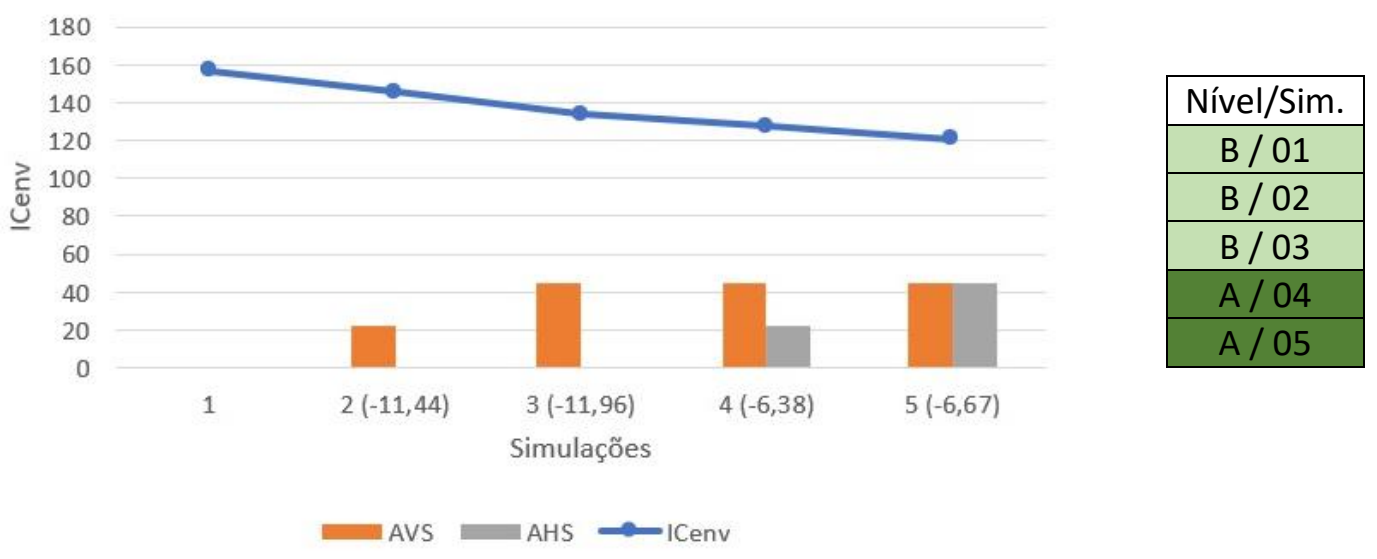

Fonte: a autora (2020) 
Figura 58 - PAFt 20\% e FS 0,60

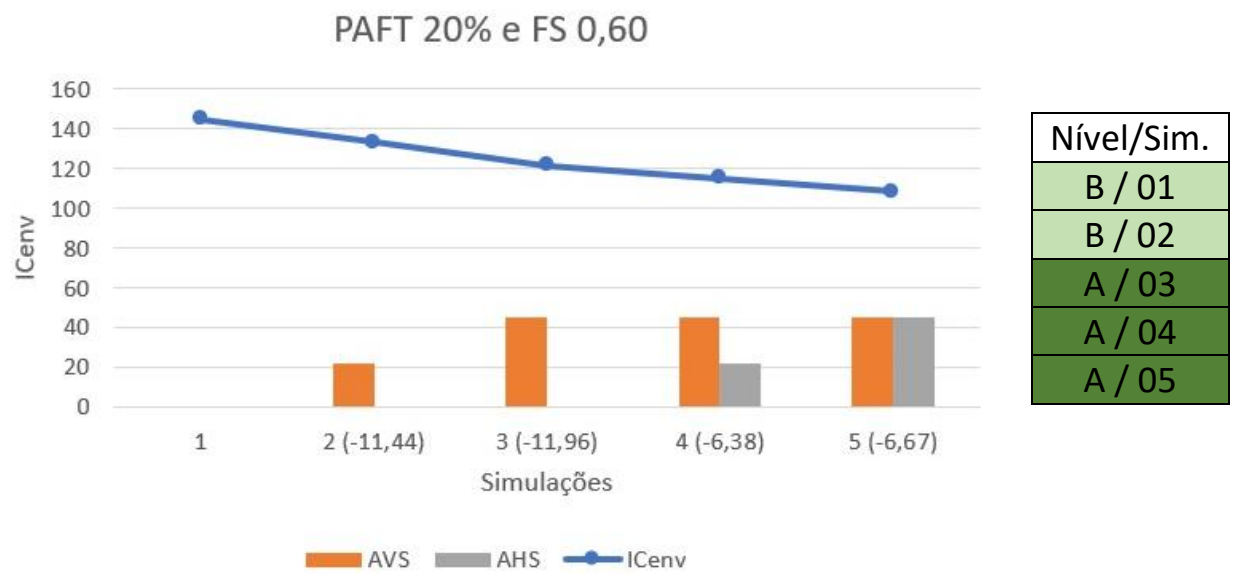

Fonte: a autora (2020)

Figura 59 - PAFt 20\% e FS 0,43

PAFT $20 \%$ e FS 0,43

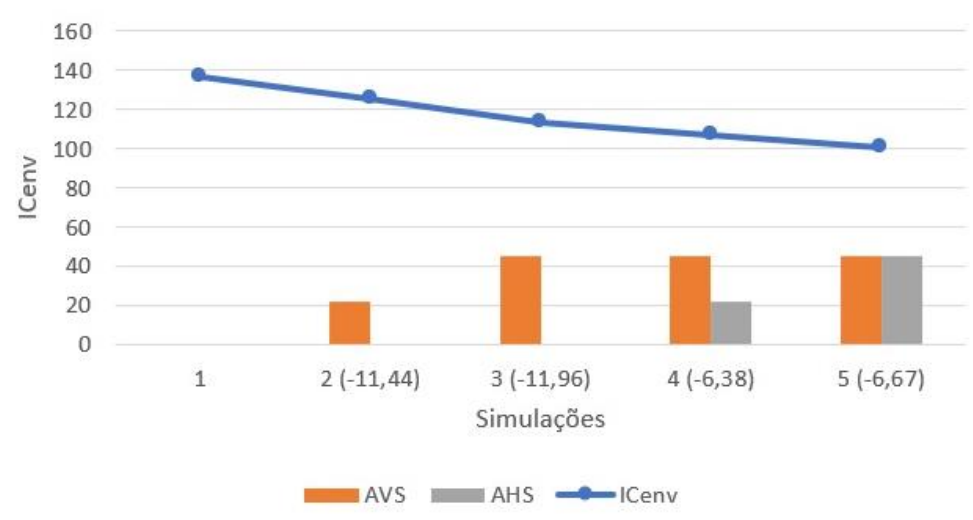

\begin{tabular}{|c|}
\hline Nível/Sim. \\
\hline$B / 01$ \\
\hline$A / 02$ \\
\hline$A / 03$ \\
\hline$A / 04$ \\
\hline$A / 05$ \\
\hline
\end{tabular}

Fonte: a autora (2020)

Figura 60 - PAFt 20\% e FS 0,27

PAFT $20 \%$ e FS 0,27

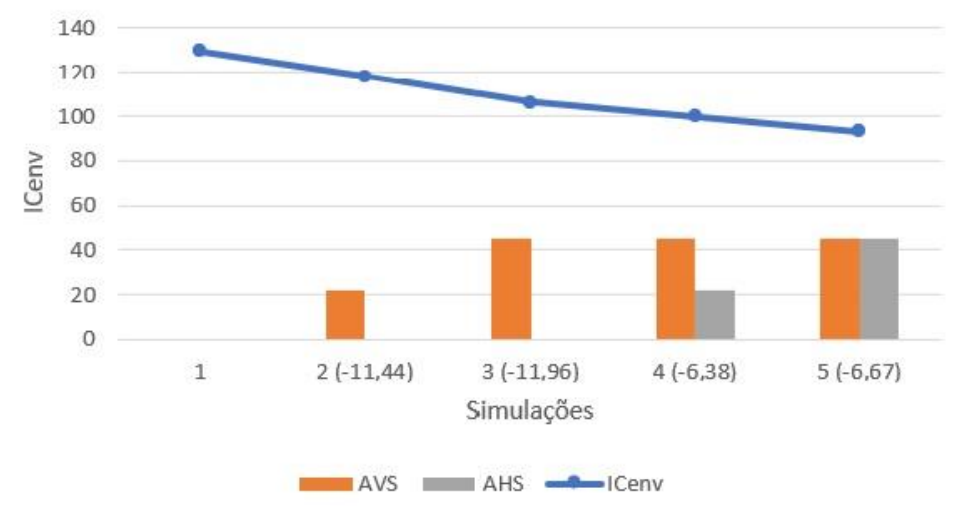

Nível/Sim.

A / 01

$\mathrm{A} / 02$

$\mathrm{A} / 03$

A / 04

A / 05

Fonte: a autora (2020) 
Os gráficos acima apresentam a redução do ICenv em relação ao aumento do AHS e AVS. Durante a simulação com o PAFt de $20 \%$ observa-se que, como aconteceram com os percentuais de aberturas anteriores, independente do FS o número de pontos da redução (não cumulativa) do ICenv entre uma simulação e outra permanecem constantes.

A tabela 30 aponta que independente do PAFT e do FS, a redução do ICenv com a aplicação do AVS e AHS é sempre constante, possuindo o AVS uma contribuição maior na redução do que o AHS. A tabela apresenta que todos os percentuais de aberturas independente do fator solar mantiveram os mesmos percentuais de redução.

Tabela 30 - Redução do ICenv (Não Cumulativa) com aumento de AVS e AHS

\begin{tabular}{ccccccc}
\hline Simulação & PAFTs & AVS $^{\circ} /$ AHS $^{\circ}$ & FS & $\begin{array}{c}\text { Redução do } \\
\text { ICenv }\end{array}$ \\
\hline 01 & $40 \%, 30 \%$ e $20 \%$ & 0 & $/$ & 0 & $.87 / .60 / .43 / .27$ & \\
\hline 02 & $40 \%, 30 \%$ e $20 \%$ & 22 & $/$ & 0 & $.87 / .60 / .43 / .27$ & $-11,44$ \\
\hline 03 & $40 \%, 30 \%$ e $20 \%$ & 45 & $/$ & 0 & $.87 / .60 / .43 / .27$ & $-11,96$ \\
\hline 04 & $40 \%, 30 \%$ e $20 \%$ & 45 & $/$ & 22 & $.87 / .60 / .43 / .27$ & $-6,38$ \\
\hline 05 & $40 \%, 30 \%$ e $20 \%$ & 45 & $/$ & 45 & $.87 / .60 / .43 / .27$ & $-6,67$ \\
\hline
\end{tabular}

Fonte: a autora (2020)

O Nível A do ICenv com o PAFt a 20\% é alcançado a partir dos cenários da tabela 31.

Tabela 31 - - Percentual de Abertura a 20\%, cenários para o Nível A do ICenv

\begin{tabular}{|c|c|c|c|c|c|}
\hline PAFT \% & Nível & ICenv & FS & $\mathrm{AVS}^{\circ}$ & $\mathrm{AHS}^{\circ}$ \\
\hline \multirow{16}{*}{20} & A & 127,43 & 0,87 & 45 & 22 \\
\hline & A & 120,76 & 0,87 & 45 & 45 \\
\hline & A & 121,37 & 0,60 & 45 & 0 \\
\hline & A & 114,99 & 0,60 & 45 & 22 \\
\hline & A & 108,32 & 0,60 & 45 & 45 \\
\hline & A & 125,51 & 0,43 & 22 & 0 \\
\hline & A & 113,55 & 0,43 & 45 & 0 \\
\hline & A & 123,90 & 0,43 & 0 & 45 \\
\hline & A & 119,13 & 0,43 & 22 & 22 \\
\hline & A & 100,50 & 0,43 & 45 & 45 \\
\hline & A & 118,14 & 0,27 & 22 & 0 \\
\hline & $A$ & 106,18 & 0,27 & 45 & 0 \\
\hline & A & 123,20 & 0,27 & 0 & 22 \\
\hline & A & 116,53 & 0,27 & 0 & 45 \\
\hline & A & 111,76 & 0,27 & 22 & 22 \\
\hline & A & 93,13 & 0,27 & 45 & 45 \\
\hline
\end{tabular}


Fonte: a autora (2020)

\section{PAFT 10\%}

A tabela 32 indica que com o PAFt de $10 \%$ o Nível A é obtido a partir de todos os tipos de vidros utilizados nas simulações, sem acréscimo dos ângulos de sombreamentos.

Tabela 32 - Simulação do PAFt a 10\%

\begin{tabular}{|c|c|c|c|c|c|c|c|}
\hline Variáveis & $\begin{array}{c}\text { Edif. } \\
01 \\
\text { ICenv }\end{array}$ & $\begin{array}{r}\text { Edif. } \\
01 \mathrm{~A} \\
\text { IC } \min \end{array}$ & $\begin{array}{c}\text { Edif. } \\
01 \text { B } \\
\text { IC max }\end{array}$ & $\begin{array}{c}\text { Sim } \\
01\end{array}$ & $\begin{array}{l}\text { Sim } \\
02\end{array}$ & $\begin{array}{l}\text { Sim } \\
03\end{array}$ & $\begin{array}{l}\text { Sim } \\
04\end{array}$ \\
\hline $\mathrm{FF}$ & 0,21 & 0,21 & 0,21 & 0,21 & 0,21 & 0,21 & 0,21 \\
\hline FA & 0,09 & 0,09 & 0,09 & 0,09 & 0,09 & 0,09 & 0,09 \\
\hline PAFT & 0,1374 & 0,05 & 0,6 & 0,1 & 0,1 & 0,1 & 0,1 \\
\hline $\mathrm{AVS}^{\circ}$ & 4,88 & 0 & 0 & 0 & 0 & 0 & 0 \\
\hline $\mathrm{AHS}^{\circ}$ & 11,59 & 0 & 0 & 0 & 0 & 0 & 0 \\
\hline FS & 0,28 & 0,87 & 0,61 & 0,87 & 0,60 & 0,43 & 0,27 \\
\hline ICmax & & & 284,88 & & & & \\
\hline $\mathrm{ICmin}$ & & 76,40 & & & & & \\
\hline ICenv & 117,13 & & & 103,3 & 110,6 & 115,2 & 119,5 \\
\hline $\begin{array}{l}\text { Nível de } \\
\text { Eficiência }\end{array}$ & Nível A & Nível A & Nível D & $\begin{array}{c}\text { Nível } \\
\text { A }\end{array}$ & $\begin{array}{c}\text { Nível } \\
\text { A }\end{array}$ & $\begin{array}{c}\text { Nível } \\
\text { A }\end{array}$ & $\begin{array}{c}\text { Nível } \\
\text { A }\end{array}$ \\
\hline
\end{tabular}

Fonte: a autora (2020)

$\mathrm{Na}$ tabela acima, percebe-se que os ICenv embora tenham permanecido no Nível A, aumentam a medida que o fator solar diminui. O que contradiz aos dados obtidos através das simulações dos demais percentuais totais de aberturas das fachadas observados neste estudo. A figura 61 apresenta esse aumento.

Figura 61 - Relação ICenv e FS com PAFT 10\%

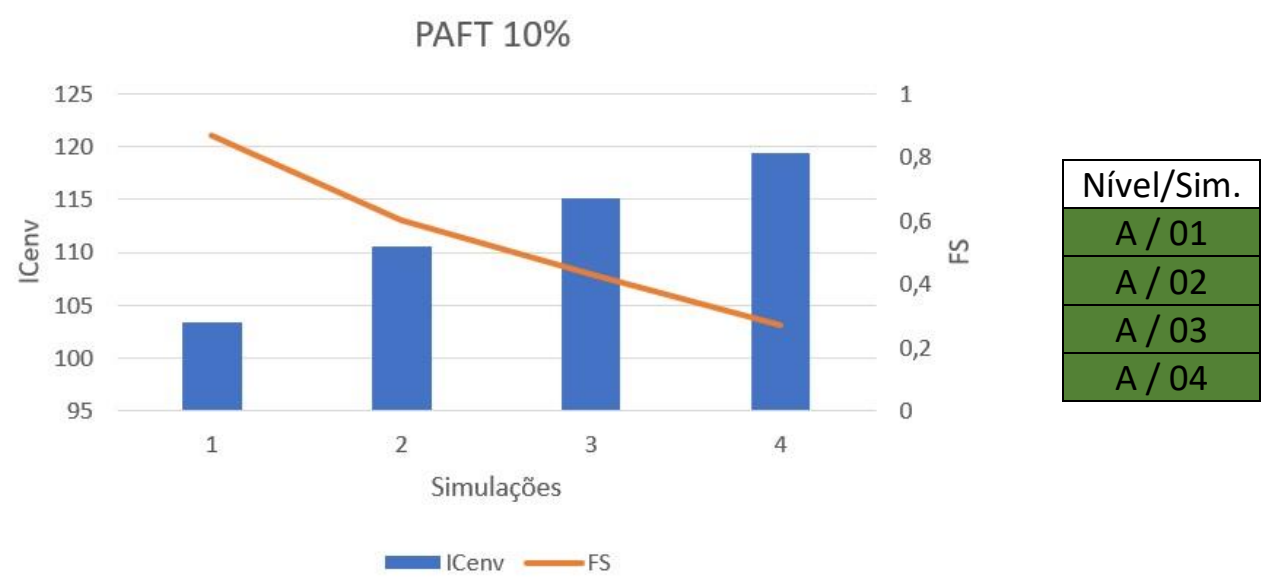

Fonte: a autora (2020) 
Com a utilização do percentual de abertura total da fachada de 10\%, o Nível A do ICenv é alcançado independente do fator solar dos vidros e dos ângulos de sombreamento.

Tabela 33 - Percentual de abertura a 10\%, cenários do Nível A do ICenv

\begin{tabular}{cccccc}
\hline PAFT \% & Nível & ICenv & FS & AVS $^{\circ}$ & AHS $^{\circ}$ \\
\hline 10 & A & $x$ & $0,27 / 0,43 / 0,60 / 0,87$ & $0^{\circ} / 22^{\circ} / 45^{\circ}$ & $0^{\circ} / 22^{\circ} / 45^{\circ}$ \\
\hline
\end{tabular}

Fonte: a autora (2020)

\subsection{Análise comparativa da influência das variáveis do Índice de Consumo da Envoltória entre as Zonas Bioclimáticas 4 e 5 e a 2 e 3.}

O mesmo edifício em climas diferenciados, segundo a NBR 15220 (ABNT,2005c), deve possuir elementos construtivos e diretrizes projetuais que o adequem as novas condições de temperatura, umidade, radiação solar e ventilação.

Levantando-se o índice de consumo das envoltórias dos mesmos edifícios em duas zonas bioclimáticas, evidencia-se a atuação dos parâmetros das aberturas envidraçadas no nível de eficiência energética, pelo RTQ-C, em climas distintos.

No sentido de aprofundar a compreensão da interferência dessas variáveis na composição de diretrizes projetuais conforme o clima da área de implantação, foi traçado um comparativo entre a ZB3 e a ZB4. Os edifícios levantados neste estudo foram observados também através da equação do ICenv para a ZB3.

A tabela 34, apresenta os dados das envoltórias dos Edifícios 01, 02 e 03 selecionados para esse estudo, e avaliados quanto a eficiência nas zonas bioclimáticas 4 e 5, 2 e 3 .

Tabela 34 - Nível de Eficiência na ZB3 e ZB4 dos edifícios analisados

\begin{tabular}{lllllcc}
\hline \multirow{3}{*}{ Edifícios } & \multicolumn{5}{c}{ Zonas Bioclimáticas } \\
\cline { 2 - 7 } & \multicolumn{1}{c}{ ZB 4 e 5 } & Nível & Pontos & IC & ZB 2 e 3 & \\
\cline { 2 - 7 } & Envoltória & B & 129,10 & Envoltória & B & Pontos \\
\hline \multirow{3}{*}{ Edifício 01 } & Lim.Max.A & A & 115,98 & Lim.Max.A & A & 75,37 \\
\cline { 2 - 7 } & Máximo & D & 272,34 & Máximo D & D & 95,39 \\
\hline \multirow{3}{*}{ Edifício 02 } & Envoltória & B & 163,87 & Envoltória & B & 55,98 \\
\cline { 2 - 7 } & Lim.Max.A & A & 130,43 & Lim.Max.A & A & 52,70 \\
\cline { 2 - 7 } & Máximo & D & 286,78 & Máximo D & D & 72,71 \\
\hline & Envoltória & A & 116,39 & Envoltória & A & 88,58 \\
\hline
\end{tabular}




\begin{tabular}{llllllc}
\hline \multirow{2}{*}{ Edifício 03 } & Lim.Max.A & A & 127,55 & Lim.Máx. A & A & 93,06 \\
\cline { 2 - 7 } & Máximo & D & 283,91 & Máximo D & D & 113,08 \\
\hline
\end{tabular}

Fonte: a autora (2019)

Segundo a tabela, as envoltórias alcançaram os mesmos níveis de eficiência em ambas as zonas bioclimáticas, porém, os pontos alcançados nos índices de consumo são bem menores na ZB3 do que na ZB4. Pode-se dizer que as envoltórias dos edifícios 1 e 2 mesmo alcançando o Nível B em ambas as zonas bioclimáticas, possuem as diretrizes projetuais das aberturas envidraçadas muito mais corretas para a ZB3 do que para a ZB4, pois alcançam mais facilmente o Nível A na ZB3 do que na ZB4 (distanciamento das envoltórias Nível B do Lim. Máx. A).

As equações abaixo apresentam os pesos das variáveis nas respectivas zonas bioclimáticas, com a área de projeção da envoltória (Ape) maior que $500 \mathrm{~m}^{2}$, que são os casos analisados nesse estudo:

Zona Bioclimática 4

- $\quad$ Ape $>500 \mathrm{~m}^{2}$

Limite: Fator de forma mínimo (Aenv/Vtot) = livre

ICenv $=$ 511, 12. FA + 0.92. FF - 95, 71 PAFT - 99, 79. FS - 0, 52. AVS - 0, 29 AHS

- 380, 83.FA. FF + 4, 27/FF + 729, 20. PAFT.FS + 77, 15

Zona Bioclimática 3

- $\quad$ Ape $>500 \mathrm{~m}^{2}$

Limite: Fator de forma mínimo (Aenv/Vtot) = livre

ICenv $=-14,14 F A-113,94 . F F+50,82 . P A F T+4,86$ FS - 0, 32. AVS - 0,26 AHS

- 35,25 / FF - 0, 54.PAFT. AHS + 277,98

A análise das variáveis do ICenv da ZB 3 foi fundamentada mediante estudo realizado por Eloy e Akutso (2016), e a análise das variáveis da ZB 4 foram amparadas nas simulações efetuadas por esse estudo. Em ambas as análise se utilizou o estudo de Carlos, Maciel (2011).

Tabela 35 - Sensibilidade das variáveis do ICenv na ZB 2 e 3 e na ZB 4 e 5

\begin{tabular}{|c|c|c|c|c|c|c|}
\hline \multirow{2}{*}{ Zonas Bioclimáticas } & \multirow{2}{*}{ Área de Projeção } & \multicolumn{5}{|c|}{ Parâmetros } \\
\hline & & PAFt $\%$ & FS \% & AVS $\%$ & AHS \% & Total \\
\hline ZB 2 e 3 & Ape $>500 m^{2}$ & 58,06 & 8,29 & 24,72 & 8,94 & $100 \%$ \\
\hline
\end{tabular}




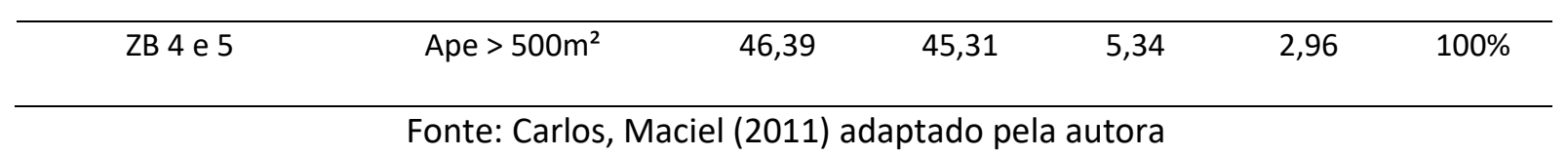

As variáveis do Fator de forma (FF) e Fator altura (FA), correspondem a volumetria do edifício, alterá-las significa modificar o edifício, desta forma, estas nos estudos apresentados permaneceram fixas durante as simulações.

Análise das Variáveis:

\section{Percentual Total de Abertura das Fachadas - PAFT}

Zona Bioclimática 3:

a) Quanto maior o PAFT, maior ICenv, em uma mesma volumetria.

Zona Bioclimática 4:

a) quanto maior o PAFT, maior o ICenv, em uma mesma volumetria;

b) nas volumetrias analisadas, o Nível A do IC é alcançado somente com a contribuição do PAFT quando este apresenta o índice de $10 \%$.

Influência da variável PAFT entre as Zonas Bioclimáticas:

a) É a variável de maior impacto nas duas zonas bioclimáticas.

A figura 62 apresenta a relação do PAFt com os níveis de eficiência dos edifícios analisados nas 504 simulações executadas.

Figura 62 - Resultado dos níveis de eficiência com relação a percentagem de abertura

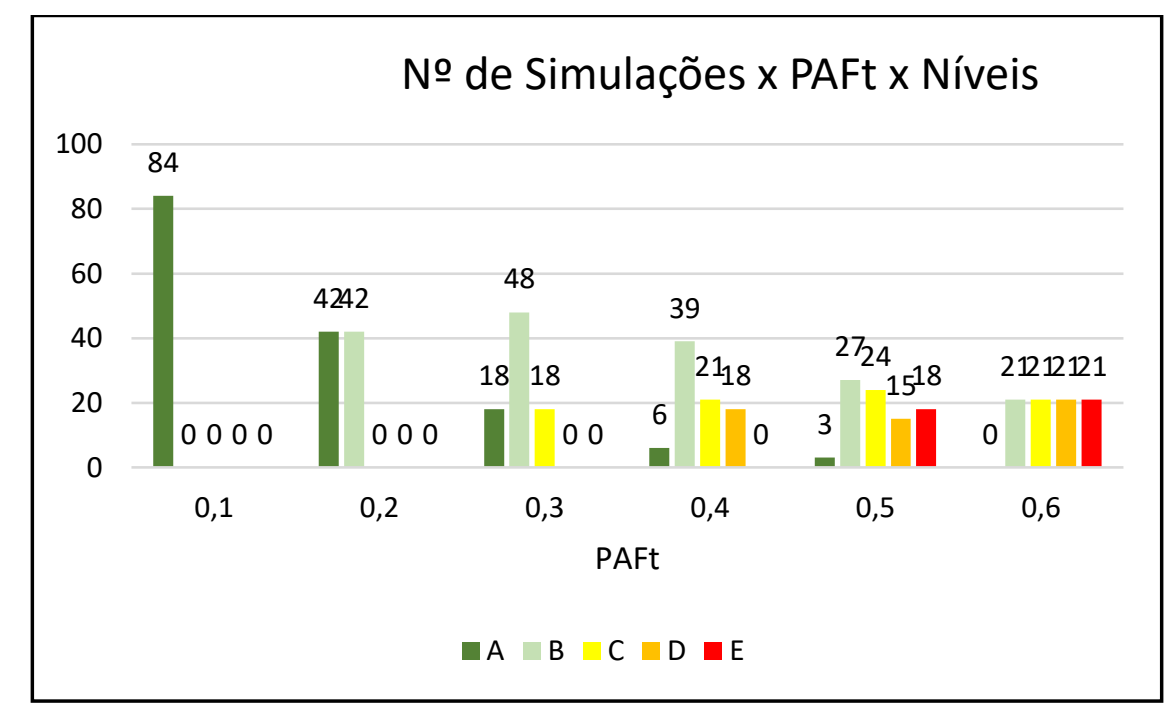

Fonte: a autora 


\section{Fator Solar - FS}

Zona Bioclimática 3:

a) O FS influencia no aumento do índice de consumo em uma menor proporção pois possui um multiplicador pequeno $=+4,86$;

b) O seu uso isolado não é suficiente para obter o Nível $\mathbf{A}$ em edificações que apresentam PAFT maior que $25 \%$.

Zona Bioclimática 4:

a) O FS se equipara ao PAFT no impacto de redução sobre o índice de consumo;

b) Como o FS está associado ao PAFT na equação, quanto maior o PAFT mais o FS contribui na redução do índice de consumo impulsionando a mudança de nível de eficiência nas volumetrias analisadas. Contudo, o seu uso isolado não é suficiente para a obtenção do Nível A em edificações que apresentam o PAFT maior que $20 \%$.

c) O FS no PAFT igual a 10\%, diminui o índice de consumo ao invés de aumentá-lo, demonstrando que em PAFT de menor valor o FS não contribui no crescimento do consumo da envoltória, no ICenv do método prescritivo.

Comparação da influência da variável FS entre as Zonas Bioclimáticas:

a) O FS impacta muito mais no aumento do ICenv da ZB4 do que na ZB3;

b) Tanto na ZB 3 quanto na ZB 4, nas volumetrias analisadas, o seu uso isolado não foi suficiente para se alcançar o Nível A no ICenv.

Ângulo Vertical de Sombreamento - AVS - (proteções horizontais)

Zona Bioclimática 3:

a) Reduz o ICenv qualquer que seja o valor aplicado;

b) O impacto das proteções horizontais (AVS) no índice de consumo é limitado visto que o multiplicador é baixo $=-0,32$, podendo alcançar no máximo 14,4 pontos $\left(0,32\right.$ a $\left.45^{\circ}\right)$;

c) Mesmo o AVS contribuindo para a redução do ICenv, sua aplicação de forma isolada não é suficiente para atingir o Nível $\mathbf{A}$.

Zona Bioclimática 4:

a) Reduz o ICenv qualquer que seja o valor aplicado; 
b) O impacto do AVS no IC é considerado visto que, possui um multiplicador $=-0,52$, podendo reduzir em 23,4 pontos $\left(0,52\right.$ a $\left.45^{\circ}\right)$ o ICenv;

c) Nos casos analisados a utilização do AVS de forma isolada não foi suficiente para atingir o Nível A no ICenv.

Comparação da influência da variável AVS entre as Zonas Bioclimáticas:

a) O AVS reduz mais o ICenv na ZB4 do que na ZB3, visto que o multiplicador na ZB4 é maior, deste modo, as proteções horizontais influenciam mais na eficiência da envoltória da ZB4 do que na ZB3;

b) Em ambas as zonas Bioclimáticas, não foi possível atingir o Nível A com a aplicação isoladamente do AVS.

\section{Ângulo Horizontal de Sombreamento - AHS - (proteções verticais)}

Zona Bioclimáticas 3:

a) O AHS reduz o valor do ICenv, mas somente quando o PAFT for maior do que $48,10 \%$, abaixo desse valor da variável se aumenta o índice de consumo, o que contradiz as expectativas a respeito dos efeitos dos sombreamentos em aberturas envidraçadas;

b) Possui influência menor que o AVS.

Zona Bioclimática 4:

a) Reduz o ICenv, seja qual for o valor aplicado;

b) Possui um impacto menor na redução do ICenv do que o AVS, reduzindo no máximo 13,05 pontos com a AHS de $45^{\circ}(0,29$ a 45$)$.

Comparação da influência da variável AHS entre as Zonas Bioclimáticas:

c) O Ângulo de Sombreamento Horizontal - AHS (representa as proteções verticais) em ambas as zonas bioclimáticas possuem menos efeito do que o Ângulo de Sombreamento Vertical - AVS (representa as proteções horizontais).

\subsection{Comparação entre o Método prescritivo do RTQ-C e o Método simplificado do INI-C.}

A nova proposta de aperfeiçoamento da metodologia de avaliação da eficiência energética dos edifícios comerciais ainda está em trâmite para a aprovação, não havendo uma data definitiva para a sua publicação. 
Torna-se importante para esta pesquisa uma primeira aproximação com a nova proposta da metodologia através do levantamento da eficiência de um dos edifícios estudados como forma de compreender as alterações propostas pelo regulamento para o sistema da envoltória.

O cálculo da eficiência da envoltória do edifício 01 efetuado pela proposta do novo regulamento, o INI-C, foi desenvolvido por meio da "Escala para a Determinação da Classe de Eficiência Energética Parcial da Edificação" (Anexo I, INMETRO n²48, p 25, 2018), mediante a determinação da classe da eficiência da envoltória.

Para a etiquetagem foram efetuados os seguintes procedimentos:

1) Analisar através da Tabela 1 da nova proposta (BRASIL, 2018), as limitações de parâmetros construtivos e projetuais que o edifício analisado deve cumprir para poder ser avaliado pelo método simplificado. A tabela 36 , corresponde a referida tabela.

Tabela 36 - Limites dos parâmetros da edificação atendidos pelo método simplificado

\begin{tabular}{|c|c|c|}
\hline \multirow{2}{*}{ Parâmetros } & \multicolumn{2}{|c|}{ Limites } \\
\hline & Valor Mínimo & Valor Máximo \\
\hline Absortância solar da cobertura ( $\alpha$ ) & 0,2 & 0,8 \\
\hline Absortância solar da parede $(\alpha)$ & 0,2 & 0,8 \\
\hline Ângulo de obstrução vizinha (AOV) & $0^{\circ}$ & $80^{\circ}$ \\
\hline $\begin{array}{l}\text { Ângulo horizontal de sombreamento ( } \\
\text { AHS) }\end{array}$ & $0^{\circ}$ & $80^{\circ}$ \\
\hline Ângulo vertical de sombreamento ( AVS) & $0^{\circ}$ & $90^{\circ}$ \\
\hline $\begin{array}{l}\text { Capacidade Térmica da Cobertura (CT } \\
\text { cob) }\end{array}$ & $0,22 \mathrm{~kJ} / \mathrm{m}^{2} \mathrm{~K}$ & $450 \mathrm{~kJ} / \mathrm{m}^{2} \mathrm{~K}$ \\
\hline Capacidade Térmica da Parede (CT par) & $0,22 \mathrm{~kJ} / \mathrm{m}^{2} \mathrm{~K}$ & $450 \mathrm{~kJ} / \mathrm{m}^{2} \mathrm{~K}$ \\
\hline Contato com o solo & $\begin{array}{l}\text { Sem contato ( ex: sobre } \\
\text { pilotis ou em balanço) }\end{array}$ & Em contato \\
\hline $\begin{array}{l}\text { Densidade de Potência de equipamento } \\
\text { (DPE) }\end{array}$ & $4 \mathrm{~W} / \mathrm{m}^{2}$ & $40 \mathrm{~W} / \mathrm{m}^{2}$ \\
\hline $\begin{array}{l}\text { Densidade de Potência de instalação } \\
\text { (DPI) }\end{array}$ & $4 \mathrm{~W} / \mathrm{m}^{2}$ & $40 \mathrm{~W} / \mathrm{m}^{2}$ \\
\hline Fator Solar do Vidro (FS) & 0,21 & 0,87 \\
\hline Pé-direito (PD) & $2,6 \mathrm{~m}$ & $6,6 \mathrm{~m}$ \\
\hline Percentual de abertura na fachada (PAF) & $0 \%$ & $80 \%$ \\
\hline Piso com isolamento & $\begin{array}{l}\text { Não, se isolamento < } \\
5 \mathrm{~mm}\end{array}$ & $\begin{array}{c}\text { Sim, se isolamento > } \\
5 \mathrm{~mm}\end{array}$ \\
\hline $\begin{array}{l}\text { Transmitância térmica da cobertura ( } \\
\text { Ucob) }\end{array}$ & $0,51 \mathrm{~W} / \mathrm{m}^{2} \mathrm{~K}$ & $5,07 \mathrm{~W} / \mathrm{m}^{2} \mathrm{~K}$ \\
\hline $\begin{array}{l}\text { Transmitância térmica da parede externa( } \\
\text { Upar) }\end{array}$ & $0,50 \mathrm{~W} / \mathrm{m}^{2} \mathrm{~K}$ & $4,40 \mathrm{~W} / \mathrm{m}^{2} \mathrm{~K}$ \\
\hline Transmitância térmica do vidro ( U vid) & $1,9 \mathrm{~W} / \mathrm{m}^{2}$ & $5,7 \mathrm{~W} / \mathrm{m}^{2} \mathrm{~K}$ \\
\hline
\end{tabular}

Fonte: Brasil, 2018.

2) Verificação através da classificação do clima proposta por Roriz (2014), em qual grupo climático, entre os 24 apresentados a cidade de Ribeirão Preto está localizada. A figura 
63 representa uma parte da tabela com a descrição das cidades e os devidos grupos climáticos a quais estas pertencem. Ribeirão Preto pertence ao $15^{\circ}$ grupo.

Figura 1 - Parte da Tabela dos Grupo climáticos: em destaque a cidade de Ribeirão Preto.

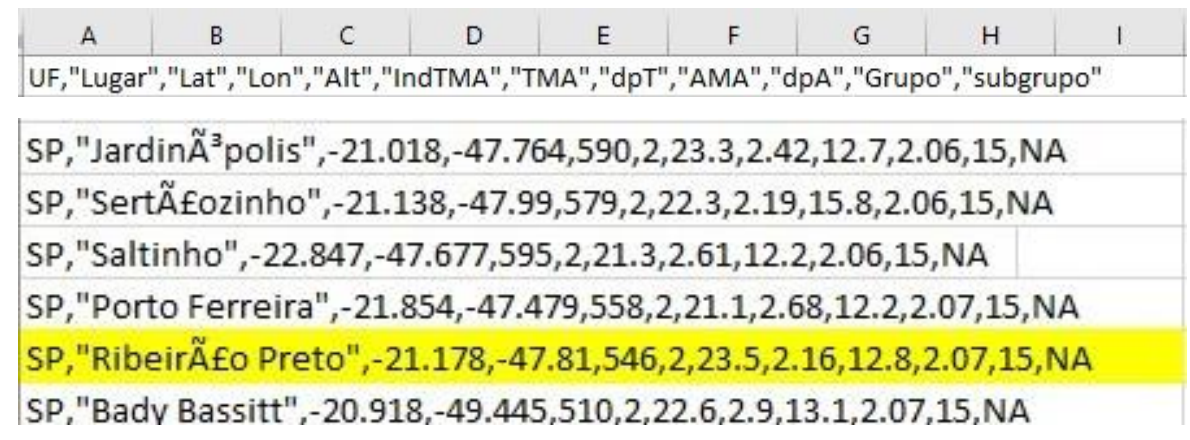

Fonte: RORIZ, 2014

3) Com o fator de forma do edifício 01, FF=0,18, e o grupo climático da cidade analisada, verifica-se através da tabela 14 do regulamento, o coeficiente de redução de carga térmica anual da classe D para a classe A (CRCgTD-A). Na tabela 37 pode-se observar o coeficiente de redução para a tipologia dos edifícios de escritório.

Tabela 37 - Coeficiente de redução da carga anual da classe D para a classe A (CRCgT D-A) para edifícios de escritório

\begin{tabular}{|c|c|c|c|c|c|}
\hline \multirow{2}{*}{ Grupo Climátic0 } & \multicolumn{5}{|c|}{$\begin{array}{l}\text { Coeficiente de Redução da carga térmica total anual de classe D para classe A } \\
\text { (CRCgT D - A) }\end{array}$} \\
\hline & $\mathrm{FF} \leq 0,20$ & $\begin{array}{l}0,20<\mathrm{FF} \leq \\
0,30\end{array}$ & $\begin{array}{l}0,30<\mathrm{FF} \leq \\
0,40\end{array}$ & $\begin{array}{l}0,40<\mathrm{FF} \leq \\
0,50\end{array}$ & $F F>0,50$ \\
\hline GCL 1 - A & 0,28 & 0,31 & 0,32 & 0,33 & 0,33 \\
\hline GCL $1-B$ & 0,23 & 0,25 & 0,27 & 0,27 & 0,27 \\
\hline GCL 2 & \multirow{3}{*}{0,32} & \multirow{3}{*}{0,34} & \multirow{3}{*}{0,36} & \multirow{3}{*}{0,36} & \multirow{3}{*}{0,369} \\
\hline GCL 3 & & & & & \\
\hline GCL 4 & & & & & \\
\hline $\begin{array}{l}\text { GCL } 5 \\
\text { GCl } 6\end{array}$ & \multirow{2}{*}{0,22} & \multirow[t]{2}{*}{0,25} & \multirow[t]{2}{*}{0,26} & \multirow[t]{2}{*}{0,27} & \multirow[t]{2}{*}{0,27} \\
\hline $\begin{array}{l}\text { GCL } 6 \\
\text { GCL } 7\end{array}$ & & & & & \\
\hline GCL 8 & 0,23 & 0,26 & 0,27 & 0,28 & 0,28 \\
\hline GCL 9 & 0,22 & 0,25 & 0,26 & 0,27 & 0,27 \\
\hline GCL 10 & 0,23 & 0,26 & 0,27 & 0,28 & 0,28 \\
\hline GCL 11 & \multirow{2}{*}{0,19} & \multirow{2}{*}{0,21} & \multirow{2}{*}{0,23} & \multirow{2}{*}{0,23} & \multirow{2}{*}{0,23} \\
\hline GCL 12 & & & & & \\
\hline GCL 13 & \multirow{2}{*}{0,19} & \multirow{2}{*}{0,21} & \multirow{2}{*}{0,22} & \multirow{2}{*}{0,23} & \multirow{2}{*}{0,23} \\
\hline GCL 14 & & & & & \\
\hline GCL 15 & \multirow{2}{*}{0,18} & \multirow{2}{*}{0,20} & \multirow{2}{*}{0,21} & \multirow{2}{*}{0,22} & \multirow{2}{*}{0,22} \\
\hline GCL 16 & & & & & \\
\hline GCL 17 & 0,12 & 0,14 & 0,15 & 0,15 & 0,15 \\
\hline GCL 18 & 0,12 & 0,13 & 0,14 & 0,15 & 0,15 \\
\hline GCL 19 & \multirow{2}{*}{0,12} & \multirow{2}{*}{0,14} & 0,15 & 0,15 & 0,16 \\
\hline GCL 20 & & & 0,15 & & \\
\hline GCL 21 & 0,14 & 0,17 & 0,18 & 0,18 & 0,18 \\
\hline GCL 22 & & & & & \\
\hline $\begin{array}{l}\text { GCL } 23 \\
G C L 24\end{array}$ & 0,13 & 0,15 & 0,16 & 0,17 & 0,17 \\
\hline
\end{tabular}

Fonte: Brasil, (2018). 
4) A análise da carga térmica real e da carga térmica do edifício de referência é efetuada através da Interface Web online (capítulo 3.3).

Aos dados do edifício real já levantados, foram efetuados os seguintes levantamentos adicionais:

a) Distribuição das zonas térmicas em planta baixa (perimetrais e internas);

b) Os percentuais de aberturas por fachada;

c) Levantamento dos ângulos de sombreamento por fachada;

d) Características térmicas dos materiais opacos das paredes, transmitância, absortância e capacidade térmica;

e) Para as características térmicas dos materiais de cobertura foram utilizados os dados do edifício de referência;

f) Densidade de Potência de Equipamento - DPE = 9,7, adotando-se o mesmo valor da condição de referência (BRASIL,2018)

g) Densidade de potência de lluminação - DPI = 14,1, segundo a norma se a avaliação for utilizada somente para a envoltória, adota-se a condição de referência.

Os dados do edifício de referência foram retirados da tabela A.1 do regulamento (Brasil, p. 39 ,2018), para a tipologia de edificações de escritórios. Na tabela 38, verifica-se os dados retirados para análise. 
Tabela 38 - Valores de referência para edificações de escritório

\begin{tabular}{|c|c|c|}
\hline \multirow[b]{2}{*}{ USO TíPICO } & \multicolumn{2}{|c|}{ EDIFICAÇÕES DE ESCRITÓRIO } \\
\hline & CONDIÇÃO REAL & $\begin{array}{c}\text { CONDIÇÃO DE } \\
\text { REFERÊNCIA }\end{array}$ \\
\hline \multicolumn{3}{|l|}{ Geometria } \\
\hline Forma & \multicolumn{2}{|c|}{ Condição Real } \\
\hline Orientação Solar (*) & \multicolumn{2}{|c|}{ Condição Real } \\
\hline Pé direito (piso a teto) $(\mathrm{m})$ & \multicolumn{2}{|c|}{ Condição Real } \\
\hline \multicolumn{3}{|l|}{ Aberturas } \\
\hline PAF - Percentual de abertura das fachadas (\%) & Condição Real & 50 \\
\hline PAZ - Percentual de abertura zenital (\%) & Condição Real & 0 \\
\hline \multicolumn{3}{|l|}{ Componentes Construtivos } \\
\hline Parede & Condição Real & $\begin{array}{c}\text { Argamassa interna } \\
(2,5 \mathrm{~cm}), \text { bloco cedrâmico } \\
\text { furado }(9,0 \mathrm{~cm}), \\
\text { argamassa externa }(2,5)\end{array}$ \\
\hline Upar - Transmitância da parede externa $\left(\mathrm{W} / \mathrm{m}^{2} \mathrm{~K}\right)$ & Condição Real & 1,39 \\
\hline aPAR - Absortância da parede (admensional) & Condição Real & 0,5 \\
\hline CTpar - Capacidade térmica da parede $\left(\mathrm{kJ} / \mathrm{m}^{2} \mathrm{~K}\right)$ & Condição Real & 150 \\
\hline Cobertura & Condição Real & $\begin{array}{c}\text { Telha fibrocimento, } \\
\text { câmara de ar }(>5 \mathrm{~cm}) \text { e } \\
\text { laje maçiça de concreto } \\
10 \mathrm{~cm})\end{array}$ \\
\hline U cob - Transmitância da cobertura $\left(\mathrm{W} / \mathrm{m}^{2} \mathrm{~K}\right)$ & Condição Real & 2,06 \\
\hline$\alpha$ cob - Absortância da Cobertura ( admensional) & Condição Real & 0,8 \\
\hline Ctcob - Capacidade Térmica da Cobertura $\left(\mathrm{kJ} / \mathrm{m}^{2} \mathrm{~K}\right)$ & Condição Real & 233 \\
\hline Vidro & Condição Real & Vidro simples incolor $6 \mathrm{~mm}$ \\
\hline FS - Fator solar do vidro (admensional) & Condição Real & 0,82 \\
\hline U vid - Transmitância do vidro $\left(\mathrm{W} / \mathrm{m}^{2} \mathrm{~K}\right)$ & Condição Real & 5,7 \\
\hline AHS - Ângulo horizontal de sombreamento $\left({ }^{\circ}\right)$ & Condição Real & 0 \\
\hline AVS - Ângulo vertical de sombreamento $\left({ }^{\circ}\right)$ & Condição Real & 0 \\
\hline AOV - Ângulo de obstrução vertical $\left({ }^{\circ}\right)^{* *}$ & Condição Real & Condição Real \\
\hline \multicolumn{3}{|l|}{ Iluminação e Ganhos } \\
\hline $\begin{array}{l}\text { DPI -Densidade de potência de iluminação }\left(\mathrm{W} / \mathrm{m}^{2}\right) \\
* *\end{array}$ & Condição Real & $14,1^{* * *}$ \\
\hline Ocupação (m²/pessoa) & 10,0 & 10,0 \\
\hline $\begin{array}{l}\text { DPE- Densidade de potência de equipamentos } \\
\left(\mathrm{W} / \mathrm{m}^{2}\right)\end{array}$ & 9,7 & 9,7 \\
\hline Horas de Ocupação (horas) & \multicolumn{2}{|c|}{10} \\
\hline Dias de Ocupação (Nano) **** & \multicolumn{2}{|c|}{260} \\
\hline Condição do piso & \multicolumn{2}{|c|}{ Condição Real } \\
\hline Condição da Cobertura & \multicolumn{2}{|c|}{ Condição Real } \\
\hline Isolamento & Condição Real & Sem isolamento \\
\hline \multicolumn{3}{|l|}{ Condicionamento de $\operatorname{Ar}$ (refrigeração) } \\
\hline COP - Coeficiente de Performance (W/W) & Condição Real & 2,6 \\
\hline Temperatura de setpoint $\left({ }^{\circ} \mathrm{C}\right)$ & \multicolumn{2}{|c|}{24} \\
\hline Aquecimento de água $* * * * *$ & \multicolumn{2}{|c|}{------- } \\
\hline
\end{tabular}

* A utilização do ângulo de obstrução vertical (AOV) é opcional e deve seguir as diretrizes do RAC

** Caso a avaliação seja realizada somente para a envoltória, deve-se adotar poara a condição real a mesma densidade de potência de iluminação (DPI) da condição de referência.

*** Adotar esse valor para a avaliação parcial da envoltória e para a utilização no método do edifício completo (subitem C.II.2). Para o método das atividades dos edifícios e para o método da potência ajustada, devem ser adotados os valores de potência de iluminação limite (DPIL) para a classe D.

**** Os dias de ocupação dessa tipologia foram com base na média por dias da semana por ano, excluindo-se os fins de semana

***** Tipologias com consumo de água quente não significativo para a avaliação do sistema 
Fonte: Brasil, 2018

O Coeficiente de performance - COP (W/W), é a relação entre a capacidade do resfriamento do sistema de condicionamento de ar e a potência absorvida pelos motores dos seus equipamentos em plena carga. Embora esse índice esteja na tabela 38, este não entra na avaliação da eficiência da envoltória, deste modo não foi levantado.

Conforme o cálculo, efetuado pela Interface Web, foram levantados os seguintes resultados:

- Carga total do edifício real, CgT TREAL $=6532,36 \mathrm{kWh}$

- Carga total do edifício de referência, $C G T$ TREF $=12657,77$ kWh

5) Definição do intervalo de eficiência da edificação será obtido através da fórmula:

Equação 5 - Cálculo do intervalo da eficiência

$$
i=\frac{\text { CgT TREF } X \text { CRCgT D }-A_{3} \quad \text { eq.05 }}{3}
$$

Onde:

CRCgTD-A: Coeficiente de redução da classe D para a classe $A=0,18$ (figura 72)

CGT TREF: Carga total do Edifício de referência

6) Preenchimento da tabela com os intervalos das classes de eficiência energética da envoltória da edificação;

Tabela 39 - Intervalos das classes de eficiência energética da envoltória da edificação

\begin{tabular}{cccccc}
\hline $\begin{array}{c}\text { Classe de } \\
\text { eficiência }\end{array}$ & A & B & C & D & E \\
\hline Limite & - & $>$ CgTTRF $-3 i$ & $>$ CgTTRF $-2 i$ & $>$ CgTTRF $-i$ & $>$ CgTTRF \\
Superior & & 10377,77 & 11137,77 & 11897,77 & 12657,77 \\
\hline Limite & $<$ CgTTRF $-3 i$ & $\leq$ CgTTRF $-2 i$ & $\leq$ CgTTR $-2 i$ & $\leq$ CgTTRF & - \\
Inferior & 10377,77 & 11137,77 & 11137,77 & 12657,77 & \\
\hline
\end{tabular}

Fonte: a autora, 2020.

7) Identificação da classe de eficiência da edificação analisada;

A edificação alcançou a classe $\boldsymbol{A}$ de eficiência conforme análise pela proposta do novo regulamento - INI-C, pois: CgT TREAL $=6532,36 \mathrm{kWh}<\mathrm{CgTTRF}-3 \mathrm{i}=10377,77 \mathrm{kWh}$. 
O resultado demonstra que a envoltória do Edifício 1, em comparação com o edifício de referência (classe D), alcançou a classe $\mathbf{A}$ em eficiência energética no INI-C, obtendo $51 \%$ de redução do consumo de energia com relação ao edifício de referência.

O Edifício 01 foi novamente etiquetado pelo RTQ-C inserindo-se os pré-requisitos de transmitância e absortância levantados para a inserção no novo regulamento. Através do WebPrescritivo foi constatado a permanência da etiqueta Nível B.

Figura 64 - Etiquetagem pelo Webprescritivo do Edifício 1 com inserção dos pré-requisitos.

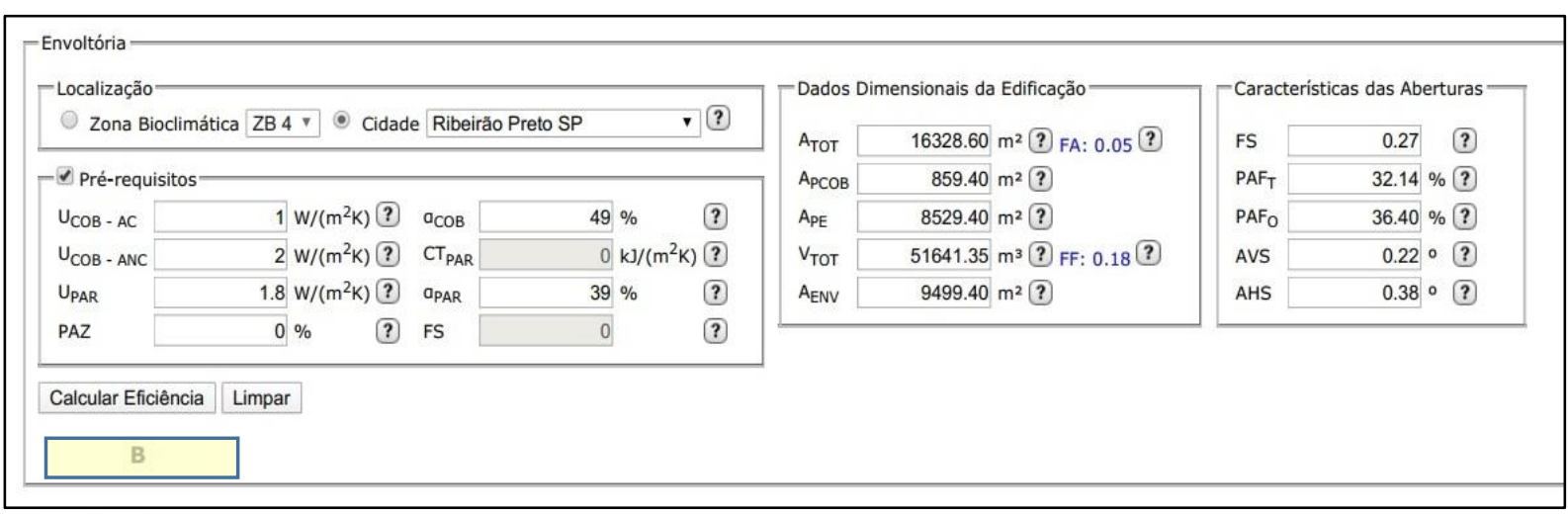

Fonte: Webprescritivo (2020)

O edifício 01, analisado pelo INI-C alcançou um nível de eficiência superior se comparado ao nível alcançado pelo RTQ-C.

De acordo com a etiquetagem pelo INI-C e pelo RTQ-C foram efetuadas as seguintes análises:

a) a tabela 40 apresenta os parâmetros utilizados para a etiquetagem pelo método prescritivo (RTQ-C) e simplificado (INI-C), seja na utilização como prérequisitos ou na aplicação da etiquetagem parcial da envoltória.

De acordo com a tabela, os limites utilizados pelo INI-C foram ampliados, tanto os limites mínimos quanto os máximos. Conforme a característica térmica dos materiais foi observada que a transmitância das paredes que no RTQ-C ficava entre 1,0 a $3,7 \mathrm{~W} / \mathrm{m}^{2} \mathrm{~K}$, no INI-C o intervalo aumenta de 0,5 a $4,40 \mathrm{~W} / \mathrm{m}^{2} \mathrm{~K}$, ampliando assim a variedade de materiais que podem ser empregados no edifício sem restrições para a aplicação da metodologia. O mesmo é constatado com relação a absortância de paredes e coberturas, transmitância de coberturas e o fator solar dos vidros. Considerando-se os vidros de controle solar, os edifícios que utilizam esse tipo de material obtêm um ganho de 
eficiência no INI-C se comparado ao RTQ-C, o que contribuiu para o Edifício1 alcançar um índice melhor de eficiência no INI-C (classe A) em comparação com o RTQ-C (Nível B).

Tabela 40 - Parâmetros limites utilizados para a etiquetagem pelo método prescritivo (RTQ-C) e simplificado (INI-C)

\begin{tabular}{|c|c|c|c|c|c|}
\hline \multirow{2}{*}{\multicolumn{2}{|c|}{ PARÂMETROS }} & \multicolumn{2}{|c|}{$\begin{array}{c}\text { RTQ-C } \\
\begin{array}{c}\text { (Independente das zonas } \\
\text { bioclimáticas) }\end{array} \\
\end{array}$} & \multicolumn{2}{|c|}{ INI-C } \\
\hline & & mínimo & máximo & mínimo & máximo \\
\hline $\begin{array}{l}\text { Percentual de } \\
\text { Abertura de } \\
\text { Fachadas } \\
\end{array}$ & PAF \% & 0,5 (ICmin) & 60 (ICmax) & 0 & 80 \\
\hline $\begin{array}{c}\text { Percentual de } \\
\text { Abertura Zenital }\end{array}$ & PAZ\% & & & 0 & 3 \\
\hline \multirow{3}{*}{ Transmitância } & $\begin{array}{c}\text { Paredes } \\
\text { Upar }=\mathrm{W} / \mathrm{m}^{2} \mathrm{~K}\end{array}$ & 1,0 & 3,7 & 0,50 & 4,40 \\
\hline & $\begin{array}{c}\text { Coberturas } \\
\text { Ucob }=\mathrm{W} / \mathrm{m}^{2} \mathrm{~K}\end{array}$ & 0,5 & 2,0 & 0,51 & 5,07 \\
\hline & $\begin{array}{c}\text { Vidros } \\
\text { Uvid }=\mathrm{W} / \mathrm{m}^{2}\end{array}$ & - & - & 1,9 & 5,7 \\
\hline \multirow{2}{*}{ Absortância } & paredes & 0 & 0,49 & 0,2 & 0,8 \\
\hline & coberturas & 0 & 0,49 & 0,2 & 0,8 \\
\hline \multirow{2}{*}{$\begin{array}{l}\text { Capacidade } \\
\text { Térmica }\end{array}$} & $\begin{array}{c}\text { Paredes } \\
\mathrm{CTcob}=\mathrm{Kj} / \mathrm{m}^{2} \mathrm{~K}\end{array}$ & $\mathrm{CT} \leq 80$ & $\mathrm{CT} \geq 80$ & 0,22 & 450 \\
\hline & $\begin{array}{c}\text { Coberturas } \\
\text { CTpar }=\mathrm{Kj} / \mathrm{m}^{2} \mathrm{~K}\end{array}$ & - & - & 0,22 & 450 \\
\hline \multirow{2}{*}{$\begin{array}{l}\text { Fator Solar do } \\
\text { vidro -FS }\end{array}$} & Cobertura & $P A Z=0,30$ & $P A Z=0,87$ & - & - \\
\hline & Fachadas & $0,61(\mathrm{ICmin})$ & $0,87(\mathrm{ICmax})$ & 0,21 & 0,87 \\
\hline \multirow{3}{*}{$\begin{array}{c}\text { Ângulo de } \\
\text { Sombreamentos }\end{array}$} & $\begin{array}{c}\text { Horizontal } \\
\text { (AHS) }\end{array}$ & $0^{\circ}$ & $45^{\circ}$ & $0^{\circ}$ & $80^{\circ}$ \\
\hline & Vertical (AVS) & $0^{\circ}$ & $45^{\circ}$ & $0^{\circ}$ & $90^{\circ}$ \\
\hline & $\begin{array}{l}\text { De obstrução } \\
\text { vertical (AOV) }\end{array}$ & - & - & $0^{\circ}$ & $80^{\circ}$ \\
\hline \multicolumn{2}{|l|}{$\begin{array}{c}\text { Contato com o } \\
\text { solo }\end{array}$} & \multicolumn{2}{|c|}{$\begin{array}{l}\text { Para o levantamento das áreas } \\
\text { da envoltória (cobertura e } \\
\text { paredes), são desconsideradas as } \\
\text { áreas das paredes em contato } \\
\text { com o solo. }\end{array}$} & Com contato & Sem contato \\
\hline $\begin{array}{l}\text { Densidade de } \\
\text { Potência de } \\
\text { Equipamento }\end{array}$ & $\begin{array}{c}\mathrm{DPE} \\
\mathrm{W} / \mathrm{m}^{2}\end{array}$ & - & - & 4 & 40 \\
\hline $\begin{array}{l}\text { Densidade de } \\
\text { Potência de } \\
\text { Iluminação }\end{array}$ & $\begin{array}{c}\mathrm{DPI} \\
\mathrm{W} / \mathrm{m}^{2}\end{array}$ & - & - & 4 & 40 \\
\hline \multicolumn{2}{|l|}{$\begin{array}{c}\text { Piso com } \\
\text { Isolamento }\end{array}$} & - & - & $\begin{array}{c}\text { Não se } \\
\text { isolamento } \leq \\
5 \mathrm{~mm}\end{array}$ & $\begin{array}{c}\text { Sim se } \\
\text { isolamento } \geq \\
5 \mathrm{~mm}\end{array}$ \\
\hline Pé Direito & PD (m) & - & - & 2,6 & 6,6 \\
\hline
\end{tabular}


Fonte: a autora

b) o percentual de aberturas das fachadas no INI-C pode chegar a $80 \%$, o que amplia o número de projetos que conseguem ser analisados pelo método simplificado, sem prejudicar a avaliação, visto que tanto as aberturas quanto as proteções e o tipo de vidro são analisados por fachada e pela orientação da mesma.

c) o levantamento de dados relativo ao edifício precisa, para ser efetuado, que o projetista forneça além do projeto arquitetônico detalhado, as características térmicas dos materiais utilizados, sendo responsável pela determinação dos sistemas construtivos utilizados, que devem ser determinados na fase de projeto.

d) o ângulo de obstrução vizinha para ser determinado pressupõe um conhecimento prévio pelo projetista do uso da carta solar e transferidores de ângulos para serem aferidos ou um software que forneça esses valores. Esse parâmetro fornece uma leitura mais adequada da edificação quanto a sua implantação e projeto, visto que, diante de sombreamentos pré-existentes nas fachadas o projeto pode ter liberdade para aumento de áreas envidraçadas sem proteções ou vidros de controle solar, estratégias estas que no regulamento corrente afetará o nível de eficiência do edifício.

Após as análises efetuadas, o capítulo a seguir apresenta diretrizes para serem utilizados na fase inicial do projeto arquitetônico com o intuito de desenvolver um edifício que consuma menos energia elétrica.

4.5 Subsídios para a obtenção do "Nível A" no índice de consumo da envoltória, pelo RTQ-C em Ribeirão Preto, Zona Bioclimática 4.

De acordo com o RTQ-C, um edifício que obtenha o Nível A no Índice de Consumo da envoltória (ICenv), possui as aberturas envidraçadas elaboradas a partir de diretrizes projetuais e materiais construtivos capazes de minimizar o seu consumo de energia. A equação do ICenv possui variáveis que representam elementos constituintes de uma fachada, como o percentual de abertura com relação a fachada do edifício (PAF), o fator solar do vidro 
que compõe essa abertura (FS) e os elementos construtivos que promovem a proteção solar dessas aberturas (AVS e AHS).

Foi realizado em três edifícios em Ribeirão Preto (ZB4), o levantamento das etiquetas parciais das envoltórias sem a avaliação dos pré-requisitos. Dois destes edifícios obtiveram a etiqueta Nível B e um a Nível A. A partir dos dados coletados de cada edifício, foram realizadas simulações através da equação do ICenv de modo a extrair os cenários que promovessem o Nível A no seu índice de consumo.

Para a realização das simulações, o Fator de Forma (FF) e o Fator Altura (FA), permaneceram inanterados (conforme cada um dos prédios) e as demais variáveis foram manipuladas de acordo com as condições de contorno apresentadas no capítulo 3.5.

Após as simulações, foram obtidos 51 cenários que alcançaram o Nível $A$, sendo que estes cenários se repetiram nos três edifícios, mesmo estes possuindo volumetrias e formas distintas (FA e FF diferenciados).

Desta maneira, é possivel pressupor que as relações estabelecidas entre as variáveis da equação do índice da envoltória podem não sofrer influência do Fator de Forma e do Fator Altura da edificação (desde que estes permaneçam inalterados durante a simulação), o que pode ser um indicativo de que estes índices, estabelecidos através das simulações, poderiam ser usados para edifícios com outras volumetrias, desde que Ape $>500 \mathrm{~m}^{2}$.

Para que essa afirmação seja confirmada, é necessário que outros edifícios com volumetrias distintas, já analisadas, sejam estudados.

A seguir, são apresentados os cenários que alcançaram o Nível A no ICenv conforme os percentuais de aberturas estudados.

\section{Percentual de Abertura das Fachadas de $60 \%$}

Para os edifícios com percentual de abertura das fachadas igual ou maiores à $60 \%$ não foi possível alcançar o Nível A, mesmo com a utilização de vidros de alto desempenho e sombreamento (AVS e AHS) com angulação máxima (45).

\section{Percentual de Abertura das Fachadas de $50 \%$}


Para os edifícios com percentual de abertura das fachadas de 50\%, o Nível A foi alcançado através do uso de vidros com $\mathbf{F S} \leq \mathbf{0 , 2 7}$ e aberturas com proteções solares horizontais e verticais com ângulos $\geq 45^{\circ}$ (AVS e AHS), aplicados simultaneamente.

\section{Percentual de Abertura das Fachadas de $40 \%$}

Em edificações com o percentual de abertura nas fachadas de 40\%, o Nível A foi alcançado utilizando-se simultaneamente vidros de alto desempenho com $\mathbf{F S} \leq \mathbf{0 , 2 7}$ e proteções solares. Porém, os ângulos dos sombreamentos produzidos pelos elementos construtivos apresentam algumas opções:

a) $\mathbf{A V S}=45^{\circ}$, utilizado isoladamente;

b) AVS $\geq 22^{\circ}$ e AHS $\geq 45^{\circ}$; AVS $\geq 45^{\circ}$ e AHS $\geq 22^{\circ}$; AVS e AHS $\geq 45^{\circ}$, aplicados simultâneamente

\section{Percentual de Abertura das Fachadas de $\mathbf{3 0 \%}$}

Nos edifícios com percentual total de aberturas das fachadas de $30 \%$, as condições para se obter o Nível A no ICenv são:

a) utilizando vidros de $\mathbf{F S} \leq \mathbf{0 , 2 7}$ :

- AVS $\geq 22^{\circ}$, utilizado isoladamente;

- AHS $\geq 45^{\circ}$, utilizado isoladamente;

- AVS $\geq 22^{\circ}$ e AHS $\geq 22^{\circ}$, aplicados simultâneamente.

b) utilizando vidros de $\mathbf{F S}=\mathbf{0 , 4 3}$ :

- AVS e AHS $\geq 45^{\circ}$, utilizados simultâneamente.

\section{Percentual de Abertura das Fachadas de 20\%}

Nos edifícios com percentual total de aberturas das fachadas de $20 \%$, as condições para se obter o Nível A no ICenv são:

a) empregando vidros de $\mathbf{F S} \leq \mathbf{0 , 2 7}$ :

- AVS $\geq 22^{\circ}$ ou o AHS $\geq 22^{\circ}$, usados isoladamente.

b) empregando vidros de $\mathbf{F S}=\mathbf{0 , 4 3}$ :

- AVS $\geq 22^{\circ}$, usado isoladamente;

- AVS $\geq 22^{\circ}$ e AHS $\geq 22^{\circ}$, aplicados simultâneamente; 
c) empregando vidros de $\mathbf{F S}=\mathbf{0 , 6 0}$ :

- AVS $\geq 45^{\circ}$, aplicado isoladamente;

- AVS $\geq 22^{\circ}$ e AHS $\geq 22^{\circ}$, utilizados simultâneamente.

c) empregando vidros de $\mathbf{F S}=\mathbf{0 , 8 7}$ :

- AVS $\geq 45^{\circ}$ e AHS $\geq 22^{\circ}$ aplicando simultaneamente.

\section{Percentual de Abertura das Fachadas de $10 \%$}

Para os edifícios com percentual de aberturas em fachadas igual ou menores de $10 \%$, alcançase o Nível $\boldsymbol{A}$ no índice de consumo da envoltória independente do fator solar ou de proteções solares.

Com o PAFT igual ou menor a 10\%, o FS não possui influência no índice de consumo (pelo RTQC), chegando até a proporcionar um ligeiro aumento no número de pontos do índice, como demonstra a figura 70 .

Esses cenários visam a contribuir para um projeto de edifício que minimize o consumo de energia. Não possui o intuito de cercear a criatividade dos projetistas, mas de informar as relações existentes entre as variáveis das aberturas envidraçadas que interferem nesse consumo.

As soluções de projeto (variáveis arquitetônicas) podem economizar mais energia do que a eficiência do ar condicionado e da iluminação artificial, transcorrendo essa verificação em diferentes orientações, (PEDRINI, 2003).

Assim, constata-se a importância da compreensão das relações entre as áreas das aberturas com a área da fachada, como essa área se relaciona com a orientação escolhida, com o tipo de vidro e com as proteções solares, visando o desenvolvimento do projeto de um edifício que possua eficiência energética.

Essas relações contribuem com o partido arquitetônico adotado e a compreenção das mesmas facilitam a tomada de decisões desde a fase inicial do projeto arquitetônico. 


\section{Capítulo 5}

\section{CONSIDERAÇÕES FINAIS}

De acordo com as simulações efetuadas utilizando-se os parâmetros do ICenv e os dados levantados dos edifícios analisados, foram obtidos subsídios a serem aplicados durante a elaboração do projeto arquitetônico para a obtenção do nível máximo de eficiência no sistema da envoltória do método prescritivo do RTQ-C. Essas informações se tornam importantes para a elaboração de projetos que minimizem o gasto de energia elétrica e podem ser utilizadas nas fases iniciais do projeto de arquitetura.

Concluiu-se através dos estudos, que os índices de $20 \%$ de aberturas nas fachadas dos edifícios analisados apresentam um maior número de cenários capazes de alcançar o Nível A no atual regulamento de eficiência, promovendo uma maior flexibilidade ao projetista na composição dessas fachadas. À medida que os percentuais de aberturas vão aumentando, esses cenários são reduzidos, até o índice de $60 \%$ que não possui nenhuma composição que alcance o Nível A. Foi levantado que os ângulos de sombreamentos utilizados na pesquisa $\left(22^{\circ}\right.$ e $\left.45^{\circ}\right)$ independente do Fator Solar e do Percentual de Abertura da Fachada, possuem uma contribuição sempre constante na redução do ICenv, possuindo o Ângulo Vertical (AVS) uma contribuição maior do que o Ângulo Horizontal (AHS).

Identificou-se que, para os edifícios analisados, os cenários levantados para alcançar o Nível A se repetem, mesmo os três edifícios possuindo volumetrias e formas diferenciadas. Essa conclusão pressupõe que as relações existentes entre as variáveis da equação do ICenv não sofrem influência do FF e do FA. Assim, de acordo com essa avaliação, os edificios com volumetrias diferentes das já analisadas poderiam seguir os mesmos cenários para alcançar o Nível A. Essa constatação diverge das pesquisas levantadas nesse estudo onde a forma do edifício influência na quantidade de radiação solar recebida pela envoltória do edifício, e consequentemente, em sua eficiência energética. Essa observação demostraria a limitação do RTQ-C ao se adotar uma equação do ICenv (ZB4) para todas as volumetrias analisadas, diferenciando-se apenas da área de projeção do edifício.

Essa hipótese poderá ser ratificada a partir de pesquisas que ampliem o conjunto de edifícios a serem analisados. 
A partir da etiquetagem do edifício 01 no método vigente (RTQ-C) e na sua proposta de aperfeiçoamento (INI-C), foi possível constatar que devido às alterações efetuadas, o edifício 01 obteve o nível máximo de eficiência em sua envoltória no INI-C, não tendo alcançado o mesmo nível máximo no RTQ-C. Esse novo patamar de eficiência alcançado pelo edifício demonstra que as alterações aplicadas no novo regulamento podem promover uma avaliação mais real do objeto analisado. Essa avaliação respalda na análise de cada fachada em separado (orientação, aberturas envidraçadas, sombreamentos e materiais) e na comparação do edifício real com um edifício de referência de mesma tipologia (seguindo os mesmos padrões de cargas témicas).

A pesquisa identificou diversas limitações existentes no RTQ-C e que buscaram ser sanadas através do INI-C. O aperfeiçoamento do regulamento procura suprir essas limitações elaborando uma investigação mais criteriosa do edifício. Dentre as inclusões feitas pelo INI-C está o estudo do Cima Brasileiro elaborado por Roriz (2014), que foi desenvolvido de modo a caracterizar melhor o clima de cada cidade levantada.

O processo de levantamento dos dados das edificações permanece o mesmo, sendo esta uma etapa trabalhosa e significativa para a etiquetagem. Informações sobre características técnicas dos materiais, dados das esquadrias e tipos de vidros são dados que muitas vezes inexistem no projeto de arquitetura, o que dificulta o processo de levantamento. Esse ponto evidencia a importância do conhecimento, por parte dos projetistas, das características técnicas dos materiais escolhidos para o edifício, para que ocorra uma especificação correta dos mesmos.

As diretrizes projetuais elaboradas através desse estudo possuem o intuito de nortear a produção de uma arquitetura que minimize o gasto de energia, e ressaltar a importância do conhecimento do conforto térmico, das normas e dos regulamentos do setor durante a concepção de uma edificação. Destaca-se também a responsabilidade da universidade na transmissão e disseminação dessas informações de um modo mais amplo para que estas alcancem os desenvolvedores dos projetos arquitetônicos.

\subsection{Recomendação para trabalhos futuros}

Devido às limitações desse estudo, seriam importantes pesquisas efetuadas no sentido de: 
- Ampliar o levantamento dos edifícios em Ribeirão Preto quanto ao Fator de Forma e Fator altura mais utilizados e empregar esses índices para refazer a análise;

- Refazer o processo de análise das diretrizes projetuais assim que o aperfeiçoamento do regulamento for promulgado, tanto pelo método simplificado quanto pela simulação. 


\section{REFERÊNCIAS}

ABNT. ASSOCIAÇÃO BRASILEIRA DE NORMAS TÉCNICAS. NRB 15220 - Desempenho Térmico de Edificações. Rio de Janeiro: ABNT, 2005b.

ABNT.NBR 15220 -3-Desempenho Térmico das Edificações: parte 3: Zoneamento Bioclimático Brasileiro e diretrizes construtivas para habitações unifamiliares de interesse social. Rio de Janeiro: ABNT,2005c

ABNT. NBR 15575 - Edifícios Habitacionais - Desempenho. Rio de Janeiro, ABNT, 2013a

BAVARESCO, M., MAZZAFERRO, L., MELLO, A., LAMBERTS, R. Análise da precisão de um metamodelo para a avaliação da envoltória de acordo com o regulamento brasileiro de eficiência energética em edificações. In: XIV ENCONTRO NACIONAL DE CONFORTO NO AMBIENTE CONSTRUÍDO, Balneário Camboriú, 2017. Researchgate. Disponível em < https://www.researchgate.net/publication/320333307_ANALISE_DA_PRECISAO_DE_UM_METAMOD ELO_PARA_A_AVALIACAO_DA_ENVOLTORIA_DE_ACORDO_COM_O_REGULAMENTO_BRASILEIRO_D E_EFICIENCIA_ENERGETICA_EM_EDIFICACOES >. Acesso, janeiro 2020.

BRANDALISE, M., ÁVILA, V., OLIVEIRA, L., CUNHA, E. Análise da sensibilidade do método prescritivo do RTQ-C quanto à variação de densidade de carga interna. In: ENCONTRO NACIONAL DE TECNOLOGIA DO AMBIENTE CONSTRUÍDO, 2014. Maceió. Anais... Maceió: ENTAC, 2014.

BRASIL. Presidência da República. Lei n. 10.295, de 17 de outubro de 2001. Dispõe sobre a Política Nacional de Conservação e Uso Racional de Energia e dá outras providências. Brasília, DF, 2001. Disponível em: < http://www.planalto.gov.br/ccivil_03/leis/LEIS_2001/L10295.htm>. Acesso em janeiro 2020.

BRASIL. Ministério do Desenvolvimento Industrial e Comércio Exterior. INMETRO - Instituto Nacional de Metrologia Normalização e Qualidade Industrial. Portaria 372, de 17 de setembro de 2010. Requisitos técnicos da qualidade para o nível de eficiência energética de edifícios comerciais, de serviços e públicos. Rio de Janeiro, 2010. Disponível em: < http://www.inmetro.gov.br/legislacao/rtac/pdf/RTAC001599.pdf >. Acesso em janeiro 2020.

BRASIL. Ministério do Desenvolvimento Industrial e Comércio Exterior. INMETRO. Portaria 18, de 16 de janeiro de 2012. Regulamento Técnico da Qualidade para o nível de Eficiência Energética Edificações Residenciais. Rio de Janeiro, 2012. Disponível em: < http://www.inmetro.gov.br/legislacao/rtac/pdf/RTAC001788. pdf >. Acesso em janeiro 2020.

BRASIL. Ministério do Desenvolvimento Industrial e Comércio Exterior. INMETRO. Portaria 50, de 01 de fevereiro 2013. Requisitos técnicos da avaliação da conformidade para a eficiência energética em edificações. Rio de Janeiro, 2013. Disponível em: < http://www.inmetro.gov.br/legislacao/rtac/pdf/RTAC001961.pdf >. Acesso em janeiro 2020. 
BRASIL. Ministério do Desenvolvimento, Indústria e Comercio Exterior. Instituto Nacional de Metrologia, Normalização e Qualidade Industrial. Anexo da Portaria no50, INMETRO, 2013. Anexo Geral V. Catálogo de propriedades térmicas de paredes, coberturas e vidros. Atualizado em 27/11/2017. Disponível em:

<http://www.inmetro.gov.br/consumidor/produtosPBE/regulamentos/AnexoV.pdf> Acesso janeiro de 2020.

BRASIL Ministério do Meio Ambiente. PBEEDIFICA. Manual para aplicação do RTQ-R 4.2, Eletrobrás / Procel, versão 1, 2014.. Portaria 16 de janeiro de 2012 do INMETRO. Disponível em <http://pbeedifica.com.br/sites/default/files/projetos/etiquetagem/residencial/downloa ds/Manual_de_aplicação_do_\%20RTQ-R-v01.pdf> Acesso janeiro de 2020.

BRASIL. Ministério de Minas e Energia. Centro Brasileiro de Informação em Eficiência Energética, 2015. PROCELINFO. Disponível em < http://www.procelinfo.com.br/main.asp?View=\%7BE85A0ACC-8C62-465D-9EBD47FF3BAECDAE\%7D> Acesso janeiro 2020.

BRASIL. Ministério do Meio Ambiente. PBEEDIFICA. Manual para aplicação do RTQ-C 4.1, Eletrobrás / Procel, versão 4, abril de 2017. Portaria 372 de 17 de setembro de 2010 do INMETRO.

Disponível em<http://pbeedifica.com.br/sites/default/files/Manual_20170411_Notas_Técnicas\%2BCap a.pdf > Acesso janeiro de 2020.

BRASIL Ministério do Desenvolvimento Industrial e Comércio Exterior. INMETRO. Portaria 248, de 10 de julho de 2018. Consulta Pública. Aperfeiçoamento do Regulamento Técnico da Qualidade para a Classe de Eficiência Energética de Edifícios Comerciais, de Serviços e Públicos. Rio de Janeiro, 2018. Disponível em < http://www.inmetro.gov.br/legislacao/rtac/pdf/RTAC002520.pdf> Acesso em janeiro de 2020.

BRSIL Ministério de Minas e Energia. Empresa de Pesquisa Energética - EPE. Balanço Energético Nacional (BEN) 2019, Relatório Síntese, ano base 2018. Rio de Janeiro 2019.67 p. Disponível em: http://www.epe.gov.br/pt/publicacoes-dados-abertos/publicacoes/balancoenergetico-nacional-2019?.pdf. Acesso em agosto de 2019.

BRASIL. Presidência da República. Decreto 9864 de 27 de junho de 2019. Regulamenta a Lei no 10.295, de 17 de outubro de 2001, que dispõe sobre a Política Nacional de Conservação e Uso Racional de Energia, e dispõe sobre o Comitê Gestor de Indicadores e Níveis de Eficiência Energética. Brasília, DF, 2001. Disponível em: < https://www.planalto.gov.br/ccivil_03/_Ato2019-2022/2019/Decreto/D9864.htm >. Acesso em janeiro 2020.

BRASIL. Ministério do Meio Ambiente. PBEEDIFICA. Tabelas de Edificações Comerciais de Serviços e Públicas. Atualização 2020. Disponível em < http://www.inmetro.gov.br/consumidor/pbe/tabelas-comerciais.pdf> Acesso em janeiro de 2020. 
BRASIL Ministério do Meio Ambiente. PBEEDIFICA. Disponível em < http://www.pbeedifica.com.br/etiquetagem/comercial > Acesso janeiro 2020.

BRASIL Ministério do Meio Ambiente. ProjetEEE - Componentes construtivos. Disponível em < http://projeteee.mma.gov.br/ > Acesso janeiro 2020.

BÉCQUE, et al. 2016. Accelerating Building Efficiency: Eight Actions for Urbans Leaders. World Resource Institute, Washington, 2016. Disponível em: http://publications.wri.org/buildingefficiency/. Último acesso em julho de 2020

BRUGNERA, R. R., MATEUS, R., ROSSIGNOLO, J. A., CHVATAL, K. M. S. Escritórios de planta livre: o impacto de diferentes soluções de fachada na eficiência energética. Ambiente Construído vol.19 no.3 Porto Alegre, 2019.

CARLO, J.C., LAMBERTS, R. Parâmetros e métodos adotados no regulamento da etiquetagem da eficiência energética dos edifícios - parte 1: método prescritivo. Ambiente Construído. Ambient. Constr. vol.10 no.2 Porto Alegre, 2010.

CARLO, J.C. Desenvolvimento de Metodologia de Avaliação da Eficiência Energética. Tese Doutorado em Engenharia Civil) - PPGEC, Universidade Federal de Santa Catarina, Florianópolis, 2008.

CARLO, J.C., MACIEL, L.F. Análise de sensibilidade do indicador de consumo frente às variáveis das equações do RTQ-C. In: XI ENCONTRO NACIONAL DE CONFORTO DO AMBIENTE CONSTRUÍDO, 2011. Búzios. Anais.... Búzios: ENTAC, 2011.

CARMODY, J.; SELKOWITZ, S.; LEE, E.S.; ARASTEH, D. Window systems for high- performance buildings. Nova York: Norton, 2004

CASALS, X.G., Analysis of building energy regulation and certification in Europe: Their role, limitations and difference. Energy and Buildings. Vol.38, Issue 5, p 381-392, 2006.

CB3E - CENTRO BRASILEIRO DE EFICIENCIA ENERGÉTICA EM EDIFICAÇÕES. Proposta de método para a avaliação da eficiência energética com base em energia primária de edificações comerciais de serviços e públicas. Versão 3, 144 p., 2017. Centro Tecnológico, Departamento de Engenharia Civil. Universidade Federal de Santa Catarina, Florianópolis, 2017. Disponível em < http://cb3e.ufsc.br/etiquetagem/desenvolvimento/atividades-20122016/trabalho-1/pesquisas> último acesso, janeiro 2020.

CEMTEC - Centro de monitoramento do tempo e do clima de MS. Escala modificada de beaufort - intensidade do vento $(\mathrm{km} / \mathrm{h}), 2015$. Disponível em < http://www.cemtec.ms.gov.br/wp-content/uploads/2019/02/ESCALA-MODIFICADA-DEBEAUFORT-INTENSIDADE-DO-VENTO-2.pdf > último acesso, junho de 2019.

CEOTTO, L. H. Avaliação de sustentabilidade: balanço e perspectivas no Brasil. In: SIMPÓSıO BRASILEIRO DE CONSTRUÇÃO SUSTENTÁVEL - SBCS 08, São Paulo, 2008. 
DESTRO, C. M.G. Análise do desempenho térmico das unidades básicas de saúde do município de São Bento do Sul: aplicação da nova proposta brasileira de etiquetagem de edificações para a envoltória. 2019.184p. Dissertação (Mestrado em Engenharia Civil). Faculdade de Engenharia Civil, Universidade do Estado de Santa Catarina, Joinville, 2019.

DORNELLES, K. A.; RORIZ, M. Thermal inertia, comfort, and energy consumption in buildings: a case study in Sao Paulo state - Brazil. International Journal for Housing and its Applications, v. 28, n. 2, p. 153-162. 2004.

DORNELLES, K., SANTOS, I.G., SOUZA, R. Absortância Solar de Superfícies e o Regulamento Brasileiro para Eficiência Energética dos Edifícios. In: XIII ENCONTRO NACIONAL DE TECNOLOGIA DO AMBIENTE CONSTRUÍDO, Canela, Anais... Canela: ENTAC, 2010.

DORNELLES, K.; RORIZ, M. Identificação da absortância solar de superfícies opacas por meio de espectrômetro de baixo custo. XI ENCONTRO NACIONAL DE TECNOLOGIA DO AMBIENTE CONSTRUÍDO, Florianópolis, Anais... Florianópolis: ENTAC, 2006.

DORNELLES, K. A. Absortância solar de superfícies opacas: métodos de determinação e base de dados para tintas látex acrílica e PVA. 2008. 160p. Tese (Doutorado em Engenharia Civil) Faculdade de Engenharia Civil, Arquitetura e Urbanismo, Universidade Estadual de Campinas, Campinas, 2008.

ELOY, D., AKUTSU, M. Diretrizes para a intervenção na envoltória de edifícios comerciais na zona bioclimática 3 para obtenção do "nível A" pelo método prescritivo da certificação procel edifica. In: ENCONTRO NACIONAL DE TECNOLOGIA DO AMBIENTE CONSTRUÍDO, Desafios e perspectivas da internacionalização da construção, 16. 2016, São Paulo. Anais... Porto Alegre: ANTAC, 2016. p. 831-842.

FERNANDES, L.O. A influência do sombreamento do entorno na etiqueta de eficiência energética de edifício comercial. Tese (Engenharia Civil, Arquitetura e Urbanismo) Universidade Estadual de Campinas. Campinas,2012.

FERREIRA, C.C., SOUZA, R., V., G. Avaliação dos impactos dos brises no conforto térmico e luminoso conforme as recomendações do RTQ-C: estudo de tribunal de justiça de Minas Gerais. In: XIII ENCONTRO NACIONAL DA TECNOLOGIA DO AMBIENTE CONSTRUÍDO, 2010, Canela. Anais... Canela: ENTAC, 2010.

FOSSATI, M., LAMBERTS, R. Eficiência energética da envoltória de edifícios de escritórios de Florianópolis: discussões sobre a aplicação do método prescritivo do RTQ-C. Ambiente Construído, Porto Alegre, v.10, n.2, p.59-60,2010.

FROTA, A.B.; SCHIFFER, S.R. Manual do Conforto Térmico. $5^{\circ}$ Edição, São Paulo: Studio Nobel, 2004.

GERALDI, R.R. A Mobilidade Urbana na Região de Ribeirão Preto, um estudo para conexões urbanas sustentáveis. 2017. Monografia. (Graduação em arquitetura) - Faculdade de Arquitetura e Urbanismo, Centro Universitário Moura Lacerda. Ribeirão Preto, 2017. 
GHISI, E., TINKER, J.A., IBRAHIM, S.H. Área de Janelas e dimensões de ambientes para iluminação natural e eficiência energética: literatura versus simulação computacional. Ambiente Construído, Porto Alegre, v. 5, n. 4, p.81-93, 2005.

HONG, T.; CHOU, S.K.; E BONG, T.Y. Building Simulation: an overview of the developments and information sources. Building and Environment, v.35, p 347-361, 2000.

Instituto de Pós-Graduação e Graduação - IPOG, 2014.Curso de Especialização em Iluminação e Design de Interiores. Ribeirão Preto, São Paulo, 2014.

INTERNATIONAL ENERGY AGENCY. IEA,2019. Word Energy outlook, 2019. Disponível em: https://www.iea.org/reports/world-energy-outlook-2019/energy-efficiency .Último acesso, junho 2019.

LAMBERTS, R., et al, 2007. Regulamentação de etiquetagem voluntária de nível de eficiência energética de edifícios comerciais e públicos. In: ENCAC 2007 - In: ENCONTRO NACIONAL, 9, ENCONTRO LATINO AMERICANO, 5. DE CONFORTO DO AMBIENTE CONSTRUÍDO, 2007, Ouro Preto, MG. Anais... Ouro Preto: ENCAC, 2007. P 1019-1028.

LAMBERTS, R., CLETO, 2019. Certificação de Sistemas PBE EDIFICA. In: SEMINÁRIO: PROGRAMA BRASILEIRO DE ETIQUETAGEM EM EFICIÊNCIA PARA SISTEMAS DE REFRIGERAÇÃO E AR CONDICIONADO, 2018. ABRAVA 2018, São Paulo. Disponível em < https://abrava.com.br/wp-content/uploads/2018/08/Seminario-PBE-RAC-03-PBE-EDIFICALamberts-e-Tomaz_compressed-1.pdf > Acesso em janeiro, 2020.

LAMBERTS, R., FOSSATI, M. Eficiência Energética da Envoltória de Edifícios de escritório de Florianópolis: discussões sobre a aplicação do método prescritivo do RTQ-C. Ambiente Construído, Porto Alegre, v. 10, n. 2, p. 59-69, abr./jun. 2010

LAMBERTS, R., DUTRA, L., PEREIRA, F.O.R. Eficiência Energética na Arquitetura. $3^{\circ}$ Edição, São Paulo: Ed. PW Brasil, 2012.

MANGKUTU, R.A., ROHMAH, M., ASRI, A.D. Design optimization for window size, orientation, and wall reflectance with regard to various daylight metrics and lighting energy demand: $A$ case study of buildings in the tropics. Applied Energy, Elsevier, vol. 164(C), pages 211-219, and 2016.

MEIER, A., OLOFSSON, T., LAMBERTS, R. What is an energy-efficient building? In: IX ENCONTRO NACIONAL DE TECNOLOGIA DO AMBIENTE CONSTRUÍDO, Anais... Foz do Iguaçu: ANTAC, ENTAC, 2002

MELO, A.P., LAMBERTS, R. Análise da influência do desempenho térmico dos fechamentos opacos através do balanço térmico. In: XII ENCONTRO NACIONAL DE TECNOLOGIA DO AMBIENTE CONSTRUÍDO, 2008, Fortaleza. Anais... Fortaleza: ENTAC,2008. 
Melo, A.P., CÓSTOLA, D., LAMBERTS, R., HENSEN, J. Determinação do nível de eficiência da envoltória de edificações comerciais de acordo com o RTQ-C. In: XI ENCONTRO NACIONAL DE CONFORTO DO AMBIENTE CONSTRUÍDO, 2011, Búzios. Anais... Búzios: ENTAC 2011.

OMER, A.M., Energy, environment and sustainable development. Renewable and Sustainable Energy Reviews, v. 12, n. 9, p.2265 - 2300, 2008.

PACHECO, R., ORDÓÑEZ, J., MARTÍNEZ, G. Energy efficient design of building: A review. Renewable and Sustainable Energy Reviews, v 16, p 3560 - 3573, 2012.

POLLOCK, M.; et al. Building simulating as an assisting tool in designing an energy efficient: a case study. Integrate Environmental Solution Limited. West of Scotland Science Park, Glasgow, 2009, G20 OSP, U.K

PEDRINI, A. Integration of low energy strategies to the early stages of design process of office buildings in warm climate. Tese (Doutorado em Arquitetura) - Department of Architecture, The University of Queensland, Queensland - Australia, 2003.

PEDRINI, A., GLÊNIO, L.F.L., PAOLO, A.de O., SILENO, C.T. Análise comparativa da eficiência energética de envoltórias segundo o regulamento de etiquetagem de edifícios. In: ENCONTRO DA TECNOLOGIA DO AMBIENTE CONSTRUÍDO, 2010, Canela. Anais... Canela: ENTAC, 2010.

PACHECO, G.U., OLIVEIRA, P.A., DRUMOND, A.R., HAZBOUN, V., MARTINS, M. R., PEDRINI, A. $A$ influência dos ângulos de sombreamento no resultado do indicador de consumo da envoltória através do método prescritivo do RTQ-C. In: XIV ENCONTRO DA TECNOLOGIA DO AMBIENTE CONSTRUÍDO, Juiz de Fora,2012. Anais... Juiz de Fora: ENTAC 2012.

RIBEIRO, L. P. Conforto Térmico e a Prática do Projeto de Edificações: recomendações para Ribeirão Preto. 2008. 213p.Dissertação (Arquitetura e Urbanismo) Instituto de Arquitetura e Urbanismo. Universidade de São Paulo, São Carlos, 2008.

RIBEIRÃO PRETO, Prefeitura Municipal. Secretaria de Planejamento. Estatísticas de Projetos e Obras. 2018, disponível em <http://www.tcinternet.coderp.com.br/xgdpr/servlet/xgd4000m > Acesso Julho, 2018.

RORIZ, M. ZBBR. Zoneamento Bioclimático do Brasil. UFSCar. Universidade Federa de São Carlos, Programa de Pós-Graduação em Construção Civil. Laboratório de Eficiência Energética em Edificações - LABEE. São Carlos, 2004. Disponível pelo site: < http://labeee.ufsc.br/downloads/softwares/zbbr >. Acesso junho de 2019.

RORIZ, M. Classificação de climas do Brasil - Versão 3.0. ASSOCIAÇÃO NACIONAL DE TECNOLOGIA DO AMBIENTE CONSTRUIDO - ANTAC. Grupo de Trabalho sobre Conforto Ambiental e Eficiência Energética de Edificações, São Carlos, 5p.,2014. Disponível em < http://cb3e.ufsc.br/sites/default/files/Roriz_2014.pdf > Acesso: janeiro 2020.

SACHT, H.M. Módulos de fachada para a reabilitação eco-eficiente de edifícios. 2012. Tese (Doutorado em Engenharia Civil). Universidade do Minho, Escola de Engenharia, Braga, Portugal, 2012. 
SANTOS, lara Gomes. Análise de envoltória e do sistema de iluminação a partir do "Regulamento Técnico da Qualidade para Eficiência Energética de Edifícios Comerciais, de Serviços e Públicos" para avaliação de desempenho de sistemas de fachada e de proteções solares. 2009. Dissertação (Mestrado em Ambiente Construído e Patrimônio Sustentável). Escola de Arquitetura e Urbanismo, Universidade Federal de Minas Gerais, Minas Gerais, 2009.

SANTOS, I. G, SOUZA, R.V.G. Proteções Solares no Regulamento brasileiro de Eficiência Energética de Edifícios Comerciais, de Serviços e Públicos. Ambiente Construído, Porto Alegre, v. 12, n. 1, p. 227-241, 2012.

SILVA, A.S.; ALMEIDA, L.S.S.; ANDREASI, W.A. Avaliação da eficiência energética de uma edificação pública de ensino superior de acordo com o RTQ-C e proposta de soluções eficientes tecnicamente. In: XIV ENCONTRO NACIONAL DE TECNOLOGIA DO AMBIENTE CONSTRUÍDO, 2012 - Juiz de Fora. Anais... Juiz de Fora: ENTAC 2012.

SOUZA, et al. Análise da configuração do SAMU utilizando múltiplas alternativas de configuração. Gest. Prod. vol.20 no.2 São Carlos Apr./junho 2013

TRIO RIBEIRÃO PRETO. Disponível em < http://www.trioribeiraopreto.com.br/trio-office/> Acesso, junho 2019.

ZHAI, Y., WANG, Y., HUANG, Y., MENG, X. A multi-objective optimization methodology for window design considering energy consumption, thermal environment and visual performance. Renewable Energy, Elsevier, vol. 134(C), pages 1190-1199, 2018.

ZAMBONI, D.P; Da terra rural à terra urbana: trajetória e características da história recente da produção urbana em Ribeirão Preto/SP. Seminário Internacional Financeirização e Estudos Urbanos: olhares cruzados Europa e América Latina. Anais... IAU/USP, São Carlos /SP, 2018.

WEBPRESCRITIVO. Ferramenta de Avaliação de Eficiência Energética de Edificações Comerciais pelo Método Prescritivo do RTQ-C. Laboratório de Eficiência Energética em Edificações - LABEE. Universidade Federal de Santa Catarina, Florianópolis. Disponível em: < http://labeee.ufsc.br/projetos/s3e/webprescritivo> último acesso, março de 2020. 


\section{ANEXO I}

\section{Forwarded message -.........}

From: Pedro HCost

Date: qua, 12 de der de 2018 as $11: 17$

Prezadas (as), barn dia.

Informamas aos integrantes da CT Eficiência Energética de Edificaçōes que, no dia 23/11/2018, após a reuniāo do GT-Edificaçōes, as equipes do Inmetro, Eletrabras/Procel e CB3E revisaram e atualizaram o cronograma de publicaçāo da INI-C, INI-R e RAC:

\begin{tabular}{|c|c|c|c|c|c|}
\hline & Ahise de NHFCpero & Trintaselo & onscita & Cenactelocta alle & 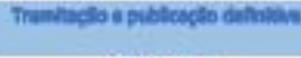 \\
\hline wioo & Canes/2017 & $06,00 / 2018$ & $12 \mathrm{NO3/2018}$ & $15 / 20 / 2018$ & $39005 / 2019$ \\
\hline \multirow[t]{2}{*}{ AM } & $06 / 02 / 2018$ & $12 / 07 / 2015$ & 15/:a/2018 & $3006 \sqrt{2019}$ & $3406 / 2019$ \\
\hline & Mhibe de Eiratren $C^{\circ}$ & Thentlegte & crestato & Onnalingle Bile & 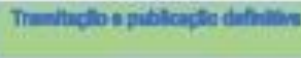 \\
\hline woo & $02 / \mathrm{Ca} / 2017$ & $3901 / 2019$ & $28 / 02 / 2019$ & $30103 / 2019$ & 390042019 \\
\hline \multirow[t]{2}{*}{ FaM } & $30 / 01 / 2019$ & $2400 / 2019$ & $30103 / 2019$ & 30 cos/2019 & $30 / 12 / 2019$ \\
\hline & Mhise de AKC & Tremitasls & ONC(a) Sal & Coneolidecto NMC & 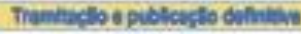 \\
\hline miko & 02pespoin & $30003 / 2019$ & $390</ 2019$ & $30 / 06 / 2019$ & 39vas/2019 \\
\hline MM & $32 / 03 / 2019$ & $30104 / 2019$ & 30106/2019 & $30 / 06 / 2019$ & $30 / 10 / 2019$ \\
\hline
\end{tabular}

LEGENDA:

Tramiteçlo: tramitação interna no Inmetro (chefias, diretarias, procuradoria federal e gabinete)

CP: cansulta pública

IMHC: instruçīo narmativa inmetro-edificaçōes comerciais, de serviço e públicas (antigo RTQ-C)

IN1-R: instruçăo narmativa Inmetro-edificaçōes residenciais (antigo RTO-RI)

RAC: requisitos de avaliação da conformidade

Informamas ainda:

1) Referente à consulta püblica da INif-C, registramos um total de 667 contrïuiçổes, provenientes de 20 propanentes:

- Academia (ersino/pesquisa/especialistas) -205 cantribuiçōes

- Indústria (entidades/fabricantes) - 68 cantribuç̧̄es

- Consultoria (empressa/profissionais) -227 contribuiçōes

- Organismos de inspeçâo-166 cantribuiçīes

- Outros -1 contribuiçãa

2) Nesse momento, estamos analisando e consolidando as contribuiç̄̄es da consulta pública da INI-C.

3) Paralelamente, também estamos revisando e finaluzando o documento do RAC e da INI-R para sua publicaçāo em consulta pública.

Estamos à dósposiç̄ōo para quaisquer dủvidas.

Atenciosamente,

\section{Pedro Henrique Pereire Costa}

Instituto Nocional de Metralogia, Qualidade e Tecnologia (Inmetro)

Diretoria de Avaliaçīo da Conformidade (Deonf)

Divisāo Qualidade Regulatória (Diqre) 


\section{ANEXO II}

Secretaria do Planejamento - Relação dos Projetos Aprovados de 2010 a 2018 - Edifícios Altos e Baixos.

Fonte - Prefeitura de Ribeirão Preto - Secretaria do Planejamento

Disponível em :<https://www.ribeiraopreto.sp.gov.br/splan/daaprojetos/estatisticas/i28indano.php>. Acesso: em novembro de 2018

\section{Edifícios Altos e Baixos - 2010}

\begin{tabular}{|c|c|c|}
\hline $\begin{array}{l}\text { 1/2/2010 } \\
\text { 2007/041718 } \\
\text { AV CEL FERNANDO FERREIRA LEITE, } 1540 \\
\text { Construção Comercial Vertical - Ed.Alto } \\
\text { CV3 } \\
27308,80 \\
\text { JOSE EDUARDO SALATA ORSI } \\
605016649 \\
1845387\end{array}$ & $\begin{array}{l}\text { 7/4/2010 } \\
\text { 2010/009079 } \\
\text { AV NORMA VALERIO CORREA, } 1200 \\
\text { Construção Comercial Vertical - } \\
\text { Ed.Baixo CV2 } \\
\text { 9621,12 EDUARDO CARLOS RODRIGUES } \\
\text { NOGUEIRA } \\
600867226 \\
567670\end{array}$ & $\begin{array}{l}\text { 16/4/2010 } \\
\text { 2009/052401 } \\
\text { AV PTE VARGAS, } 950 \\
\text { Construção Comercial Vertical - } \\
\text { Ed.Alto } \\
\text { CV3 } \\
40611,74 \\
\text { SERGIO ROBERTO JULIO PITTA } \\
601340350 \\
6118\end{array}$ \\
\hline $\begin{array}{l}\text { 9/4/2010 } \\
\text { 2008/029389 } \\
\text { RUA THOMAZ NOGUEIRA GAIA, } 750 \\
\text { Construção Mista Vertical - Ed.Alto MV3 } \\
\text { 9460,15 } \\
\text { JOSE EDUARDO SALATA ORSI } \\
605016649 \\
80554953\end{array}$ & $\begin{array}{l}\text { 29/4/2010 } \\
\text { 2008/029389 } \\
\text { AV PTE VARGAS, } 1265 \\
\text { Construção Mista Vertical - Ed.Alto MV3 } \\
\text { 43693,82 } \\
\text { JOSE EDUARDO SALATA ORSI } \\
605016649 \\
8055\end{array}$ & $\begin{array}{l}\text { 7/5/2010 } \\
\text { 2010/004807 } \\
\text { RUA MARCOS MARKARIAN, } 485 \\
\text { Construção Comercial Vertical - } \\
\text { Ed.Baixo CV2 } \\
\text { 557,46 BOTELHO E BORGES ENG. } \\
\text { CONSTR. } \\
1087725 \\
16996\end{array}$ \\
\hline $\begin{array}{l}\text { 8/6/2010 } \\
\text { 2010/006476 } \\
\text { AV LUIZ EDUARDO TOLEDO PRADO, } 1900 \\
\text { Construção Comercial Vertical - Ed.Alto } \\
\text { CV3 } \\
4037,91 \\
\text { FERNANDO FERRUCIO RIVABEN } \\
601006385 \\
364689\end{array}$ & $\begin{array}{l}\text { 7/6/2010 } \\
\text { 2009/014844 } \\
\text { RUA BELA VISTA, } 974 \\
\text { Construção Comercial Vertical - } \\
\text { Ed.Baixo CV2 } \\
\text { 904,70 } \\
\text { SERGIO BRANQUINHO } \\
\text { 5060238031 } \\
251941\end{array}$ & $\begin{array}{l}\text { 12/7/2010 } \\
\text { 2010/020879 } \\
\text { AV PTE VARGAS, } 1617 \\
\text { Construção Comercial Vertical - } \\
\text { Ed.Baixo CV2 } \\
27392,62 \\
\text { MARIO JOSE DA SILVA } \\
600855530 \\
1056874\end{array}$ \\
\hline $\begin{array}{l}\text { 19/7/2010 } \\
\text { 2010/012176 } \\
\text { AV PTE VARGAS, } 639 \\
\text { Ampliação Comercial Vertical - } \\
\text { Ed.Baixo CV2 } \\
\text { 334,02 } \\
\text { WILSON ROBERTO BALDIN } \\
600792252\end{array}$ & $\begin{array}{l}\text { 20/7/2010 } \\
\text { 2010/031881 } \\
\text { AV PTE VARGAS, } 2121 \\
\text { Construção Comercial Vertical - } \\
\text { Ed.Alto } \\
\text { CV3 } \\
\text { 30495,04 PEREIRA ALVIM } \\
\text { INCORPORADORA E } \\
\text { CONSTRUTORA LTDA } \\
\text { 1083362 }\end{array}$ & $\begin{array}{l}\text { 26/7/2010 } \\
\text { 2010/014262 } \\
\text { AV BRAZ OLAIA ACOSTA, } 1880 \\
\text { Construção Comercial Vertical - Ed.Alto } \\
\text { CV3 } \\
\text { 209,22 } \\
\text { LUCIANO BALDO CARVALHO } \\
5060897426 \\
777546 \\
\text { 26/7/2010 }\end{array}$ \\
\hline $\begin{array}{l}\text { 26/7/2010 } \\
\text { 2010/017117 } \\
\text { ET MUNICIPAL (ROYAL PARK), 2700 } \\
\text { Construção Comercial Vertical - Ed.Alto } \\
\text { CV3 } \\
27834,11 \\
\text { CHEN SHIH PIN } \\
5062620933 \\
380506\end{array}$ & $\begin{array}{l}\text { 26/7/2010 } \\
\text { 2010/021943 } \\
\text { RUA JOAO ARCADEPANI FILHO, } 138 \\
\text { Transformação Comercial Vertical - } \\
\text { Ed.Baixo CV2 } \\
\text { 145,87 CRISTIANE SANTOS SILVA } \\
\text { ARAUJO } \\
\text { 5061400593 } \\
1201198\end{array}$ & \\
\hline $\begin{array}{l}\text { 2/8/2010 } \\
\text { 2009/046934 } \\
\text { AV PTE VARGAS, } 1515 \\
\text { Ampliação Comercial Vertical - } \\
\text { Ed.Baixo CV2 } \\
935,74 \\
\text { JOSE VICENTE ELIAS AMENDOLA } \\
605016223 \\
1197208\end{array}$ & $\begin{array}{l}\text { 13/8/2010 } \\
\text { 2010/012399 } \\
\text { AV BRAZ OLAIA ACOSTA, } 705 \\
\text { Construção Comercial Vertical - } \\
\text { Ed.Baixo CV2 } \\
\text { 39161,60 } \\
\text { JOSE EDUARDO SALATA ORSI } \\
605016649 \\
6\end{array}$ & $\begin{array}{l}\text { 0/8/2010 } \\
\text { 2010/028110 } \\
\text { AV MARIA DE JESUS CONDEIXA, } 600 \\
\text { Construção Comercial Vertical - } \\
\text { Ed.Baixo CV2 } \\
29921,04 \\
\text { NAO CONSTA PROFISSIONAL } \\
6527 \\
605055669\end{array}$ \\
\hline $1 / 8 / 2010$ & $31 / 8 / 2010$ & $31 / 8 / 2010$ \\
\hline
\end{tabular}




\begin{tabular}{|c|c|c|}
\hline $\begin{array}{l}\text { 2009/018057 } \\
\text { RUA ODILON ARCENCIO, } 250 \\
\text { Construção Comercial Vertical - } \\
\text { Ed.Baixo CV2 } \\
301,05 \text { AD ARQUITETURA E DESIGN } \\
\text { LTDA } \\
62843\end{array}$ & $\begin{array}{l}\text { 2010/026959 } \\
\text { AV INDEPENDENCIA, } 3757 \\
\text { Construção Comercial Vertical - } \\
\text { Ed.Baixo CV2 } \\
\text { 177,50 ANTONIO CARLOS DE OLIVEIRA } \\
\text { JR } \\
6850468\end{array}$ & $\begin{array}{l}\text { 2010/026959 } \\
\text { AV INDEPENDENCIA, } 3761 \\
\text { Construção Comercial Vertical - } \\
\text { Ed.Baixo CV2 } \\
177,50 \text { ANTONIO CARLOS DE OLIVEIRA } \\
\text { JR } \\
685046851 \\
1423852\end{array}$ \\
\hline $\begin{array}{l}\text { 27/9/2010 } \\
\text { 2010/026961 } \\
\text { RUA TRIUNFO, } 1358 \\
\text { Construção Comercial Vertical - } \\
\text { Ed.Alto } \\
\text { CV3 } \\
121,83 \text { ANTONIO CARLOS RIBEIRO DA } \\
\text { SILVA } \\
600810124\end{array}$ & $\begin{array}{l}\text { 27/9/2010 } \\
\text { 2010/026961 } \\
\text { RUA MILTON JOSE ROBUSTI, 55 } \\
\text { Construção Comercial Vertical - Ed.Alto } \\
\text { CV3 } \\
\text { 121,83 ANTONIO CARLOS RIBEIRO DA } \\
\text { SILVA } \\
\text { 600810124 }\end{array}$ & $\begin{array}{l}\text { 27/9/2010 } \\
\text { 2010/026961 } \\
\text { RUA MILTON JOSE ROBUSTI, } 75 \\
\text { Construção Comercial Vertical - Ed.Alto } \\
\text { CV3 } \\
\text { 17680,32 ANTONIO CARLOS RIBEIRO DA } \\
\text { SILVA } \\
600810124 \\
14694\end{array}$ \\
\hline $\begin{array}{l}\text { 1/10/2010 } \\
2010 / 030650 \\
\text { Construção Industrial Vertical } \\
\text { Ed.Baixo IV2 } \\
\text { 3228,44 EDUARDO CARLOS RODRIGUES } \\
\text { NOGUEIRA } \\
\text { 600867226 }\end{array}$ & $\begin{array}{l}\text { 5/10/2010 } \\
\text { 2010/040941 } \\
\text { Construção Comercial Vertical } \\
\text { - Ed.Alto } \\
\text { CV3 } \\
8620,97 \text { CARLOS AGUINALDO DA SILVA } \\
\text { TROCA } \\
600925664 \\
1797489\end{array}$ & $\begin{array}{l}\text { 18/10/2010 } \\
\text { 2009/010820 } \\
\text { Construção Comercial Vertical } \\
\text { - } \\
\text { Ed.Baixo CV2 } \\
\text { 749,75 PAULO ROBERTO GARRIDO } \\
\text { ZANIN } \\
600740733\end{array}$ \\
\hline $\begin{array}{l}\text { 4/11/2010 } \\
\text { 2010/023084 } \\
\text { RUA JOSE BIANCHI, } 555 \\
\text { Construção Comercial Vertical - } \\
\text { Ed.Alto } \\
\text { CV3 } \\
\text { 32584,49 PAULO DE TARSO GARCIA } \\
\text { JUNQUEIRA } \\
\text { 600483804 } \\
76418\end{array}$ & $\begin{array}{l}4 / 11 / 2010 \\
\text { 2010/051191 } \\
\text { AV MARIA DE JESUS CONDEIXA, } 600 \\
\text { Construção Comercial Vertical - Ed.Alto } \\
\text { CV3 } \\
\text { 29921,04 } \\
\text { NAO CONSTA PRO }\end{array}$ & $\begin{array}{l}\text { 5/11/2010 } \\
\text { 2010/031246 } \\
\text { VIA MAESTRO TOM JOBIM, } 2450 \\
\text { Construção Comercial Vertical - } \\
\text { Ed.Baixo CV2 } \\
\text { 5517,25 MARCIO EUGENIO MONTEIRO DE } \\
\text { LA CORTE } \\
601723962\end{array}$ \\
\hline $\begin{array}{l}\text { 10/11/2010 } \\
\text { 2010/037696 } \\
\text { RUA JOAQUIM ANTONIO NASCIMENTO, } 136 \\
\text { Construção Comercial Vertical - Ed.Alto } \\
\text { CV3 } \\
\text { 6334,07 } \\
\text { CONSTRUTORA PAGANO LTDA } \\
100970 \\
1628450\end{array}$ & $\begin{array}{l}\text { 16/11/2010 } \\
\text { 2010/010848 } \\
\text { AV COSTABILE ROMANO, } 3230 \\
\text { Construção Comercial Vertical - } \\
\text { Ed.Baixo CV2 } \\
\text { 630,74 } \\
\text { LEONARDO CURVAL MASSARO } \\
\text { 5061741554 }\end{array}$ & $\begin{array}{l}\text { 17/11/2010 } \\
\text { 2008/036532 } \\
\text { ROD JOSE FREGONESI, } 100 \\
\text { Construção Comercial Vertical } \\
\text { - Ed.Alto } \\
\text { CV3 } \\
\text { 33240,24 PAULO DE TARSO GARCIA } \\
\text { JUNQUEIRA } \\
600483804 \\
80640632\end{array}$ \\
\hline $\begin{array}{l}\text { 24/11/2010 } \\
\text { 2010/030809 } \\
\text { AV WLADIMIR MEIRELLES FERREIRA, } 1776 \\
\text { Construção Comercial Vertical - } \\
\text { Ed.Baixo CV2 } \\
\text { 1416,75 } \\
\text { SYLVIO DE SOUZA NOGUEIRA }\end{array}$ & $\begin{array}{l}6 / 12 / 2010 \\
2010 / 021884 \\
\text { RUA JOSE ROBERTO VITTORAZZI, } 80 \\
\text { Construção Comercial Vertical - } \\
\text { Ed.Baixo CV2 } \\
1113,65 \\
\text { DANIEL GENTILE BITONDI } \\
600638498 \\
1201901\end{array}$ & $\begin{array}{l}\text { 7/12/2010 } \\
\text { 2009/032379 } \\
\text { AV ANHANGUERA, } 484 \\
\text { Construção Comercial Vertical - } \\
\text { Ed.Baixo CV2 } \\
249,88 \\
\text { PAULO POLESEL } \\
39813\end{array}$ \\
\hline $\begin{array}{l}\text { 17/12/2010 } \\
\text { 2010/058299 } \\
\text { VIA MAESTRO TOM JOBIM, } 2450 \\
\text { Construção Comercial Vertical - } \\
\text { Ed.Baixo CV2 } \\
\text { 5517,25 MARCIO EUGENIO MONTEIRO DE } \\
\text { LA CORTE } \\
601723962\end{array}$ & $\begin{array}{l}\text { 20/12/2010 } \\
\text { 2007/039711 } \\
\text { AV MAURILIO BIAGI, } 800 \\
\text { Construção Comercial Vertical } \\
\text { - Ed.Alto } \\
\text { CV3 } \\
\text { 35109,69 } \\
\text { COPEMA ENG.CONST.LTDA } \\
\text { 326894 }\end{array}$ & $\begin{array}{l}\text { 28/12/2010 } \\
\text { 2010/025668 } \\
\text { RUA SEVERIANO AMARO DOS SANTOS, } 475 \\
\text { Construção Comercial Vertical - } \\
\text { Ed.Baixo CV2 } \\
288,16 \\
\text { CONSTRUTORA RIMO } 7 \text { LTDA } \\
655662 \\
124386\end{array}$ \\
\hline
\end{tabular}

\section{Edifícios Altos e Baixos - 2011 - Relação dos Projetos Aprovados no Ano}

\begin{tabular}{|l|l|l|}
\hline $13 / 1 / 2011$ & $24 / 2 / 2011$ & $9 / 2 / 2011$ \\
2010/041051 & 2010/048819 & $2009 / 047357$ \\
AV PORTUGAL, 1675 & RUA ALICE ALEM SAADI, 774 & AV PIO XII, 1170 \\
Ampliação Comercial Vertical - & Construção Comercial Vertical - & Construção Institucional Vertica \\
Ed.Baixo CV2 & Ed.Baixo CV2 & InV \\
12963,09 & 425,79 MARCIA T. CHICONELLI C. & RONALDO JOSE DA SILVA \\
PAULO ROBERTO MACHADO & FERREIRA & 5060129159 \\
99573 & 601209840 & 1136844 \\
1768955 & 1993488 & $4 / 5 / 2011$ \\
\hline $20 / 4 / 2011$ & & $2011 / 013836$ \\
\hline $2010 / 053414$ & $4 / 5 / 2011$ & \\
\hline
\end{tabular}




\begin{tabular}{|c|c|c|}
\hline $\begin{array}{l}\text { AV BRAZ OLAIA ACOSTA, } 1920 \\
\text { Construção Comercial Vertical - } \\
\text { Ed.Alto } \\
\text { CV3 } \\
3267,99 \\
\text { SERGIO PACHECO ARAUJO } \\
400352710 \\
2095985\end{array}$ & $\begin{array}{l}\text { RUA GALILEU GALILEI, } 1800 \\
\text { Construção Comercial Vertical - } \\
\text { Ed.Alto } \\
\text { CV3 } \\
7246,25 \text { PAULO DE TARSO GARCIA } \\
\text { JUNQUEIRA } \\
\text { 600483804 }\end{array}$ & $\begin{array}{l}\text { RUA GALILEU GALILEI, } 1810 \\
\text { Construção Comercial Vertical - } \\
\text { Ed.Alto } \\
\text { CV3 } \\
555,76 \text { PAULO DE TARSO GARCIA } \\
\text { JUNQUEIRA } \\
600483804 \\
58579\end{array}$ \\
\hline $\begin{array}{l}\text { 16/6/2011 } \\
\text { 2009/060382 } \\
\text { AV JERONIMO GONCALVES, } 640 \\
\text { Construção Comercial Vertical - } \\
\text { Ed.Baixo CV2 } \\
\text { 15721,60 } \\
\text { URBANO MARTINS DO VALLE } \\
\text { 5060573804 }\end{array}$ & $\begin{array}{l}\text { 17/6/2011 } \\
\text { 2010/055225 } \\
\text { RUA ALTINO ARANTES, } 503 \\
\text { Construção Comercial Vertical - } \\
\text { Ed.Baixo CV2 } \\
660,00 \\
\text { LUIZ ANTONIO CABRAL JUNIOR } \\
\text { 5062625335 } \\
2131460\end{array}$ & $\begin{array}{l}\text { 28/6/2011 } \\
\text { 2008/029506 } \\
\text { RUA ERMELINDA CORRADO, } 72 \\
\text { Construção Comercial Vertical - } \\
\text { Ed.Baixo CV2 } \\
\text { 746,84 } \\
\text { FERNANDO ALVES FONTES JR } \\
5061314337 \\
531166\end{array}$ \\
\hline $\begin{array}{l}\text { 28/6/2011 } \\
\text { 2010/013164 } \\
\text { AV CARLOS CONSONI, } 170 \\
\text { Construção Comercial Vertical - } \\
\text { Ed.Baixo CV2 } \\
\text { 422,80 } \\
\text { MARCAL FARNOCHI } \\
\text { 5061397682 }\end{array}$ & $\begin{array}{l}\text { 28/6/2011 } \\
\text { 2010/013164 } \\
\text { AV CARLOS CONSONI, } 180 \\
\text { Construção Comercial Vertical - } \\
\text { Ed.Baixo CV2 } \\
\text { 1134,82 } \\
\text { MARCAL FARNOCHI } \\
\text { 5061397682 }\end{array}$ & $\begin{array}{l}\text { 30/6/2011 } \\
\text { 2009/028482 } \\
\text { VIA ANHANGUERA, } 0 \\
\text { Construção Comercial Vertical - } \\
\text { Ed.Baixo CV2 } \\
85261,97 \\
\text { NAO CONSTA PROFISSIONAL } \\
6527\end{array}$ \\
\hline $\begin{array}{l}\text { 1/7/2011 } \\
\text { 2011/024795 } \\
\text { AV PFO JOAO FIUSA, } 2006 \\
\text { Construção Comercial Vertical - } \\
\text { Ed.Baixo CV2 } \\
\text { 345,30 } \\
\text { MARIA ROSA LOPES FERREIRA } \\
\text { 5061314590 }\end{array}$ & $\begin{array}{l}\text { 1/7/2011 } \\
\text { 2011/024795 } \\
\text { AV PFO JOAO FIUSA, } 2010 \\
\text { Construção Comercial Vertical - } \\
\text { Ed.Baixo CV2 } \\
\text { 345,30 } \\
\text { MARIA ROSA LOPES FERREIRA } \\
\text { 5061314590 }\end{array}$ & $\begin{array}{l}\text { 26/7/2011 } \\
\text { 2011/028389 } \\
\text { AV COSTABILE ROMANO, } 3248 \\
\text { Construção Comercial Vertical - } \\
\text { Ed.Baixo CV2 } \\
647,26 \text { SILVIO MARCIO DE PAULA } \\
\text { JUNIOR } \\
5061861744 \\
56796\end{array}$ \\
\hline $\begin{array}{l}\text { 19/8/2011 } \\
\text { 2010/058815 } \\
\text { RUA MARCOS MARKARIAN, } 595 \\
\text { Construção Comercial Vertical - } \\
\text { Ed.Baixo CV2 } \\
772,44 \\
\text { PAULO POLESEL } \\
\text { 5061399134 } \\
2217264\end{array}$ & $\begin{array}{l}\text { 22/8/2011 } \\
2011 / 010232 \\
\text { AV PFO JOAO FIUSA, } 1445 \\
\text { Construção Comercial Vertical - } \\
\text { Ed.Baixo CV2 } \\
\text { 462,77 } \\
\text { LUCIANO BALDO CARVALHO } \\
\text { 5060897426 } \\
1860969\end{array}$ & $\begin{array}{l}\text { 22/8/2011 } \\
2011 / 010232 \\
\text { AV PFO JOAO FIUSA, } 1449 \\
\text { Construção Comercial Vertical - } \\
\text { Ed.Baixo CV2 } \\
\text { 398,30 } \\
\text { LUCIANO BALDO CARVALHO } \\
\text { 5060897426 }\end{array}$ \\
\hline $\begin{array}{l}\text { 24/8/2011 } \\
\text { 2011/016507 } \\
\text { RUA BENEDICTA RODRIGUES DOMINGO } \\
\text { S, } \\
614 \\
\text { Construção Comercial Vertical - } \\
\text { Ed.Baixo CV2 } \\
\text { 536,15 MARIA HELENA RIUL } \\
\text { NUNCIATELLI } \\
\text { 5060896915 } \\
270543\end{array}$ & $\begin{array}{l}\text { 20/9/2011 } \\
\text { 2011/028389 } \\
\text { AV COSTABILE ROMANO, } 3248 \\
\text { Construção Comercial Vertical - } \\
\text { Ed.Baixo CV2 } \\
647,89 \text { SILVIO MARCIO DE PAULA } \\
\text { JUNIOR } \\
5061861744 \\
5679\end{array}$ & $\begin{array}{l}\text { 2/9/2011 } \\
\text { 2010/051235 } \\
\text { RUA LUIZ BARIZON, } 101 \\
\text { Construção Comercial Vertical - } \\
\text { Ed.Baixo CV2 } \\
2045,49 \\
\text { JOSE VICENTE ELIAS AMENDOLA } \\
605016223 \\
2015994\end{array}$ \\
\hline $\begin{array}{l}\text { 27/9/2011 } \\
\text { 2011/036402 } \\
\text { RUA VSC RIO BRANCO DO, } 1151 \\
\text { Construção Comercial Vertical - } \\
\text { Ed.Baixo CV2 } \\
\text { 1848,21 ANTONIO CARLOS BOMFIM } \\
\text { MATTIOLI } \\
601795232 \\
756057\end{array}$ & $\begin{array}{l}\text { 6/10/2011 } \\
\text { 2011/046185 } \\
\text { AV LUIZ EDUARDO TOLEDO PRADO, } 800 \\
\text { Construção Comercial Vertical - Ed.Alto } \\
\text { CV3 } \\
18024,28 \\
\text { ROBERTO CANDUSSO } \\
600694318 \\
11000748\end{array}$ & $\begin{array}{l}\text { 6/10/2011 } \\
\text { 2011/046185 } \\
\text { AV LUIZ EDUARDO TOLEDO PRADO, } 870 \\
\text { Construção Comercial Vertical - Ed.Alto } \\
\text { CV3 } \\
17566,03 \\
\text { ROBERTO CANDUSSO } \\
600694318 \\
11000748\end{array}$ \\
\hline $\begin{array}{l}\text { 6/10/2011 } \\
\text { 2011/046185 } \\
\text { AV LUIZ EDUARDO TOLEDO PRADO, } 900 \\
\text { Construção Comercial Vertical - Ed.Alto } \\
\text { CV3 } \\
\text { 107963,13 } \\
\text { ROBERTO CANDUSSO } \\
600694318 \\
11000748\end{array}$ & $\begin{array}{l}\text { 18/10/2011 } \\
\text { 2011/034119 } \\
\text { AV PTE VARGAS, } 1375 \\
\text { Construção Comercial Vertical } \\
\text { - Ed.Alto } \\
\text { CV3 } \\
\text { 48312,11 FERNANDO FERRUCIO } \\
\text { RIVABEN } \\
601006385 \\
110646025\end{array}$ & $\begin{array}{l}\text { 18/10/2011 } \\
2011 / 038914 \\
\text { AV HERACLITO FONTOURA SOBRAL P } \\
\text { INTO, } \\
31 \\
\text { Construção Comercial Vertical - Ed.Alto } \\
\text { CV3 } \\
6102,50 \\
\text { COPEMA ENG.CONST.LTDA } \\
326894 \\
730517\end{array}$ \\
\hline $\begin{array}{l}18 / 10 / 2011 \\
2011 / 038914\end{array}$ & $\begin{array}{l}18 / 10 / 2011 \\
2011 / 038914\end{array}$ & $\begin{array}{l}0 / 11 / 2011 \\
2011 / 039918\end{array}$ \\
\hline
\end{tabular}




\begin{tabular}{|c|c|c|}
\hline $\begin{array}{l}\text { AV HERACLITO FONTOURA SOBRAL P } \\
\text { INTO, } \\
41 \\
\text { Construção Comercial Vertical - Ed.Alto } \\
\text { CV3 } \\
672,13 \\
\text { COPEMA ENG.CONST.LTDA } \\
326894 \\
730517\end{array}$ & $\begin{array}{l}\text { AV HERACLITO FONTOURA SOBRAL P } \\
\text { INTO, } \\
91 \\
\text { Construção Comercial Vertical - Ed.Alto } \\
\text { CV3 } \\
801,96 \\
\text { COPEMA ENG.CONST.LTDA } \\
326894 \\
730517\end{array}$ & $\begin{array}{l}\text { AV PFO JOAO FIUSA, } 1635 \\
\text { Construção Comercial Vertical } \\
\text { - Ed.Alto } \\
\text { CV3 } \\
26618,68 \\
\text { LUIZ FERNANDO COZAC } \\
601817283 \\
111290012\end{array}$ \\
\hline $\begin{array}{l}\text { 7/11/2011 } \\
2011 / 038228 \\
\text { RUA MARCELLO SARTI, 99 } \\
\text { Construção Comercial Vertical - } \\
\text { Ed.Baixo CV2 } \\
6929,45 \text { MARCIO EUGENIO MONTEIRO } \\
\text { DE } \\
\text { LA CORTE } \\
601723962 \\
1841007\end{array}$ & $\begin{array}{l}\text { 3/12/2011 } \\
2011 / 046185 \\
\text { AV LUIZ EDUARDO TOLEDO PRADO, } \\
800 \\
\text { Construção Comercial Vertical - Ed.Alto } \\
\text { CV3 } \\
18024,28 \\
\text { ROBERTO CANDUSSO } \\
600694318 \\
11000748\end{array}$ & $\begin{array}{l}\text { 13/12/2011 } \\
2011 / 046185 \\
\text { AV LUIZ EDUARDO TOLEDO PRADO, } \\
870 \\
\text { Construção Comercial Vertical - Ed.Alto } \\
\text { CV3 } \\
\text { 17560,01 } \\
\text { ROBERTO CANDUSSO } \\
600694318 \\
11000748\end{array}$ \\
\hline $\begin{array}{l}\text { 22/12/2011 } \\
\text { 2009/054683 } \\
\text { RUA SALDANHA MARINHO, } 980 \\
\text { Construção Comercial Vertical - } \\
\text { Ed.Baixo CV2 } \\
6873,79 \\
\text { CARLOS PEREIRA COUTINHO } \\
1545\end{array}$ & $\begin{array}{l}\text { 22/12/2011 } \\
\text { 2010/038355 } \\
\text { RUA MARCOS MARKARIAN, } 355 \\
\text { Construção Comercial Vertical - } \\
\text { Ed.Baixo CV2 } \\
\text { 1101,68 } \\
\text { SEBASTIAO PASSAGEM FILHO } \\
601221380 \\
839376\end{array}$ & $\begin{array}{l}\text { 29/12/2011 } \\
\text { 2011/050044 } \\
\text { RUA JOSE BORGES DA COSTA, } 785 \\
\text { Construção Comercial Vertical - } \\
\text { Ed.Baixo CV2 } \\
\text { 199,28 } \\
\text { POLVERINI ARQUITETURA } \\
1720685 \\
11320\end{array}$ \\
\hline $\begin{array}{l}\text { 29/12/2011 } \\
\text { 2011/050045 } \\
\text { RUA JOSE BORGES DA COSTA, } 775 \\
\text { Construção Comercial Vertical - } \\
\text { Ed.Baixo CV2 } \\
\text { 212,41 } \\
\text { POLVERINI ARQUITETURA } \\
1720685 \\
1132406\end{array}$ & & \\
\hline
\end{tabular}

\section{Edifícios Altos e Baixos - 2012 - Relação dos Projetos Aprovados no Ano}

\begin{tabular}{|c|c|c|}
\hline $\begin{array}{l}\text { 10/1/2012 } \\
\text { 2011/051160 } \\
\text { RUA CESAR TUPINAMBA ROSELINO, } 433 \\
\text { Construção Comercial Vertical - } \\
\text { Ed.Baixo CV2 } \\
287,40 \\
\text { BOTELHO E BORGES ENG. } \\
\text { CONSTR. } \\
\text { 1087725 } \\
1113457\end{array}$ & $\begin{array}{l}1 / 1 / 2012 \\
2011 / 045440 \\
\text { RUA MATO GROSSO, } 362 \\
\text { Construção Comercial Vertical - } \\
\text { Ed.Baixo CV2 } \\
1223,01 \\
\text { JOAO EVITO SEMPRINI } \\
400216082 \\
1014172\end{array}$ & $\begin{array}{l}31 / 1 / 2012 \\
2011 / 054752 \\
\text { RUA ANTONIO MOISES SAADI, } 800 \\
\text { Construção Comercial Vertical - } \\
\text { Ed.Baixo CV2 } \\
2319,03 \\
\text { WAGNER ANTONIO DE ALMEIDA } \\
5060556686 \\
1318598\end{array}$ \\
\hline $\begin{array}{l}\text { 01/02/2012 } \\
\text { 2011/049680 } \\
\text { VIA ANHANGUERA, 0 Construção } \\
\text { Comercial Vertical - } \\
\text { Ed.Baixo CV2 } \\
72279,76 \text { WILNEY MARCIO BARQUETE } \\
601356299\end{array}$ & $\begin{array}{l}\text { 06/02/2012 } \\
\text { 2011/054231 } \\
\text { AV SUMARE, } 402 \\
\text { Construção Comercial Vertical - } \\
\text { Ed.Baixo CV2 } \\
\text { 1888,94 PAULO HENRIQUE DO VAL } \\
\text { 5061193878 }\end{array}$ & $\begin{array}{l}17 / 02 / 2012 \\
2011 / 038480 \\
\text { AV COSTABILE ROMANO, } 2810 \text { Construção } \\
\text { Comercial Vertical - } \\
\text { Ed.Baixo CV2 } \\
\text { 1300,49 CLAUDIA HELENA MILANI } \\
\text { NOVAES } \\
5060557316 \\
783417\end{array}$ \\
\hline $\begin{array}{l}23 / 02 / 2012 \\
2011 / 050018 \\
\text { AV NOVE DE JULHO, } 1451 \text { Construção } \\
\text { Comercial Vertical - } \\
\text { Ed.Baixo CV2 } \\
1715,76 \text { RODOLFO ROCHA AUGUSTO } \\
601101755 \\
1148140\end{array}$ & $\begin{array}{l}\text { 24/02/2012 } \\
\text { 2011/019555 } \\
\text { AV PFO JOAO FIUSA, } 1780 \text { Construção } \\
\text { Comercial Vertical - } \\
\text { Ed.Baixo CV2 } \\
736,32 \text { EDUARDO GREGGI } \\
5060081735 \\
3393387\end{array}$ & $\begin{array}{l}\text { 8/3/2012 } \\
\text { 2012/003533 } \\
\text { AV SUMARE, } 808 \\
\text { Construção Comercial Vertical - } \\
\text { Ed.Baixo CV2 } \\
\text { 3759,32 } \\
\text { SERGIO LUIZ COELHO } \\
601446042 \\
1662739\end{array}$ \\
\hline $\begin{array}{l}\text { 9/3/2012 } \\
\text { 2010/060748 } \\
\text { AV WLADIMIR MEIRELLES FERREIRA, } \\
1695 \\
\text { Construção Comercial Vertical - } \\
\text { Ed.Baixo CV2 }\end{array}$ & $\begin{array}{l}\text { 9/3/2012 } \\
\text { 2011/045103 } \\
\text { AV CEL FERNANDO FERREIRA LEITE, } \\
1540 \\
\text { Ampliação Comercial Vertical - } \\
\text { Ed.Baixo CV2 }\end{array}$ & $\begin{array}{l}\text { 4/3/2012 } \\
\text { 2011/039254 } \\
\text { AV DRA NADIR AGUIAR, } 1805 \\
\text { Construção Comercial Vertical - } \\
\text { Ed.Baixo CV2 } \\
7481,51\end{array}$ \\
\hline
\end{tabular}




\begin{tabular}{|c|c|c|}
\hline $\begin{array}{l}8904,49 \\
\text { ARNALDO FERRARO PAVAN } \\
601434720 \\
2062909\end{array}$ & $\begin{array}{l}80690,74 \\
\text { JOSE EDUARDO SALATA ORSI } \\
605016649 \\
994735\end{array}$ & $\begin{array}{l}\text { CAIO GRACO H. V. BRAGA } \\
5060096623 \\
1394153\end{array}$ \\
\hline $\begin{array}{l}\text { 14/3/2012 } \\
2011 / 054094 \\
\text { AV PFO JOAO FIUSA, } 1137 \\
\text { Construção Comercial Vertical - } \\
\text { Ed.Baixo CV2 } \\
327,49 \\
\text { CARLOS MAGNO ALVES } \\
601505820 \\
1295627\end{array}$ & $\begin{array}{l}\text { 26/3/2012 } \\
\text { 2011/007884 } \\
\text { RUA AUXILIAR CHACARAS OLHOS } \\
\text { DAGUA, } 105 \\
\text { Construção Comercial Vertical - } \\
\text { Ed.Baixo CV2 } \\
\text { 43258,46 } \\
\text { SERGIO P. A. REIS } \\
\text { 5060393784 } \\
12201100296\end{array}$ & $\begin{array}{l}\text { /4/2012 } \\
2012 / 009272 \\
\text { AV WLADIMIR MEIRELLES FERREIRA, } \\
1660 \\
\text { Construção Comercial Vertical - Ed.Alto } \\
\text { CV3 } \\
20557,47 \\
\text { ANDERSON MICHIELETO } \\
5060555962 \\
176191\end{array}$ \\
\hline $\begin{array}{l}\text { 4/4/2012 } \\
2012 / 009272 \\
\text { AV WLADIMIR MEIRELLES FERREIRA, } \\
1660 \\
\text { Construção Comercial Vertical - Ed.Alto } \\
\text { CV3 } \\
20557,47 \\
\text { ANDERSON MICHIELETO } \\
5060555962 \\
176191\end{array}$ & $\begin{array}{l}\text { 4/6/2012 } \\
\text { 2010/018172 } \\
\text { RUA AMADEU GIACHETTO, } 239 \\
\text { Construção Comercial Vertical - } \\
\text { Ed.Baixo CV2 } \\
\text { 3334,68 } \\
\text { SERGIO BRANQUINHO } \\
\text { 5060238031 } \\
839378\end{array}$ & $\begin{array}{l}\text { 14/6/2012 } \\
\text { 2010/057054 } \\
\text { RUA LUCIANA MARA IGNACIO, } 825 \\
\text { Construção Comercial Vertical - } \\
\text { Ed.Baixo CV2 } \\
\text { 3106,20 } \\
\text { VALTER LUIS SECCO FELIX } \\
601639011 \\
203397\end{array}$ \\
\hline $\begin{array}{l}\text { 02/07/2012 } \\
\text { 2012/018061 } \\
\text { RUA JOSE ROBERTO VITTORAZZI, } 350 \\
\text { Construção Comercial Vertical - } \\
\text { Ed.Baixo CV2 } \\
\text { 3282,07 LUIS ANTONIO BARALDI } \\
400371199 \\
815971\end{array}$ & $\begin{array}{l}\text { 13/07/2012 } \\
\text { 2012/025004 } \\
\text { AV NOVE DE JULHO, } 355 \text { Construção } \\
\text { Comercial Vertical - } \\
\text { Ed.Baixo CV2 } \\
\text { 1953,00 ALEXANDRE AURELIO DE } \\
\text { CASTRO NETTO } \\
5060369652 \\
634242\end{array}$ & $\begin{array}{l}\text { 17/07/2012 } \\
2011 / 055246 \\
\text { RUA MARCOS MARKARIAN, } 595 \\
\text { Construção Comercial Vertical - } \\
\text { Ed.Baixo CV2 } \\
748,37 \text { LUCIANO BALDO CARVALHO } \\
5060897426 \\
2210593\end{array}$ \\
\hline $\begin{array}{l}\text { 18/07/2012 } \\
2011 / 059915 \\
\text { AV DR CELSO CHARURI, } 7500 \text { Construção } \\
\text { Comercial Vertical - } \\
\text { Ed.Baixo CV2 } \\
3723,62 \text { HERMINIO ANGELO BONFIM } \\
\text { MATTIOLI } \\
685047419 \\
1442895\end{array}$ & $\begin{array}{l}\text { 20/07/2012 } \\
\text { 2012/007368 } \\
\text { PCA BONFIM, } 253 \\
\text { Construção Comercial Vertical - } \\
\text { Ed.Baixo CV2 } \\
793,76 \text { RITA MARIA DE MARTIN } \\
685046762 \\
88478\end{array}$ & $\begin{array}{l}31 / 07 / 2012 \\
2012 / 006147 \\
\text { AV ANTONIO DIEDERICHSEN, } 667 \\
\text { Construção Comercial Vertical - } \\
\text { Ed.Baixo CV2 } \\
\text { 288,62 DANIEL GENTILE BITONDI } \\
5061398207 \\
40718\end{array}$ \\
\hline $\begin{array}{l}\text { 7/08/2012 } \\
2012 / 020048 \\
\text { RUA JOSE CURVELO DA SILVEIRA JR, } \\
95 \\
\text { Construção Comercial Vertical - } \\
\text { Ed.Baixo CV2 } \\
1619,40 \text { MARILIA NARDIN BATISTA } \\
1183800 \\
187762\end{array}$ & $\begin{array}{l}21 / 08 / 2012 \\
2011 / 030968 \\
\text { AV PFO JOAO FIUSA, } 2340 \text { Construção } \\
\text { Comercial Vertical - } \\
\text { Ed.Baixo CV2 } \\
\text { 1188,60 RENATA LUIZA FURLAN DE } \\
\text { OLIVEIRA } \\
5062352675 \\
110610827\end{array}$ & $\begin{array}{l}23 / 08 / 2012 \\
2012 / 023714 \\
\text { VIA ANHANGUERA, } 0 \text { Construção Comercial } \\
\text { Vertical - Ed.Alto } \\
\text { CV3 } \\
70857,34 \text { AIRTON FERNANDES PEDREIRA } \\
300036486 \\
309255\end{array}$ \\
\hline $\begin{array}{l}20 / 09 / 2012 \\
2012 / 023572 \\
110641 \\
\text { AV PFO JOAO FIUSA, 2200 } \\
\text { Construção Comercial Vertical - } \\
\text { Ed.Baixo CV2 } \\
697,64 \text { VIVALDO DOS REIS DE MORAES } \\
400168238 \\
453310\end{array}$ & $\begin{array}{l}\text { 26/09/2012 } \\
2011 / 057290 \\
5005 \\
\text { RUA STELIO MACHADO LOUREIRO, } 480 \\
\text { Construção Comercial Vertical - } \\
\text { Ed.Baixo CV2 } \\
506,16 \text { MARCUS COTRIM CUNHA } \\
262080 \\
1153302\end{array}$ & $\begin{array}{l}\text { 03/10/2012 } \\
2012 / 026230 \\
15560 \\
\text { AV MAURILIO BIAGI, } 476 \\
\text { Ampliação Comercial Vertical - } \\
\text { Ed.Baixo CV2 } \\
\text { 3495,98 FRANCISCO LEGNAME MARTINS } \\
\text { 5060301740 }\end{array}$ \\
\hline $\begin{array}{l}31 / 10 / 2012 \\
2011 / 023640 \\
131699 \\
\text { AV CEL FERNANDO FERREIRA LEITE, } \\
1520 \text { Construção Comercial Vertical - } \\
\text { Ed.Baixo CV2 } \\
27308,80 \text { AIRTON FERNANDES PEDREIRA } \\
300036486 \\
8501\end{array}$ & $\begin{array}{l}\text { 01/11/2012 } \\
2011 / 047282 \\
286923 \\
\text { RUA AURELIANO GARCIA DE OLIVEIRA, } \\
372 \text { Construção Comercial Vertical - } \\
\text { Ed.Baixo CV2 } \\
\text { 1140,00 SERGIO PACHECO ARAUJO } \\
\text { 400352710 }\end{array}$ & $\begin{array}{l}06 / 11 / 2012 \\
2010 / 030711 \\
244359 \\
\text { RUA REINALDO SANDRIN, } 1670 \\
\text { Construção Comercial Vertical - } \\
\text { Ed.Baixo CV2 } \\
5366,13 \text { FERNANDO JOSE THOMAZELLA } \\
601539960 \\
546912\end{array}$ \\
\hline $\begin{array}{l}\text { 06/11/2012 } \\
2012 / 034734 \\
16749 \\
\text { AV CALIFORNIA, } 707 \\
\text { Construção Comercial Vertical - } \\
\text { Ed.Baixo CV2 } \\
\text { 395,30 JOSE LUIZ FRANCO MARGATHO } \\
600979220\end{array}$ & $\begin{array}{l}\text { 07/11/2012 } \\
2012 / 000865 \\
18136 \\
\text { AV COSTABILE ROMANO, } 2868 \\
\text { Construção Comercial Vertical - } \\
\text { Ed.Baixo CV2 } \\
603,84 \text { IGOR DE LUCENA MARQUES } \\
\text { ASSE } \\
5061194\end{array}$ & $\begin{array}{l}07 / 11 / 2012 \\
2012 / 047078 \\
131698 \\
\text { AV PTE VARGAS, } 2970 \\
\text { Construção Comercial Vertical - } \\
\text { Ed.Baixo CV2 } \\
59275,00 \text { JOSE DE BARRI NETO } \\
682558288 \\
866135\end{array}$ \\
\hline
\end{tabular}


$09 / 11 / 2012$

$2012 / 043260$

238635

AV CELSO DANIEL, 1625

Construção Comercial Vertical -

Ed.Baixo CV2

1097,44 HENRIQUE VICTORAZZO HALAK 605231636

924714

22/11/2012
$2012 / 035564$
8523
AV ITATIAIA, 390
Construção Comercial Vertical -
Ed.Baixo CV2
1100,40 CONSTRUTORA BRECI LTDA
1084850
712440

8523

1100,40 CONSTRUTORA BRECI LTDA

\section{Edifícios Altos e Baixos - 2013 - Relação de Projetos Aprovadas no Ano}

\begin{tabular}{|c|c|c|}
\hline $\begin{array}{l}27 / 02 / 2013 \\
2012 / 044077 \\
150137 \\
\text { RUA BENEDITA VIEIRA EUGENIO, } 290 \\
\text { Construção Comercial Vertical - } \\
\text { Ed.Baixo CV2 } \\
1083,89 \text { MARCUS COTRIM CUNHA } \\
262080 \\
618325\end{array}$ & $\begin{array}{l}\text { 09/04/2013 } \\
2011 / 056432 \\
266274 \\
\text { RUA } 18 \text { (SITIO SAO BENTO I), } 6391 \\
\text { Construção Comercial Vertical - } \\
\text { Ed.Baixo CV2 } \\
\text { 4845,54 SERGIO LUIZ COELHO } \\
601446042\end{array}$ & $\begin{array}{l}2 / 04 / 2013 \\
2011 / 036444 \\
18598 \\
\text { RUA ALBERTO COSELLI, } 460 \text { Construção } \\
\text { Comercial Vertical - } \\
\text { Ed.Baixo CV2 } \\
464,40 \text { SYLVIO DE SOUZA NOGUEIRA } \\
600666389 \\
571112\end{array}$ \\
\hline $\begin{array}{l}\text { 7/04/2013 } \\
2012 / 048666 \\
150291 \\
\text { AV INDEPENDENCIA, } 3840 \text { Construção } \\
\text { Comercial Vertical - } \\
\text { Ed.Baixo CV2 } \\
13867,58 \text { TULIO DE ARAUJO PAGANO } \\
5061401010 \\
13666683\end{array}$ & $\begin{array}{l}\text { 17/05/2013 } \\
2012 / 058369 \\
84784 \\
\text { AV WLADIMIR MEIRELLES FERREIRA, } 1455 \\
\text { Construção Comercial Vertical - Ed.Alto } \\
\text { CV3 } \\
18990,61 \text { ANDERSON MICHIELETO } \\
5060555962 \\
11532\end{array}$ & $\begin{array}{l}10 / 07 / 2013 \\
2013 / 041022 \\
131698 \\
\text { AV PTE VARGAS, } 2970 \\
\text { Construção Comercial Vertical - } \\
\text { Ed.Baixo CV2 } \\
58859,55 \text { JOSE DE BARRI NETO } \\
682558288 \\
866135\end{array}$ \\
\hline $\begin{array}{l}\text { 12/07/2013 } \\
2012 / 039482 \\
221101 \\
\text { AV BRAZ OLAIA ACOSTA, } 1975 \text { Construção } \\
\text { Comercial Vertical - } \\
\text { Ed.Baixo CV2 } \\
\text { 7210,21 ALEXANDRE AURELIO DE } \\
\text { CASTRO NETTO } \\
5060369652 \\
8505\end{array}$ & $\begin{array}{l}16 / 07 / 2013 \\
2013 / 020648 \\
38140 \\
\text { RUA JOSE PIERRI, } 145 \\
\text { Construção Comercial Vertical - } \\
\text { Ed.Baixo CV2 } \\
336,90 \text { SERGIO PACHECO ARAUJO } \\
400352710 \\
13711\end{array}$ & $\begin{array}{l}16 / 07 / 2013 \\
2013 / 039320 \\
16891 \\
\text { AV CALIFORNIA, } 538 \\
\text { Construção Comercial Vertical - } \\
\text { Ed.Baixo CV2 } \\
\text { 860,56 JOSE LUIZ FRANCO MARGATHO } \\
600979220 \\
529464\end{array}$ \\
\hline $\begin{array}{l}\text { 19/07/2013 } \\
2012 / 036897 \\
227629 \\
\text { RUA PASCHOAL BARDARO, } 1206 \text { Construção } \\
\text { Comercial Vertical - } \\
\text { Ed.Baixo CV2 } \\
\text { 1052,73 PAULO POLESEL } \\
5061399134 \\
484257\end{array}$ & $\begin{array}{l}1 / 08 / 2013 \\
2012 / 053585 \\
215249 \\
\text { RUA SETE DE SETEMBRO (BONFIM), } 320 \\
\text { Construção Comercial Vertical - } \\
\text { Ed.Baixo CV2 } \\
2024,92 \text { PAULO ROBERTO LOCCE JUNIOR } \\
570320 \\
729689\end{array}$ & $\begin{array}{l}\text { 06/08/2013 } \\
2011 / 060605 \\
293091 \\
\text { AV WLADIMIR MEIRELLES FERREIRA, } \\
1465 \text { Construção Comercial Vertical - } \\
\text { Ed.Baixo CV2 } \\
\text { 12537,55 FERNANDO FERRUCIO RIVABEN } \\
155713\end{array}$ \\
\hline $\begin{array}{l}\text { 09/08/2013 } \\
2012 / 058330 \\
254155 \\
\text { RUA DR ELPIDIO DE ALMEIDA CAMPOS, } \\
1150 \\
\text { Construção Industrial Vertical - } \\
\text { Ed.Baixo IV2 } \\
9204,33 \text { TATIANE G. WAGNER GIANNINI } \\
375365 \\
834102\end{array}$ & $\begin{array}{l}2 / 08 / 2013 \\
2013 / 045838 \\
12085 \\
\text { RUA JOSE BORGES DA COSTA, } 775 \\
\text { Construção Comercial Vertical - } \\
\text { Ed.Baixo CV2 } \\
\text { 199,28 POLVERINI ARQUITETURA E } \\
\text { GERENCIAMENTO DE OBRAS } \\
\text { LTDA } \\
502260 \\
1266767\end{array}$ & $\begin{array}{l}20 / 08 / 2013 \\
2013 / 018692 \\
227932 \\
\text { RUA PASCHOAL BARDARO, } 1825 \\
\text { Construção Comercial Vertical - } \\
\text { Ed.Baixo CV2 } \\
930,06 \text { VINICIUS ADELINO DE AFONSECA } \\
5061528417 \\
114589\end{array}$ \\
\hline $\begin{array}{l}23 / 08 / 2013 \\
2009 / 037173 \\
228914 \\
\text { RUA TRIUNFO, } 1369 \\
\text { Construção Comercial Vertical - } \\
\text { Ed.Baixo CV2 } \\
6379,27 \text { MARCOS ROBERTO R. DA SILVA } \\
601160210 \\
747304\end{array}$ & $\begin{array}{l}\text { 6/08/2013 } \\
2013 / 042269 \\
265170 \\
\text { VIA ANHANGUERA, } 317 \\
\text { Construção Comercial Vertical - } \\
\text { Ed.Baixo CV2 } \\
67272,45 \text { AIRTON FERNANDES PEDREIRA } \\
\text { 300036486 }\end{array}$ & $\begin{array}{l}\text { 4/09/2013 } \\
2010 / 020346 \\
38445 \\
\text { RUA JOAO ARCADEPANI FILHO, } 177 \\
\text { Construção Comercial Vertical - } \\
\text { Ed.Baixo CV2 } \\
639,88 \text { THAIS DOS SANTOS LIPARI } \\
5061397739 \\
1164601\end{array}$ \\
\hline $\begin{array}{l}6 / 09 / 2013 \\
2012 / 048940 \\
221179\end{array}$ & $\begin{array}{l}03 / 10 / 2013 \\
2012 / 042365 \\
227665\end{array}$ & $\begin{array}{l}3 / 10 / 2013 \\
2012 / 042634 \\
238837\end{array}$ \\
\hline
\end{tabular}




\begin{tabular}{|c|c|c|}
\hline $\begin{array}{l}\text { AV BRAZ OLAIA ACOSTA, } 1940 \text { Construção } \\
\text { Comercial Vertical - } \\
\text { Ed.Baixo CV2 } \\
1344,82 \text { REINALDO VALENTINI } \\
600875080 \\
1164116\end{array}$ & $\begin{array}{l}\text { RUA PASCHOAL BARDARO, } 1265 \\
\text { Construção Comercial Vertical - } \\
\text { Ed.Baixo CV2 } \\
\text { 1594,62 CBN CALIL OLIVEIRA } \\
\text { CONSTRUTORA LTDA } \\
665808 \\
39446\end{array}$ & $\begin{array}{l}\text { RUA REINALDO SANDRIN, } 1288 \\
\text { Construção Industrial Vertical - } \\
\text { Ed.Baixo IV2 } \\
\text { 2544,94 LEONARDO MARIN } \\
\text { FERNANDEZ } \\
5061591216 \\
22889\end{array}$ \\
\hline $\begin{array}{l}\text { 04/10/2013 } \\
\text { 2013/054212 } \\
255061 \\
\text { AL PAULO REZENDE DE OLIVEIRA, } 355 \\
\text { Construção Comercial Vertical - } \\
\text { Ed.Baixo CV2 } \\
10191,49 \text { JOSE RENATO MAGDALENA } \\
600599782 \\
1709848\end{array}$ & $\begin{array}{l}\text { 08/10/2013 } \\
2013 / 021998 \\
4634 \\
\text { RUA JOSE LEAL, } 1318 \\
\text { Ampliação Comercial Vertical - } \\
\text { Ed.Baixo CV2 } \\
\text { 428,21 ALBERTO HEREDIA QUARTIM } \\
\text { DE } \\
\text { MORAES } \\
\text { 643289 }\end{array}$ & $\begin{array}{l}\text { 10/10/2013 } \\
2012 / 053897 \\
301687 \\
\text { AV HERACLITO FONTOURA SOBRAL } \\
\text { PINTO, } \\
1175 \\
\text { Construção Comercial Vertical - } \\
\text { Ed.Baixo CV2 } \\
\text { 2989,66 MILTON SANTANA MARTINS } \\
5068920417\end{array}$ \\
\hline $\begin{array}{l}\text { /10/2013 } \\
\text { 2012/056121 } \\
241460 \\
\text { RUA THOMAZ NOGUEIRA GAIA, } 2835 \\
\text { Construção Comercial Vertical - } \\
\text { Ed.Baixo CV2 } \\
\text { 640,11 RENATA LUIZA FURLAN DE } \\
\text { OLIVEIRA } \\
471860\end{array}$ & $\begin{array}{l}\text { 0/10/2013 } \\
\text { 2012/058095 } \\
275596 \\
\text { ROD ALEXANDRE BALBO (SP 328), } 0 \\
\text { Construção Comercial Vertical - } \\
\text { Ed.Baixo CV2 } \\
\text { 25507,59 FABIO MARTINS VALENTE } \\
5062323190 \\
1282911\end{array}$ & $\begin{array}{l}\text { 11/10/2013 } \\
2012 / 013864 \\
38194 \\
\text { RUA FRANCISCO PEREIRA LIMA, } 484 \\
\text { Construção Comercial Vertical - } \\
\text { Ed.Baixo CV2 } \\
\text { 989,07 CBN CALIL OLIVEIRA } \\
\text { CONSTRUTORA LTDA } \\
665808 \\
625596\end{array}$ \\
\hline $\begin{array}{l}\text { 23/10/2013 } \\
2011 / 041287 \\
239713 \\
\text { RUA PAULO VELLONI, } 175 \\
\text { Construção Comercial Vertical - } \\
\text { Ed.Baixo CV2 } \\
\text { 1252,65 CONSTRUPAULO } \\
\text { CONSTRUTORA } \\
\text { LTDA } \\
\text { 1084523 } \\
10493104\end{array}$ & $\begin{array}{l}\text { 29/10/2013 } \\
2013 / 058429 \\
271362 \\
\text { AV HERACLITO FONTOURA SOBRAL } \\
\text { PINTO, } \\
31 \\
\text { Construção Comercial Vertical - } \\
\text { Ed.Baixo CV2 } \\
\text { 6102,50 COPEMA ENGENHARIA E } \\
\text { CONSTRUCOES LTDA } \\
\text { 315005 } \\
730517\end{array}$ & $\begin{array}{l}\text { 0/10/2013 } \\
2013 / 045972 \\
206184 \\
\text { ROD JOSE FREGONESI, } 3095 \\
\text { Construção Comercial Vertical - } \\
\text { Ed.Baixo CV2 } \\
1967,94 \text { FABIANO MASSAKI HAYASAKI } \\
618110 \\
1272381\end{array}$ \\
\hline $\begin{array}{l}\text { 5/11/2013 } \\
2013 / 051249 \\
227612 \\
\text { RUA DR BENJAMIM ANDERSON } \\
\text { STAUFFER, } \\
801 \\
\text { Construção Comercial Vertical - } \\
\text { Ed.Baixo CV2 } \\
5371,79 \text { REINALDO VALENTINI } \\
600875080 \\
828693\end{array}$ & $\begin{array}{l}\text { 25/11/2013 } \\
2012 / 042046 \\
18138 \\
\text { AV COSTABILE ROMANO, } 2900 \\
\text { Construção Comercial Vertical - } \\
\text { Ed.Baixo CV2 } \\
\text { 497,13 MARCIA REGINAS MARTINS } \\
\text { OKAMURA } \\
417262 \\
302304\end{array}$ & $\begin{array}{l}\text { 05/12/2013 } \\
\text { 2012/045418 } \\
109568 \\
\text { RUA JORDAO FAVERO, } 615 \text { Construção } \\
\text { Comercial Vertical - } \\
\text { Ed.Baixo CV2 } \\
\text { 445,03 MARIA HELENA RIUL } \\
\text { NUNCIATELLI } \\
\text { 5060896915 } \\
452683\end{array}$ \\
\hline $\begin{array}{l}\text { 10/12/2013 } \\
2012 / 047941 \\
308659 \\
\text { AV DR JOSE CEZARIO M. DA SILVA } \\
\text { FILHO, } \\
150 \\
\text { Construção Comercial Vertical - Ed.Alto } \\
\text { CV3 } \\
28353,38 \text { AIRTON FERNANDES PEDREIRA } \\
300036486 \\
164763\end{array}$ & $\begin{array}{l}\text { 13/12/2013 } \\
2013 / 030104 \\
270903 \\
\text { AV INDEPENDENCIA, } 5000 \text { Construção } \\
\text { Comercial Vertical - } \\
\text { Ed.Baixo CV2 } \\
2755,88 \text { ABADIA DONIZETE REZENDE } \\
5061594159 \\
321997\end{array}$ & $\begin{array}{l}\text { 13/12/2013 } \\
2013 / 060923 \\
36178 \\
\text { RUA GUARUJA, } 251 \\
\text { Construção Comercial Vertical - } \\
\text { Ed.Baixo CV2 } \\
511,82 \text { GISELA GOMES BENINTENDI } \\
\text { MAZER } \\
101117 \\
1723600\end{array}$ \\
\hline $\begin{array}{l}\text { 23/12/2013 } \\
2013 / 047135 \\
5095 \\
\text { AV PFO JOAO FIUSA, } 1754 \\
\text { Construção Comercial Vertical - } \\
\text { Ed.Baixo CV2 } \\
987,38 \text { ORLANDO BARBOSA DE FREITAS } \\
760463 \\
1507757\end{array}$ & & \\
\hline
\end{tabular}




\begin{tabular}{|c|c|c|}
\hline $\begin{array}{l}\text { 25/02/2014 } \\
2013 / 041139 \\
116981 \\
\text { AV AUREA APP BRAGHETTO MACHADO, } \\
220 \\
\text { Construção Comercial Vertical - } \\
\text { Ed.Baixo CV2 } \\
653,36 \text { MARCELO SANCHEZ PANICO } \\
351059 \\
570635\end{array}$ & $\begin{array}{l}\text { 06/03/2014 } \\
2013 / 038235 \\
305588 \\
\text { AV PTE KENNEDY, } 1657 \\
\text { Construção Comercial Vertical - Ed.Alto } \\
\text { CV3 } \\
32335,28 \text { FABIO VILLAS BOAS } \\
5062124267 \\
196176\end{array}$ & $\begin{array}{l}\text { 7/03/2014 } \\
2009 / 054683 \\
232760 \\
\text { RUA SALDANHA MARINHO, } 980 \\
\text { Construção Comercial Vertical - } \\
\text { Ed.Baixo CV2 } \\
6873,79 \text { CARLOS PEREIRA COUTINHO } \\
15450 \\
744464\end{array}$ \\
\hline $\begin{array}{l}\text { 7/03/2014 } \\
2011 / 055594 \\
10529 \\
\text { AV INDEPENDENCIA, } 2950 \text { Construção } \\
\text { Comercial Vertical - } \\
\text { Ed.Baixo CV2 } \\
1092,88 \text { LUCIANO BALDO CARVALHO } \\
5060897426 \\
1226375\end{array}$ & $\begin{array}{l}27 / 03 / 2014 \\
2013 / 044976 \\
12153 \\
\text { RUA CAP ADELMIO NORBERTO DA } \\
\text { SILVA, } \\
785 \\
\text { Construção Comercial Vertical - } \\
\text { Ed.Baixo CV2 } \\
660,63 \text { DANIEL GENTILE BITONDI } \\
327573\end{array}$ & $\begin{array}{l}31 / 03 / 2014 \\
2014 / 007511 \\
230819 \\
\text { AV LEAO XIII, } 1720 \\
\text { Construção Comercial Vertical - } \\
\text { Ed.Baixo CV2 } \\
1759,55 \text { FABIO VILLAS BOAS } \\
5062124267 \\
64454\end{array}$ \\
\hline $\begin{array}{l}\text { 07/04/2014 } \\
2013 / 068940 \\
2450 \\
\text { RUA ALVARES CABRAL, } 930 \\
\text { Construção Comercial Vertical - } \\
\text { Ed.Baixo CV2 } \\
\text { 3629,70 IVO CESAR NICOLETTI } \\
601427479 \\
48588\end{array}$ & $\begin{array}{l}\text { 1/04/2014 } \\
2010 / 013253 \\
314039 \\
\text { AV PORTUGAL, } 1397 \\
\text { Construção Comercial Vertical - } \\
\text { Ed.Baixo CV2 } \\
\text { 5688,47 MARIA LUCIA CHAGAS VALLE } \\
\text { SOUBIHE } \\
601171961 \\
80779747\end{array}$ & $\begin{array}{l}\text { 17/04/2014 } \\
2012 / 030057 \\
221257 \\
\text { RUA PFO FRANCISCO ORLANDO } \\
\text { ALONSO- } \\
\text { DR } 645 \\
\text { Construção Comercial Vertical - Ed.Alto } \\
\text { CV3 } \\
\text { 5045,65 CARLOS GERONIMO PODIX } \\
488628094\end{array}$ \\
\hline $\begin{array}{l}\text { 07/05/2014 } \\
2013 / 066543 \\
228264 \\
\text { AV CARLOS EDUARDO DE G. CONSONI, } \\
1690 \\
\text { Construção Comercial Vertical - } \\
\text { Ed.Baixo CV2 } \\
\text { 199,63 RODOLFO ROCHA AUGUSTO } \\
601191755 \\
1449284\end{array}$ & $\begin{array}{l}\text { 07/05/2014 } \\
2013 / 066543 \\
228264 \\
\text { AV NORMA VALERIO CORREA, } 516 \\
\text { Construção Comercial Vertical - } \\
\text { Ed.Baixo CV2 } \\
308,70 \text { RODOLFO ROCHA AUGUSTO } \\
601191755 \\
1449284\end{array}$ & $\begin{array}{l}\text { 8/06/2014 } \\
\text { 2013/069366 } \\
227697 \\
\text { PCA ALINE PATRICIA REZEN } \\
\text { DE BESERRA, } \\
25 \\
\text { Construção Comercial Vertical - } \\
\text { Ed.Baixo CV2 } \\
\text { 529,80 } \\
\text { REINALDO VALENTINI } \\
\text { 600875080 }\end{array}$ \\
\hline $\begin{array}{l}\text { 23/06/2014 } \\
\text { 2013/069054 } \\
53776 \\
\text { RUA CEL AMERICO BATISTA, } 1713 \\
\text { Ampliação Comercial Vertical - Ed.Alto } \\
\text { CV3 } \\
407,35 \\
\text { PAULO ROBERTO GABARRA } \\
600677319 \\
766259\end{array}$ & $\begin{array}{l}\text { 4/08/2014 } \\
2013 / 071513 \\
18520 \\
\text { AV LEAO XIII, } 650 \\
\text { Construção Comercial Vert } \\
\text { ical - } \\
\text { Ed.Baixo CV2 } \\
1133,24 \text { THELMA LUIZA DE ARAUJO } \\
\text { CARDOSO } \\
701645 \\
1799067\end{array}$ & $\begin{array}{l}\text { 5/08/2014 } \\
2012 / 051040 \\
10343 \\
\text { AV INDEPENDENCIA, } 1009 \\
\text { Construção Comercial Vert } \\
\text { ical - } \\
\text { Ed.Baixo CV2 } \\
1131,54 \\
\text { JORGE DE ALMEIDA } \\
601326065 \\
1164451\end{array}$ \\
\hline $\begin{array}{l}\text { 5/09/2014 } \\
2013 / 047993 \\
239898 \\
\text { AL AMERICO FALASCO, } 530 \\
\text { Construção Comercial Vertical - } \\
\text { Ed.Baixo CV2 } \\
5452,71 \text { RODOLFO BIAGI BECKER } \\
54523 \\
1646200\end{array}$ & $\begin{array}{l}\text { 09/09/2014 } \\
\text { 2006/040139 } \\
34762 \\
\text { RUA ALBUQUERQUE LINS, } 383 \\
\text { Regularização Comercial Vertical - } \\
\text { Ed.Baixo CV2 } \\
1013,46 \text { SILVIA HELENA BALTAZAR } \\
\text { MARTINS } \\
510637 \\
2047557\end{array}$ & $\begin{array}{l}\text { 10/09/2014 } \\
2014 / 000371 \\
205677 \\
\text { AV MAURILIO BIAGI, } 555 \\
\text { Construção Comercial Vertical - } \\
\text { Ed.Baixo CV2 } \\
\text { 8501,50 FERNANDO FERRUCIO } \\
\text { RIVABEN } \\
910678 \\
2672891\end{array}$ \\
\hline $\begin{array}{l}\text { 1/09/2014 } \\
2014 / 018689 \\
16965 \\
\text { AV COSTABILE ROMANO, } 842 \\
\text { Construção Comercial Vertical - } \\
\text { Ed.Baixo CV2 } \\
1401,38 \text { CARLOS EDUARDO LOPES } \\
601353593 \\
141061145\end{array}$ & $\begin{array}{l}\text { 23/09/2014 } \\
2013 / 066544 \\
38933 \\
\text { RUA JOSE ANTONIO ROSAS, } 470 \\
\text { Ampliação Comercial Vertical - } \\
\text { Ed.Baixo CV2 } \\
5584,39 \text { LUCIANO BALDO CARVALHO } \\
276766 \\
1647640\end{array}$ & $\begin{array}{l}\text { 09/12/2014 } \\
\text { 2014/048864 } \\
221034 \\
\text { AV BRAZ OLAIA ACOSTA, } 246 \text { Construção } \\
\text { Comercial Vertical - } \\
\text { Ed.Baixo CVeb } \\
\text { 374,86 DANIEL GENTILE BITONDI } \\
\text { 5061398207 } \\
983838\end{array}$ \\
\hline
\end{tabular}


Edifícios Altos e Baixos - 2015 - Relação de Projetos Aprovados no Ano

\begin{tabular}{|c|c|c|}
\hline $\begin{array}{l}1 / 02 / 2015 \\
2014 / 040262 \\
153950 \\
\text { RUA ADOLFO MANTOVANI, } 232 \\
\text { Construção Comercial Vertical - } \\
\text { Ed.Baixo CVeb } \\
2648,00 \text { SPRINT ENGENHARIA E } \\
\text { COMERCIO LTDA } \\
1086807 \\
123\end{array}$ & $\begin{array}{l}\text { 02/03/2015 } \\
\text { 2012/057994 } \\
315480 \\
\text { AV LUIZ EDUARDO TOLEDO PRADO, } \\
2675 \text { Construção Comercial Vertical - } \\
\text { Ed.Alto } \\
\text { CVea } \\
\text { 9164,64 PAULO ROBERTO MACHADO } \\
600995734 \\
40984621\end{array}$ & $\begin{array}{l}\text { 10/03/2015 } \\
\text { 2014/043596 } \\
327948 \\
\text { RUA CDL ARCOVERDE, } 490 \text { Construção } \\
\text { Comercial Vertical - } \\
\text { Ed.Baixo CVeb } \\
\text { 592,41 FRANCISCO CARLOS } \\
\text { FAGIONATO } \\
\text { 600875196 } \\
2799982\end{array}$ \\
\hline $\begin{array}{l}\text { 13/03/2015 } \\
2014 / 019840 \\
3321 \\
\text { AV NOVE DE JULHO, } 1777 \\
\text { Construção Comercial Vertical - } \\
\text { Ed.Baixo CVeb } \\
849,01 \text { UBIRATAN TADEU JATOBA } \\
600784945 \\
1579254\end{array}$ & $\begin{array}{l}\text { 09/04/2015 } \\
2014 / 022288 \\
72979 \\
\text { AV ABD CONSTANTINO, } 174 \\
\text { Construção Comercial Vert } \\
\text { ical - } \\
\text { Ed.Baixo CVeb } \\
\text { 8469,81 } \\
\text { SILVIO ANTONIO NUCCI } \\
601116399\end{array}$ & $\begin{array}{l}27 / 04 / 2015 \\
2013 / 061804 \\
225200 \\
\text { AV SEN CESAR VERGUEIRO, } 480 \\
\text { Construção Comercial Vertical - } \\
\text { Ed.Baixo CVeb } \\
6413,02 \text { MARCOS MENDES BIASOLI } \\
\text { MAZER } \\
600898408 \\
1369063\end{array}$ \\
\hline $\begin{array}{l}\text { 07/05/2015 } \\
2014 / 008716 \\
220818 \\
\text { RUA MARCOS MARKARIAN, } 585 \\
\text { Construção Comercial Vertical - Ed.Alto } \\
\text { CVea } \\
\text { 3010,39 } \\
\text { ELIANE HAKIM TRAD } \\
600880180 \\
17485\end{array}$ & $\begin{array}{l}13 / 05 / 2015 \\
2013 / 058538 \\
226592 \\
\text { ET PFO JOSE ALMEIDA, } 500 \\
\text { Construção Comercial Ver } \\
\text { tical - } \\
\text { Ed.Baixo CVeb } \\
\text { 1066,24 ROBERTO CARLOS BARBOZA } \\
\text { DOS SANTOS } \\
\text { 685047354 }\end{array}$ & $\begin{array}{l}27 / 05 / 2015 \\
2014 / 046871 \\
15449 \\
\text { AV PORTUGAL, } 1013 \\
\text { Ampliação Comercial Verti } \\
\text { cal - } \\
\text { Ed.Baixo CVeb } \\
\text { 320,30 } \\
\text { ALINE SOARES QUEIROZ } \\
323241 \\
2868764\end{array}$ \\
\hline
\end{tabular}

Edifícios Altos e Baixos - 2016 - Relação de Projetos Aprovados no Ano

\begin{tabular}{|c|c|c|}
\hline $\begin{array}{l}\text { 05/01/2016 } \\
2014 / 039727 \\
197815 \\
\text { ROD JOSE FREGONESI, } 3505 \text { Construção } \\
\text { Comercial Vertical - } \\
\text { Ed.Baixo CVeb } \\
4001,42 \text { MARIA LUCIA SOUBIHE } \\
84751 \\
3595060\end{array}$ & $\begin{array}{l}\text { 05/01/2016 } \\
2014 / 039727 \\
197815 \\
\text { AV ANGELO ANTONIO COLAFEMINA, } 65 \\
\text { Construção Comercial Vertical - } \\
\text { Ed.Baixo CVeb } \\
\text { 143,16 MARIA LUCIA SOUBIHE } \\
84751 \\
3595060\end{array}$ & $\begin{array}{l}\text { 21/01/2016 } \\
\text { 2015/024658 } \\
336786 \\
\text { AV WLADIMIR MEIRELLES FERREIRA, } \\
1015 \text { Construção Comercial Vertical - } \\
\text { Ed.Baixo CVeb } \\
1251,92 \text { HELCIO ELIAS FILHO } \\
600886959 \\
60009714\end{array}$ \\
\hline $\begin{array}{l}05 / 02 / 2016 \\
2015 / 042854 \\
9997 \\
\text { RUA MAL DEODORO, } 2090 \\
\text { Construção Comercial Verti } \\
\text { cal - } \\
\text { Ed.Baixo CVeb } \\
\text { 470,10 HELVECIO DE MENDONCA } \\
\text { HENRIQUES JUNIOR } \\
\text { 600584193 } \\
51455798\end{array}$ & $\begin{array}{l}\text { 05/02/2016 } \\
\text { 2015/042854 } \\
\text { 9997 } \\
\text { RUA ITACOLOMI, } 399 \\
\text { Construção Comercial Verti } \\
\text { cal - } \\
\text { Ed.Baixo CVeb } \\
\text { 845,36 HELVECIO DE MENDONCA } \\
\text { HENRIQUES JUNIOR } \\
\text { 600584193 } \\
\text { 51455798 }\end{array}$ & $\begin{array}{l}\text { 12/04/2016 } \\
2015 / 025381 \\
36438 \\
\text { RUA ITAPIRA, } 555 \\
\text { Construção Comercial Vertical - Ed.Alto } \\
\text { CVea } \\
6031,06 \text { ALEXANDRE J. DIAS TERRA } \\
5061860060 \\
580577\end{array}$ \\
\hline $\begin{array}{l}20 / 04 / 2016 \\
2009 / 054683 \\
232760 \\
\text { RUA SALDANHA MARINHO, } 980 \\
\text { Construção Comercial Vertical - } \\
\text { Ed.Baixo CVeb } \\
6873,79 \text { CARLOS PEREIRA COUTINHO } \\
15450 \\
744464\end{array}$ & $\begin{array}{l}\text { 26/07/2016 } \\
2016 / 017029 \\
340324 \\
\text { AV PFO JOAO FIUSA, } 3000 \\
\text { Construção Comercial Vertical - } \\
\text { Ed.Baixo CVeb } \\
726,20 \text { MANOEL FRANCISCO ARAUJO } \\
\text { DOS SANTOS } \\
68373 \\
4600316\end{array}$ & $\begin{array}{l}27 / 07 / 2016 \\
2015 / 044264 \\
131390 \\
\text { AV CARAMURU, } 3565 \\
\text { Construção Comercial Vertical - } \\
\text { Ed.Baixo CVeb } \\
\text { 443,32 GLAUCO DAMASCENO } \\
\text { JUNQUEIRA } \\
601392180 \\
1522874\end{array}$ \\
\hline $\begin{array}{l}09 / 08 / 2016 \\
2014 / 017325\end{array}$ & $\begin{array}{l}12 / 08 / 2016 \\
2016 / 008862\end{array}$ & $\begin{array}{l}29 / 09 / 2016 \\
2015 / 002368\end{array}$ \\
\hline
\end{tabular}




\begin{tabular}{|c|c|c|}
\hline $\begin{array}{l}17365 \\
\text { AV COSTABILE ROMANO, } 1723 \\
\text { Construção Comercial Vertical - } \\
\text { Ed.Baixo CVeb } \\
642,75 \text { JOSE CLAUDIO GOMES DOS } \\
\text { SANTOS } \\
600592509 \\
1394377\end{array}$ & $\begin{array}{l}293778 \\
\text { AV DR CELSO CHARURI, } 7500 \text { Construção } \\
\text { Comercial Vertical - } \\
\text { Ed.Baixo CVeb } \\
4856,17 \text { HERMINIO ANGELO BONFIM } \\
\text { MATTIOLI } \\
685047419 \\
213807\end{array}$ & $\begin{array}{l}256873 \\
\text { RUA CATARINA APARECIDA NAVIS } \\
\text { SILVA, } \\
110 \\
\text { Construção Comercial Vertical - } \\
\text { Ed.Baixo CVeb } \\
1365,53 \text { MARCELO DE OLIVEIRA } \\
605231423 \\
1521861\end{array}$ \\
\hline $\begin{array}{l}\text { 23/11/2016 } \\
2016 / 033702 \\
9096 \\
\text { RUA ALTINO ARANTES, } 922 \text { Construção } \\
\text { Comercial Vertical - } \\
\text { Ed.Baixo CVeb } \\
\text { 2020,34 MARCOS VINICIUS ROSSATO } \\
\text { 5063277539 } \\
9287778\end{array}$ & $\begin{array}{l}\text { 29/11/2016 } \\
1973 / 024881 \\
6135 \\
\text { AV JERONIMO GONCALVES, } 475 \\
\text { Construção Comercial Vertical - } \\
\text { Ed.Baixo CVeb } \\
827,40 \text { OSCAR COLETTY } \\
700014499 \\
59039\end{array}$ & $\begin{array}{l}\text { 27/12/2016 } \\
2016 / 011501 \\
277151 \\
\text { AV PARANAPANEMA, } 715 \text { Construção } \\
\text { Comercial Vertical - Ed.Alto } \\
\text { CVea } \\
748,15 \text { ABRANCHE FUAD ABDO } \\
600563384 \\
60254314\end{array}$ \\
\hline $\begin{array}{l}\text { 28/12/2016 } \\
\text { 2016/045983 } \\
\text { 239464 } \\
\text { AV WLADIMIR MEIRELLES FERREIRA, } \\
1586 \text { Demolição Comercial Vertical - } \\
\text { Ed.Baixo CVeb } \\
\text { 1000,08 PEDRO BRUNO PAPA } \\
\text { 5069490654 } \\
1247675\end{array}$ & $\begin{array}{l}\text { 29/12/2016 } \\
2013 / 068824 \\
25928 \\
\text { RUA ROMEU CEOLOTO, } 300 \text { Construção } \\
\text { Comercial Vertical - } \\
\text { Ed.Baixo CVeb } \\
4231,81 \text { ALEX DOS SANTOS } \\
493872 \\
1571183\end{array}$ & $\begin{array}{l}\text { 30/12/2016 } \\
2014 / 053117 \\
106333 \\
\text { AV MONTEIRO LOBATO, } 2100 \text { Ampliação } \\
\text { Comercial Vertical - } \\
\text { Ed.Baixo CVeb } \\
671,63 \text { SARAH BORIN SARILHO } \\
1450379 \\
3067884\end{array}$ \\
\hline
\end{tabular}

\section{Edifícios Altos e Baixos - 2017 - Relação de Projetos Aprovados no Ano}

\begin{tabular}{|c|c|c|}
\hline $\begin{array}{l}\text { 21/03/2017 } \\
2016 / 046761 \\
228760 \\
\text { AV PFO MARIO AUTUORI, } 70 \text { Construção } \\
\text { Comercial Vertical - } \\
\text { Ed.Baixo CVeb } \\
2686,15 \text { ALBERTO HEREDIA QUARTIM } \\
\text { DE } \\
\text { MORAES } \\
643289 \\
493639\end{array}$ & $\begin{array}{l}27 / 03 / 2017 \\
2016 / 026317 \\
5194 \\
\text { AV PFO JOAO FIUSA, } 1325 \\
\text { Construção Comercial Vertical - } \\
\text { Ed.Baixo CVeb } \\
\text { 795,91 HUGO FORNI FERRIANI } \\
\text { 5061568118 } \\
717930\end{array}$ & $\begin{array}{l}26 / 04 / 2017 \\
2014026.5801 \\
\text { Construção Comercial Vertical - } \\
\text { Ed.Baixo } \\
\text { 591,9300 } \\
\text { LUCIANA CHIORO ANGOTTI } \\
\text { 2360453 } \\
\text { AV EDUARDO GOMES DE SOUZA } 761 \\
\text { 443140 } \\
\text { - SUBSET.S-6 }\end{array}$ \\
\hline $\begin{array}{l}\text { 5/10/2017 } \\
2014003.1991 \\
\text { Construção Comercial Vertical - } \\
\text { Ed.Baixo } \\
\text { 245,8400 } \\
\text { AMANDA FONTELLAS TAVEIRA } \\
\text { 6143598 } \\
\text { 32469 } \\
\text { RUA VICTOR REBOUCAS } 182 \\
3\end{array}$ & $\begin{array}{l}\text { 23/10/2017 } \\
2015 \text { 026.298 } 8 \\
\text { Construção Comercial Vertical - } \\
\text { Ed.Baixo } \\
\text { 251,7600 } \\
\text { HENRIQUE DIAS FEITEIRO JUNIOR } \\
3628741 \\
32735 \\
\text { RUA HENRIQUE DUMONT } 926\end{array}$ & $\begin{array}{l}\text { 4/10/2017 } \\
2012004.2548 \\
\text { Construção Comercial Vertical - } \\
\text { Ed.Baixo } \\
\text { 311,0000 } \\
\text { ALEXANDRE KITAZONO FRANCA } \\
\text { 4251589 } \\
\text { 85924 } \\
\text { RUA GETULINO DE CARVALHO } 260\end{array}$ \\
\hline $\begin{array}{l}\text { 30/10/2017 } \\
2015013.3614 \\
\text { Construção Comercial Vertical - } \\
\text { Ed.Baixo } \\
340,0000 \\
\text { SERGIO PACHECO DE QUEIROZ } \\
\text { 1541234 } \\
35668 \\
\text { AV TREZE DE MAIO } 500\end{array}$ & $\begin{array}{l}\text { 06/11/2017 } \\
2016039.732 \text { 0 } \\
\text { Construção Comercial Vertical } \\
\text { - Ed.Baixo } \\
6.031,0600 \\
\text { AJD ENGENHARIA E CONST. LTDA } \\
580577 \\
\text { 36438 } \\
\text { RUA ITAPIRA } 555\end{array}$ & $\begin{array}{l}\text { 23/11/2017 } \\
2017034.1042 \\
\text { Construção Comercial Vertical } \\
\text { - Ed.Baixo } \\
\text { 302,9800 } \\
\text { MARCOS ANTONIO BRONDI } \\
2534634 \\
80177 \\
\text { RUA RIO CLARO } 1677\end{array}$ \\
\hline
\end{tabular}




\section{Edifícios Altos e Baixos - 2018 - Relação de Projetos Aprovados no Ano}

\begin{tabular}{|c|c|c|}
\hline $\begin{array}{l}\text { 16/01/2018 } \\
2017035.1552 \\
\text { Construção Comercial Vertical - } \\
\text { Ed.Baixo } \\
\text { 952,8500 } \\
\text { GILBERTO FARNOCHI } \\
2577517 \\
34750 \\
\text { RUA ALBUQUERQUE LINS } 479\end{array}$ & $\begin{array}{l}\text { 24/01/2018 } \\
2017007.4648 \\
\text { Construção Comercial Vertical - } \\
\text { Ed.Baixo } \\
\text { 221,6600 } \\
\text { LUIS FERNANDO GARCIA VOLPE } \\
2944246 \\
\text { 12974 } \\
\text { AV PTE VARGAS 585 }\end{array}$ & $\begin{array}{l}\text { 25/01/2018 } \\
2017032.2889 \\
\text { Construção Comercial Vertical - } \\
\text { Ed.Alto } \\
6.940,0400 \\
\text { JOAO ALBERTO MELLO } \\
1442965 \\
222863 \\
\text { AV DR FRANCISCO JUNQUEIRA } 3375\end{array}$ \\
\hline $\begin{array}{l}\text { 16/03/2018 } \\
2015036.5493 \\
\text { Construção Comercial Vertical - } \\
\text { Ed.Baixo } \\
\text { 162,8200 } \\
\text { NATALIA BALDO MARQUES } \\
3960493 \\
228748 \\
\text { PCA ONDINA MOSCA } 51 \text { - SALAS } \\
0 \\
\text { PAV SUPERIOR }\end{array}$ & $\begin{array}{l}\text { 16/03/2018 } \\
2015036.5493 \\
\text { Construção Comercial Vertical - } \\
\text { Ed.Baixo } \\
335,9800 \\
\text { NATALIA BALDO MARQUES } \\
3960493 \\
228748 \\
\text { PCA ONDINA MOSCA } 57 \text { - SALAO }\end{array}$ & $\begin{array}{l}\text { 19/03/2018 } \\
2017032.2196 \\
\text { Construção Comercial Vertical - } \\
\text { Ed.Baixo } \\
\text { 1.193,0100 } \\
\text { MANOEL LUIZ NUNES FERREIRA } \\
2432342 \\
\text { 10340 } \\
\text { AV INDEPENDENCIA } 1275\end{array}$ \\
\hline $\begin{array}{l}28 / 03 / 2018 \\
2017027.1729 \\
\text { Construção Comercial Vertical - } \\
\text { Ed.Alto } \\
4.818,4500 \\
\text { ROGERIO LUIZ DUO } \\
876961 \\
301646 \\
\text { RUA AMERICO BRASILIENSE } 1828\end{array}$ & $\begin{array}{l}\text { 10/05/2018 } \\
2018005.8394 \\
\text { Construção Comercial Vertical - } \\
\text { Ed.Baixo } \\
3.073,4400 \\
\text { ADILSON JOSE DA SILVA } \\
147433 \\
152306 \\
\text { RUA PASCHOAL BARDARO } 526\end{array}$ & $\begin{array}{l}\text { 24/05/2018 } \\
2017043.9581 \\
\text { Construção Comercial Vertical - } \\
\text { Ed.Alto } \\
1.996,8900 \\
\text { FLAVIO BISTANE } \\
799864 \\
324419 \\
\text { RUA MARIO DE ANDRADE } 715\end{array}$ \\
\hline $\begin{array}{l}29 / 06 / 2018 \\
2018014.8083 \\
\text { Construção Comercial Vertical - } \\
\text { Ed.Baixo } \\
1.331,3300 \\
\text { IARA MARTA DA SILVA MANERIN } \\
1180032 \\
12471 \\
\text { AV ANTONIO DIEDERICHSEN } 650\end{array}$ & $\begin{array}{l}\text { 24/07/2018 } \\
2017028.4006 \\
\text { Construção Comercial Vertical - } \\
\text { Ed.Baixo } \\
\text { 15.551,1300 } \\
\text { RODRIGO DE AZEVEDO } \\
2167148 \\
353499 \\
\text { RUA ANTENOR DE SOUZA } 605\end{array}$ & $\begin{array}{l}\text { 31/07/2018 } \\
2018017.1875 \\
\text { Construção Comercial Vertical - } \\
\text { Ed.Baixo } \\
\text { 1.108,8600 } \\
\text { SERGIO PACHECO ARAUJO } \\
502483 \\
334187 \\
\text { PCA ALINE PATRICIA REZENDE } \\
\text { 400352710 } \\
\text { BESERRA } 45\end{array}$ \\
\hline $\begin{array}{l}\text { 02/08/2018 } \\
2017035.5388 \\
\text { Construção Comercial Vertical - } \\
\text { Ed.Baixo } \\
539,4600 \\
\text { SERGIO HUMBERTO CAVALHEIRO } \\
2585275 \\
227982 \\
\text { RUA LUCIANA MARA IGNACIO } 400\end{array}$ & $\begin{array}{l}02 / 08 / 2018 \\
2018 \text { 012.624 } 1 \\
\text { Construção Comercial Vertical - } \\
\text { Ed.Alto } \\
1.494,7100 \\
\text { FABIO BOTTURA PIMENTA } \\
\text { 1059815 } \\
\text { 340124 } \\
\text { RUA MITSO SHIMOKOMAKI } 496\end{array}$ & $\begin{array}{l}\text { 03/08/2018 } \\
2015044.2641 \\
\text { Construção Comercial Vertical - } \\
\text { Ed.Baixo } \\
443,3200 \\
\text { GLAUCO DAMASCENO JUNQUEIRA } \\
\text { 1522874 } \\
\text { 131390 } \\
\text { AV CARAMURU } 3565 \text { - }\end{array}$ \\
\hline $\begin{array}{l}\text { 07/08/2018 } \\
2018 \text { 023.428 } 1 \\
\text { Construção Comercial Vertical - } \\
\text { Ed.Baixo } \\
\text { 10.903,2400 } \\
\text { GUSTAVO FERNANDES DE FREITAS } \\
7121909 \\
\text { 352517 } \\
\text { RUA DANTE FEREZIN } 400\end{array}$ & $\begin{array}{l}\text { 23/08/2018 } \\
2017005.2377 \\
\text { Construção Comercial Vertical - } \\
\text { Ed.Baixo } \\
1.029,6900 \\
\text { FLAVIO BISTANE } \\
1421646 \\
150283 \\
\text { RUA BENEDITA VIEIRA EUGENIO } \\
\text { 5060688180 }\end{array}$ & $\begin{array}{l}\text { 15/10/2018 } \\
2017030.6751 \\
\text { Construção Comercial Vertical - } \\
\text { Ed.Baixo } \\
769,1200 \\
\text { ROGERIO LUIZ DUO } \\
2350246 \\
\text { 153667 } \\
\text { RUA ARNALDO VICTALIANO } 1126\end{array}$ \\
\hline
\end{tabular}

